\title{
Productive fandom : intermediality and affective reception in fan cultures
}

Citation for published version (APA):

Lamerichs, N. A. S. (2014). Productive fandom : intermediality and affective reception in fan cultures. [Doctoral Thesis, Maastricht University]. Maastricht University. https://doi.org/10.26481/dis.20140326nl

Document status and date:

Published: 01/01/2014

DOI:

10.26481/dis.20140326nl

Document Version:

Publisher's PDF, also known as Version of record

\section{Please check the document version of this publication:}

- A submitted manuscript is the version of the article upon submission and before peer-review. There can be important differences between the submitted version and the official published version of record.

People interested in the research are advised to contact the author for the final version of the publication, or visit the DOI to the publisher's website.

- The final author version and the galley proof are versions of the publication after peer review.

- The final published version features the final layout of the paper including the volume, issue and page numbers.

Link to publication

\footnotetext{
General rights rights.

- You may freely distribute the URL identifying the publication in the public portal. please follow below link for the End User Agreement:

www.umlib.nl/taverne-license

Take down policy

If you believe that this document breaches copyright please contact us at:

repository@maastrichtuniversity.nl

providing details and we will investigate your claim.
}

Copyright and moral rights for the publications made accessible in the public portal are retained by the authors and/or other copyright owners and it is a condition of accessing publications that users recognise and abide by the legal requirements associated with these

- Users may download and print one copy of any publication from the public portal for the purpose of private study or research.

- You may not further distribute the material or use it for any profit-making activity or commercial gain

If the publication is distributed under the terms of Article $25 \mathrm{fa}$ of the Dutch Copyright Act, indicated by the "Taverne" license above, 


\section{PRODUCTIVE FANDOM}

Intermediality and Affective Reception in Fan Cultures 
All images in this dissertation have been reproduced with the permission of their rightful owners. The author adhered to the standards of fair use.

(C) Nicolle Lamerichs

Cover design: Tamar Visscher

Cover photograph of Louise Ogg by Liyen Siaw

Print by: Datawyse

The research has been made possible by the NWO program Cultural Dynamics. 


\title{
PRODUCTIVE FANDOM \\ Intermediality and Affective Reception in Fan Cultures
}

\author{
PROEFSCHRIFT \\ ter verkrijging van de graad van doctor aan de Universiteit Maastricht, \\ op gezag van de Rector Magnificus, Prof. dr. L.L.G. Soete \\ volgens het besluit van het College van Decanen, \\ in het openbaar te verdedigen \\ op woensdag 26 maart 2014 om 12.00 uur \\ door
}

Nicolle Arnold Sibilla Lamerichs 


\section{Supervisor:}

Prof. dr. M.J.H. Meijer

\section{Co-supervisor:}

Dr. K. Wenz

\section{Assessment Committee}

Prof. dr. S. Wyatt (voorzitter)

Dr. I. Kamphof

Dr. L. Plate, Radboud University, Nijmegen

Prof. dr. J.F.F. Raessens, Utrecht University

Prof. dr. R. van de Vall 


\section{TABLE OF CONTENTS}

1. Shared Narratives: Intermediality in Fandom 1

Introduction $\quad 1$

Fan Studies $\quad 4$

$\begin{array}{ll}\text { Historical Perspectives } & 7\end{array}$

$\begin{array}{lr}\text { Productivity and Affectivity } & 9\end{array}$

Intermediality 11

$\begin{array}{ll}\text { Transmedia Design } & 15\end{array}$

Conceptualizing Productive Fandom 19

$\begin{array}{ll}\text { Outline } & 21\end{array}$

Elf Fantasy Fair 2010: Nerd Spotting 26

2. Fan Membership: Traditional and Digital Field Work 33

$\begin{array}{ll}\text { Introduction } & 33\end{array}$

Methods of Audience Studies $\quad 34$

Insider Ethnography $\quad 35$

"Aca-Fan" and "Geek Feminist”

$\begin{array}{ll}\text { Online Ethnography } & 40\end{array}$

Ethical Guidelines $\quad 42$

$\begin{array}{ll}\text { Conclusion } & 43\end{array}$

F.A.C.T.S. 2010: Treasure Hunt 45

3. Naturalizing Sherlock

Dutch Fans interpret the Famous Detective 53

Introduction $\quad 53$

Sherlock $\quad 55$

Reader-Response Criticism $\quad 58$

$\begin{array}{ll}\text { Naturalization } & 61\end{array}$

$\begin{array}{ll}\text { Experientiality } & 64\end{array}$

Dutch Sherlock Fans $\quad 66$

Online Sherlock Fandom $\quad 68$

$\begin{array}{ll}\text { Cultural Repertoires } & 71\end{array}$

$\begin{array}{ll}\text { British detectives } & 77\end{array}$

$\begin{array}{ll}\text { Modernity } & 79\end{array}$

$\begin{array}{ll}\text { References and Characterization } & 81\end{array}$

Conclusion 86

FedCon 2011: Meeting the Media Stars 90 


\section{Queer Teen Drama}

Rewriting and Narrative Closure in Glee Fan Fiction 97

Introduction $\quad 97$

Glee $\quad 100$

Narrative Closure 103

Literary Analysis and Method 106

Pick Up Right Where We Left 109

Queer Bully 110

The Lost Nightingale 116

Darkening Glee 118

Mostverse 123

Growing Up 124

Conclusion 128

Otakon 2011: The Intimacy of Strangers 132

5. Transmedia Play: Approaching the Possible Worlds of Firefly 139

Virtual Encounters 139

Firefly 142

Transmedial Worlds 146

Game World 150

Role-Playing 153

Online Firefly Role-Playing $\quad 155$

Serenity Table-Top 158

The Many Suitors of Lady Arden 161

Medium-Specificity of Serenity 164

Boarding New Carolina 167

Design of the Fan Game 168

Mediation and Embodiment of Firefly 172

Conclusion 174

WCS \& Comic Markets 2012: Pilgrimage to Japan 178

6. Embodied Characters: The Affective Process of Cosplay 185

Introduction 185

Ludology of Cosplay 187

The Affective Process 191

Grounding Identity and Gender $\quad 195$

The Felt and Fashioned Body 199

Engaging with Media Texts 202

Becoming the Character 206

Crafting and Preserving the Outfit 210 
7. Conclusion: Prospects for Fan Studies 215

Challenges of an Emerging Field $\quad 215$

Ethnographic Approaches $\quad 217$

Core Concepts and Findings 218

Fan Identity $\quad 220$

Future of Fandom $\quad 222$

Bibliography of Fan Works 223

Bibliography $\quad 224$

Summary 233

Curriculum Vitae $\quad 235$ 



\section{ACKNOWLEDGEMENTS}

I wish to thank all academics, fans and informants who have participated in this study and helped give shape to Productive Fandom. The various chapters have been presented at different sites including research networks, conferences and fan conventions. The feedback of readers and listeners was integral to advancing this project.

I would like to thank my colleagues at Maastricht University at Arts, Media and Cultures. In particular, I thank our NWO team on Narrative Fan Practices, headed by Karin Wenz. Our interests amounted to the conference MASH 2013 where I profited from presenting my results to like-minded scholars. Likewise, I am indebted to the colleagues at Center of the Study of Digital Games and Play at Utrecht University where I resided as a guest lecturer for the Master in New Media and Digital Cultures. My office pals - Karlijn, Koen, Miranda and Kim - also supported me with their ethnographic expertise.

Different research networks were vital to this project, in particular the Organization of Transformative Works (OTW), the Digital Games Research Association (DiGRA) and the Fan Studies Network (FSN). Their online support and conferences provided me an academic home. On a local level, the National Research School for Gender (NOG) and the Research School for Media Studies (RMeS) guided me through the research process. The annual Under the Mask conference for the study of play was another platform where I could present my work as early as 2010. I also profited from fan studies conferences held by ASCA, Interdisciplinary.net and the conference Narrative Minds and Virtual Worlds.

I would like to thank the editors, reviewers and authors of the edited volumes and journals to which I contributed outcomes and selections of this book: Sherlock and Transmedia Fandom (Stein \& Busse, 2013); The Companion to Fan Studies (De Zwaan, Duits, Reijnders, 2013); the special issue on fandom in Participations (2013); the "game love" anthology (MacCallum-Stewart, Enevold, forthcoming) and Everyday Feminist Research Praxis (Leurs, Olivieri, forthcoming). Working with you, and learning from you, was a joy. In addition, I thank Niki Haringsma for proofing several of the chapters.

Last but not least, I thank all the participating fans, artists and informants. Without your efforts, this book would have been impossible. 



\title{
1.
}

\section{SHARED NARRATIVES}

\author{
Intermediality in Fandom
}

\section{Introduction}

Whenever I wonder what being or becoming a fan means, I think about the first time that I attended a convention for Japanese popular culture. I had been a fan for years and subscribed to online forums to discuss "manga" (Japanese comics) and "anime" (Japanese cartoons). Still, I only had a handful of offline friends who understood how much this fiction actually meant to me. When I was eighteen, I travelled across the country to a weekend-long event where fans met up to enjoy Japanese popular culture. This convention, Animecon (2005), was held in a hotel, and nearly a thousand people were supposedly attending as visitors and volunteers.

My best friend had sewn me an outfit belonging to Aerith, a fictional character from a game that I liked (Final Fantasy VII) and had told me that many other attendees would also be dressed up. I knew that many fans engaged in different creative hobbies, such as sewing or writing, and I showcased my own drawings of Final Fantasy characters on different Internet sites as well. Japanese popular culture inspired young fans like me to engage in arts and crafts. I heard that these practices were motivated at the convention through costume competitions, workshops and much more. Still, wearing a costume of one of my favorite characters seemed somehow odd; then again, the whole convention seemed odd. My friend described it as a type of Disneyland where fiction would be all around you. We had made a little group of Final Fantasy characters with whom we would compete in the costume competition and had practiced weeks before. I had prepared for the convention for a long time, but really, I had no idea what to expect.

Upon arrival, I was dazzled by the busy, colorful atmosphere. In the lobby of the hotel, many people sat in costume and seemed to know each other. Characters that I had only seen on the screen passed me by: Mrs. Hellsing, Lulu, Rinoa. It was uncanny. Everywhere, fans discussed animation and games excitedly, admired characters and quoted their favorite lines. Many fans were so excited that I did not really know how to converse with them. This was my community, and many of the fans were undoubtedly on the same Dutch online forums that I frequented, but I did not really feel at home. The 
convention fell outside all of the social categories that I had ever seen. Many people wore geek shirts; there were men dressed up as women and people playing card games at tables in the lobby. It seemed as if everyone communicated through fiction but did not really communicate with each other.

Somehow, the convention was very different from online fan forums, where I could simply comment on anything and discuss with everyone. Back then, I was already subscribed to several fan communities. Since the late 1990s, I had been active on MangaDVD, a Dutch forum for Japanese popular culture. The Internet had been in its early stages when I had subscribed, but by now, many users had affordable and unlimited access to this technology. Through my online activities, I made many new friends, some of whom I had already met, whom I hoped to meet at this convention. The Internet enlarged my world, as I know it did for many other people at that time. Distant places suddenly seemed nearby.

I had long defined myself as a fan and felt comfortable in online fan spaces. At Animecon, I started to doubt myself. Who were these eccentric people and what did we actually have in common? A friend saw that I was uncomfortable and took me to the video game room to show me the titles that we could play. We battled in Soul Calibur 2 and just talked about the characters. I was more at ease and started to get accustomed to the atmosphere. Yes, as fans we did share some things that united us: not personal knowledge about one another but a different type of capital, related to the subculture in which we engaged. We shared knowledge, social contacts, creativity and, above all, a passion for particular stories and visual designs.

When I donned my costume the next day, I gained a sense of belonging. The outfit made me fit in visually and became a greeting card. Conversations became easier because fellow fans found topics to converse with me about: my character, Final Fantasy, video games. Some visitors recognized me from the forum because they knew that I was going to be wearing an Aerith outfit. They called me by my nickname, "Setsuna." By the end of the weekend, I had made many new friends while watching anime, playing games and attending workshops. From that point on, fan conventions seemed exotic and diverse to me, as well as attractive. Increasingly, they became a social context that I could fall back on: a place called home.

Fan conventions are only one manifestation of a fan community and its organizational structures. Fans come in all shapes and sizes, ranging from gamers to 
sport fans, from Harry Potter readers to collectors of Beatles records. It is often tricky to pinpoint what all of these groups have in common. Although we have our assumptions about what makes a real fan, we can only examine our own fan loyalties or recognize them as a social stance of others. As a cultural trope, fandom is not always recognized as a creative pursuit, but it is instead equated with obsession and excess (Bailey, 2005). The media serve us images of men as "Trekkies", addicted gamers or hooligans, while women are seen as groupies, sobbing over pop music or indulging in celebrity gossip. Fans are prone to be stigmatized, even by those who are part of the communities. Through their behavior, fans seemingly transgress social norms and are easily labeled as deviants as opposed to other types of audiences, such as those of the high arts.

I am particularly concerned with media fans who invest in popular culture and are inspired by television series, movies or digital games. These fans engage in a wide range of activities to pay tribute to the stories that they love. Some collect signatures, merchandise or blog images of their favorite shows; others attend concerts to be as close to their favorite bands as possible, and yet others share passionate reviews online. My interest, however, lies in the productive activities that fans undertake. Creatively, fans publish written stories ("fan fiction"), sew costumes of their favorite characters' outfits ("cosplay"), design different types of games and make visual art and videos, among other outlets. Thus, fans produce different types of narratives and objects and express themselves through play and performances. Through these homages, fans mediate existing symbols, plot lines, characters and settings. These fan creations are heavily inspired by the existing text or "source text", but they also create new textual relationships.

Although contemporary media fandom flourishes in offline sites such as fan conventions, the Internet has increased the visibility of fan practices and the number of people who actively engage in them. On distinct media platforms - here defined as unique software environments with specific social and technological affordances - fans show their creative products and discuss or refer to popular culture. Such fan activities may occur on blogs and forums, but they can also be staged in digital games or elsewhere. These organized fan activities are captured under the term "fandom". This concept refers to the sum total of the fan communities and individuals who are connected by their love for a particular text. Moreover, fandom refers to the interpretive and creative practices in which invested audience members engage. Fans and scholars 
alike use the term fandom to depict the activity of fans as a genre phenomenon (anime fandom) or as related to a particular text (Harry Potter). Online fan communities often celebrate particular content, ranging from texts to characters (Booth, 2010).

Productive Fandom offers a detailed study of fan cultures as they are lived - social, creative and affective spaces of productive reception. By drawing from insider experiences, this study provides a rich tour of the worlds of fans, but it stresses that these domains have much to offer to the study of narratives and media audiences. While my ethnographic methods are detailed in the next chapter, I shall briefly note that I understand ethnography as the study of lived cultures in their natural settings or fields through the use of qualitative methods. I support these findings with methods of narrative inquiry to generate further insights into the themes and structures of fan works.

Theoretically, I am interested in charting how fan practices migrate across different media and production contexts. I signify these processes of transfer through the concept of "intermediality". These migratory structures are not only apparent in fandom, but they have also increasingly characterized the production culture of the media industry itself. In this chapter, I describe the creative activities of fans and how they have been researched in previous studies. Subsequently, I discuss my own theoretical framework and provide an overview of the book.

\section{Fan Studies}

Historically, the earliest research on audiences developed as a socio-psychological field that deployed quantitative methods. Specifically, from the 1940s until the 1980s, researchers generally favored "uses and gratification" models that could measure how media fulfill the needs of their audiences. The qualitative study of media audiences was pioneered in the 1980s through the works of Stuart Hall (1980) and David Morley. Specifically, John Fiske (1990) studied the reception of popular culture in his early work and showed that audiences are not passive consumers but resistant readers and consumers who adapt culture. A ground-breaking work in the turn to qualitative study was Ien Ang's study (1985) of Dallas audiences, in which fans were the topic of an extensive study for the first time.

Inspired by this field of thought and by fandom itself, the first fan scholars started their research in the late 1980s. Henry Jenkins (1992) and Camille Bacon-Smith (1992) 
provided insights into how fan communities operate at conventions. They also paid attention to how fans analyze and subvert source texts by producing their own fiction based, for instance, on Star Trek. Notably, "slash" - the queering of fictional characters is explored in their writings as an interpretive anomaly and is also the subject of Constance Penley's early ground-breaking feminist essay Brownian Motion: Women, Tactics and Technology (1991). This early research showed a positive image of fandom because the studies aimed to correct the stereotypes surrounding fans as deviant or obsessed. In a similar vein, it emphasized the subversive and critical elements of fandom to validate these cultures as topic of research. By portraying fans as creative women and social individuals, these early publications set the tone for fan studies, but also proved that fan studies ran the danger of glorifying its informants.

The development of the field since the early 1990s has been highly interdisciplinary. I agree with Busse and Hellekson (2006), who emphasize the diversity of fan studies in terms of theory and approaches. Over the years, scholars have approached fandom as a form of religion (Couldry, 2003) and as a performance (Coppa, 2006b; Lancaster, 2001), but other scholars have studied it using psycho-analytical concepts (Matt Hills, 2002a) and feminist thought (Penley, 1991). Moreover, fan studies have increasingly flourished in relation to Internet studies. The intense user practices of fans exemplified online group formation and knowledge practices (Baym, 2000).

The online turn towards social networking sites and user-generated content influenced the field. Industries started to encourage migratory and interactive behavior across media platforms through the production of extensive websites, discussion pages and promotion tools (Ross, 2008). Since the late 1990s, television changed from "mustsee TV," structured around prime time, to "must-click TV," structured around interactive models (Gillan, 2010, pp. 1-3). Henry Jenkins (2006a) in particular has shown that fandom is intimately connected to the development of a mainstream participatory culture in which the industries increasingly share spaces with their audiences and spur them to become co-creators. He argued that this increased dialog between users and producers even has political implications and shapes a new public sphere (id., pp. 2122).

The terminology of Jenkins has been influential in the field thus far; however, his view of technology and participation has also been advanced to reveal the underlying power dynamics and competences that are central to media use (Burgess \& Green, 2009, 
p. 6; Schäfer, 2011, pp. 42-45). In recent years, the emphasis in fan studies has been on digital technologies rather than offline practices. The focus on the media industry itself sparked audience studies on labor and leisure to discern the liminal position of fan participants. Scholars also defined fandom as "serious leisure" (Stebbins, 2007): "The systematic pursuit of an amateur, hobbyist or volunteer core activity sufficiently substantial, interesting, and fulfilling in nature for the participant to find career there acquiring and expressing a combination of its special skills, knowledge, and experience' (p. xii). This concept has been applied to explore the motivations of those who, for instance, modify computer software (Postigo, 2007) and can helpfully illuminate other fan practices, such as writing fiction.

The concept of leisure is put to the test, however, by those who interrogate fandom as a form of labor and emphasize that the media industry increasingly profits from the activities of fans. These two concepts do not exclude each other: what the industry considers to be profitable can be entertainment for fans and provide a sense of ownership over the fiction that they love (Banks \& Humphreys, 2008). Still, in an economy where work and play increasingly coincide, labor and leisure may not be the best ways of framing audience engagement (Deuze, 2007).

What theories on labor do show well is that the competences individuals acquire in fandom can be operationalized in other domains. These communities function as "affinity spaces" (Gee, 2003; Knobel \& Lankshear, 2007) in which like-minded individuals find each other and advance each other's skills. Such spaces foster a broad "media literacy" that is not limited to interpretation but stimulates technological interaction and the development of creative skills (Alvermann \& Hagood, 2000; Buckingham, 2003; Ito, 2010). The critical competences that fans learn are particularly apparent in digital fan cultures that offer playful learning spaces in which fans can experiment and collaborate in their interaction with technologies and texts.

The question of the ways in which fandom is different from other audience cultures fascinates me, especially in the case of digital fandom (Booth, 2010). The media industry increasingly stimulates audiences to interact with their content intensively and socially. Early research has already depicted fans as active audiences, but this activity needs to be specified in light of the changing media landscape. My study analyzes fan activity in two unique ways. First, I investigate online and offline spaces in relation to each other to provide a coherent view of fandom as it is lived. I make room to discuss offline spaces, 
such as fan conventions, but I also include personal reflections. Second, I argue that fans are not characterized primarily through their social and participatory relationships but instead, as discussed in the next section, through their creative practices and their feelings.

\section{Productivity and Affectivity}

Influential studies have already depicted fandom as productive, and I want to use these studies as a jumping board for my own definition. The creativity of fans can be read as a type of appropriation that borrows and repurposes existing cultural materials to produce something new. Productive fandom has often been compared to quilting, wherein old materials are torn apart and reassembled (Bacon-Smith, 1992, p. 57; Bird, 2003, pp. 51-85). An equally appropriate term to describe this phenomenon is rewriting, which highlights how fans attribute new values to existing stories (Plate, 2011). Fandom cannot be understood solely as a reiteration or recombination of source texts.

For instance, the literary activity of fans is comparable to that of postmodern authors who re-interpreted classic stories in their novels, such as The Hours (based on Woolf's Mrs. Dalloway), Wicked (based on Baum's The Wizard of Oz) and Foe (based on Defoe's Robinson Crusoe). Derivative writing has a larger history and presence than fandom itself and is not without political or subversive implications. Such critical perspectives also emerge in fandom where the source text is not only copied but also subverted, in terms of gender, for instance. Fans actively work with the blanks in the source text that spark their imagination and give way to oppositional readings.

Fiske (1992) in particular has theorized fandom as a "textual productivity" that is characterized by the virtuosity and creativity of the audience rather than emotional or social investment. He also offers two other lenses through which we can analyze fandom: "semiotic productivity", which is integral to all audience behavior as a need to make sense of the text at all, and "enunciative productivity", which covers meanings that are shared and spoken and through which fans perform their identity to insiders and outsiders. According to Fiske, only textual productivity is specific to fandom, and this concept has received much attention in fan studies as a way to demarcate fans from other audience groups (Abercrombie \& Longhurst, 1998, p. 148; Crawford, 2012, pp. 120-137). 
I understand fans' textual productivity in a broad sense in this book and want to include creative processes, not only finished texts or products. I am particularly inspired by studies on creativity that foreground how interpersonal relationships are an integral part of creative processes and growth (Gauntlett, 2011). I interpret textual productivity as the creation of fan works that are intimately connected to the source text. I am interested first and foremost in charting the narrative relationships between the source text and the fan text. I do not limit fan texts to written texts but include forms of play, critical interpretations and material or embodied performances. Earlier narratological studies, such as Barthes' work on fashion (1990), have advanced my understanding of the text as something that is not purely written but can convey messages through other forms of communication, such as fabric. Thus, I speak of fan practices and works frequently to avoid the connotation with the purely written.

In addition to textual productivity, I believe that affectivity is crucial for fans. In their reception, fans draw from a felt and embodied response towards the text and its characters; in other words, being a fan is an experience that is grounded in a feeling - an admiration of texts that are used to connect to others and the world itself. Thus, affect is closely related to social formations online and offline. Fandom is a particular type of interest group, however, that often foregrounds the feelings towards the media text rather than social relationships. Fans are deeply engaged with popular content that leads to specific structures of close-reading and emotional forms of reception (Meers, 2006; Jenkins, 2006a, p. 204; Kaplan, 2006, p. 150-151). This comes with a certain ambiguity because fans may also maintain critical distance and judge a product aesthetically within their communities.

Ultimately, affect helps construct the identity of the fan, which is grounded in an emotional ownership over media content. This emotional ownership is achieved through creative practices, the purchase of objects or memorabilia and establishing social bounds with like-minded individuals. Alignment with the media text is a purposeful and reflexive activity because fans consciously reiterate their feelings toward the source text. These feelings are not purely aesthetic but are hailed by fans in other social domains. That is to say, fandom is a way of making sense of the world through felt and shared experiences. 


\section{Historical Perspectives}

The origin of the term fandom is rather unclear. Its earliest media citation appears in a sports column of the Washington Post on October 10, 1896. The word "fan", in turn, is an abbreviation of fanaticus or "fanatic", which has connotations of "fancy", religious zeal, and overactive engagement. It is debatable where and when the actual history of fandom as a social and cultural phenomenon began. Since Ancient Greece, storytelling has always been an active and dynamic process that relied on appropriation and catered to its audiences (Landow, 2006; Ong, 2002). Fandom is often compared to this tradition of folk culture where myths are shared and retold (Jenkins, 1992, pp. 268-274). Thereby, it opposes the recent historical emphasis on authorship (Foucault, 1984).

The history of being infatuated by fiction is integral to the reception of art and literature as aesthetic practices that should overwhelm their audiences. However, the division between high and low art led to different prototypes of how these audiences where viewed. Since the seventeenth century, enthusiastic audience members of high art have been captured by the term "lover". The lover is a figure that has a long cultural history in the Netherlands as the "liefhebber" (Keller, 2011). Similar to the verb "fan", the term "lover" implies an emotional attachment to a particular subject. This term has been carefully construed around discourses of art and around mastering art as an apprentice. As Keller (id.) argues, the "lover" is closely related to later types of fandom that celebrated the literary genius. Another earlier term is that of the "connoisseur", the expert who is highly knowledgeable about a certain topic. Today, the fan is often distinguished from such high arts audiences or experts as someone who is excessively affected by existing material and engages with popular culture rather than the arts.

As early as the nineteenth century, fan practices started to flourish around literature and scholarship. Esteemed authors as Lord Byron, Walter Scott and Rousseau already had a following of individuals whom we could describe as fans (Watson, 2011). Admirers made pilgrimages to their houses, hoping to catch a glimpse of these extraordinary individuals. Others would send fan letters, a practice that was already fairly common in the nineteenth century (id). Through new communication technologies such as the telegram this practice increased. For example, after Arthur Conan Doyle allowed the famous detective Sherlock Holmes to die, he received so many protest letters and comments that he eventually raised the character from the dead. Although these images are rather positive, at the same time, the image of the fanatic became 
stronger. In Germany, Goethe received a large fan following at the end of the nineteenth century, especially with his novel Die Leiden des Jungen Werthers (1774). There are contemporary accounts of young boys who dressed up as Werther, a phenomenon dubbed "Werther Fieber". The media related strongly this to fanaticism, blaming a supposed increased suicide rate on Goethe’s book (Ziegler \& Hegerl, 2002).

The rewriting practices of media fandom, however, are a fairly new phenomenon that coincided with the founding of modern popular literature. Writing derivative stories has an extensive history in the reader communities of Jane Austen, Lewis Carroll and Arthur Conan Doyle (Pugh, 2005; Stein \& Busse, 2012). The emergence of amateur and fan fiction at the end of the nineteenth century coincided with the increased literacy of the population and the founding of magazines, newspapers and the book industry targeting a mainstream audience (Landow, 2006). This popular literature was easily readable and interesting to explore. Characters such as Mister Darcy and Sherlock Holmes captivated audiences and were re-imagined in personal stories.

The first traces of fandom as an institutionalized phenomenon can be found in the 1930s when several literary fan clubs for the Sherlock Holmes novels were founded (Coppa, 2006a). In the 1950s, the institutionalization of fan practices continued with the founding of the first fan conventions: readers of science fiction would meet up in hotels to attend events such as panels in which they could discuss the material with its creators or amongst themselves. Today, fan conventions have become widely attended. The San Diego Comic Con draws over a hundred thousand visitors annually. In Japan, fan comic fairs such as Comiket can draw several hundred thousand visitors.

Fan practices were initially organized locally offline, but today they are also embedded in online communities. As the Internet began to gain ground in the 1990s, fan practices became more visible. Fans could now meet up with like-minded individuals virtually and publish their products. Early online fan practices operated through listservs, news servers and message boards. Media platforms for fan activities such as FanFiction.net (1998) were established later, while blogs such as LiveJournal (1999) increasingly became a way to communicate about media and publish fan fiction. The founding of these sites coincided with the development of online social media, which has been captured under the marketing term Web 2.0, popularized by Tim O'Reilly.

Although fandom has historically flourished in autonomous and domestic spaces, modern fandom is staged across different online and offline sites that are increasingly 
shared with media producers. While modern fandom is deeply embedded in online media, however, it is not restricted to these platforms. One danger of fan studies is overlooking those individual fans who do not participate in digital or traditional fandom. As Sally Wyatt (2003) noted, the "non-users" of the Internet are especially worth studying, despite being difficult to locate, because their active resistance and social motivations are key to understanding the technology. Similarly, those fans who are not active in fan communities can provide valuable insights into the participatory culture around media. They may, for instance, reveal criticisms of the social norms and conditions of fandom. Increasingly, fan studies have also focused on those who not only reject fandom but interact with others by showing their disgust for particular media content or celebrities - the "anti-fans" (Gray, Sandvoss, \& Harrington, 2007). Starting from these critical investigations, this study hopes to capture the figure of the fan through diverse affective investments and modes of belonging.

\section{Intermediality}

Fan practices can best be understood through the concept of intermediality. My working definition of intermediality is: a transfer or combination of form and/or content that relates an individual media text to other media texts of the same or a different medium. In this section, I explain how the term clarifies the dispersion of media content. I also suggest a typology that breaks down intermediality into several subsets that signify the different patterns in which these intermedial processes are formed.

Defining today's media relationships is a rather daunting challenge because intermediality is defined in different and competing terms. Moreover, the interpretation of the concept differs by academic context and author. As Grishakova and Ryan (2010, p. 3) write,

While the concept of medium has become very prominent in narratology, there are so many candidates available to refer to the relations between narrative and media that terminology has become a true nightmare: what, if any, are the differences between transmediality, intermediality, plurimediality, and multimediality (not to mention multimodality)? 
My choice for intermediality is led by the belief that it is a suitable umbrella term that emphasizes exchanges within and between media in the broadest sense, as suggested by the prefix "inter" or between. This has also been argued by Grishakova and Ryan (id.). In a similar fashion, literary critic Brillenburg Wurth (2013) states that intermediality is applicable to the analysis of contemporary media texts and the complex ways in which one medium summons or includes another.

While intermediality is still subject to critical attention, I believe that the concept can helpfully illuminate the unique qualities of particular media and signify what is gained and lost in any mediation process. My understanding of intermediality is operational. Intermediality forms a guiding concept that I articulate by showing how it functions in practice, by drawing attention to what it can do. I use the term to investigate the structures of media content and to explain how fans and the media industry construct relationships between media texts.

In my categorization, intermediality is an inclusive process that covers not only the relationships between media but also their "medium specificity": the distinctive features, modes and aesthetic conventions of an individual medium in its interplay with other media (Doane, 2007). N. Katherine Hayles (2004) in particular has made a claim for medium/media specific analysis of online texts that should account for their unique properties, including their material and spatial presence. Through Bolter and Grusin's concept of "remediation" (1999), she argues that we must not understand the media text in isolation but rather in relation to other media. 'Whether in print or on screen, the specificity of the medium comes into play as its characteristics are flaunted, suppressed, subverted, reimagined' (id., p. 10). Hayles' plea for situating the materiality and architecture of the particular medium has informed my understanding of intermediality.

To account for medium-specificity, I speak of different media modes (e.g., visual, auditory) in my analyses. I am particularly inspired by Kress and Van Leeuwen (2006), who have written amply about the cultural modes within one medium, and by the work of Karin Wenz (2006), which has captured the modes of digital games as an inter/transmedial phenomenon. She shows that digital games rely fundamentally on other media, such as literature. This focus on modes helps distinguish patterns of difference and similarity among individual media texts and between old and new media. This resonates well with Bolter and Grusin's concept of "remediation" (1999), which has grounded this study. The two authors argue that new media often integrate properties 
of old media, whereas old media repurpose themselves with features of new media. Thereby, media engage in an ongoing competition with each other by integrating each other's modes.

Although intermediality has gained new relevance today, the exchanges between media are historically ingrained in the practice of art. The relationship between the visual arts and literature, for instance, has often been subject to analysis. Historically, intermediality stems from "intermedium", a term coined by Samuel Taylor Coleridge (1812) to discuss aesthetic modes in various media. Higgins used the concept again in the 1960s in his manifest Statement on Intermedia (1967), and it quickly became integrated into the art scene through the artist network Fluxus. Using the term "intermedia", Higgins described art forms that blur the distinctions between individual media by combining different media modes. His example was visual poetry, which conceptually relies on a visual and linguistic mode. The concept was further developed in Germany in late-twentieth-century aesthetic and literary studies as well as media studies (Helbig, 1998; Krewani, 2001; Müller, 1996; Rajewsky, 2002; Spielmann, 1998), a debate that advanced my understanding of the term.

The German debate brings to light that relationships among media must be distinguished on several levels. First, intermediality can mean combining various media in one product or artwork (Rajewsky, 2005, pp. 51-52). For instance, a game can be intermedial by using music, voices, movies and text. The combination of media can be rather self-contained, which is often called "multimediality": a combination in which each medium does what it does best and still remains distinctive in the text. German theorists often describe this as "nebeneinander" or next to each other. Think of a book that makes sounds when you press it or a slideshow that uses an embedded video. In other cases, however, the different media are much more dependent on each other, which is often described as "integration". In this case, the different media work together, or "miteinander". The different media then construct the artwork together, as, for example, in an opera, which can present music, visuals and entourage as a combination of media.

Second, intermediality can be understood as a process of transfer or "transmediality" when content flows across unique media and media platforms. Transfer can be a migration of many parts of the narrative or just a few elements. In a broad sense, the narrative can be extended to other media through spin-offs (e.g., Star Wars: 
The Clone Wars), or it can be related to particular genres, such as film noir (e.g., Who Framed Roger Rabbit). However, these transfers can also be thematic in that they mediate specific aesthetic or textual cues. The concept "adaptation" is at hand when a narrative is reiterated anew or repurposed for a different medium (Hutcheon, 2006).

Transfer does not always imply a thorough adaptation of the entire text. The process can also be limited to a small wink or a "reference", such as the quotation of a movie line. Critically, it is important to note that media texts not only mediate each other's narrative content but can also transfer the aesthetic conventions of a medium. An example of this is the mediation of the video game Heavy Rain (2010) in the television text Sherlock (2010-), which particularly mimics its stylistic visualization of the player's options. In addition to these transmedial processes, several authors have also stressed the need for a separate category of "intramediality" that describes processes of transfer or combination between media texts of the same medium, as summarized by Dena (2009) and Rajewsky (2005).

Within this exploration of intermediality, two competing terms require unpacking. First, my understanding of transmediality emphasizes a process of transfer, as outlined above, but the term remains contested today. In German theory, transmediality is often discussed as a subset of intermediality or as a semiotic transfer, comparable to a theme or motive (Rajewsky, 2002). However, Anglo-American theories often explore transmediality more colloquially to highlight relations between and combinations of media content (Jenkins, 2006a; Ryan, 2004; Stein \& Busse, 2012). Specifically, Henry Jenkins has molded the concept to "transmedia storytelling", in which a narrative is told across different media such as comic books or movies. While I explain this concept in detail in the following sections, it is important to note that I consider transmedia storytelling to be a subset of transmedia design, which captures not only processes of storytelling but also transmedia performances and play.

Second, contemporary understandings of intermediality are closely aligned with the discourse of "intertextuality," which defines the relations between texts. Intertextual analysis shows how textual meaning is always shaped by other, older texts (Kristeva, 1981). Some scholars such as Genette (1997) understand the concept narrowly as literal citations or identifiable references to other texts. Other critics, such as Julia Kristeva, however, understand intertextuality more freely as cultural discourses that thrive around a text. Thus, the definitions of "text" in intertextuality studies are diverse. 
Moreover, they are often not limited to written texts but also cover spoken texts, generic conventions, images, ideologies and cultural clichés. Maaike Meijer (2006) helpfully distinguishes all these different layers of intertextuality. I favor intermediality as a term because it focuses less on the (literary) text and more on relationships of form and content across media. It must be noted, however, that intertextuality in its narrow sense - the phenomenon that literary texts can refer to, or use, other literary texts of the same medium - is a subform of intermediality that is similar to intramediality.

My own terminology thus captures intermediality as an overarching concept and puts it to use in a narrow sense as a combination of content within one medium. The two related terms that I deploy are transmediality and multimediality. I consider transmediality to be a subset that captures the transfer of media content and form to other media. Multimediality refers to those texts whose media modes can be understood in isolation, or as separate within the media text. Thereby, I understand both as specific structural process within intermedial texts. This division is in line with the German discourse on media relationships as nebeneinander (next to each other) and miteinander (with each other).

I do not operationalize the term intramediality, however, because it does not resonate with my understanding of remediation as taken from Bolter and Grusin (1999), who stress that the modes or qualities of one particular medium can be adopted in another. In other words, it is not easy to analytically distinguish a mediation process within the same medium from a mediation process between different media. In the next sections, I will particularly detail the cultural implications of convergence - the repurposing of media content and functions across media systems - through my own term transmedia design.

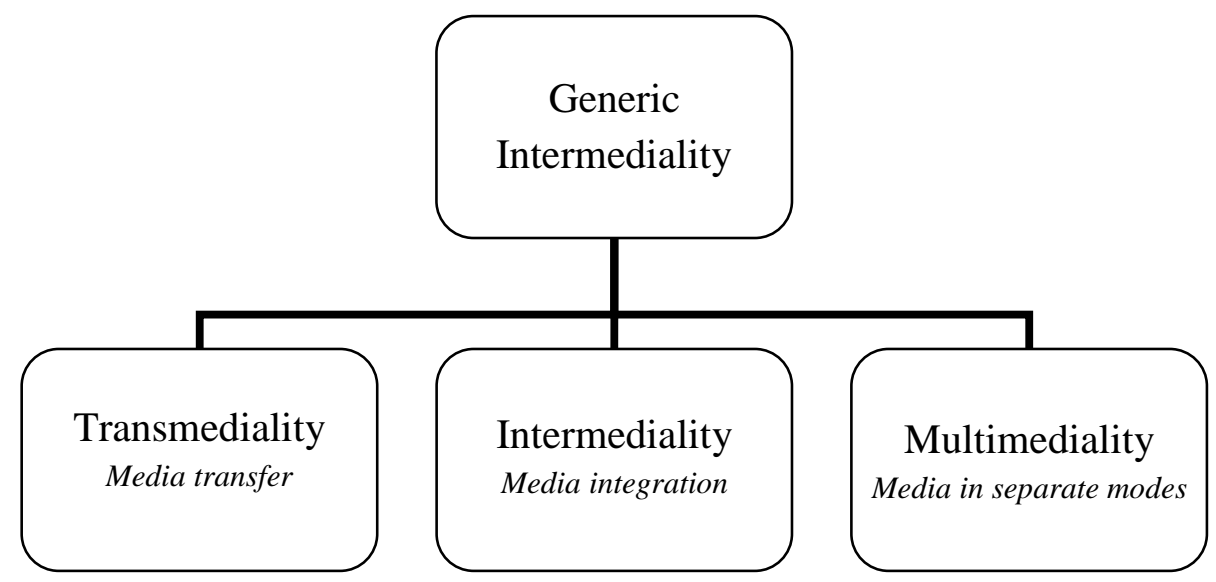

Figure 1: Typology of intermediality 


\section{Transmedia Design}

Contemporary media content flows across individual media and is repurposed, branded, and discussed. Henry Jenkins (2006a) conceptualized modern media culture through the concept of "convergence" - a technological phenomenon in which systems innovate towards performing similar tasks and functions. However, Jenkins rephrased the concept as "convergence culture", suggesting that these technological innovations have wide-ranging cultural implications. He describes convergence culture as a landscape in which 'old and new media collide, where grassroots and corporate media intersect, where the power of the media producer and the power of the media consumer interact in unpredictable ways' (id., p. 2). Media convergence is upheld by the industry's participatory culture in which producers and consumers increasingly interact.

The ideals of media convergence increasingly shape the designs and content of the industry itself; that is to say, the combination of different media platforms is also the core business of the media industry. The concept of "transmedia storytelling" points towards these changes in how the industry extends, promotes and narrates its stories (Jenkins, 2006a). The media industries increasingly spread and extend their narratives across diverse media that range from comics and animation series to games and movies. Henry Jenkins coined this term in Technology Review (2003) to account for how a story is co-created by various corporations to include new information, thus establishing a larger story world or franchise. His key example is the narrative structure of The Matrix (1999-2003), which consisted of three movies and a digital game that together established its story world (Jenkins, 2006a). While a television series or movie used to limit the story to that medium, today, bits and pieces are smeared over various platforms: 'Younger consumers have become information hunters and gatherers, taking pleasure in tracking down character backgrounds and plot points and making connections between different texts within the same franchise' (Jenkins, 2003).

Transmedia storytelling establishes an overarching narrative and fictional world across media platforms. Individual media may add background information, new characters or deepen plot lines. This also opens marketing venues because different media products have the potential to draw new audiences. Ideally, this narrative results in "hypersociality", as Mimi Ito argues (2005, p. 32). Audiences are thus motivated to familiarize themselves with instances of the narrative and discuss them in their respective audience communities. Jenkins' use of transmediality is inspired by Marsha 
Kinder's study (1991) that had already captured franchises such as the Teenage Mutant Ninja Turtles in terms of "transmedia intertext" (p. 38). Kinder argues that transmediality favors active readership as a type of literacy that teaches children how to connect media products and recognize certain tropes (id., pp. 49-50). Ideally, the children also grow up with new installments of the texts suitable for their age that foster their attachment to the narrative world.

Critically, the concept of transmedia storytelling has been subjected to debate. Authors have argued for the inclusion of marketing texts, such as billboards, and merchandise, such as toys or stickers (Hardy, 2011; Long, 2007). I agree that such peripheries are increasingly rich in terms of narrativity and require theorization. However, transmedia storytelling raises the fundamental question of if and how fan works are part of this cultural dynamics. By emphasizing industry-driven practices, Jenkins (2006) neglects the liminal examples of transmedia storytelling that stand between fandom and official production. For instance, the current Doctor Who (2005-) series is innately tied up with its fandom, which kept the doctor's adventures going when the BBC cancelled the series in 1989 (Perryman, 2008). Specifically, Big Finish Productions (1998) was central to the revival of Doctor Who. Prior to the establishment of "Big Finish", many of their employees worked for the unlicensed "Audio Visuals" series, which produced audio plays. The employees befriended the previous cast and crew, and managed to obtain the copyright for the series audio material. They established "Big Finish" to produce official audio books and invited fellow fans, previous actors and writers to join their endeavors. In this fan-driven context, many of the current Doctor Who writers and actors met.

While transmedia storytelling is clearly visible in modern media, I propose the use of the alternative "transmedia design" for two reasons. First, my cases indicate that many of these designs are not limited to storytelling but include transmedia performances or play. The term storytelling may be misleading because these products may have narrative qualities but do not further the storytelling process. Moreover, the concept of storytelling presumes coherence among the different media products during design implies the building of a franchise. Design can refer to multi-authored production and the fabrication of different products that have different material, narrative and interactive features. This resonates with our current media landscape, in which production companies promote and extend their narratives through a heteroglossia of 
products with fundamental differences in appraisal and authorship. These transmedia instances diverge and do not necessarily add up to a grand narrative. Different versions and adaptations of a text that may conflict are made. The Star Trek series and films, for instance, offer many contradictions for the observant viewer. However, while the events and stories may conflict, recognizable characters and the story world itself give coherence to these transmedia products.

Second, design emphasizes that the media industry has a clear commercial gain with transmedia content. Plenary texts are meant to create brand loyalty, draw new followers or maintain the fan base when the show is on hiatus. The True Blood (2008-) billboards and promotion sites, as described by Hardy (2011), may have some narrative value but aim to draw new viewers. The online platform for the series Psych (2006-) or "Club Psych" rewards viewers with an elaborate point system and extra video material when they engage in discussions or games. Club Psych echoes the recent trends towards "gamification" or the application of game design strategies such as rewards and rules to non-game contexts (Deterding, Dixon, Khaled, \& Nacke, 2011). The participatory strategies of Psych are highly interactive but are not purely defined through narrative structures. The forum relies on play that motivates consumer loyalty through points and special perks. Transmedia design helpfully rephrases these practices that are on a sliding scale between branding and narrative or playful extension.

The increase in transmedia design and participatory regimes in media culture raises critical questions. Today, scholars analyze how the industry caters to its visible audience by exploiting, rewarding and engaging fans (Banks \& Humphreys, 2008; Consalvo, 2003; S. Murray, 2004). Studies on fans show that the negotiation between the audience and industry is complex and that producers are still seeking new ways to share their content with their audiences (Gwenllian Jones, 2003; Shefrin, 2004). However, transmedia design often implies a particular audience that is loyal to the text and its distributed canon. As Suzanne Scott (2009) argues, transmediality creates a complicated place for fan products as certain products are capitalized by the industry through contests, licenses or otherwise. This creates a culture in which fan content is incorporated by the industry: 'Media producers, primarily through the lure of "gifted" ancillary content aimed at fans through official Web sites, are rapidly perfecting a mixed economy that obscures its commercial imperatives through a calculated adoption of fandom's gift economy, its sense of community, and the promise of participation.' 
At the same time, media producers continue to emphasize their authorship through modern communication technologies, such as DVD commentaries in which they comment on the creation process (Shefrin, 2004). The industry increasingly motivates fan practices of television series and profits from them. Fandom is licensed, promoted through contests and made visible on the industry's website.

This is not without problems. For example, after a contest held for the television series Heroes (2006-2010), the writers used the ideas of fans in their second season without crediting them (Hassapopoulou, 2010). The mediation between the industry and fans presses questions not only of labor and agency but also of different value systems. The creative industries appropriate fan practices, which results in a phenomenon of re-appropriation. Critically, this phenomenon also implies that the industry may shy away from the resistive and queer content of fandom that does not resonate with their envisioned audience. Following the logic of transmediality, the industry can favor particular content that is loyal to their narrative while being more transformative and critical expressions run the danger of being marginalized further. Thus, transmedia design can be a regulating practice that edits and curtails the creativity of fans. It sometimes shows censoring and corrective traits.

\section{Conceptualizing Productive Fandom}

This study sets out as an ethnographic investigation of texts and textual meaning. Several core concepts have shaped this study on productive fandom and characterize my approach.

Intermediality: While I have already introduced intermediality, I want to briefly summarize my approach in this conceptual model. Intermediality is used on two levels in this book. First, I view fan works as intermedial structures that are inspired by particular source texts and other fan works. Second, I pay ample attention to transmedia design by the media industry. I argue that the logic of transmediality increasingly shapes the production and reception of fan works. While fan works are perceived to be creations in their own right, they are also considered to be interpretive expressions of the source text. These fan narratives are not limited to written texts but include visuals, such as art works, or material objects, such as costumes. 
Characters and story world: Fandom offers alternatives to plot and focalizations that enable characters to live well beyond their original texts. This study pays specific attention to characters and fictional universes. In fandom, characters and worlds are endowed with an emotional life. Through transmedia fan products, the universe and the development of existing characters is extended, questioned and re-imagined. I read these interpretations as singular and personal, but they may be multiplied in fandom when fans reach a literary consensus over these transformations. Another line regarding characters and fans and their shared common ground emerges through the queer reading practices of fans that provide fluid sexual and gendered portrayals of fictional characters. Liberal fan practices, such as cross-dressing, also demonstrate this awareness.

Affective reception: Media texts generate affects with their audiences. I suggest that meaning is not allocated within the text but is generated by its audiences. They are at once a disposition for viewing and an after-effect, visible in sentiments such as nostalgia. The media experience of fans is embodied and affective, which has consequences for their sense of identity. Fans interpret media experiences as an intense aesthetic experience that also differentiates them from others, both within the fan community and outside it. The production of the fan work coincides with the re-contextualization and re-imagining of the source text. Both fan authors and readers actively interpret, contextualize and situate the source text. This source text can be transformed through different interpretive strategies, but this transformation is already part of the work that a reader has to do to decode it at all. Reading implies reproducing texts according to contexts, learned systems and codes. Reading also means engaging in a deeply felt and embodied experience.

Networks of production: Fan works increasingly share spaces with the media industry, thereby reaffirming its status and copyrights. In fandom, authors and readers engage in interpretive work and textual production together. Media fans have a shared lingua franca and social protocols. However, they also have hierarchies that result in part from their interpretive and creative competences. Social status may be awarded to fans who have been in communities for a long time but can also pertain to their skills and the quality of their fan texts. Although retelling goes back to oral cultures, in the modern 
media landscape, it is connected to politics and commerciality as audiences speak up against the media industry itself.

Identity: The identity of the fan is constructed through interpersonal relations and feelings. The fan creator is especially central in this study of productive fandom. Fans learn to classify and cultivate their feelings for and knowledge about media texts. In terms of social background, I refrain from essentialist readings based on the sociocultural backgrounds of fans. While I account for the gender, ethnicity and sexuality of fan authors, I do not want to provide an essentialist view of these identity markers. The fannish self is not a given, but a socially constructed concept: a project of self-formation that is constantly enacted in fan practices. Fan identity comes to the fore through several lenses that structure this book.

a) The interpretations of the text that are grounded in social networks of locality and nation-states but also of global fan communities.

b) The queer and gendered identity of the fan that surfaces in fan practices and structures the norms, sexual practices and embodiment of the fan.

c) The identity of the fan as a player who combines pop cultural elements and structures these through fannish play.

d) The identity of the fan as constructed along affects. These affects are embodied but can be cultivated within fan networks and through creative fan practices.

This framework is at the heart of my study and has grounded the core concepts that are addressed in the various chapters. Every chapter examines one aspect of this framework, but these mission statements surface throughout the book. Thus, this study explores the afterlife of popular stories and the ways in which audiences express their feelings for them time and again.

\section{Outline}

This book explores the various ways in which fans rework stories and the intermedial relations that they thereby establish. Popular culture contains characters, worlds and plot lines that speak to us. To give a multi-dimensional view of fan practices and allow for some comparisons between different fandoms, each chapter focuses on a fan community that thrives around a particular television series or game. I have sampled the 
cases strategically as informed by theory. Moreover, they are connected to my European viewpoint, which forms a unique entry point to the field of fan studies that has predominantly focused on Anglo-American texts and audiences. This is not to say that the book is limited to European data because it also includes many American and nonWestern examples. In fact, I want to press the reader to understand fandom as a transcultural space where fans with different national experiences and memberships come together.

I have chosen to limit myself to a specific medium or fan practice in each chapter to allow for in-depth analysis. The different television shows or genre fandoms have been selected on the basis of their genre, popularity and the diverse make-up of their audience community. This cross-comparative design is necessary for two reasons. First, the cases show the heterogeneity of fandom by focusing on local contexts and cultural practices. I advance the specificity of these communities: their differences and commonalities. Second, the different cases support the investigation into unique sets of transmedia design propelled by the media industry and shed light on our current media landscape.

Between the main chapters, I embed ethnographic vignettes that chronologically describe my fieldwork at fan conventions, fantasy fairs and other platforms where fans meet. Thus, I divide my personal experiences and encounters from the more tangible data to provide a descriptive idea of what fandom means today. The vignettes capture fan communities in which I was already engaged, particularly the Dutch anime scene and the conventions that thrive around this genre. However, I also explored other local fan cultures that were distant from my own Dutch context, such as Comiket in Japan. Each vignette is placed between the chapters but should be read on its own terms; that is to say, the vignettes do not function as bridges or introductions to the following chapter but have thematic connections with the empirical cases. Specifically, the vignettes detail how the experience of fandom can be understood from the inside out. The vignettes reflect on my own status as a fan and the people whom I met in these communities. The next chapter is a short methodological overview that explains the different methods that I use and positions me as a scholar and ethnographer.

The first case discusses the BBC series Sherlock, an adaptation of Doyle's Sherlock Holmes stories. As an introduction to fan cultures, I discuss the viewership of fans and how they make sense of a text. Through several in-depth interviews, I highlight the 
literary competences of fans. The chapter shows how fans interpret characters in light of previous texts and their own experiences. I elaborate upon the reader-centered theories by Jonathan Culler (Culler, 1975) and Monika Fludernik (1996) that focus on the "naturalization" of texts, by which viewers and readers make sense of existing texts by relating them to what they have read and experienced, as well as what they expect from a text based on cultural and literary conventions. Within the fan communities of Sherlock, naturalization becomes particularly apparent because the series is based on older stories that have been reworked throughout the years. The central questions in this chapter are as follows: What are important themes for fans when they interpret the source text? How do they make sense of characters in relation to earlier (fan) texts?

The second case discusses specific genres that fans establish in their practices by focusing on fan fiction inspired by Glee. I sampled and closely read several exemplary fan texts with permission from their fan authors to frame the literary landscape of Glee fan fiction. The chapter examines the online context of fan fiction through intermediality. For instance, queer themes emerge in Glee quite regularly and are mediated in its fan fiction. In addition, I operationalize the concept of narrative closure to analyze how fans resolve the events and characterizations from the source text. I seek to understand how fans remediate the source text in terms of genre and focalization. Important questions in this chapter are as follows: What literary strategies do fans display? Which narrative themes are reproduced or subverted in Glee fan fiction?

The third case discusses a role-playing game based on Firefly, a television series that was cancelled in 2002. Since the series has not reached narrative closure, it persists in the hearts of fans who rework the story world in new and unexpected ways. Specifically, I discuss different role-playing games of Firefly audiences that develop the potential of the text. Theoretically, I emphasize the fictional world through the concept of the "transmedial world" (Tosca \& Klastrup, 2011), which depicts a universe that is established across different media. I add to this concept with possible world theory. The study problematizes fandom as a phenomenon by relating it to game culture. The games are analyzed as cultural products that combine various media and also purposely appropriate existing fictional content. I pose questions such as the following: How do fans perform existing story worlds? How do they remediate a television text into a game and what does this mean for the medium-specificity of a narrative? How can we distinguish between fandom and practices of play? 
The fourth case focuses on the performance of cosplay or dressing up as fictional characters. Specifically, I analyze the practices of fans of Japanese popular culture. Through interviews and ethnographic observations, I show different motivations and feelings related to cosplay. Fans purposely create their own identity within cosplay by identifying themselves with fictional characters and explicitly actualize narratives in daily life to bring characters to life. This chapter shows the many ways in which fans relate to existing characters and how they inspire them in their daily life. Theoretically, I frame cosplay through affect theory. Affect is understood as a fundamental condition that allows us to make sense of aspects of our life and valorize them. Central questions in this chapter are as follows: How do fans establish a sense of identity through cosplay? What types of affective relationships are constructed by cosplaying?

The conclusion recapitulates this study with a summary of the findings and revisits my conceptual framework. This chapter also has two specific focal points. First, I reflect on the various ethnographic methods that I use throughout this research and outline the benefits and drawbacks of the various participatory stances that I adopt. Second, I raise several methodological and theoretical concerns for future fan studies.

I hope that this book will provide inspiring accounts of fandom for both academics and fans themselves. I have written the book in an accessible way so that professionals and interested readers with different backgrounds can use it to get an idea of fandom and relate it to different viewpoints and theoretical considerations. For scholars of arts, literature and new media, this work provides new views on how audiences interpret and extend popular culture. Media are not secluded in their black boxes but constantly spill over into everyday life. Reception is more than just making sense of a text; fictional characters are felt, imagined and believed in. Fandom shows the scope and breadth with which stories affect us and the ways in which we maintain these stories, even long after they are finished. 


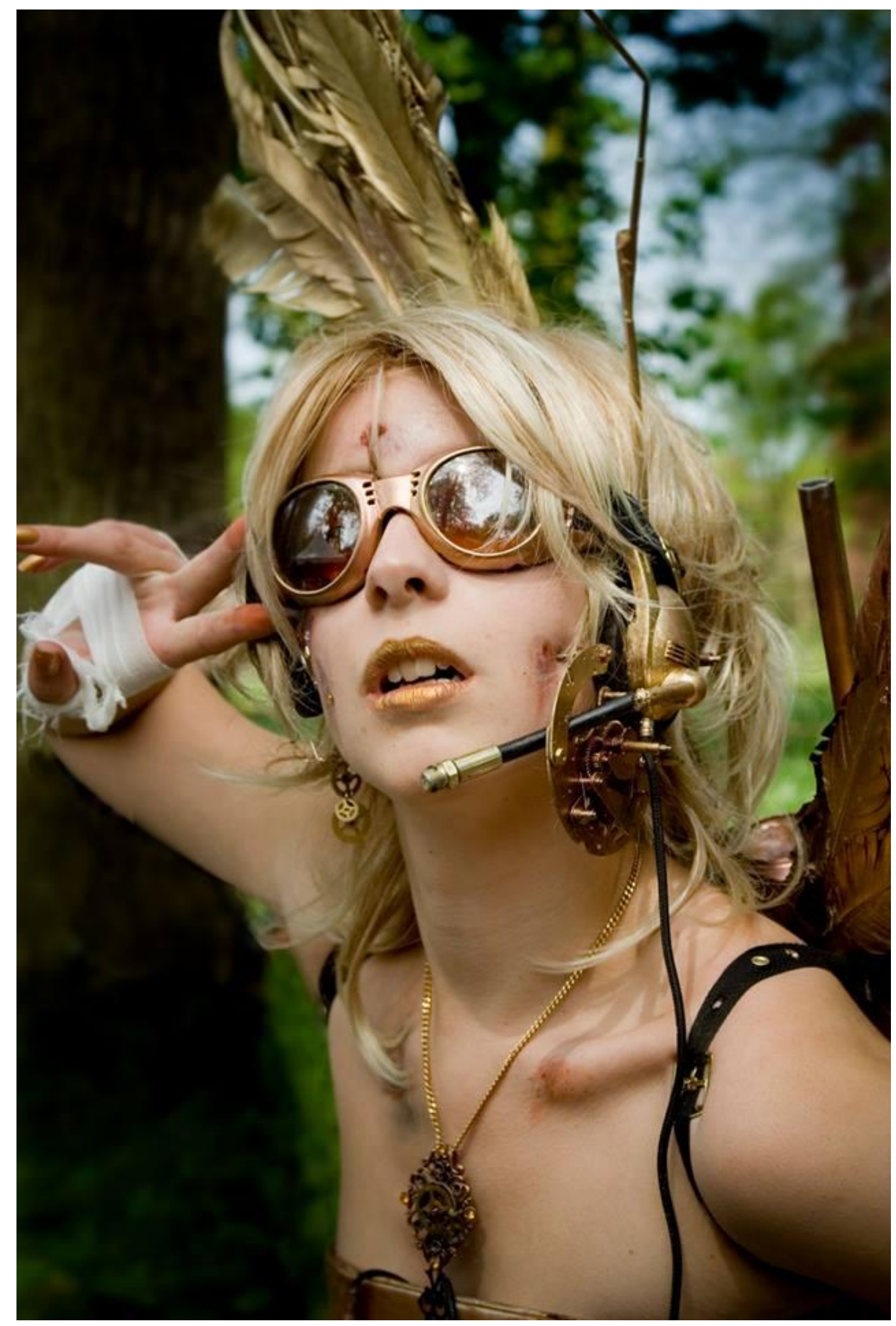

Photograph of Diana de Mol by Elf Fantasy Fair 
$\infty$

\title{
ELF FANTASY FAIR 2010
}

\author{
Nerd Spotting
}

\section{Fantasy Fairs}

Historically, fantasy fairs are a typical continental event but amply inspired by American Renaissance fairs. The first Renaissance fair in the United States was a weekend event held for charity by a school teacher in 1963 which has been organized annually ever since. The European tradition has held events similar to Renaissance Fairs for many years, based on previous eras or historical fiction, such as Dickens' novels. However, these events often have a strong educational component to them and are often captured as "living history" that re-enacts the past. On a local level, the Netherlands has various events that display its folklore, such as nostalgic markets that include the re-enactment of historical labor and technologies. More permanent institutes have rebuilt entire towns, such as the medieval and Graeco-Roman theme park Archeon. However, events like the Elf Fantasy Fair have clear commercial aims and emphasize fiction over history.

Often promoted as the biggest fantasy event in Europe, the Elf Fantasy Fair gives range to about 25,000 people each year. The event is held on a Saturday and Sunday. While some visitors enjoy it for two days, most attend the festival only for a day. The Elf Fantasy Fair typically engages in a type of world building around its event. Its lore and myths flourish around the idea that the terrain of Haarzuilens is transformed into the mystic land of Elfia. Rituals and parades in honor of Elfia, symbolized by an annual king and queen, are meant to foster this fictional immersion.

For a scholar who wants to dive into media fandom, this fair is surely a good place to start. The fair is held outdoors at castle De Haar in Haarzuilens, near Utrecht. A special bus takes visitors from local train stations to the festival grounds. Others travel by car, which is what my friend Shanna and I do. On April 25, we drive from the south of the country to the tenth edition of this festival. It is the fifth time that I join the fair.

\section{Fictional Bricolage}

The fair has diverse settings that allude to historical and fictional genres. We are supposed to volunteer at the "Manga Holodeck" which blends science fiction and 
Japanese popular culture. Since we have ample time before Shanna's workshop starts, we explore the Elf grounds and meet up with Karlijn, a fellow artist of our doujinshi ${ }^{1}$ circle OpenMinded. The three of us admire the sights, but do not look at the merchandise that much. None of us is really interested in buying things. We attend the fair for the people, the atmosphere and to see some familiar faces every once in a while.

Our hike takes us from the "Dark Woods" to "Medieval Road" and back to the castle. Our friend Diana has a stand somewhere but we have some trouble finding it. She has made a very elaborate fantasy costume with huge wings and lots of laces, she told us, and should be easy to spot. Eventually we find her surrounded by a group of photographers and take some photos of her ourselves. Diana is also the official Elf model this year. She is featured on the posters in her "steampunk" 2 costume, a nostalgic outfit with goggles and mechanical wings (see figure) that has won a prize last year. She is also on the back of the festival map with a previous dragon costume of hers.

During our walk, Karlijn excitedly envisions the next anime convention. Karlijn works for the manga library "Mangakissa" with two good friends of hers and hopes to introduce me to them. A simple stroll over the festival's ground takes us roughly two hours since the fair has expanded immensely compared to previous years. The stands sell commodities that vary from books, mead and jewelry to gothic outfits. The musical atmosphere is created by bands and taiko drums to which some visitors start to dance. Since it is a warm day, local stands host readings and workshops outside rather than in the designated tents. Some stands focus on Japanese popular culture but strikingly, these are not located near the manga platform.

The Elf Fantasy Fair is a highly diverse bricolage: an immense flock of fictional characters and genres. The conversations that I have with friends and acquaintances are about any and all fiction. Karlijn, who knows that I am into Wicked, talks to me about her experiences of visiting the musical but quickly migrates to Disney television series. Others recommend new television series or discuss fiction based on costumes that they see walking by. Some of my informants show open disregard to some mainstream series. The many Naruto cloaks and blue Avatar (2009) costumes are seen as a sign of bad taste and juvenility. Thus, fan hierarchies are constructed at the fair, based on what people

\footnotetext{
${ }^{1}$ Japanese fan comics or original comics that are self-published. Dutch comics tend to be original works inspired by the aesthetics of manga and its production models.

2 Steampunk is a hybrid genre of speculative fiction that is staged around mechanical technology driven by steam. Its pseudo-Victorian visual style is composed of material and technological tropes (e.g., gears).
} 
wear and do. While the space may seem inclusive, celebratory and immersive at first, exclusion is also a part of its social dynamics.

\section{Dress Up}

Though visitors clearly attend the Elf Fantasy Fair for diverse reasons, they share an interest in self-expression. Clothing is an important way of connecting with the others at the fair: even if that clothing only consists of a Power Rangers shirt or gothic jewelry. The diversity of the fair is supported by the visitors themselves, who have dressed up appropriately. While many visitors have donned their own designs or gothic dresses, others have made fan costumes of existing characters. While fans are often liberal in terms of gender and sexuality, the fair shows few signs of this. During our walk, we see hardly any visitors cross-dress - save for a male Snow White whom we immediately photograph.

The nice thing about the Elf Fantasy Fair is that you never really know what to expect. Any minute you can bump into Cleopatra, Jack Sparrow or a Naruto cosplayer. I wear an outfit from the G.I. Joe comics which does not draw that much attention. At the Flemish convention F.A.C.T.S. (2009), I had been recognized by many people in their twenties who had grown up with the cartoon. At the fair, compliments are scarcer, though some photos are taken.

Those who are not dressed up are usually photographers, parents or wingmen. They can also be attending for the first time or be frequent visitors that have skipped a costume for practical reasons. For instance, I bump into an acquaintance of mine who had been working on an elaborate guard outfit based on Burton's Alice in Wonderland (2010). However, after having arrived at the fair, he had ruined his costume when he tried to put it on at the parking lot. Naturally, he is still upset. He had spent hours on painting the outfit. He tells me that he has not seen the movie yet but that he is quite fond of Alice stories in general. The tale itself and the design of the outfits was a primary reason for him to pursue the costume.

I meet another friend later that day: Kees, an older fan and amateur photographer. He has attended the Fair for many years. We sit on the grass and discuss the festival. He accurately describes it as "nerd spotting". 'Most people', he says, 'go here to show themselves off and watch others do it too.' He states that the costumes and the atmosphere are what draw people to the castle. The Elf Fantasy Fair has a long history 
and is conveniently located near Utrecht, but the castle and its impressive garden are above all a sight to behold. The terrain offers enough space to hang out, plenty of grass to sit on and enough fellow geeks to watch.

Still, a visitor of the fair can make new friends too. For instance, I bump into a Takarazuka ${ }^{3}$ cosplayer who portrays the Japanese version of "der Tod", the male lead from the musical Elisabeth. The Japanese appropriation of this Austrian classic stands out from its original. I recognize the costume immediately through the white wig and the black, feathery cape that symbolizes the wings of death. The encounter with this fan excites me since Takarazuka fans in the Netherlands are hard to find. She tells me that she has become acquainted with Takarazuka through musical fandom. She is an Elisabeth fan like me, and eager to see more of the Japanese shows. The woman explains to me that she wants to go to Japan - luckily her boyfriend's brother lives there - to visit a show and get the DVDs. After this short chat, we disperse without each other's contacts.

Visitors of the Elf Fantasy Fair have undoubtedly had the same experience that I had: one of marveling at the characters and fans that you meet. My friend Karlijn, for instance, is wearing her cosplay of the Ghibli movie Kiki's Delivery Service (1989) and is recognized by a few enthusiasts, among whom an eight-year old girl. She is also wearing a Kiki outfit. The two of them take several pictures together and Karlijn is more than excited that she shares common ground with such a wonderful, shy kid. The sport of recognizing characters is part of the fair and also one of the elements that makes a stroll across the festival grounds so much fun.

\section{Labor}

The fair is also a place to promote your own shop and crafts. My friend Christel has a stand where she sells corsets. While I am chatting with her, several members of anime fan club drop by that we have not seen for ages as well as a staff member from our former LARP society. Christel's table quickly turns into a fan hub. We are all at the table to support her and are connected by our friendship to her. Christel started her own company two years ago when she had finished her fashion education. Sewing had been her thing for years. She had always been willing to help me out when my own cosplays

3 Takarazuka is a theater school and show choir in Japan for young women. In their shows, women play all leads, including the male ones. 
became bothersome and difficult. Ever since med school, she had dreamed of becoming a professional seamstress. Finally, she realized that she needed to switch her education and just give it a try.

Now Christel is standing at the fair for the second time to sell corsets and jewelry. Since a few months, she has been working for the atelier of celebrity violinist André Rieu. The day before the fair a documentary had been on TV about Rieu starring Christel, who had been too shy to tell everyone about it. For her, it had always been about the dresses. She was doing what she loved the most by working in the theatre on pretty attires. When I leave her stand, I wonder if I might visit Rieu's concert at the Vrijthof this summer to see the dresses on stage.

Usually the Elf Fantasy Fair is also populated by various LARP groups who give demonstrations of their play. This year, the groups are practically absent. On the map, I see that there is at least one group present that I overlooked: "Fase 3". Its players can easily be recognized because this particular role-playing game focuses on warfare and is inspired by military genres rather than fantasy fandom. Many players wear uniforms or steampunk gear. Rumor has it that during their sessions they are up all night in the woods and stand on guard. That is to say, they battle and behave like actual troops. The LARP stems from science fiction and tactical shooters, a genre of digital games rather than fantasy.

At the end of the day, I attend a movie workshop. This session is about movie making and Shanna is eager to go there since it is related to a project that she is working on. She has gotten a job as a freelance artist to make a comic based on the novel Fantasiejagers (2007) by Mel Hartman. This is Shanna's first job since she has graduated in illustration. Years ago, I lured Shanna into drawing comics for our artist group OpenMinded. She is not our only artist who went professional, since many of them got jobs in the media industry or art scene. Shanna is now working with Mel Hartman's script and has also brought her large A3 drawings to show the author.

As with any story that is produced these days, a novel version and a comic version are not enough. Fantasiejagers has gotten another grant for a movie version, Fantasy Hunters (2012). The director, Pedro Chaves, hosts the workshop while smoking and with his sun glasses on. All of us sit on the grass and Shanna and I hope that he mentions the Fantasiejagers project, but he does not. He has recently directed a low-budget $(6,000$ euros only) movie called Reiki (2009). This is the subject of his talk that instructs us on 
how to make a cheap movie. Reiki has been produced solely through fan labor by a team of amateur editors, crew and actors. Pedro tells us that as long as you are creative, make good use of various online platforms and are willing to work with other young professionals, you can pretty much do anything. Reiki seems a fine example of a cult movie that includes zombies and science fiction themes. Only one member of our small audience has actually seen the movie, but he admits that he liked it.

Though his talk is not very engaging, I admire Chaves. He tries to motivate ten people sitting in the grass who are not professionals but simply interested in what he does. Flagging his small-press edition of Reiki with manga art on the cover, I can only smile at him. He shares many qualities with us doujinshi artists who keep investing in small projects, hoping that the readers will show up. He extensively promotes his content online, but with an overflow of creative products today, his work may not stand out.

In times when I am cynical about the professional opportunities for fan works, Chaves' optimism is striking. I am weary of these kinds of talks that make everything sound easy and doable; talks that emphasize talent and creativity. They make me itchy because I have seen how hard my artist friends have worked to get where they are. Shanna, for instance, got her contract because she had worked hard to improve her drawings and constantly studied characters, objects and landscapes. Christel made many LARP costumes and cosplay outfits since she was a teenager, before Rieu employed her. Karlijn started a webcomic from scratch and is now studying animation. Every second of footage requires her to draw countless frames.

In terms of creative labor, fans work hard and can excel in their craftsmanship. Some become professionals while others remain highly appreciated within the creative culture of fandom. The fair is run by passionate individuals who sell their own clothing, art and literature. This is one of the most interesting aspects of the festival. It showcases the sheer passion of crafters, storytellers and hobbyists. I have seen many fans go stellar in pursuit of their dreams. Still, I always remind myself of how hard they worked to make this happen. 


\section{2.}

\section{FAN MEMBERSHIP \\ Traditional and Digital Fieldwork}

\section{Introduction}

The study of fans requires a methodological framework that can account for its social, creative and affective features. My cases address textual and visual consumption as a lived experience and are investigated through methods from both the social sciences and the humanities. This study is interpretive and therefore relies on various qualitative rather than quantitative methods.

My methodology can be summarized in two ways. First, ethnography allowed me to collect information by participating in fandom both online and offline. In addition, I used both informal and in-depth interview techniques to shed light on what fandom meant to my informants and how they viewed their creative practices. I did, however, also include my own affective experiences of fandom. By incorporating my own voice, I felt that I could better signify what certain creative and playful practices are like and what a source text does to fans.

Second, I have combined these social methods with a medium-specific analysis of the fan texts themselves and their source texts. This combination of narrative analysis and ethnographic methods is innovative and necessary. Important claims have been made to combine close-reading with other types of data, such as in-depth interviews (see also Gray, 2003). A good example of this two-fold method is the study by Joke Hermes (2004), who discovered in her research on detective novels that fans highlighted specific textual structures that she had interpreted differently (pp. 79-96). My credo is that a scholar's method is related to the type of data that s/he wants to unearth and that one should not be afraid to use inventive methods to provide a valid overview.

In this short chapter, I provide a critical overview of the methodological underpinnings of this study. First, I address traditional fieldwork and the challenges in researching these communities while I am a fan myself. Then, I discuss this qualitative approach to online platforms and digital media. Finally, I end with ethical notes that are useful for future fan research. 


\section{Methods of Audience Studies}

Over the past decades, we have seen an increase in the application of qualitative methods such as ethnography and interviewing in cultural studies. Historically, the analysis of texts, movies and their audiences clearly belonged to the humanities and involved methods such as close-reading and discourse analysis. The social sciences, in turn, examined lived cultures. In the 1980s, this trend slowly started to shift when cultural studies began to gain more ground. In their media studies, scholars such as Michel de Certeau (1984), Stuart Hall (1973), and John Fiske (1990) combined insights from different disciplines. At the same time, literary scholars realized that they could no longer make strict divisions between the text and the reader.

From this period, the feminist studies of Janice Radway (1987) and Ien Ang (1985), who combined reception studies with feminist theory and explained how texts were situated by their largely female audiences, especially stand out. While Radway formed focus groups to study the readers of romance novels, Ang let fans of Dallas write letters to her and studied these letters to get a better understanding of the reception of this soap opera. These are only two examples of a wider shift in academic thinking about texts. More scholars started to realize that, as Gray stipulates, 'the text must be seen as both a product of particular social, cultural, and historical conditions and as an agent in circulation' (2003, p. 14).

Paramount to these innovations, the study of the audience itself developed into a wider field. Today, the audience is not studied as a tool to better understand the text and its dominant interpretations, but it has instead become an autonomous field of inquiry. By audience studies, I refer to those studies that investigate the formation of cultural identities related to texts; these studies may come from various disciplines. Cultural studies, literary studies and media studies became interested in audiences as a way to analyze how people react to and appropriate cultural products (Fiske, 1990; Jenkins, 1992). In short, we have gone from text to context, from art to lived cultures that can be studied in mutual dependency. Today, the reception of texts is even more pertinent because our identities are increasingly anchored in global and dispersed media networks. This study continues in the vein of these earlier works that have approached textual studies in relation to social sciences. 


\section{Insider Ethnography}

Another important aspect of the method used is my positioning of myself as an insider in the field. I have already referred to my own experiences as a fan of media texts, and those lived experiences shaped this research in many ways. This ethnography relies on two approaches: participant observation and auto-ethnography. The first position means that I gathered data through an ethnographic stance as a researcher who not only observes but generates knowledge by participating in these communities (Spradley, 1980). Participatory fieldwork has been conducted in several online and offline communities. I attended relevant field sites, such as fan conventions. Because digital methods have specific implications for transparency, data use and ethnographic stances, my approach to online fields is detailed in a separate section. Comparable audience studies have been conducted on video game players (Pearce, 2009; Taylor, 2006) and Internet users (Markham, 1998).

I noted my experiences by applying Geertz's (1973) "thick description", in which the researcher makes extensive field notes that are not just observations but also include interpretations of the actors involved and reflexive notes (pp. 5-6). My participant observation was also structured along different memberships. Adler \& Alder (1987) defined two stances within participant observation, namely an "opportunistic" position and a "convert" one (pp. 67-84). The opportunistic researcher conducts a study on a community in which s/he is already active; the convert becomes an insider through the research. In practice, it is difficult to distinguish between just these two positions. My own research shifted between close contacts and new fields. My cases were also sampled based on the idea of moving closer to some fields than to others. For my study of Sherlock, for instance, I drew data from communities to which I subscribed for my research but also included interviews with people whom I found through my own social networks.

Different stances can thus be adopted to represent one's data and research topic. Influential scholars have suggested that ethnographers adopt modes of increased participation and revisit their data multiple times (Spradley, 1980, pp. 53-58). Others are weary of the emotional or psychological bias that such a social performance implies. Conquerhood (1985) laments the ethnographer who acts too cynically and distances himself excessively from the material and who has a similar analytical bias to his optimistic counterpart. Ideally, scholars should not forge distance from or closeness to 
informants but should instead find a healthy middle ground between the two. The analysis can also be enriched through close interaction with the informants, which he calls "dialogical performance" (id., p. 10).

In addition, this study deploys auto-ethnography to make sense of fan cultures. Auto-ethnography is a type of insider's ethnography that reflects on the life history of the researcher and thereby provides tentative conclusions about certain historical, social or artistic issues. Ethnography and qualitative methods in general have often been credited as being suitable ways to unravel actors' lived experiences (Gray, 2003, p. 16). Notions of identity can be tackled especially well through this type of research because it can amply reflect on how the self is positioned in the world and shaped by discourses. This method has been applied to unearth what it means to belong to a certain community and how its social hierarchies function (Chang, 2008).

Using an insider approach to discuss the impact of popular culture, or consumption patterns at large, is nothing new. Holbrook (1995) uses auto-ethnography to address issues such as shopping and collecting. McLelland (2002) draws from his own experience as a homosexual to investigate gay life and dating in Japan. In research on fandom, adopting an insider's approach has been positively valued. Henry Jenkins (1992), for instance, relied on his experiences as a Star Trek fan in his earliest book but made new contacts for case study on Beauty and the Beast.

In this auto-ethnography, I reflect on my own engagement in fandom. I not only draw from prior knowledge and make this transparent but also reflect on my feelings when producing or consuming media texts. What I also consider is my development as a researcher within a certain community and the way my presence has given shape to a field in which I am personally invested. This method differs from participant observation, which I believe to be more socially situated and extroverted: whereas this method turns outwards, auto-ethnography turns inwards and uses one's own body as an instrument. What I learn, what I feel and how I experience fandom myself is of the highest importance in this research. Especially in the ethnographic vignettes, this stance becomes explicit. I am an insider who does not hide her alliance to the subject but instead analyzes her own investment.

Auto-ethnographies also familiarize the reader with the field in an engaging way. In particular, these accounts help explain specific social contexts to an unfamiliar reader. This exploration and understanding is essential in the study of fans especially because 
many people do not actively engage in fan communities. Simultaneously, autoethnography can be a way to add nuance to theoretical stances, provide casual counterexamples to wider debates, and show what types of feelings and meanings are generated in relation to particular cultures. The benefits of the methodology are its focus on immediate, lived experiences as the researcher has perceived them and its attention to membership and personal learning curves.

However, it can sometimes be difficult to balance what experiences are representative for the research and how many biographical elements are appropriate in a close-reading or social study. For instance, in his media analysis of the Wizard of $\mathrm{Oz}$ (1939), Alexander Doty (2000) admits that he had to carefully weigh the relevance of his personal experiences (p. 13). I solve this balance through methodological triangulation, as explained in the next section. I combine participant observation with interviews and online data as well as the close-reading of source texts and fan practices. Rather than producing personal anecdotes, I test my own experiences and give them validity by combining them with other methods. I realize that my ethnography is highly situated and can only be generalized to a certain extent. I have undertaken this research with self-reflexive awareness and an understanding of the contextual limits of personal ethnography. I realize that this mode of analysis is deeply informed by my gender, sexuality and race, as well as my ethical responsibilities as a human being.

\section{"Aca-Fan" and "Geek Feminist"}

The role of the researcher has been discussed in fan studies at large. Matt Hills provides a framework for the insider's stance in Fan Cultures (2002a). He describes the figure of the "scholar-fan" or "aca-fan" as a scholar who also happens to be a fan or becomes a fan through the cases that s/he researches. This is in opposition to the "fan-scholar," who is primarily a fan who applies scholarly methods to arrange and produce knowledge about the texts that s/he loves. Since Jenkins published Convergence Culture in 2006 and started his blog Confessions of an Aca-Fan (2006-ongoing), the figure of the aca-fan has been widely popularized and has become a template for many fan scholars and media scholars at large. The methodology that the aca-fan deploys is a strand of autoethnography or participant observation, depending on how the researcher uses his or her experiences and contacts. As in any type of insider's ethnography, being an aca-fan allows for many levels of participation. 
In contrast to auto-ethnography, an additional claim is made against the aca-fan. Certain critics believe that the figure's enthusiasm may hinder criticality. Notably, Ian Bogost (2010) stirred a methodological debate about the strength of the aca-fan model. 'Embracing aca-fandom is a bad idea', he argued. 'Not because it's immoral or crude, but because it's too great a temptation. Those of us who make an enviable living being champions of media, particularly popular media, must also remain dissatisfied with them. We ought to challenge not only ourselves, our colleagues, and our students - but also the public and the creators of our chosen media. We ought not to be satisfied.'

Bogost's entry was visited by many prominent media scholars, including Henry Jenkins and Kristina Busse. What made a proper ethnographic stance? Was Bogost not glorifying research on the high arts and criticizing scholars of popular culture? I argued in the comment thread that the aca-fan point of view granted me many advantages. The insider's perspective allows me to tackle easy mistakes because I am knowledgeable about fan cultures. Informants not only knew that they could trust me, but they also often approached me directly or shared my work. However, academic fans have different memberships in the communities that they research and often subscribe to new ones to get a different perspective and new contacts. Even if they research fan communities around the texts that they love, doing so does not imply that they already know the fans, the relevant platforms and situations.

The criticism of ethnography, however, has less to do with opportunism and more with the idea that the media ethnographer has an interpretive bias because $\mathrm{s} / \mathrm{he}$ is too overwhelmed by the research topic, a problem that exceeds fan studies and is relevant to many other types of cultural studies. Scholars of media and literature are always first and foremost audience members and must not be read as privileged. They are inherently involved with their research topic. Even in the hard sciences, we cannot remove affect from the equation. Most scholars grow to care about the topics that they research as well as their informants. Every qualitative method balances between intimacy and distance. This is a challenge in all disciplines. An ethnographer in Ghana may face similar problems negotiating the social and affective relationships with informants as a fan scholar. At the other end of the spectrum are those who purposefully position themselves close to their informants. Scholars of sexuality and intimacy have often addressed the need to reflect even more on feelings regarding their informants (McLelland, 2002). 
Ethnographic criticism can only be countered with self-reflexivity and proving the method's worth. As Joke Hermes (2005) writes, 'Interpretive ethnography questions the position and authority of the researcher her or himself, and urges her or him to be selfreflective to a much higher degree than mainstream research would ask for' (pp. 146147). Being explicit about your position as an insider offers opportunities to be trustworthy, to position yourself in the field and to be reflexive. As a reflexive practice, ethnography allows the scholar to move closer at times and to be more distant at others. Ethnography means being surprised by the field, which also requires one to stand back, marvel, and experience situations anew when possible. The artistic guide How to be an Explorer of the World (K. Smith, 2008), with its highly visual exercises in collecting and documenting the everyday in new ways, helped me develop my sense of wonderment.

Although I have defended the concept of insider ethnography until now, I must admit that the aca-fan model also has its downsides. Its strength is that it emphasizes fan loyalties, but this stance is too narrow to describe my activity and engagement with the source texts. That is to say, I am certainly not a fan of all of my cases and am even highly critical of some of the series that I investigated. Moreover, the aca-fan model does not include the dimension of social awareness and activism within media cultures. Throughout the conduct of this research, I engaged deeply with issues of representation in media culture. I often felt that my position as an adolescent female fan informed my opinions more than my affect towards certain genres of fiction.

Therefore, I feel that it is more accurate to describe my viewpoint as aligned with "geek feminism," which promotes women's critical online activity and their engagement with media technologies. Linguist Bucholtz (2002) coined the term in her studies on female computer users to outline a theoretical and socially engaged view point informed by the legacy of feminism while retaining geek identity: 'Geek feminism, like all political affiliations and identities, is not a category with which to classify individuals but a stances that shapes and is shaped by social practice' (id., p. 282). Bloggers have been quick to pick up the term and developed the platform Geek Feminism, founded in 2009. This blog articulates female geek identity and critically assesses media representations and user cultures. More than ever, the term "geek" refers to a positive alignment with popular culture rather than a pejorative one. Geek connotes enthusiasts and hobbyists and even suggests a particular life style that revolves around Internet or gaming capital. Merchandise lines from Hot Topic and ThinkGeek increasingly cater to "geek girls" as 
well. Geek is becoming a female, marketable identity but also one that is increasingly associated with a critical subculture.

I believe that geek feminism, rather than aca-fandom, accurately captures my independent critical perspective that unites my roles as a fan and scholar. Similar to my informants, I invest in resistive creativity, emancipatory media representations and free culture. I do not shy away from progressive discussions and interventions with my subjects. As an anime fan and science fiction enthusiast, I am well aware of the heteronormative context of media culture and the social protocols within fandom. I engage in many creative fan practices myself and invest in critical approaches to popular culture. To me, geek feminism means a critical pursuit of media content and its social wealth, as well as an agenda for social change.

\section{Online Ethnography}

This ethnography is not only characterized by its insider views, but also by its combination of online and offline data. Online spaces have specific implications for participation which require further unpacking. Online ethnographies such as my own have been explored under the headers of "virtual ethnography" (Hine, 2000), "netnography" (Kozinets, 2010) or "cyberethnography" (Ward, 1999). Still, every concept has its own nuances and implications. I use the more neural term "online ethnography" because I have drawn insights from all of these methods and do not want to enter ontological debates about the virtuality of the Internet. More importantly, I do not want to make online ethnography into something innately different from traditional ethnography. Although some would highlight the differences between Internet spaces and traditional fields, I also want to be clear about the similarities. Annette Markham (1998) shows that, in online contexts, the body of the researcher facilitates social experiences. The Internet cannot easily be separated from one's habits or home. Like any other ethnographic undertaking, it involves journeying towards a field and taking notes on it. Studying the web is a journey with real consequences for the researcher.

Moreover, online ethnography addresses sites that are mediated and technological constructs. I have used studies on science and technology to theorize how Internet use functions in practice. Technologies do not produce certain effects but are given meaning by the social groups that operate them. Although common user patterns may arise, there is great leeway in how we understand these technologies and what types of culture can 
form around them. Technology is not a neutral tool but is always given meaning by the users themselves. The Internet is but one example of how people have constructed social and cultural patterns around a new technology.

Online platforms are a clearly mediated space that can best be understood in combination with other qualitative methods and offline spaces. These spaces cannot be divided easily, though some methodologies describe the Internet as a separate space. As Kozinets (2010) writes, 'The virtual intended to signal an effort that is necessarily partial and inauthentic because it only focuses on the online aspect of the social experience, rather than the entire experience' (p. 5). The Internet is as much its own culture as it is part of other traditional cultures. To understand this new technology, we must look at actual user practices. As an online ethnographer, it is my job to understand online culture as part of culture as a whole: a lived and shared experience, rather than a textual or mediated experience.

Membership in digital communities bears many resemblances to its traditional counterparts. The question of membership, for instance, is an important one in both fields and has frequently been discussed in the context of online environments. In her study on multi-player virtual worlds, Annette Markham (1998) has shown that individual users valued the role of such communities differently. While some informants clearly considered these spaces to be an enrichment of their social lives, others had more reservations and discussed them as a form of entertainment. As in traditional communities, members may develop important social relationships in these communities depending on the frequency of their participation and how well they are embedded within its social structures.

Online communities also pose specific challenges for the researcher, however. First, they allow for more modes of interacting with the field. Kozinets (2010) describes the scholar's development in the field from an outsider to an insider that can increasingly participate, by not only posting comments but also engaging in feedback processes and projects and even taking up leadership roles (pp., 74-95). In my research, I experimented with these levels of participation and closeness to one's informants. This choice was related not only to the questions that I wanted to pose but also to the structures of these communities. Sites such as YouTube or DeviantArt function less as discussion forums and more as portfolios where many users host their work. Here, getting a large overview is almost impossible, and scholars are forced to "lurk" at a site, 
i.e., observing a community without others being aware of his/her presence (id., p. 35). Online, it is possible to be invisible, which makes an enormous methodological difference. Although I tried to stay visible, meaningful interaction was not always possible because on larger sites with networking features, discussions tend to take place on people's profiles or in response to art works or videos.

Second, online data can be recorded very differently than in traditional fields. I stored a great deal of data by pasting them in Word documents, taking daily screenshots, and scribbling notes with interpretations. These notes fundamentally differed from my traditional field notes, which were more personal and involved fewer quotations. Moreover, my traditional notes were mediated at least twice as I initially penned down thoughts in the field and then substantiated them at home - a process during which I was already interpreting their meaning. Many contemporary scholars also use data mining or other tools to get a larger overview of relevant statistics and issues. In my case, such methods did not contribute to the research because the online communities were relatively small and the insights that I gained were always triangulated with other qualitative data.

Third, online research is very delicate in terms of presence because the researcher is not always present as a researcher or leaves traces as one. This raises ethical questions that often scare young researchers such as myself. Luckily, many rules about online research have been written down. The Association of Internet Researchers formulated guidelines to preserve quality and integrity of online research (Ess \& AoIR, 2002). These carefully phrased recommendations bring to mind Markham and Baym (2009)'s warrant that research in online environments should not be rule-driven as "the ethical treatment of human subjects is inductive and context-sensitive" (p. xviii).

By speaking to my informants and keeping them posted, I tried to treat my informants respectfully and make my research as accessible to them as possible. To be sure that people knew I cited them, I always contacted informants. However, I met similar challenges in my traditional ethnography and am not eager to see these as new online problems. Rather, these challenges are integral to any type of research design that engages with human subjects and cultures; however, there are a few ethical considerations specific to fandom that I would still like to share. 


\section{Ethical Guidelines}

The book has been written in a constant dialog with the communities that I investigated. Throughout this project, I tried to be clear about my membership in both fan communities and academia. I let myself be surprised by new situations and encounters. In addition, I asked for permission to cite fan texts and comments, in line with the policies of the fan research organization Organization of Transformative Works. Their rules on the quotation and treatment of human subjects also deeply encouraged me to stay in touch with my online informants. Keeping these users informed without seeing them on a regular basis offline proved to be a daunting challenge, as some informants left the Internet spaces that we shared.

Moreover, in terms of time, I could not participate in some fan spaces as much as I would have liked. This ethos also pressed me to think about how deeply I wanted to engage with certain fan sites and whether announcing myself there was at all possible. I studied various online communities with different stances. When I studied online communities in detail, I made it a rule of thumb to contact moderators and users to announce myself as a researcher. However, many sites also had an exploratory function in my research as a space in which I could make my primary observations. In such cases, I was more liberal with how I presented my research and data collection.

To facilitate an open dialog, I kept my close informants updated on the progress of the book and the study. This allowed me to generate interest in my research as well as feedback. I created a blog to encourage more transparency in this process and sent relevant chapter drafts to fans. I viewed this collective process as a valuable one and hope that I may explore it further in the future. As Celia Pearce (2009) notes, ethnography is a social construct that influences the group as much as the researcher, who should not pose as an authority but should be on equal level with the others (pp. 64-65). This was my rule of thumb throughout the study.

\section{Conclusion}

Thus, Productive Fandom has a unique methodology in several ways. First, many of the chapters rely on traditional data such as in-depth interviews and participant observation. Within fan and audience studies, these methods have moved to the background in favor of online methods and investigations of digital culture. My own hybrid method aims to capture fandom as a rich and social space of production. The 
combination of digital and traditional fieldwork is an important characteristic of this book. While online data reveals patterns in fan interpretation and creativity, the offline space may generate more insights in fan cultures as they are lived and felt. The offline space can also be used in addition to online findings in a mixed method approach. I believe that such a combination of fields and approaches is suitable for future fan studies. While research on fans tends to demarcate online spaces or communities, fandom is a dynamic phenomenon and its communities are heterogeneous and diverse. This combination of lived and mediated insights can effectively capture the experience of fandom which is never isolated, but always embedded in different social contexts. 


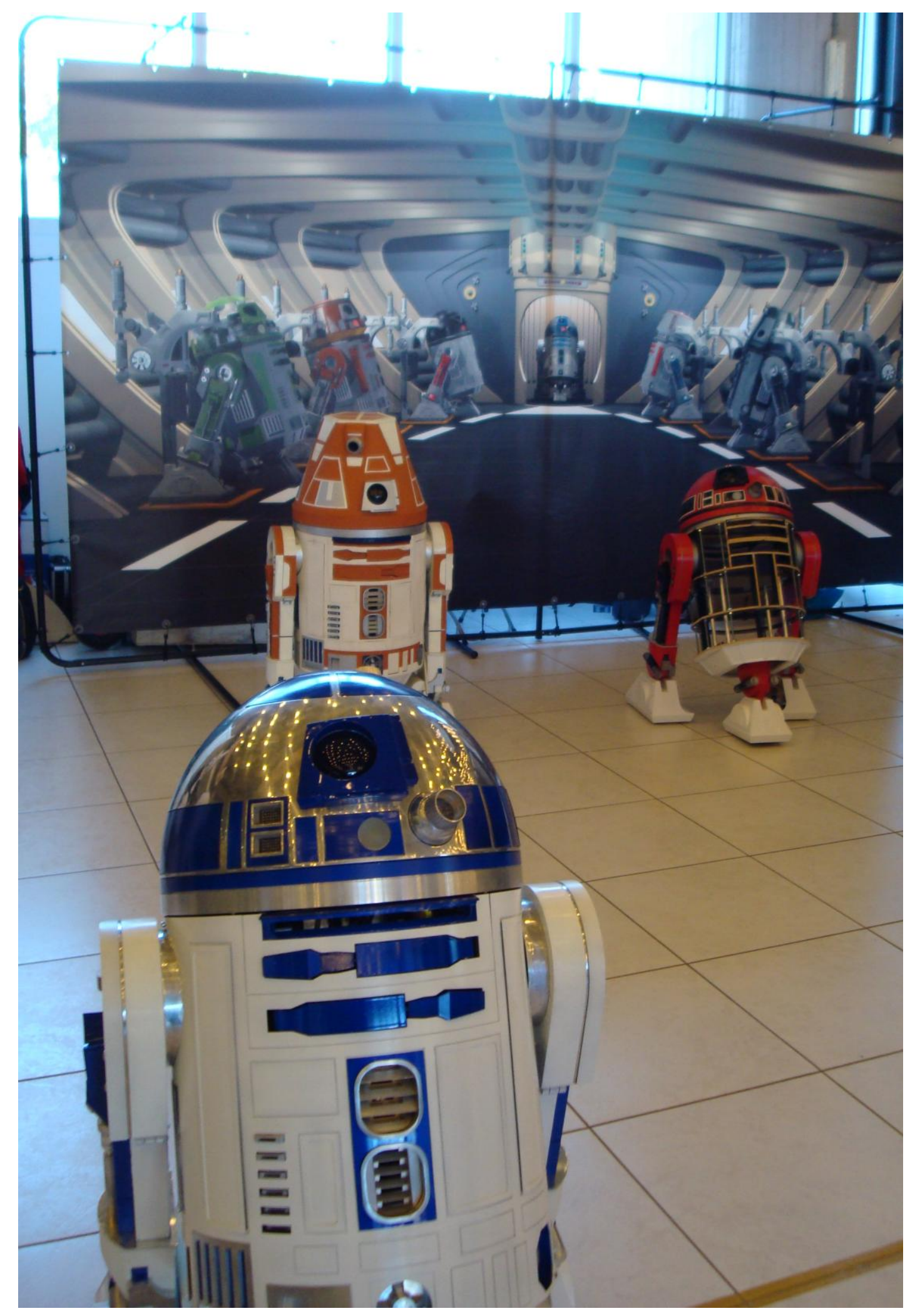

Photograph of fan-made R2D2 by Nicolle Lamerichs 


\section{F.A.C.T.S. 2010}

\section{Treasure Hunt}

\section{Guests}

Since the summer of 2010, I have been looking forward to attending F.A.C.T.S. in Belgium. The festival has invited interesting celebrities this year. Usually, I do not care about special guests but there are exceptions. When my friend Roderick and I had our picture taken with Richard Hatch from Battlestar Galactica (2004-2009) at F.A.C.T.S. in 2008, I realized that standing close to someone you have admired on screen for a long time feels special and intimate. Television suddenly becomes real. This closeness is valuable for us fans and cannot readily be captured in words. At a signing session or photography session, you get to meet a person behind the fiction, which can be inspirational or disappointing. Either way, shaking hands with the actors intimately connects you with the story that you love.

The twentieth edition of F.A.C.T.S. features guests such as Jewel Staite from Stargate Atlantis (2004-2009) and Firefly (2002) and Robert Picardo, renowned for his role as The Doctor from Star Trek: Voyager. My friends have travelled through the country to see Picardo and get his autograph. Star Trek: Voyager (1995-2001) is one of the most important science fiction series to date for us. The Doctor is iconic of the show and someone that we look up to. He has character, even though he is just a technical program, a medical hologram. Although he constantly belittles humans in the show, he longs to be like them and envies them for their freedom.

At the convention, we carefully try to plan our questions for Picardo and line up early. In the cue, I ask other fellow fans what they are going to ask Picardo. Most have trouble coming up with a good question. A few German girls behind us say you really cannot plan this. In the end, I just ask him how his flight went. He tells me that it was fine and that he rode the bicycle the previous day, just like a native. Nervously, I respond that I find that "extremely cool". We quickly take pictures of our friends when Picardo signs the official cast photographs. I admire the picture of him and the character named Seven of Nine with the scribble that is addressed to me. I got autographs from people before, but in less institutionalized settings. The autographs are important memorabilia to us: 
keepsakes of the shows that we enjoyed. Since all of my friends have picked different photos of Picardo, we take pride in their exclusivity. These exclusive strategies characterize the fan collector who often favors unique merchandise of particular characters and stories. For such a collector, F.A.C.T.S. has much to offer.

\section{Expo}

F.A.C.T.S. is an acronym for Fantasy Anime Comics Toys Space, a name that reveals a broad interest in popular culture and collecting. F.A.C.T.S. has a set-up and atmosphere that is quite different from that of Dutch conventions. The event is quite big for European standards and promotes itself as the "largest comics, science fiction and anime festival of the Benelux". As with many other conventions, the public visitor numbers are shady at best and estimated at 10,000 visitors each year. Since many fans attend the event only for one day, the convention never hosts quite that many visitors at the same time. Moreover, F.A.C.T.S. is more commercial than most conventions that I have attended. It comes closer to what we call a trade fair or "expo" that specializes in commerce. The festival is a marketplace that favors the commodity culture of fandom over events, guests, panels and workshops.

The earliest tagline of F.A.C.T.S. was "kopen, verkopen, ruilen" (buying, selling, trading) and it seems this motto is valid at F.A.C.T.S. today. Fan practices are present through the individual artists that represent them, those who sell prints or self-made comics. The only fan event at the convention is a cosplay competition on a small stage. Most participants do not engage in elaborate theatre skits but rather perform a choreography that reminds one of a fashion show. Others dance or quote a few lines from their favorite shows. Though F.A.C.T.S. prides itself on being international, its language culture is predominantly French and Dutch. For example, the cosplay competition is presented in Dutch and in French so that most visitors attending F.A.C.T.S. understand it. However, the dialogue of the skits themselves is frequently in English to readily mediate the language of the source texts.

For F.A.C.T.S. and Halloween, I made an outfit of the protagonist from American McGee's Alice (2000) in anticipation of its upcoming sequel. The story is an adaptation of Carroll's famous novel set after the death of Alice's parents. Depressed, Alice returns to Wonderland but her imagination is out to get her. I had never finished the game myself since it was complicated and unsettling. Still, I identified with Alice closely and that is 
partly why I could not end the game. Even though I had initially planned to wear my Alice outfit at Halloween, I thought that I might debut it at the convention early. Apparently, other girls had the same idea because I bump into three other Alices. One of

them hardly exchanges a glance, but the other two are chatty. We talk about how they tackled the outfit and what the game means to them. They describe Alice as striking and empowered.

Seeing other people dress up as the same character can be a wonderful encounter but also awkward. By announcing their costumes online early, Dutch fans often try to prevent others from dressing up as the same character at fan events. However, with popular series doubles can hardly be avoided. No one owns a character but fans often create strategies to show that something belongs to them. I care about Alice but my relationship with the game is not solely constructed around pleasure but also includes sadness and disgust. Though I feel that I look like her, there is something uncanny about performing a suicidal character. Alice is special to me in a morbid way.

\section{Fan clubs}

Aside from artists and conventions, fan clubs also have a special place at F.A.C.T.S. and bring costumes and props. We pass a Star Wars bar, for instance, and the Stargate portal that was also sported at the Elf Fantasy Fair. There is also an R2D2 club present whose members construct their own Star Wars robots (see figure). The robots track the convention floor and visitors can tell when a droid approaches by its cute electronic sounds. Members of the club built these robots themselves. I inquire with one of its members how the R2D2s are made, assuming that they buy parts of them online. However, the builder explains to me that they make the robots themselves from scratch and sometimes group together to work on them.

Even though the droids look and respond just like the real thing, they are remote controlled and contain no sensors. The builders purposely hide in the crowd when they navigate their R2D2s to maintain the illusion of autonomy. Most of the robots are made with aluminum and a lot of hardware. For instance, their sounds are produced by an MP3 player, hidden within the robot. As our conversation continues, the robots seem less real - a feeling that unnerves me. I am quite fond of the robots and want to see them as more real than they are. The R2D2s have been sliding over F.A.C.T.S. for as long as I remember. Sometimes they purposely bump into fans as a friendly gesture. Many people 
strike a pose in front of the robots. 'That one is a real attention whore,' my sister says when a particular R2D2 is bleeping near her again, endowing him with a sense of realness.

Other fan clubs are more traditional, such as the Flemish Star Trek fan club. The Dutch Star Trek fan club, ironically called "The Flying Dutch", has not actively been present at fairs and conventions for a while. I approach one of the volunteers of the Belgian fan club for information about their organization. She explains that the club has had a fair number of members throughout the years. They organize their meetings across the country every two months. 'Some of our members we never see, they only subscribe to the fan club because they are interested in the magazine, Warp 9, that the club publishes'. Others frequent the pub nights and are happy to engage in games such as Star Trek trivia.

\section{Commodities}

The main attention point at this event is commerce, for even though many people note that they come to F.A.C.T.S. to socialize or dress up, they also admit that the largest part of the con experience is the treasure hunt for cool items. F.A.C.T.S. caters to many fandoms and interest groups with its diverse merchandise. A visitor can search for comics and DVDs, but also trading cards, action figures, posters and statues. At the convention you can see products as diverse as Thunderbirds dolls; swords from The Lord of the Rings; the bathrobe from Rocky; Japanese Pokémon candy, and special edition Barbie dolls. F.A.C.TS. is the ultimate treasure hunt through popular culture. It seems as though anything can be bought while socializing deliberately makes up a small part of the experience. This is foregrounded in the convention's lay-out, for instance, which leaves little room for hanging about or chatting. The café is too small and there are barely any spots to sit down. Visitors are expected to move around and buy things.

At the stands themselves, there are some fan artists, comic artists, and one craftsman who carves wood into fantasy statues. Artists pay slightly less for their tables than commercial dealers who sell merchandise mostly for profit. Some of the artists who are invited are special guests like Dave Gibbons. He drew the critically acclaimed graphic novel Watchmen (1986). Most artists are locals though. Our artist group is present, for instance, and sells booklets and tickets for the Dutch convention YaYCon. Other Dutch fan conventions have their own stand, such as Tsunacon. F.A.C.T.S. is a good space to 
promote our festivals because the Belgium fans are not always familiar with the conventions in the Netherlands, though more specialized conventions like YaYCon capture their attention.

Though I am not keen on buying merchandise, I am swayed away by the luxurious geeky items that F.A.C.T.S. has to offer. I buy a Rose of Versailles statue of Lady Oscar, one of my favorite fictional characters. Other fans shop until they drop. They look for missing figurines and comics. They bring bags and ask vendors for rare items. I am not a real collector myself, but I understand why people like it. They make a hobby out of completing something. Having a great collection - whether that is in art or popular culture - gives a certain kick but is also an investment. However, I suspect that even diehard collectors may find the convention wanting. In general, it offers cool objects at a fair price, but nothing you cannot find online. Interestingly, several stands do sell first prints and autographs related to particular shows. Whether all of these activities can be signified as collecting is debatable. Most fans look for commodities that they like for a good price. In addition, they make products themselves or customize them.

Collecting offers a sense of ownership over the text and meanwhile, also preserves it. Like autographs or costumes, particular objects strongly mediate a show and become memorabilia. Other merchandise and representations, however, do not feel quite right. With two fans, I discuss the quality of the merchandise at the convention. We are particularly critical of the franchise of Toy Story 3 (2010). The movie had premiered in the cinemas a few months ago. 'If you want a Buzz, you want it to be the actual thing, the correct size,' said one, staring intently at a Buzz who was not quite right; 'otherwise it's beside the point.' She suggested that the toys of toy characters needed to be exact replicas and clear look-a-likes, or they could not be satisfying representations. Here, the desire of fans to actualize the narrative in an intimate way is central again as a form of reception.

At a Disney stand, my sister buys an exemplary mock-up of Lotso, the benign teddy bear from Toy Story 3. The size is correct and he smells like strawberries, just like in the movie. He even feels perfect, though perhaps a bit too soft for an old bear. At home, I try to find the perfect frame for my autograph of Robert Picardo but, until then, cherish the picture in a binder which I preserve near old action figures. I realize that for us fans, merchandise is just one way to bring a text closer to home. 


\section{3.}

\section{NATURALIZING SHERLOCK}

\section{Dutch Fans Interpret the Famous Detective}

\section{Introduction}

For international readers, Sherlock Holmes has always been considered the epitome of English culture. We picture him riding in a hansom cab through London, investigating dark alleys and tracing clues at a crime scene near the Thames. Throughout the years, pastiche writers have reworked the Sherlock Holmes stories by relating its main character to the cultural history of Britain and Europe, to other fictional texts such as gothic novels, or by introducing him to local detectives such as Arsène Lupin and scientists such as Freud (Boef, 2005). The staff of the BBC series Sherlock (2010) explicitly revises this characterization and chooses to portray Holmes in a contemporary setting. Writer Mark Gattis stresses in the documentary Unlocking Sherlock (2010): 'Sherlock Holmes has become so much about the trappings, about the hansom cabs, about the costumes, the fog, Jack the Ripper will creep in here. It's become a strange maelstrom of stuff.' In contrast, Mark Gattis and Steven Moffat give a fresh spin in a new time and setting.

Sherlock transforms some of the recognizable Sherlock Holmes features while simultaneously echoing an awareness of the stories and the history of their reception. International readers often have their own ideas of Holmes as a figure that are not influenced by the novels but by popular and local culture. Some audiences know him from movies, such as Guy Ritchie's Sherlock Holmes (2009) or The Case of the Silk Stocking (2004). Others picture him in relation to the Disney movie The Great Mouse Detective (1986), House M.D. (2004) or even Data from Star Trek: The Next Generation (1987-1994), who frequently played Holmes on the virtual "holodeck". The minute a reader starts to reflect on Sherlock Holmes, numerous images that are linked to locally and internationally known texts pop up.

This chapter focuses specifically on Dutch fans and how they understand a foreign series such as Sherlock and interpret its transmediality in practice. Dutch broadcasting and literature is influenced by Anglo-American media, and as a result, the image of Sherlock Holmes is constituted in relation to derivative works. At the same 
time, local adaptations shape the image of the famous detective. Dutch television or movie versions of Sherlock Holmes are non-existent, but the stories have been mediated into stage adaptations and pastiches (Den Boef, 2005, 97-98). In the theatre play Hond van de Baskervilles (2011), for instance, a few English actors gather in a mansion to reenact The Hound of the Baskervilles. By depicting these actors as English, rather than the well-known Dutch actors they are, the play explicitly categorizes Sherlock Holmes as the terrain of England's cultural heritage.

Dutch culture is a good example of how international viewers make sense of Sherlock because it has a different literary canon than Anglo-American countries and, at the same time, a local culture of detectives and procedural dramas, such as Baantjer (1995-2006) or Flikken Maastricht (2007-), that influence the reading process. Sherlock has been broadcast in Belgium (Canvas) and the Netherlands (KRO) as part of the KRO detective evening. Unlike Germany and France, the Dutch networks showed the original version of the series with subtitles. Fans of Sherlock focus on this broadcast version, a downloaded version, or on the local or imported DVDs. Despite the accessibility of the series, there are no local fan communities of BBC's Sherlock for Dutch-speaking fans. Small discussion threads can be found on the forums of broadcast communities.

Fans also communicate about Sherlock in English-speaking fan communities. The drawback of this is that the audience is spread globally. Dutch fans find each other haphazardly by meeting other local fans through each other's profiles on larger online boards (e.g., Bakerstreet Supperclub) or on specific national threads. Some stumble upon fans in real life or recruit them by recommending the show. The Dutch fan culture of Sherlock is thus not a coherent community but rather a label that helps analyze how a heterogeneous group of people, who identify themselves as fans, makes sense of the series. Whether the repertoires of Dutch fans differ fundamentally from English, American or other continental groups will be closely examined. In terms of fan identity, this chapter will thus also pay attention to local backgrounds and how Englishness emerges as a romantic ideal conveyed by Dutch respondents.

Based on seven in-depth interviews with Dutch fans and an exploratory reading of online discussions, I argue that although Dutch culture is influenced by AngloAmerican media texts, the Dutch fans still understand Sherlock as foreign, English content that fits into a particular popular culture. My findings show that fans explore a 
transmedia text not only by relating it to its source texts but also through their implicit understanding of related genres and local and global imagery.

\section{Sherlock}

Sherlock stands out in terms of the inter-/transmediality of its content as well as its place in the media landscape. This remediation covers several levels similar to the ones that I outlined in chapter one: content, form and storytelling; first and foremost, however, it pertains to the representation of (new) media within Sherlock. Media is a central theme in the series' plot. The contemporary modernization imagines John Watson as a blogger who shares his adventures with Sherlock online. The freelancing detective himself also has a website, The Science of Deduction, to attract clients. Moreover, Sherlock relies on new technologies to solve his crimes. He uses his smartphone to gather clues at the crime scene, browses the Internet, and communicates through text messages. The series interrogates the media-saturation of modern life through the detective figure who is aided in his investigations by new technologies.

Media also form a distinctive part of the series' cinematography. Sherlock's thoughts are often envisioned as an interface with different options, and his navigation through London is structured as a GPS map. In the second season, this style is carried even further, when we see Sherlock retrieving memories in his "mind palace," moving through visuals as though he interacts with a touch screen. The use of such interfaces not only is an aesthetic example of intermediality as a formal device but also stages a complex interplay between the character and technology that supports the show's themes of rationality and embodiment. The characterization of Sherlock as an emotionless character who is enhanced through technological design evokes the metaphor of the cyborg. This interpretation of the character has also been proposed by Francesca Coppa (2012), who reads Sherlock as a "postmodern man-machine” (p. 210). Following Donna Haraway, Coppa suggests that this hybridity of technology and organic material creates a site of progressive possibilities in terms of gender and identity.

The interpretation of Sherlock as a cyborg draws attention to the body of the detective, whose emotions and sexuality are rendered absent in the series in favor of a techno-rational interpretation of the original Holmes character. I would propose that Sherlock is not only a deeply intermedial series in its events and cinematography but that his hybrid characterization is also representative of intermediality itself as a blend 
of different texts, technologies and cultural repertoires. Moreover, this intermedial characterization suggests that media have a deep effect on their users and audiences by visualizing organic thought processes as technologically mediated. The body is portrayed as an interface that we could master, control and play with. The cyborgcharacter of Sherlock mirrors that of the observant viewer and fan who also displays critical and interpretive skills that contextualize the characters and their motives.

Sherlock is also an example of a transmedia show that disseminates its content online. BBC has launched the websites of John and Sherlock and occasionally updates them with new entries. However, during the span of the first season, the sites offered only marginal teasers for upcoming episodes that evoked speculation in the fan communities at best. The transmedia design of Sherlock clearly functions as a promotional model rather than a narrative model that distributes the story across different media platforms (Jenkins, 2006); however, I would argue that despite their minor narrative role, the sites cannot be seen as separate from the narrative. In fact, the pleasure of these sites does not relate to the information that they offer but to their aesthetic form and authenticity. The sites have a visible presence and narrative meaning in the series; as a result, their actual online presence materializes the fictional world. Moreover, through minor updates, the sites establish the online presence of Sherlock and John and attribute a sense of realness to the characters themselves. This is a sense of realness that current transmedia theory hardly accounts for because the theory focuses on the extension of plot lines rather than the conceptualization of narratives through visual or material objects.

Sherlock is deeply entrenched in other texts because it comments on a long history of Sherlock Holmes interpretations and fandom. The tagline of the series, 'a classic sleuth for the modern age', already displays Sherlock as an anachronistic narrative and constructs a close connection between Doyle's "classic" and its modernization. These intermedial relations are furthered in the series through meticulous references to Doyle's stories. The tagline also positions Sherlock as a classic BBC production that, despite its modern sensibilities, also borrows from British heritage. Although the episodes focus on more modern London sites, its opening shots feature typical landmarks such as the Big Ben and thus frame the content in a long tradition of BBC heritage drama. 
The production team of Sherlock allows for other textual connections based on authorship and the authority of genre. The head writers of Sherlock write together on BBC's Doctor Who (2010-), which also allows its audiences to make many intermedial connections between the two shows. The youthful appeal of Sherlock easily connects it to "buddy cop" series and films in which a male police duo solves crimes together. Commenting on the long tradition of queer interpretations of Sherlock Holmes and the buddy cop genre, the series often hints at Sherlock and John as a potential couple. Already in the pilot episode, a waiter places a romantic candle on their table when they are dining together.

As a result of its rich intermediality, Sherlock draws diverse media audiences that include fans of the traditional text, referred to as "Sherlockians", who have a long tradition of fan clubs and activities. Roberta Pearson (2012) mentions that one main difference between these two groups is that Sherlockians are more "affirmational" in their fan fiction. Their derivative writing or pastiche is clearly embedded in Doyle's universe and mimics his style. Their discussions also follow the stories closely and refer to them as the "canon", the legitimate Holmes stories and information as opposed to the fan texts. The media fans or "fan studies fans", however, are more "transformational" in their reworkings of Sherlock. They take more liberty in developing their own voices and narratives with these characters. Their discussions relate Sherlock to media culture at large. Despite these cultural differences between the two fan cultures, Pearson does not mean to suggest that these groups exist fully independently: the members of these groups overlap, and their fan practices are also shared. Series such as Sherlock function as a bridge to further communication between these two groups of fans.

When analyzing Sherlock, we can thus wonder how viewers understand and contextualize a text that is so deeply entrenched within a network of other texts. As discussed in the first chapter, Jenkins (2006a) argues that transmediality, and more specifically, transmedia storytelling, implies a content model in which viewers seek to connect disseminate parts. In marketing terms, Jenkins refers to this as "additive comprehension". He explains: 'Additive comprehension is a key aspect of transmedia entertainment/branding since it allows some viewers to have a richer experience (depending on what they know or which other media they have consumed) without in any way diminishing the experience of someone who only encounters the story on a single media platform' (Jenkins, 2006b). Following Jenkins, inter-/transmediality results 
in an engagement model in which viewers follow particular references or narrative paths. The model assumes that audiences who are familiar with all of the texts of a franchise will understand the story better or feel motivated to discuss it among each other. Transmedia storytelling thus amounts to a type of collective intelligence.

The intermediality of Sherlock, however, allows connections to a wide variety of texts and contexts. As an adaptation, Sherlock provides meaning to existing narratives by remediating the content and form of earlier texts, a process that is never a direct translation. As a modernization, it also has original qualities because it remediates the existing versions of Sherlock Holmes more liberally. How do viewers make sense of this rich textual network, and how do they try to master the text? Following Jenkins, they may display knowledge patterns, individually or with other audience members, to make sense of the series.

I aim to capture how fans make sense of the intermediality of today's television texts. I analyze the viewing process of Sherlock fans in two ways. First, I explore the web of associations that fans mobilize. I examine whether explicit inter-/transmedial elements in Sherlock enable a more active reading, as Jenkins (2006a) implies when he argues that these elements function as cues that guide readers to related texts. Second, I examine the social protocols of fans as a local, interpretive community and seek to position the conventions that inform them. This intermedial strategy draws attention to the cultural backdrop that informs today's readers/viewers. This study seeks to explore a vital theoretical and methodological concern within fan studies: the assumption that fans have particular competences and protocols that must be analyzed and that may vary even within one media fandom. I analyze these intermedial connections through reception theory, predominantly Jonathan Culler's idea of naturalization.

\section{Reader-Response Criticism}

Intermediality helps define the relationships between various media and their content, but it fails to explain how a reader or fan consumes or experiences a text. As such, it can describe appropriation but does not go into fans' deeper motivations. I draw from reception theory, more particularly, "reader-response criticism," to analyze the role of the reader. This field combines reception theories that stem from different literary traditions and emerged in the 1970s and 1980s in Germany and America. Poststructuralist continental writers such as Roland Barthes paved the way for such 
reception studies. Despite their theoretical background, the scholars have a similar agenda: to analyze the text not as a formal construct but as a construct that the reader actively interprets.

Reader-response criticism thus focuses on the literary work of the reader, rather than the structures of the text. In literary and media studies, reader-response theories have been the groundwork for many studies that analyze how (local) groups of readers and viewers are affected by texts (Ang, 1985; Radway, 1987). After framing exemplary German and Anglo-American theories, I focus on the theory of Jonathan Culler and Monika Fludernik's interpretation of his work. Their theories have informed this analytical study on the interpretations of Sherlock.

German reader-response theory draws attention to the text as a construct that needs to be actualized and depends on the reader and his or her own world view. Each reader will interpret a text differently because $s /$ he has different cultural repertoires, tastes and sets of lived experiences. This critical stance is proposed by the "Konstanzer Schule", where different authors theorize against formalism and in favor of the effects generated by the text. Hans Robert Jauss (1984) argues that the text posits, and constantly suspends, its "Erwartungshorizont" (horizon of expectations). The possible meanings and endings of the texts are shaped, first by an intentional play of textual cues that constantly suspends this horizon. This first horizon can be revealed through methods of literary analysis. The second horizon is shaped by the experiences of the readers themselves, who unearth possible meanings of a text that is rife with textual potential. The active reader thus brings his own mind set to the text and is not just a reader-recipient who is affected by the expectations that a text provides. The aesthetic distance of a work is predetermined by these two horizons and shaped by the textual effects that resonate with the reader's expectations (see also Kunne-Ibsch, 1977; Meijer, 1988, pp. 363-366).

Wolfgang Iser theorizes these textual effects in his work through his concept of the "implied reader". Rather than an ideal reader, this concept signifies a process of 'both the prestructuring of the potential meaning by the text, and the reader's actualization of this potential through the reading process' (1974, p. xii). The potential meaning of the text is captured by different textual cues and signals that guide the reading process and the personal strategies that envision the text. As Ryan (2004) suggests in her account of Iser's theory: 'This actualization requires of the reader a filling 
in of gaps and places of indeterminacy that can take a highly personal form, since every reader completes the text on the basis of a different life experience and internalized knowledge' (p. 44).

Throughout the reading process, the reader has to make sense of the text continuously. Inspired by Ingarden, Iser marks particular blanks in the text in which the textual meaning is unclear. Within these Leerstellen, the reader needs to organize the story again. Leerstellen press the reader to imagine or re-imagine the events of the texts and adjust his or her expectations. Instead of the need to complete a text and find closure, Leerstellen signify a moment in which the text needs to be reordered and understood anew. Leerstellen also draw attention to the moment of personalization and actualization of the text. They allow the reader to engage in a dialog with the text and draw personal connections.

The text is thus not an object but a process in which the signs are transformed by the reader. Iser states, '[t]he fact that completely different readers can be differently affected by the "reality" of a particular text is ample evidence of the degree to which literary texts transform reading into a creative process that is far above mere perception of what is written.' (1974, p. 279). The reading process is dynamic and shaped by possibilities and alternatives. During the process, some alternatives become more plausible, while others are excluded. Although the text presses the reader to form expectations, these expectations can be completely shattered, which creates part of the aesthetic pleasure of consuming a text (id., p. 287-288). The text is thus not something visual or material but virtual, singular and personal.

German reader-response criticism suggests that reading a text means engaging in a creative act that requires both text and reader. There is no ideal reader, only a reader with a certain disposition. The text as read emerges as a dialog between the actual text and signs, and our culture, conventions and preferences. The television text is scarcely different. Leerstellen might emerge through the storytelling or the form as the cinematography. The focalization may focus on a single character, leaving particular events untold, and visual strategies may purposely leave some information off-screen. This sense of wonder is the start of fannish interpretation of characters, events and textual histories. However, the television text differs from the literary text in that it is characterized by dialog rather than internal focalization, which also presses fans to consider character behavior and motivations. 
The Anglo-American strand of reception theory focuses less on textual effects and more on the text as an artifice that requires decoding through social contexts. Stanley Fish (1980) developed ideas on how readers' interpretive strategies are developed within "interpretive communities" (pp. 147-174). Through this concept, Fish gives a situated view of reading processes by showing how readings flourish within particular social communities that reach a consensus about a text. Literary competence is not a given but is learned as codes within these groups, resulting in specific interpretive strategies (id., p. 172). We can describe fans as one interpretive community, as Fish does when he discusses scientific disciplines as separate, interpretive communities (id., pp. 338-343); however, fans are also members of different audience groups, such as the nation state, that construct social repertoires. This makes it difficult to signify what social protocols they take from fandom and what corpus they mobilize from other institutions. While the concept of interpretive communities has inspired many scholars, demarcating who belongs to the interpretive community and what readings distinguish it from other communities create theoretical challenges.

\section{Naturalization}

To analyze fan reception, I use Culler's Structuralist Poetics (1975), in which he coins the concept of "naturalization" to explain how readers make sense of the text - a strange and alien construct that has to be decoded. Culler draws from French structuralism to construct his theory of reading as a process between the reader and the text, rather than a structure that emerges from textual signs. Similar to the German reader-response critics, Culler draws attention to reading as a delicate interplay of textual signs and a reader's individual competences. 'Reading is not an innocent activity,' Culler poses. 'It is charged with artifice, and to refuse to study one's modes of reading is to neglect a principal source of information about literary activity. By seeing literature as something animated by special sets of conventions one can attain more easily a sense of specificity, its peculiarity, its difference, shall we say, from other modes of discourse about the world. Those differences lie in the work of the literary sign: in the ways in which meaning is produced' (id., p. 129).

Culler explains this interpretation process or naturalization through the idea of "literary competence". The ability with which we interpret texts depends not only on our reading skills but also on connecting what we read to meaningful discourses, such as the 
critical institute of literary studies (id., pp. 113-130). As a result, Culler sometimes refers to a reader who is especially competent, such as the critic, who is seen as being more on par with these discourses and thus more knowledgeable. The concept is not limited to literary studies and the privileged critic: literary competence can be a fruitful way to understand the competences that fans display, which are shaped by diverse repertoires and associations.

In the construction of textual meaning, readers rely on conventions that make the deviant familiar. 'To assimilate or interpret something,' Culler explains, 'is to bring it within the modes of order which cultural makes available, and this is usually done by talking about it in a mode of discourse which a culture takes as natural' (id., p. 137). In structuralist writing, this process is known as naturalization, or vraisemblalisation. Culler distils five repertoires or competences - five modes of "vraisemblance" - on which readers can rely to make sense of a text: the relationship between text and reality, shared cultural knowledge, genres, conventions of the story or medium and lastly, references to other texts (id., p. 131-161). Although I develop the first strategy below, the latter four structure this chapter.

The first naturalization process that Culler highlights is the interpretation of the text as a representation of reality. The text is positioned as part of our world and our natural responses. 'We speak of people as having minds and bodies, as thinking, imagining, remembering, feeling pain, loving and hating, etc., and do not have to justify such discourse by adducing philosophical arguments' (id., p. 140). The text evokes a "natural attitude" (id.). If the text uses metaphors, the reader translates these into natural actions or patterns. Certain rudimentary actions may lead to simple consequences. Culler exemplifies this as follows: 'if someone begins to laugh, they will eventually stop laughing, if they set out on a journey, they will either arrive or abandon the trip' (id., p. 141). The first strategy then is concerned with the contextualization of the text as fiction. We compare the text to our general experience of the world and familiarize ourselves with it. This basic notion of naturalization is less applicable to fan interpretation as it suggests a primary understanding of the text as the expression of a fictional world.

Cultural "vraisemblance", then, is the second naturalization strategy that readers deploy. Culler highlights the social discourse around a work, which may involve the naturalization of stereotypes or cultural models. These are not recognized as self- 
evident as in the first strategy, but "the culture itself recognizes them as generalizations" (id., p. 141). The social discourse allows for connections between the text and the world, which permit certain interpretive actions. As Culler explains, 'When a character in a novel performs an action, the reader can give it a meaning by drawing upon this fund of human knowledge which establishes connections between action and motive, behavior and personality. Naturalization proceeds on the assumption that action is intelligible and that cultural codes specify the forms of intelligibility' (id., pp. 142-143). In this social context, I also examine the cultural membership of fans and the competences that they display, particularly in relation to the different interpretive communities in which they reside. These cultural competences can be shaped by global fan cultures but also by national backgrounds.

Expectations of the genre are a third naturalization strategy that Culler suggests. Viewers of Sherlock familiarize themselves with the text by focusing on its format as a detective television series. A key feature of detective stories such as Sherlock Holmes, for instance, is their interactivity. Viewers are prompted to think along with the mystery and receive clues in the reading process (MacCracken, 1998). The fact that Sherlock Holmes is a classical text also shapes the expectations of Sherlock fans, who may in turn speak about it in critical terms and consider its literary qualities. In a similar vein, Culler mentions a fourth strategy in which the text exposes itself as "conventionally natural" (p. 148) and draws attention to itself as a textual artifice. He writes, '[t]he introductions to eighteenth century novels which explain how the diary or manuscript came into the narrator's possession, the use of external narrators who vouch for the truth of the tale told by another, are, of course, conventions in their own right which pay upon the opposition between truth and fiction. Alternatively, the narrator may simply exhibit his awareness of the conventions of literary vraisemblance and insist that the improbability of what he is recounting guarantees its truth' (id., p. 148). In the original Sherlock Holmes texts, such statements were often posited by Watson as the biographer-narrator. In line with other media and literary theories, I understand the notion of the "conventionally natural" more liberally as self-reflexivity, a sentiment and strategy that can be revealed in Sherlock as the awareness of the text as a Holmes-related and British television text.

Finally, readers naturalize a text through references to other texts. These allusions are crucial for this study of the inter-/transmedial features of Sherlock. Culler describes this as "intertextuality," but I prefer to call these intermedial references in line 
with my introductory chapter. In my analysis, I explore whether readers are familiar with the original Sherlock Holmes texts and how this affects their viewing of Sherlock, or whether they examined Sherlock's transmedia texts, such as the tie-in websites. This last strategy is the interpretation that transmedia storytelling emphasizes: the explicit textual cues that readers may seek to master. As we have seen, however, this is only one of several naturalization strategies.

Naturalization thus signifies a deeply intermedial reading process. This process illuminates the paths that readers might follow and the cultural conventions that shape their interpretations, as opposed to Jenkins' model of transmedia consumption. Jonathan Culler, meanwhile, refers to these strategies as literary competences, suggesting that the ability with which we interpret texts does not depend only on reading skills but also on connecting the reading to meaningful discourses that are shaped through different social and educational contexts (pp. 113-130). While Fish (1980) connects literary competence to interpretive communities, Culler provides a more nuanced view of the repertoires readers may evoke through his understanding of naturalization. Literary competence, however, raises questions as to what competences are the most important and what skills or interpretations the most valid. The competences that fans value in fan communities may not correspond with those of the literary interpretation of Sherlock Holmes. Within the transcultural realm of fandom, global competences or sentiments may also outweigh national backgrounds, ideals or thoughts. This study thus investigates what binds the interpretive community of Dutch Sherlock fans.

\section{Experientiality}

Naturalization leaves out thoughts on characters and the affects that they generate. Media fans pay close attention to characters and study them through their discussions and their own creative texts. Other literary scholars have also shifted the attention towards the construction of character. Marie Laure-Ryan (1994), for instance, suggests that the humanity of characters is central to immersion in stories and can only result from emotional response: 'And if readers experience genuine emotions for the characters, they do not relate to these characters as literary creations nor as "semiotic constructs" but as human beings' (p. 12). These notions are comparable to Ang's study of Dallas (1985), in which she outlines that fans invest in the "emotional realism" of characters and plot. The soap is a highly dramatic and unrealistic representation of 
everyday life, but the emotional associations and responses of the characters provide a space of identification for its viewers. Through the emotional depth of the characters, viewers can suspend their disbelief and relate to the cast of Dallas.

To include the interpretation of the fictional character, Monika Fludernik furthered the naturalization concept. In Fludernik's reading of Culler, she proposes her own concept of "narrativization", which includes the naturalization process, to which she helpfully adds her own term, "experientiality". She defines this concept as "the quasimimetic evocation of "real-life experience"' (1996, p. 12). Naturalization and experientiality create the narrativization process, which should not be seen as a property of the text, but as a conscious act by the reader who dynamically constructs the text. The reader naturalizes it as a narrative. Fludernik's theory is inspired by "natural narratives" such as dialogs and conversations and suggests that the realness of characters and fiction depends on our conscious mental and physical alignment with, and investment in, narratives. Similar to narrativity, experientiality is an effect that can be generated by texts that draw responses from the reader. I believe the concept to be vital in the understanding of Sherlock fandom and its understanding of the text as real.

Fludernik's notion of experientiality finds new meaning in Sherlock fandom, where experientiality is not only a quality of narratives but also a literary strategy that emerges from the works. Make-believe has a long, self-conscious tradition in Sherlock Holmes fandom. For example, the experience of characters has always played an important part in the history of Sherlock Holmes, which was written at the advent of modern serial fiction. The focalization of the stories, which are written as though they were biographies, influenced the interpretation of early fans who adopted this language. As a result, Sherlock Holmes fandom has gone through a long history in which fans discussed the characters as if they were real. This type of "ironic belief" is underlined in the audience studies of Sherlockians by Saler (2003). Fans have long since tried to make sense of the stories by reconstructing facts and creating character biographies or studies by means of pastiche. This means of interpreting Doyle's characters as though they were real has also been called "the grand game" and remains a common practice of Holmes fans today (Polasek, 2012). Media fans do not necessarily engage in the grand game and are not necessarily aware of it at all, but they do judge characters if they are real and consistent personae. Fans describe them as "in character" or "out of character", depending on whether they believe them to behave as they would in the source text or 
not. These reading processes demonstrate a different but equally deliberate experientiality.

Although the Sherlockians and the media fans rely on different interpretive frameworks, both share an interest in the study of character. The character engagement of both types of Sherlock fans is not only in line with Fludernik's experientiality, but is also a very conscious re-enactment of the sense of realness that characters evoke. A narrative should thus not only be understood in a spacio-temporal sense but also as a construction of plausible characters and events. Fludernik argues that characters have consciousness and that they are "existents" with real qualities that behave in a certain manner with which readers can empathize. 'Existents', according to Fludernik, are 'prototypically human and can perform acts of physical movement, speech acts, and thought acts, and their acting necessarily revolves around their consciousness, their mental centre of self-awareness, intellection, perception and emotionality' (id., p. 19). Experientiality thus becomes a primary feature of characters and our understanding of them, signifying an interpretive process rather than a formal characteristic of narratives.

Experientiality relates to transmediality in two ways. On the one hand, transmedial elements complicate characterization because characters are also understood in the light of previous texts. On the other hand, transmedia texts ensure that certain readings of characters will become more dominant because, as interpretations of these characters, they solidify certain readings.

\section{Dutch Sherlock Fans}

As a modern BBC text that rejuvenates a classic detective, Sherlock draws many different audiences, making it an outstanding subject of study. I am concerned with the readings that individual Dutch fans construct of Sherlock and how different expectations, genres, texts and the fan community itself shape their reading process.

To achieve more insights in the literary competence of Sherlock's fan community, I used a combined method. First, I conducted an exploratory reading of online discussions and fan texts of Sherlock to provide general insights on its fandom. Although I checked different online boards to get a general idea of Sherlock fan activity, detailed information stems from the Bakerstreet Supperclub, whose moderators gave me permission to conduct a preliminary study. Second, the study is based on seven in-depth 
interviews with Dutch fans of the series. I analyzed the interviewees' understanding of the modern aspects of Sherlock, its characters and its Englishness.

The empirical data for this study were gathered early in 2011, before the second season of Sherlock aired and prior to Ritchie's Sherlock Holmes: A Game of Shadows (2011), which premiered in the winter. The interpretations and expectations of my informants were thus framed by the first three episodes of the series and by information and speculation about the second season of Sherlock.

To explore the specific ways Dutch Sherlock Holmes fans responded to Sherlock, I recruited interviewees by posting at fan communities or SNS sites. I met two interviewees at a Sherlock board to which I subscribed for this study: The Bakerstreet Supper Club. All of the informants were in their twenties or thirties and either have earned college degrees or are currently enrolled. Most of the interviewees were women because Sherlock fandom overall draws many active, female fans. While I strived to include more men in my sample, two ultimately declined.

In general, the interviews took at least an hour and were conducted either in real life or, due to logistical difficulties, via Skype or over the telephone. I asked interviewees whether they wanted to be anonymous, published with their nickname, with their actual first names or a variation thereof. Although some interviewees had no particular opinion about this, others showed a strong preference for getting credit and being cited by their first name, especially because the information was not deemed sensitive. In the end, I decided to use first names to provide some anonymity but remain faithful to the interviewees' expressed wishes.

The selected fans all have different repertoires concerning Sherlock and Sherlock Holmes. One of the moderators of The Bakerstreet Supperclub, Sanne, is mostly interested in the series rather than the books, while another regular visitor, Margriet, emphasized her long-lasting passion for the books since she was a teenager. Astrid is passionate about the Holmes' stories and detective series in general but is not active in fan communities. The others are either not or barely familiar with the original books. Iris is active in some of the Sherlock fan communities and interested in BBC productions as such. Marissa, Shanna and Roderick are all active in fan communities but not those of Sherlock. Nonetheless, all three of them are enthusiastic about the series and familiar with different television and movie versions of Sherlock Holmes. 
The selected set of interviewees thus reflects a strategic sampling of diverse audience members. The sample has a small scale, and while using small sets is not uncommon in ethnographical audience studies (Hermes, 2005; Thomas, 2002), the drawback is that the data are difficult to generalize and cannot be seen as fully representative for Dutch Sherlock fans. Still, the sample suffices for my purpose, which is to highlight the singularity of reading processes rather to make general claims about the local fandom of Sherlock. This suits the continental approach of this book that phrases an approach to fan identity as a global phenomenon with local tendencies, implications and appropriations.

\section{Online Sherlock fandom}

Fans have devoted a number of sites for the discussion of Sherlock and its fan practices. Some communities show an interest in a broad area of Sherlock Holmes adaptations, such as A Study in Sherlock, but others are devoted solely to Sherlock, such as The Bakerstreet Supperclub and Sherlockology. Fans have also founded Sherlock communities on blogs such as LiveJournal.com or Tumblr. Some of these sites focus on sharing fan art and fan fiction, while others offer more general discussion threads. Other sites are devoted to individual characters or particular interpretations. The Livejournal community Asexy_Sherlock, for instance, discusses asexual fiction and interpretations of BBC's Sherlock, while other sites invest in homosexual fiction commonly known as "slash". Aside from these fan platforms, media fans also discuss Sherlock on their own private networks (e.g., on Facebook) or on prominent media sites such as IMDB, YouTube and Den of Geek (see also Pearson, 2012).

Between February and April 2011, I visited The Bakerstreet Supperclub, a Sherlock community with approximately 200 members and a small group of regular attendees. The members are international, although many of the regular visitors are European or North American. The primary language is English, although the Dutch fans also have a Dutch thread in the off-topic section. The forum is informal and off-topic threads suggest that some members meet up regularly offline. The sections are structured along different interests and playfully refer to settings from Sherlock. At “221B Bakerstreet,” members discuss Sherlock but also other installments of Sherlock Holmes and the original stories. In “Mrs. Hudson's Kitchen,” members post fan fiction or fan art and other creations such as Sherlock-inspired crochets and costumes. "Scotland 
Yard" is devoted to other projects from the cast and crew of Sherlock, while "Molly's Morgue" features debates the use of science and technology in the series and the analysis of its settings. Finally, "Northumberland Street" brings together off-topic chats, other fandoms in which fans are interested and a puzzle corner where the fans, as does the detective himself, solve small knowledge games.

The online fans of Sherlock are interested in sharing their passion for the series and interpreting the episodes. In their threads, meticulous details of setting and dialog are discussed. Fans even trace props from the series or post coats that resemble Sherlock's. Some members scout the various locations that the series features and share their experiences and pictures. Others write episode recaps and character studies. Their fan practices and discussions show sympathy for the characters and often defend particular interpretations. Those interpretations not only include those of fans themselves but also those of the Sherlock writing team, which creates an interpretation of Sherlock Holmes that can be subject to debate.

Sherlock is a text that is situated among other Sherlock Holmes adaptations. The second Guy Ritchie film, Game of Shadows (2011), is in production and a clear comparison to the upcoming Sherlock season. One thread revolves around Stephen Fry, who has just been confirmed as the actor to portray Mycroft Holmes. In the thread, Fry is often compared to Mark Gattis, who plays Mycroft on the television series. The anticipation for the new Guy Ritchie film is similar to that of the second season of Sherlock, but the fans often emphasize that they care less about the Guy Ritchie films than Sherlock, thereby confirming their loyalty to the BBC-text, which identifies them as Sherlock fans rather than fans of all Holmes texts.

Character relationships are an important discussion point in the community. The relationship between Sherlock and Moriarty or between Sherlock and his brother are often scrutinized. The relation between Holmes and Watson in particular raises many questions. Although some fans actively support them as a couple, others consider them to be male friends and substantiate their views in a "male friendship" thread that discusses homosociality among men. The intimate male friendship and its resulting subtext appeals to many fans. This theme also hails many fans from anime and manga fandom that also have a long history of queering male characters. The fan art of Sherlock clearly shows the overlap in audiences, as some of it is inspired by Japanese visual styles. The "asexuality thread" analyzes Sherlock as asexual, but it uses the series as a 
discussion point about what sexuality means today and how different types of asexuality can be defended as a lifestyle.

Because the fans are waiting for the series' second season, many threads anticipate what the episodes will revolve around and construct a pre-text of the episodes. The writers of Sherlock revealed to The Guardian that the second season would feature "Adler, Hound, Reichenbach" (Frost), which alludes to the stories A Study in Scarlet, Hound of the Baskervilles and Fall from Reichenbach. The fans wonder how the upcoming episodes will mediate prominent plot points from these narratives, such as Holmes' demise at the hands of Moriarty. Their speculations reflect what themes they find characteristic of Sherlock, as some fear that Irene Adler's appearance will threaten their asexual interpretation of the detective.

It becomes clear from different threads that the interpretation of Sherlock also influences those of other Sherlock Holmes installments and fan texts. Culler's category of intertextuality (or intermediality) resonates in many discussions as the members actively connect Holmes texts. Some members are reading Laurie R. King's pastiches of Mary Russell, for instance, that feature new adventures of an elderly Sherlock Holmes with the titular character as his wife. Their relationship is analyzed in-depth and the interpretations of Holmes as asexual, which also influenced Sherlock, wear off on the discussions of their marriage. The Sherlock fans also show an active interest in texts that are related to the cast and crew. The Frankenstein (2011) production starring the actor who plays Sherlock, Benedict Cumberbatch, gives fans a reason to meet up at the theater or in cinemas that show live broadcasts of the show. The members give detailed posts about their experiences and about Benedict's performance.

The Bakerstreet Supperclub clearly shows that fans who watch Sherlock have different interests and fictional repertoires. The members also reflect on this in a thread on the pilot, "Study in Pink", when they share their motivations to start watching Sherlock. Although some had read Doyle's stories, others had an interest in the actors or were active Doctor Who fans who supported the writers. The forum members are also interested in meeting Sherlockians and bridging the two fan cultures. Some subscribed to "The Sherlock Holmes Society in London" and share detailed experiences about the fan club meetings, the magazines that the society publishes, and the social make-up of the community. 
Overall, the Dutch fans participate in the community without much reference to their locality. They share the same fan vocabulary and interests. However, specific threads, such as "I want to be English", reveal the romantic qualities that non-English members assign to England, and their love for its culture and fiction. This exoticism shows that Sherlock's Englishness connects fans, presses them to think about their local backgrounds, and creates a space that brings together the international fan community.

\section{Cultural Repertoires}

The exploratory online study reveals some common patterns and themes in Sherlock Holmes fandom that also shine through in the interviews. The international make-up of the community, however, makes it difficult to analyze how foreign viewers interpret the content because they display a similar cultural capital and affinity for British television as the other members. The interpretation of Sherlock online proved to be interesting but did not signal enough about the individual reading processes or backgrounds.

As a follow-up to the research described above, I conducted interviews with several Dutch Sherlock fans to explore how they made sense of the British series. Because I had a broad interest in the local identity of fans and their lingua franca, I concentrated on the modernization of the series, characters and relationships to other British texts during the interviews. In this empirical account of the interviews, I focus on how Culler's strategies emerge from the answers, while a more grounded empirical account is provided in another publication (Lamerichs, 2012). Because the interviews were semi-structured, the answers were more associative interpretations, in line with the fans' own opinions about the text. Furthermore, the application of Culler's strategies should not be taken as a strict typology, and these categories are by no means exclusive. At many moments, the fans relied on several of these elements to construct their reading.

The first form of naturalization that fans demonstrate is that of general cultural knowledge and ideas or generalizations. Two cultural texts surface most in the readings of Dutch Sherlock fans: first, notions of Englishness that are innately tied up with their views of London and the representation of modern Western life; and second, readings on the performance of gender and sexuality. Within these readings the fans reveal both Dutch characteristics in correspondence with Western and European ideas, as well as 
conventions of Western identity politics that are contrasted with the emancipative ideals of fan communities.

The interviewed fans mentioned first and foremost that they find the series to be a refreshing and exemplary model of media use. The incorporation of technology in the series is compared to the detective genre, as addressed below, but is also naturalized as a motive that resonates with the fans' own media-saturated lives. When the fans explicitly address cultural frameworks, however, it is often in relation to the narrative representation of London and Western culture. In terms of Englishness, Sherlock's views of London stand out. 'It is very realistic instead of Victorian,' Margriet says, 'which adds up to the London background. They also say on the DVD that London is an extra character here and you can see that very well.' Iris and Shanna note that it is a very realistic view of London, differing greatly from its portrayal in American series, with its touristic hallmarks like Big Ben featured prominently in the background. Indeed, one can draw comparisons here with Guy Ritchie's film, which shoots London as a harbor town with an emphasis on the Thames, boats, streets crowded with cabs and the tower bridge still under construction. Sherlock, then, depicts London as a dynamic town with large, modern buildings and very specific urban settings such as a skate track.

As the interviewees implicitly note, couleur locale is an important feature in most detective fiction (Reijnders, 2009). The murder changes an ordinary landscape into an active place of imagination, a story that slowly reveals itself. Gattis and Moffat also show an awareness of the setting when they describe London as an extra character in Unlocking Sherlock. Indeed, at Sherlock fan sites such as The Bakerstreet Supper Club, attention is paid to the settings of the series, visiting them and capturing a few pictures for the site. This type of location scouting is similar to studies on media tourism, which suggest that visiting a place that is intimately connected to fiction - a movie set, a fictional setting, a site of re-enactment - can be a primary motive to travel somewhere and create a unique experience of spatiality (Reijnders, 2009; Rice \& Saunders, 1996). Being at a spot intimately connected to a narrative allows for the actualization of said narrative in an immersive manner. In other words, the story is relived on the spot. These motives are also foregrounded in the fan community where Sherlock's locations are vital to fans' experiences of the show.

Many interviewees mention that views of London in Sherlock stand out as realistic. Some, such as Iris, reflect on their own experiences of London and find that 
Sherlock rings true with the atmosphere of the metropolis. Iris and Shanna find this a very different portrayal of London than in American series, which often showcase touristic hallmarks like Big Ben. Indeed, most interviewees value Sherlock because it does not overtly emphasize British heritage. Later in the interview, however, Iris provides a more nuanced view when she suggests that the show does feature landmarks because it positions itself through touristic sights in the opening credits. She is quick to reveal the dual, almost anachronistic nature of Sherlock which relies on cultural capital associated with historic London (e.g., the Big Ben) on the one hand and modern sites on the other. The various settings of Sherlock (e.g., the South Bank skate park; Chinatown; the National Antiques Museum) emphasize the ethnic and subcultural diversity of London. Iris mentions that she finds that the series exaggerates these motives because she highly doubts that Chinese culture has the amount of visibility in London suggested by the episode The Blind Banker.

The interviewees compare the more urban, modern Sherlock with traditional series in terms of location and atmosphere. Other detective series seem to take place in remote, local communities. Iris, Astrid and Roderick refer to the closed environments of Agatha Christie that feature vacation houses, islands and trains as crime scenes, and only a few suspects. As Margriet mentions, 'Midsomer Murders is much more local and small. It often starts with local clubs of bird watchers or so in which a body is found.' Most interviewees think the series has little in common with Dutch police series, though some mention Baantjer, a local detective show that takes place in Amsterdam and is shot in characteristic spaces such as its canalside houses. Recognizably, it stars an elderly police officer and his younger sidekick. While Baantjer is seen as a traditional representation of urban life, Sherlock is naturalized as innovative and modern. This naturalization process combines strategies of the cultural texts, which are generated by stereotypes that emerge in fiction and everyday life but also pertain to genre and the show's locality.

In addition to thoughts on urban representation, the Dutch fans interpret modern British life in the metropolis and reflect on what it means to live in London. Margriet, for instance, is surprised by the ease with which some of the motives could be transferred to modern London. She explains that the Holmes formula is still very modern and works surprisingly well today. 'They are still two guys living together in one apartment to be able to pay the rent, for instance.' Margriet also reflects on the cab rides, suggesting that this is perhaps not a good representation of being in London, where taking a cab is very 
expensive today. She cannot imagine that the two men living on a limited budget can afford the cab fares and jokes that they should take the tube instead. Still, she naturalizes this motive using another strategy: considering it a reference to the hansom cab rides from the original stories.

The Dutch fans reveal thoughts on Englishness and internationality in the discussion of politics in the series. Margriet and several other interviewees mention the war with Afghanistan as being a one-to-one relation with the original text that works especially well. The war is also considered to be an interesting cultural representation. Whereas other versions of the Holmes stories never reflected on the war, Sherlock explores the results of the war and the trauma that Watson had to endure. The pilot episode immediately depicts John Watson as damaged by the horrors of Afghanistan, shocked and isolated. He is in therapy, unemployed and tired. The interviewees explain that this really contributed to their view of Watson as a character and the dynamics between Sherlock and John. Their mutual dependency is more meaningful now that Sherlock brings some color back into John's life. John's therapy sessions and depression are seen as modern cultural elements that the series introduced well. Thus, in this naturalization strategy, references to the original stories again go hand in hand with a cultural understanding of modernity.

In terms of Western culture, the Dutch fans praise Sherlock in terms of gender and sexuality. The show plays with the identity of its protagonists but never makes Sherlock's sexuality explicit. In terms of gender, some of the fans suggest that Watson is an everyday man, as opposed to Sherlock, who comes across as dandy, young, posh and even slightly effeminate. Sherlock is not naturalized as a standard, heterosexual man, but fans do not necessarily assign a particular gender identity to him. They naturalize his behavior as supportive of his eccentricity and rationality rather than a characteristic of his masculinity. His appearance and behavior are thus read as signposts of his mentality.

The sexual identity of Sherlock is interrelational and shaped by the interplay with Watson as his closest friend or potential partner. Interviewees perceive the relationship between Sherlock and John to be portrayed well in the series. Most interviewees highlight that they complement each other and three explicitly state that Sherlock makes John's life less boring. The intimate friendship with romantic aspects is often addressed. 'It's friendship, but there are hints that there might be more,' Shanna says. Marissa 
describes how they remind her of a married couple: 'They have a household to run as well and make remarks about their groceries.' As an outsider to fan communities, Astrid notes that she appreciates this homoerotic subtext in the longer, literary tradition of romantic interpretations of Sherlock and John.

Some of the fans explicitly position these elements in relation to the cultural texts of the fan communities. Notably, Sanne, Shanna and Marissa are active readers of Sherlock/John slash fan fiction, stories written by fans in which characters are portrayed as romantically or sexually involved. They also explain elements of the text, such as the awkward restaurant scene from Study in Pink, in relation to this genre. Although many of the fans are aware of the erotic interpretations of Sherlock Holmes, not all interviewees are equally positive about slash. Iris likes reading about the characters as friends, whereas slash fan fiction makes the general stories she would like to read harder to find. 'Welcome to online fandom,' she states sarcastically.

In their readings, the fans reveal their own cultural lingua franca that incorporates words as "slash" or "bromance" (a portmanteau of "bro" and "romance") to signify the intimate friendship between the male protagonists. Margriet, for instance, naturalizes the male friendship as a "bromance" by comparing it to relationships in her personal life: 'I recognize this relationship with my own husband and his best friend; they never talk about it but it's clear that they are very committed to each other. It's really a "bromance" between men; they are on a different level than us (women).' This combination of subcultural and private repertoires leads her to conclude that the relationship between John and Sherlock is not romantic per se but a good representation of homosocial relationships generally.

Although some fans naturalize Sherlock and John's relation as homosexual, other fans consider Sherlock to be asexual. Throughout the episodes, he suggests that he is not interested in romance or in emotions altogether. This is more in line with readings that consider Sherlock and John to be an example of an exceptional male friendship ("bromance") rather than possible partners. Both Iris and Margriet are well aware that entire online communities flourish around the character's possible asexuality and also refer to discussion threads and communities such as asexy_sherlock on LiveJournal. Asexuality is understood as an emerging identity in the sexual landscape but is more emancipated in the landscape of gay (LGBT) communities. The lack of sexual and 
romantic interest that Sherlock displays is seen to fit this emancipation of asexual identity.

Although I believe that Sherlock helps contribute to the visibility of asexuality as an emerging sexual identity, the fans frame asexuality differently. Margriet, for instance, thinks that asexuality might be too narrow for Sherlock, who has little interest in emotions and is portrayed as overly rational rather than asexual by choice. She suggests that Sherlock would not even be concerned with such labels. This brings about the question of whether sexual identity is explicit self-formation and a lifestyle choice or a behavioral phenomenon that can be attributed to individuals. The naturalization of Sherlock's sexuality presses the boundaries of contemporary identity politics and the representation of characters with a non-normative "queer" gender identity.

Iris naturalizes the asexuality motive slightly different, not by aligning it to a Western cultural text of identity politics but by comparing it to fan practices that celebrate Sherlock's asexuality. She thinks that in the end, asexual fan fiction is still about romance and character psychology rather than a representation of an asexual lifestyle: 'There is a whole group of people that believe that he is asexual, but after that, they wonder: How can we fix this?' Indeed, such asexual stories tend to fit in the romance genre that is dominant in fan fiction and portray Sherlock according to the standard slash formula in which the character explores his sexuality (Jenkins 1992, pp. 206-219).

However, the detective as asexual seems to be a historical trope related to the view of detectives as loners or priest like figures proclaiming rationality (MacCracken 1998, p. 60). The use of such cultural imagery in Sherlock echoes these older discourses of the detective as a disembodied mediator of truth. While many detectives or cops today, however, are portrayed as having sensual vices or even dark cravings, as in Dexter (2006-), Sherlock is still an anachronistic character who has not evolved into an emotional, embodied human being. Fans' responses thus naturalize his personality through cultural texts such as asexuality and autism.

Within these answers, a cultural understanding of fandom itself emerges as a Western, global phenomenon with its own lingua franca and practices, rather than a Dutch phenomenon. The literary representation of characters was captured in relation to fan cultures and modernity at large (e.g., generalizations of urban life, gender identity). Dutchness seldom emerged in the answers, but is sometimes used in contrast 
to urban life and television traditions. The latter will be further developed in genre, where fans compared the English genres to local variations.

\section{British Detectives}

During the interviews, I also asked fans to reflect upon Sherlock's genre qualities. They often compare the $\mathrm{BBC}$ production to the global media industry at large. In these qualities, the locality of the Dutch fans, who align themselves with European content such as Sherlock rather than American content, often shines through.

On the whole, the series is perceived as an essentially British production in terms of writing. Many interviewees mention that Sherlock reminds them of a movie, in contrast to American series that stick to a 40-minute formula but have longer seasons. Iris explains that this results in a different storytelling format that has a greater focus on plot within episodes but that still comprises its arcs within seasons. Because Dutch television also features other European series and networks, some draw comparisons with content that is not Anglo-American or Dutch. Astrid compares Sherlock to Tatort, a German police series that also lasts one and a half hours but has a more specific format. 'You can set your clock to when the body's found,' she says. She thus naturalizes Sherlock's formula as more innovative based on its pacing and closure.

The interviewees distil different English elements from the text. Some mention the humorous undertones in Sherlock as specifically English. By relating Being Human (2008-) and Sherlock, Marissa argues that BBC series focus better on smaller, everyday domestic issues. Others draw comparisons in terms of casting and argue that British television is more prone to casting regular-looking people who are not made up to be as overtly good looking as American actors. The authors, Steven Moffat and Mark Gattis, are also stressed in this discussion. Sanne and Iris think that the series has been written much like Moffat's (also BBC-produced) Doctor Who episodes and compare Sherlock with the eleventh Doctor, who appears to have some eccentricities in common with Sherlock.

As a detective series, the original English Sherlock Holmes stories are considered by the Dutch interviewees as a hallmark of the genre that have influenced many other works. Sherlock, as a later adaptation, is of course influenced by a wider tradition of detective and police series. Astrid, for instance, mentions that Sherlock's third episode reminds her of Agatha Christie's The Big Four in which Poirot faces similar intellectual 
challenges as Sherlock. The interviewees often oppose Sherlock's eccentric, younger titular character to the traditional English detective as depicted by characters such as Inspector Morse and Miss Marple. The afore-mentioned characters are considered to be textbook examples of English detectives, portrayed as older, single characters who indulge in leisure activities such as going to the pub or knitting. This is comparable to the findings of Thomas (2002), who argued that fans understood Inspector Morse (19872000) as an example of English culture because of, among others, the characterization of Morse as a bachelor in Oxford (pp. 31-58).

These traditional detectives often have two faces, however 'Miss Marple, for instance, poses as a fluffy old lady, but she is anything but that,' Margriet tells. Astrid alludes to Miss Marple as well as to Patricia Wentworth's Miss Silver, a governess who, while knitting, cleverly distils knowledge from the witnesses. Roderick also says the following: 'That is an entire genre in England, detective land. Older people that are knitting but meanwhile, they are fighting crime!' The methods that these traditional English detectives embody are juxtaposed with various Sherlock Holmes texts. While detectives like Miss Marple obtain knowledge by talking to people, Holmes relies on factual knowledge and forensics. Shanna notes that most detectives, including the American ones, appear to lean more on knowledge of people and finding out their dramatic life stories and motives. Others draw comparisons with American crime series that are more "official" or "bureaucratic" and "involve a lot of shooting" as opposed to Sherlock's atmosphere. These series are considered to appeal less to the intelligence and creativity for which Holmes stands.

Although Dutch people see Holmes as a very English character, at the same time, the interviewees' remarks often imply that there are detectives whom they consider to be even more English. Likewise, some interviewees imply that they consider Holmes to be a traditional English detective but Sherlock less so, though he is described as a typical inhabitant of modern London. They claim that Sherlock fits in with a stream of newer detective series featuring eccentric detectives and cops. Marissa for instance, compares him to the brilliant but flawed Monk (Monk, 2002), who has many compulsive disorders reminiscent of Sherlock's obsessions and possible autism. Interviewees like Margriet, however, also stress that the original Holmes was already that character: an eccentric, middle-aged, and authentic detective. The qualities that are in Sherlock and its "new" portrayal of the detective were in the old novels all along. 
The genre of Sherlock is thus qualified as being a detective series and a British BBC series that shapes the viewers' experiences of the text. Sherlock also talks back to traditional detective series through its modern cinematography and deconstruction of earlier Holmes texts. This is where the self-reflexivity of the text is located.

\section{Modernity}

The discussion of the text reveals traditional genre patterns and expectations but also notions as to how Sherlock innovates in the detective genre and heritage drama, as well as television formats. When the interviewees are asked at the start of the interviews to generally describe what they like about the series, they independently mention its modernity as its most entertaining aspect. This is less an emotional judgment than a statement that emphasizes the series' most apparent feature. Perhaps my occupation as a scholar or the educational setting influenced them to justify their pleasure in watching Sherlock through a more formal response. However, modernization also teases out the qualities of the show that they find unique and enjoyable and the ways in which Sherlock is an atypical detective series and television text.

When pressed for more details regarding their investment in Sherlock's modernity, the interviewees often elaborate the series' use of modern media such as iPhones and Internet sites. Most interviewees do not just mention the use of new media but also how new media are visualized in the cinematography. Roderick says, 'Sherlock's most apparent feature is that it wants to be very modern. Examples of that are the camera tricks, the introduction as well as the texts that are being visualized.' The interviewees stress the importance of these digitally influenced visual features in their viewing pleasure and the ways in which they contribute to the atmosphere of Sherlock. Both Astrid and Sanne state that they were drawn to the series during an early shot in the first episode when all of the phones at the police station go off simultaneously during a presentation. We see Sherlock's text message hovering above them stating "wrong". 'At that moment,' Sanne tells me, 'I was sold.'

In a comparison with the movie Sherlock Holmes and House M.D., Roderick describes how Sherlock's visualization stands out as innovative but at the same time confirms a larger detective tradition: 'Modern means are used very well here to show what happens in the minds of these characters. That is entertaining but it is certainly not a must. In the past you could express this just as well in an explanation scene in which 
everyone is locked in the same room and the killer is revealed.' Here, Roderick naturalizes Sherlock's visuals by placing the series in a wider tradition and pointing out the explanatory function of Sherlock's stylistic flourishes.

The use of technology is not seen as intrusive but as a perfect fit with the Holmes format. Astrid and Roderick mention how technology makes the surveillance of all the parties, such as criminals and the police, more feasible. Others state that technology contributes to the investigation itself. Iris describes this phenomenon: 'With Google at your disposal on your cell phone it is much more credible that you can find out all of these obscure facts you did not know ten minutes ago. It is much easier now to collect information that the older Sherlock Holmes had to know about on the spot.' Conversely, Margriet, when talking about Internet use in the series, is somewhat concerned. She feels that most fans and viewers forget that Holmes is a character who employs many methods to gain and order knowledge, such as indices and telegrams. Thereby, she shows that Sherlock is a dominant interpretation of the original that already showed Holmes as technologically savvy and modern. The readers thus naturalize new media use according to cultural texts about modernity alongside expectations of the genre and the original Holmes text.

The methods of obtaining knowledge in Sherlock differ from the original books, however (Matt Hills, 2012). Roderick emphasizes that Holmes was a bit of a genius, while Sherlock works differently. 'Everything he knows is based on immediate knowledge and lab research and forensics.' Iris describes that it has become more essential for Sherlock to combine facts in his deductions. 'The art is not obtaining knowledge any more but bringing together disparate parts.' Many interviewees emphasize that Sherlock selects information. Still, some, like Astrid, are concerned about what this entails for the Holmes formula. She states that the series features little actual deduction as such and that it bases itself on different types of knowledge. The first episode, she says, clearly shows Sherlock's deductive skills by bringing together facts; the second relies on finding codes, while the third is linked by fast trials comparable to Christie's The Big Four (1927). Although the other interviewees think that Sherlock features a specific research method, Astrid discerns different styles that draw from a variety of crime series. Self-reflexivity, to her, means that Sherlock shows awareness of different knowledge practices in crime novels. 
Some aspects of Sherlock lead to mixed interpretations, notably the titular character's occupation as a consulting detective. Astrid naturalizes this motive in two ways. First, she connects it to her passion for other American and English detective novels that also feature private investigators. By explaining the trope and its occurrence throughout the genre, she gives plausibility to this motive. Second, she naturalizes this motive as a cultural, Western text by interpreting the profession within the wider job market. She sees Sherlock as characteristic of today's labor in that it exposes trends in freelancing and working from home. Moreover, Sherlock represents trends in media labor and visibility to her by representing (online) services within particular niches, as both Sherlock and Watson do with their sites. Roderick, however, is hindered in his viewing: 'First, I find it less credible that in our present day the police would be so ignorant that they need to hire an external employee; and second, that they would accept him. I think that used to be more credible, when forensic science was not really a science yet. You can imagine that a genius, a savant, just shows up and tackles a case.' The two readers highlight a gap in naturalization that can be explained because they both rely on different repertoires of detective fiction and ideas about labor in the past and today.

Although Sherlock is a modernization, some interviewees feel that Victorian or historical motives still play a role in the setting and narrative. For instance, the evocation of gothic themes is picked up by Roderick, who also noticed this supernatural tension in Guy Ritchie's Sherlock Holmes (2009): 'The good thing about these cases is that you believe something supernatural is happening, not the kind of Ghostbusters' ectoplasm but more in the sense that these events are not possible at all. The cab driver in the first episode for instance creates this air he can make people kill themselves.' Although the supposed supernatural is a theme in The Hound of the Baskervilles, for example, Roderick is not familiar with the original texts. By comparing adaptations of Sherlock Holmes, he naturalizes the gothic motives in Sherlock.

Although the interviewees mention Sherlock's modernity as its most apparent feature, it becomes clear that many elements they consider to be modern (e.g., technology) or traditional (e.g., gothic) are naturalized as characteristic of Sherlock Holmes texts. The self-reflexivity of Sherlock is intimately related both to its traditional genre qualities and in the ways it plays with, deconstructs or talks back to these motives. 


\section{References and Characterization}

Another particular strand of naturalization that Culler mentions is that of intertextual references, here rephrased as intermedial references. This type of intermediality should be understood as direct and identifiable references to other texts through which readers interpret the new text. This is a naturalization strategy that Sherlock fans deploy immediately and with great attention to prior Holmes-texts. Many interviewees mention certain references as being very clever, such as John's blog, Sherlock's The Science of Deduction site, and the use of nicotine patches. The awareness of both genres (as mentioned above) as well as its mastery over the original text is seen as exemplary.

As a result, the fans praise the writers and their interest in the historical canon of Sherlock Holmes. The television writers are seen as authors who create such references to appeal to knowledgeable Sherlock Holmes fans. Sometimes, the fans do show a preference for one of writers of the text. Iris, for instance, does not approve of the second episode of the series and explains that this author also writes the Doctor Who episodes, of which she is less fond. The intermedial connections that fans make are thus not only related to Sherlock Holmes but also to similar texts and the authors' oeuvres.

Most interviewees, however, do not show great interest in the transmedia design that Sherlock deploys. Iris and Marissa specifically mention the tie-in websites as an interesting move by the $\mathrm{BBC}$, although they are not enthusiastic about the site's maintenance. Although I undertook this research with the idea that such texts might inspire the fans, I found little evidence of this here. Partly, I think that this lack of enthusiasm also depends on the design of the sites as I signaled above, which emphasizes realness over narrativity.

To demonstrate how fans make sense of the intermediality of Sherlock, I also asked fans about their interpretations of, and affect for, Sherlock, John, and Moriarty. I was specifically concerned about their understanding of the characters and what features they found defining for them. During the interviews, I also asked what texts and other media characters had informed their readings. These answers exemplified how fans interpreted Sherlock's intermedial references and revealed experientiality as a rich understanding of characters as having an authenticity that could be mediated in different texts.

First, what becomes apparent at the start of the interviews is that the characterization of Sherlock is often addressed through his accessories and hobbies 
rather than his personality features. For the broader public, the standard image of Holmes is indeed that of a slender man wearing a travel coat and deer stalker cap, smoking a pipe. Most interviewees start by referring to that image and describe how the coat is a great mediation of the travel cape. Others draw on details from the books. Sherlock plays the violin, is bored when he is not working, and shoots at the wall. Although the original Holmes depended on cocaine to alleviate boredom, some feel that the implied drug use in Sherlock is a weak reworking of this motive. Iris compares it to the scene in the Guy Ritchie movie in which Holmes is caught red-handed by Watson after using opium. Similarly, Margriet draws comparisons with The Case of the Silk Stocking (2004), in which Holmes uses cocaine in the rest room. The interviewees feel that part of the character is lost in the translation because the drug addiction has always been a vital element in other Holmes texts.

Sherlock's personality in the series, as in the books, evokes very different opinions. Iris thinks Sherlock makes a "very strong, charming figure," while Marissa calls him a "dandy". Margriet, however, perceives Sherlock as being too rude compared to the books. She thinks the original Holmes is an elegant, rational man who pays less attention to trivialities that do not fit in his world view. Marissa explicitly notes how the BBC's Sherlock comes across as autistic through his social mistakes rather than purposely rude. She finds this to be quite cleverly done. Indeed, there is a long history of interpreting Holmes as autistic, albeit one with which the interviewees seem less familiar (Maher 1994).

The interviewees are quick to draw comparisons with other recent Holmes adaptations. Iris compares Sherlock to House M.D. and finds House "a much bigger bastard." Roderick thinks exactly the opposite. He sees BBC's Sherlock as annoying, while he finds House charming: 'He has a kind of natural authority.' Those who allude to Robert Downey, Jr. consider him to be scruffy like House but less mean and more eccentric. Marissa, though, thinks that Downey echoes House a great deal as "the type of grumpy older man, limp, badly shaven, that calls people off." She thinks that this type of character has definitely put its stamp on Holmes, and she is glad Sherlock revolves less around a snarky character who enjoys outsmarting others. Other interviewees, however, such as Roderick, perceive Sherlock precisely as arrogant and smug.

The appeal of Sherlock is often related to his age. Margriet finds this very true to the source text. 'During the first case, they are not very old, so it makes sense.' Iris and 
Shanna are very pleased with the youth of the characters and think this helps draw in different audiences. Roderick naturalizes this differently. He argues that Sherlock's age affects the narrative and gives it a competitive edge: 'It immediately changes Sherlock's dynamic, because the police get even more frustrated because he is young. If he is just a forty-five year old man, a genius, you assume he is right.'

In their interpretations, the interviewees speak highly of John. Many of them stress that they had few expectations of him when they tuned in for the series. Some explicitly evoke the popular image of Watson. Roderick describes: 'Watson always seems a bit of a dumb, fat guy to me. Pretty incompetent too.' Marissa, mainly drawing from The Great Mouse Detective (1986), stresses that aside from being the narrator, Watson often functions as comic relief. The interviewees praise John's skills in Sherlock that show him as a war veteran and doctor. 'I used to always argue in favor of Watson to friends,' Margriet tells me, 'but they never bought it. Until now!'

Many informants note that John functions as the everyday character with whom the viewer can identify, rather than a narrator or guide through whom Sherlock's thoughts are channeled. Both Iris and Astrid feel that John could have been even more "bad-ass", however, seeing as he is an ex-soldier. Meanwhile, Marissa interprets the war motif as trauma: 'He is a sad character, someone who is at odds with himself.' She naturalizes the character more according to his depression and therapy sessions, which distinguish him from other Watson portrayals and give the character a modern vibe.

One final characterization about which I inquired is that of Sherlock's Moriarty. The character raises mixed opinions in fan communities and the interviewees underline this as well. All interviewees stress that they find he comes across as creepy or insane. Some feel that this could have been carried further, while others find the character over the top. Magriet and Astrid mention that they were very excited to find out what Moriarty was like. Margriet describes this: 'I just did not know what to expect. I was prepared to see him as a woman, even.' Others also stress their theories that Mycroft, or in the third episode, John, would be Moriarty. Notably, Astrid describes a slight disappointment about the character and prefers Ritchie's version as being more true to the book: 'He is a kind of puppeteer who pulls the strings but you hardly ever see him.' What she likes about Sherlock's Moriarty is that he is on an equal level with Sherlock as a consulting criminal: 'They are literally opposites.' Marissa emphasizes the thinness of 
the line between Moriarty and Sherlock: 'By blurring his morals and social features, Sherlock is portrayed as a freak that approaches criminality and the evil master mind.'

Although Moriarty does not reflect the features he has in Conan Doyle's original as a professor and criminal of status, most interviewees do not see this as a problem. They experience Moriarty's revamped character as fascinating and, sometimes, as more authentic. Marissa in particular thinks that Sherlock's Moriarty is what a criminal mastermind should be like, as opposed to Disney's version of Moriarty, an insane "monster" who loses his rationality. Insanity, however, is the standard by which Sherlock's Moriarty is measured. His sociopathic nature and acts of terrorism in urban London are ultimately what define the character, in her opinion. Most interviewees describe the villain's age and normal appearance as standing in contrast to his creepy personality. Astrid, Margriet, and Iris in particular stress that Moriarty comes across as normal and young. Interestingly, all three naturalize this by speculating about his history and argue that his normal appearance is an advantage in the criminal circuit. Cultural ideas about criminality thus help to naturalize the features that contradict other Holmes texts.

Here, experientiality as a behavior befitting a character differs widely based on the texts and popular types to which the fans relate. Those unfamiliar with the books sometimes imagine Moriarty differently based on the few images they have come across. 'I am not sure who the classic Moriarty is,' Roderick says, 'but he is probably eccentric, that type of old treasure collector who has become a villain.' Fans naturalize Moriarty's role as the antagonist in Sherlock differently. Marissa considers Moriarty a traditional mastermind, a credible villain who 'keeps his calm when he hunts you down, knowing he is going to win.' In contrast, Roderick argues that Moriarty is nothing like the clichéd, rational villains from James Bond who plot elaborate schemes. He compares Moriarty to The Dark Knight's version of The Joker (2008) in a sense that both villains are chaotic and unpredictable. Indeed, both villains have similar narrative roles and underline the fragility of urban landscapes through acts of terrorism that are defined by insanity and experimentation rather than ideological motivations. These villains pose a threat to the order and rationality that the detective heroes Sherlock and Batman represent.

This classification of characters according to fictional tropes is a particular literary competence that the interviewees display and that they use to justify their interpretations. Some of these tropes, such as the standard villain and the atypical one, 
exclude each other and highlight how fans naturalize this content differently. The fans' explanations of the characters also steer towards experientiality. The fans speak of the characters vividly, as actants who have specific features that are coherent and evoke a sense of realness.

Experientiality also shows as they speak of the characters in doting ways and when they equate the actors with their characters. Moreover, experientiality is revealed when the fans naturalize the online sites of Sherlock and John as real, thereby allowing the online presence of the characters to affect them. Not all of the fans mention the sites, but those who do refer to them address the updates as real events and perfectly timed teasers between episodes. The tie-in websites allow fans to view the narrative time of Sherlock as immediate, suggesting that the 'terrorist' acts of Moriarty and Sherlock's urban strolls through London are happening in the here and now.

\section{Conclusion}

I have shown that viewers actively connect the transmedia text of Sherlock with the original texts and legacy of Sherlock Holmes. In the interpretations, three themes emerged upon which I reflect in this conclusion: first, the local competences of Western fans; second, the theoretical endeavor to analyze intermedial reading processes, and, third, questions about how textual interpretation of intermedial narratives can be furthered.

Although the Dutch fans' interpretations are influenced by their culture, this is less the case than I had initially presumed. Fan competences shaped the reading process more than national sentiments of identity and belonging. When sentiments of belonging echoed through the interviews, they pertained to Western and European identities rather than local ones. For instance, fans drew from their own experiences of London to personalize the series rather than "other" it. In fact, what emerged was a European identity in which the Netherlands was closely aligned to Britain rather than an exotic view of England; however, some informants conveyed romantic, affective ideals about England that created a context in which to discuss the Englishness of the text and cultural differences between English and continental or Dutch repertoires. Englishness formed a discourse for fans to share their passion for the country and its fiction. Sherlock was seen as an example of this Englishness that was associated with television quality, as well as historical and cultural richness. 
When local readings appeared, it was often to contrast the British television to Dutch culture. This is no surprise, considering that Dutch popular culture consists largely of Anglo-American television series. The Dutch television tradition was often seen as being cheap or lacking in creativity, while the English tradition was seen as aesthetic and pleasant. Both traditions were effectively contrasted with the American tradition. These television texts were acquainted with cultural ideas and were often alluded to by interviewees when they evaluated Sherlock's quality, characters, and setting. Still, we have seen that fans articulate local interpretations of foreign content, for example, by relying on elements that they find distinctive about the English detectives or by elaborating on London as a scene of production. Even without the Victorian entourage, Sherlock is still understood as an iconic English character.

I analyzed the interpretations of Western fans through the application of Culler's different naturalization strategies. That framework has complemented Jenkins' notion of transmedia storytelling as a literary mechanism that evokes the reader's activity. However, the ways in which fans interpret the texts are not necessarily the active viewing that Jenkins describes because he assumes viewers familiarize themselves with other versions of the text and rely more on fan communities in this process. In contrast, my interviewees show that viewers have a wide range of repertoires that guide them in their readings.

Intermedial elements form cues for audiences that they often bridge with other experiences and fiction. Aside from alluding to other versions of Sherlock Holmes, viewers rely on their own experiences, knowledge of popular culture and literature. Furthermore, although interpretive communities shape the viewers' interpretations of the material, shared community interpretations do not appear to conclusively determine an individual viewer's interpretation of Sherlock. The interviewees engage with fan communities in various degrees. Some use them only as a resource while other active users clearly reflect on what they observe there, especially in relation to "hot topics" of fan discussion. The naturalization strategies could not always be separated easily but were often combined to interpret Sherlock's content. The readings of Sherlock as a detective, for instance, relied on repertoires of Western culture as well as the detective genre and its local variations.

While I found the different competences to be a helpful tool to analyze the readings, I missed three elements in the concept that I perceive to be challenges in 
Culler's understanding of naturalization and literary competence as such. First, literary competence seems to be a narrow concept to understand the different ways in which fans move through an increasingly intermedial landscape. Rather, they display a "transmedia competence" that could be further theorized in which they make connections between different media, and they consciously speak of what certain media can do and how they tell stories. In other words, the media literacy of fans should find a place in the model of literary competence. Second, Culler's ideas leave little room to discuss the phrasing of personal experiences of the world and the emotions generated by the text. Although Culler's strategy is reader-oriented, it is still a literary study that rationalizes and contextualizes the effects of the work but gives little context to the effects themselves. The theory does not speak of what a work does to readers or how it morally or affectively enriches them. The personal discourses perhaps resonate more closely with the ideas of German reader-response theories and the idea of Leerstellen. Readers construct individual readings that are constantly adjusted and create expectations of a text. There is much room for moving between texts and cultural elements, but Culler's strategies leave out fans' personal preferences and ideas.

Such a personal discourse also leaves more room to discuss the experientiality of characters, the sense of realness and the affects that they provoke. Intermediality, as I have sketched in this chapter, shows us little of the audience's desire to rework characters and stories and why it is that certain features stick more than others. In the character discussions of the Dutch fans, something else happened that current inter/transmedia theory hardly accounts for: a desire for the characters themselves. As a theoretical concept, intermediality is invested in narrative overflow and draws attention to the multiplicity of the text, but thereby neglects other narrative elements such as characterization. Studies on inter-/transmediality should look not only at the excess of plot and events but also at characters themselves and their tenability. A good transmedial story does not depend on backgrounds and extra plots but rather on strong characters. The portrayal of the character on different platforms (e.g., tie-in websites) can contribute to the sense of realness of that character and emphasize his or her features. Transmedia design can foster this experientiality.

As a character, Sherlock Holmes is very recognizable and can constantly be given new life. His features, however, are not just prototypical but also deeply humane. In the original stories, we know little of his love life, ambitions, dreams or thought patterns. 
Holmes' private life, his emotions and his mindset are withheld from us, and while readers can enjoy the results of his deductive patterns, they never see quite how his thought patterns really work. The readerly fascination for Holmes is strengthened by Watson's colored focalization and his misunderstandings of Holmes. Readers receive a subjective, clinical view of a fascinating character. These elements construct Leerstellen in which the reader can personalize Holmes and fantasize about, for instance, his sexual identity and his psychology. Even in a postmodern setting, Holmes retains his recognizability, which shows what an extraordinary individual he is.

If we want to understand fan interpretations fully, our focus should not be solely on the events or backgrounds of the narrative, but it should start with the responses of the reader and the affects generated by the text. Television characters can be understood as embodied vessels of these desires. The reception of fans and producers shows a love for re-introducing characters and deepening them. That is not surprising. Real emotions, after all, are not triggered by events but by the characters who endure them, the memorable individuals like Sherlock Holmes whom we learn to know and love time and time again. 


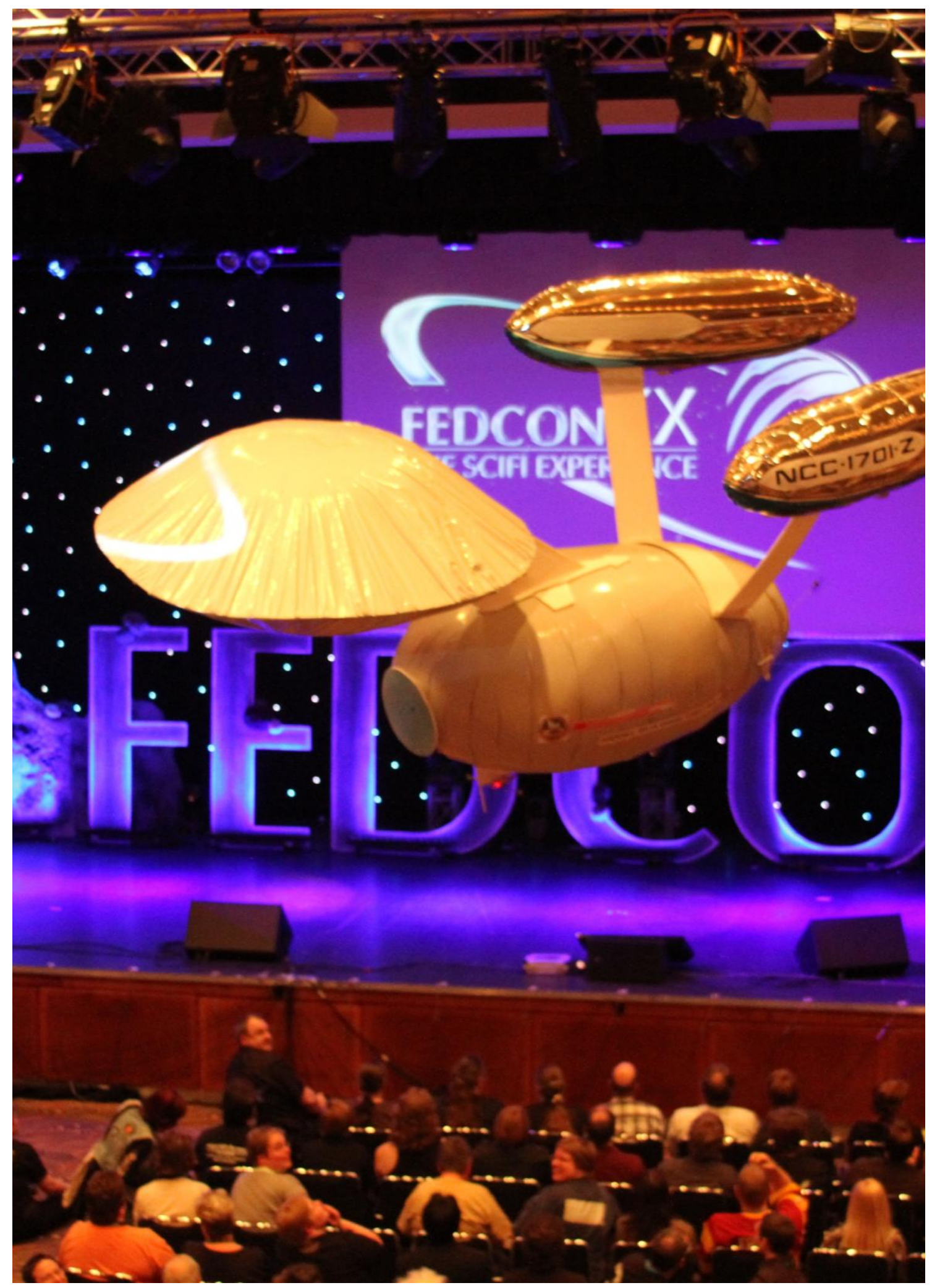

Photograph of FedCon Ceremony by Thomas Brückl 


\title{
FEDCON 2011
}

\author{
Meeting the Media Stars
}

\section{Celebrity Culture}

May $18^{\text {th }}, 2011$, my sister and I drive to Germany again for another event: the largest European Star Trek and science fiction convention, FedCon. The convention is held for the twentieth time in Düsseldorf, capital of the German state North-Rhine Westphalia. It started out as a Star Trek convention but broadened its horizons by including science fiction, such as Babylon 5 (1994-1998) and Battlestar Galactica (2004-2009). Star Wars is slightly underrepresented, perhaps because of the old rivalry between the fan communities of Star Trek and Star Wars. While F.A.C.T.S. focuses on merchandise, FedCon specializes in inviting special guests. Indeed, our main reason for attending this convention is to see a few of our childhood heroes in real life: the actors that played Tom Paris and Harry Kim in Star Trek: Voyager (1995-2001).

FedCon resides in hotel Maritim next to Düsseldorf's terminal, an accessible location for all visitors and special guests. The downside is that we spend a fortune on parking costs and eventually arrive late to get our tickets. With our tickets, we receive a complimentary bag that contains, amongst others, the program schedule and promotional breath mints of a new Star Trek game. Flipping through the schedule, we realize that we have missed the panel of Kate Vernon, Ellen Tigh in Battlestar Galactica. That is a pity since this science fiction series is dear to me.

We decide to explore the lobby of the hotel which has several booths and an information desk for the convention. The most prominent booth belongs to Paramount Pictures, the studio that produced the Star Trek movies. The stand features a large promotional banner for their other recent shows. In front of the booth, a life-sized Seven of Nine figurine from Star Trek Voyager watches over the fans. We decide to wait for some of our friends here and read the program which is predominantly devoted to the actors who FedCon has invited. Detailed biographies, a full page each, are provided of the attending guests and the roles that they have portrayed. It is quite difficult to find the floor plan in the booklet and many events, such as the lectures, are not even mentioned. 
At FedCon, the main attractions are not other visitors or workshops, but the actors themselves who represent popular culture and its production. The celebrity culture at FedCon is striking. I am overwhelmed by the list of names, rankings and autograph prices. However, the beauty of FedCon is that actors also walk around the convention and can be spotted in less formal settings. Fans and stars share the same space and connect.

\section{Star Trek, Chuck and Fan Activism}

Eventually, we head for the panel with Robert Duncan McNeill, Tom Paris from Star Trek Voyager and producer of the geeky spy series Chuck (2007-2012). He is introduced by Garrett Wang, Harry Kim from Star Trek Voyager, who we are happy to see in real life as well. From the balcony where we sit, we applaud McNeill loudly when he comes on stage. One fan in particular wonders if the actors of Star Trek Voyager were as close as the show suggests. McNeill tells us that he still meets up with the male actors regularly and that they had an intimate party in Kate Mulgrew's trailer after shooting the episode in which Tom and B'Elanna got married. Sometimes, Garrett comes on stage to join him and talk about his character. It is interesting to observe the good dynamics between the two actors whose characters were also best friends in the series.

McNeill shares some personal information, such as his love for donuts, and also tells us about his personal life, which influenced how Tom Paris was written. Apparently the actor's love for tinkering on cars and machines was mediated in the show, when Tom Paris started to work on a new shuttle from scratch, "The Delta Flyer". Other fans are interested in McNeill's work as a director and ask questions about Chuck. He has also brought a special Chuck shirt that is eventually won by a fan in Chuck cosplay, who answers his trivia question correctly.

Throughout his talk, he is very supportive of his fans. Companies gain a great deal from listening to fans, in his opinion. 'It's a great relationship - to hear what you fans like and to make what you want us to make.' He admires the investment and commitment of fans to a series and also sees it as a source of power. He describes how the fans' loyalty kept Chuck afloat when it was on the verge of being cancelled. Before the season finale in 2009, fans initiated a "Save Chuck" campaign and visited the Subway chain en masse to encourage NBC to continue the show. Subsequently, the restaurant chain struck a major sponsorship deal with NBC to help cover costs of the third season. 
The investors were surprised and convinced by the fan activism. 'Companies notice that,' McNeill says, and he underlines that the following season would not have been possible without this lobbying. Ultimately, he hopes that series will become less dependent of such investments though. In the current media landscape, he claims, downloading episodes globally against a small fee is a smarter move than relying on oldfashioned broadcasting models. In response, the entire audience applauds loudly.

\section{Vendors, Autographs and Donuts}

After the panel, we take some time to meet up with our friends and explore the dealer room which is not very big. The merchandise is diverse: patches and buttons with the logos of series, trading cards, action figures, DVDs but not too much of anything. Some of the stands are pretty special. One man sells hand-made costumes that are apparently also sold to film studios. He bought part of Paramount's costume archive to recreate the costumes and sell them on sites as Anovos which sells high-quality prop and costume replicas. Some fans made their own special props which are featured in an exhibition that includes life-sized plush versions of Star Wars characters that are only outsized by a Klingon bar, run by another fan club.

In terms of dress-up, some of the attendees wear fan costumes but certainly not all of them. Many have bought their own Star Fleet or Star Wars outfits while others have sown their own Seven of Nine outfit. Other fans sport geeky shirts and science fiction T-shirts. The most surprising costume that we come across is a girl dressed up as the police booth from Doctor Who, the time machine TARDIS. Her interpretation of the blue box draws much attention from photographers.

Though the convention is European-oriented, many people speak German. I notice a few Dutch and Flemish people that I have come across at F.A.C.T.S. as well. The Belgian and Dutch fan clubs are also attending as well as a group of builders that make their own R2D2 robots. At the McDonald's in the terminal, a few German ladies clearly understand our conversation about the original Star Trek series though, and play us a voice clip from Doctor McCoy that we refer to: 'He's dead, Jim.' When they leave, a Dutch lady hears us talk and sits down next to us. We admire her Battlestar shirt and talk about how we would have loved to have attended FedCon last year, when a few of the main actors of the series were visiting. I strike up a conversation about the Dutch science 
fiction conventions decreasing, at which point her husband, active in the Dutch Star Trek fan club, also joins in.

In a short but interesting conversation, they describe how difficult it is to organize a convention and get all the actors to come. 'They're so expensive,' she tells us, 'I mean, FedCon has Scott Bacula this year but he's an A-list actor!' I tell them it is pretty easy to have fun without actors and that socializing should be the point of a convention. They disagree and talk about the actors who were invited to F.A.C.T.S. and the Dutch convention Utopia, which stopped a few years ago. They are older than us and act as long-term Star Trek fans who act like they know everyone in the community. 'Like you don't know anything about organizing conventions,' Tamar winks when we politely say goodbye to them. At the terminal, we buy a donut to give to McNeill.

The line to get autographs is a long one leading to the center of a room - the repurposed main theater of the hotel - where all the stars are seated. I go to McNeill immediately and find him to be approachable; he even asks me about my trip - my pilgrimage from the Netherlands to Fedcon. I am hesitant to explain how much I liked his work and how much Star Trek: Voyager meant to me when I was younger, so instead I ask him about his own travel. I also decide to present the autograph to my father, who had introduced me to Star Trek, and McNeill says that is a nice gesture and inscribes it to him. At that point I grasp the moment and give him the donut, referring to the panel: "We heard you like donuts!" The donut is slightly squished from the long wait in line, but he thanks us and a staff member next to him put the pastry on the side of the table.

Afterwards - when I realize that I should not care about the donut, that it is the gesture that counts - I re-evaluate this affective moment. He was a nice guy, I concluded, but he certainly was not "Tom Paris," the character. He was older, wore glasses, and was a different person altogether. The autograph, to me, is not what counts but the encounter itself does. I envision that other fans have similar experiences and cherish that one minute in which they can pose a personal question and meet the actor up close.

We spend some time in the large lecture hall that has been redecorated for the signing. I am again amazed how approachable these actors are. Indeed, many fans actively discuss Kate Vernon's panel that I have sadly not seen. They are amazed that she is shy in daily life and quiets down after answering each question. This stands in stark contrast with the promiscuous character who she portrays in Battlestar. Some of the actors show genuine affinity for fan communities. 'We have to support our audience like 
they support us,' McNeill told us earlier. Many media producers or actors, like many artists, are increasingly dependent on their fans but also perceive the interest as flattering. Though I attach little value to the autographs themselves, the immediacy of the stars is soothing. An autograph gives me a reason to address them, pose a unique question and shake their hand.

\section{The Loss of Our Favorite Shows}

Afterwards, I join another event room where a German journalist is informing fans about the classic science fiction Raumpatrouille (1966). Old footage is played of fans dancing. I am unfamiliar with this local content and ask the visitors next to me what I am looking at. They explain me in detail that this is a German cult series, filmed in black and white, broadcast roughly at the same time as Star Trek: The Original Series (1966-1969). It is still very popular and the journalist explains us in detail why the show is still relevant today. Finally, I visit a panel by Sean Maher whom I mostly know as Doctor Simon Tam from Firefly (2002). Like Robert Duncan McNeill, he describes his daily life and upcoming projects. He is somewhat sarcastic but becomes more enthusiastic when he describes the intimate friendship of the Firefly cast and crew.

Though he shares personal experiences, like anecdotes about his daughter, and elaborates upon his part in Warehouse 13, many fans ask him about Firefly. They start their questions with compliments about the show and its characters. Some of them wear shirts with the logo of the ship. They ask about experiences on the set, the acting styles of the cast and whether they knew which characters would die in Serenity. In an ongoing joke at the FedCon, one of the fans asks him whether he saw Nathan Fillion naked. Sean is open about a lot of things and happily jokes along. He disappoints one fan though who longingly asks whether there will be a sequel to Serenity. 'I would have heard.' It is clear that Firefly is still alive in the heart of the fans but that Sean has moved on.

The most interesting moment is when he tells us about his co-star Nathan Fillion. Just a week before the convention, Nathan had tweeted that if he had all the money in the world, he would produce a new Firefly movie. This caused a stir in Firefly fandom where fans offered to readily fund this project even though Nathan had only made a joke. 'And fans offered to give him cash! It's wonderful, really, but in the end I think you shouldn't pay for it, but the studios.' It is clear that Firefly is a closed book but that fans still care about the series so much that they are willing to continue it by any means. The 
audience is shy though and the microphone often remains abandoned since there is no host to spice things up. 'Should I dance and sing now? I left my tap-dance shoes at home!' Sean laughs, poking fun at himself as a star, a rarity.

After this event, we go home with our autograph as a trophy. I am surprised about what we heard and about the information the actors gave us. It felt like a very close peek behind the scenes of the series. Star Trek, amongst others, became a bit more real, not some distant television world with which I grew up. These special allow fans to connect more deeply to the narrative and its production. It seems that the celebrity culture at FedCon is largely about the afterlife of stories and memorizing them through the bodies and stories of actors. 


\section{4.}

\section{QUEER TEEN DRAMA}

\section{Rewriting and Narrative Closure in Glee Fan Fiction}

\section{Introduction}

Fan fiction refers to a generous field of self-published and derivative texts that have been largely published online. The writing and reading of fan fiction brings together creative fans and constructs a safe environment in which they can share their fantasies, explore their writing styles and receive or provide feedback. The intermediality of the "fan fic" or fan text covers an array of textual relationships - an interplay of genre characteristics, media aesthetics, references and even personal and social experiences (Hellekson \& Busse, 2006; Stein \& Busse, 2012). In the previous chapter, I showed that fans use different repertoires to construct their reading of a text. These interpretations also create a fertile ground for the writing of fan fiction as both a creative act and an interpretive process.

In this chapter, I offer an intermedial reading of three fan fictions of the popular drama series Glee (2010-). This television series follows the events of several teenagers in the conservative state of Ohio who participate in a show choir, or "glee club". Glee has the highest number of fan stories based on any television series on the popular archive Fanfiction.net (January, 2013), and the generic intermediality of the source text creates ample analytical potential. Through the example of Glee, I explore the mediation from the television text to creative writing. This mediation takes places on several narrative levels, the most notable being focalization, genre and narrative time. I understand this process as a sliding scale between textual fidelity and transformation, as the fan narrative transfers the themes and aesthetics of the source text but narrates new insights, combinations and ideas. Moreover, the motivation to rewrite the story is read as a desire for narrative closure by the audience that is the result of the unfinished, episodic television text.

Because the industry and consumers increasingly share spaces and dialog, the need arises to understand fan fiction as an interpretive rather than a resistive process. The fan author intensely studies the existing material, plays with the characters and story lines, and creates an outlet for the affect generated by the source text. Fan fiction 
can function as a tool to resolve textual problems or inconsistencies in the episodically written television series that are produced by different authors and creative teams. Moreover, fan writing explores the dramatic relationships among characters in new combinations, settings or events. It signifies a wish to reach a deeper understanding of the media content and its protagonists and to extend the story (Pugh, 2005). This engagement with existing material is complex and relies on both an understanding of the textual facts - described by fans as the "canon" - and originality. Fandom often requires a mixture of closeness and distance, both in its social norms and in its maintenance of affective relationships (phrased as intimacy by Kelly, 2004, p. 10). As an affective act, fan fiction can be understood as the desire to deepen the source text and personalize its characters and events; at the same time, the writing signifies distance from the material as the fan author intensely studies the characters and rationalizes their actions.

This play between textual fidelity and infidelity has been considered more deeply in recent fan studies. Inspired by a post on Obsession_inc (2009), fans and scholars observe a difference between the fan practices that mimic the media text and those that do not (Busse, 2013; Pearson, 2012). The first strategy is considered to be "affirmational" because the fans closely follow the source text and the industrial discourses through which it emerges. The second "transformational" strategy pertains to textual appropriation through extension and alteration of textual meaning. Affirmational practices include the reviewing of the text, collecting merchandise and autograph hunting. Transformational practices range from producing fan videos and writing fan fiction to activism (Fanlore, 2012). Fans themselves have suggested that the divide between affirmation and transformation is a matter not only of industry-driven and autonomous fan practices but also of gender (Obsession_Inc, 2009). Male authorities such as reviewers are thus contrasted to creative female fans.

I do not believe that this gendered division must be readily accepted because particular transformative practices, such as video editing and remixing, draw many male fans; however, certain gendered patterns did emerge within this case study of television fandom. Glee fan fiction draws a considerable female authorship, which came to the fore in online profiles. The gendered identity of the fan authors has two implications for my research. First, the identity of the female authors suggests a culture of female authorship that has been noted by many fan scholars (Lothian, Busse, \& Reid, 2007). Fiction creates 
a zone in which fantasies about media characters can be shared but with ample distance due to its online mediation.

Second, such rewriting practices are a hallmark of feminist authorship. Historically, writing and creating derivative works gave women a chance to establish alternative gender and sexuality portrayals, among others. Fan fiction can be understood as a contemporary equivalent of this feminist tradition in which women use derivative writing to create an art and voice of their own (Lanser, 1992). In Transforming Memories (2011), Liedeke Plate explores the understudied relationship between women's rewriting and the commoditization of the past. Plate argues that feminist rewriting is a "central technology for memory" (p. 5) through which the past is reconsidered from marginalized viewpoints. However, she goes beyond these mechanisms and explores how rewriting has informed the commercial literary market. She argues that rewriting transforms the past into a "prime commodity, sold on the cultural market for consumption and profit" (p. 34).

Derivative writing is deeply entwined with commercial markets to the point that franchises such as Disney have profited from this model by reproducing heteronormative and patriarchal structures. The commercialization of rewriting tests the longstanding idea in gender studies that appropriation necessarily implies subversion. Likewise, this history presses us to think through the vocabulary of fan studies that emphasizes the transformative dimension of rewriting. Although fan communities do not often profit from rewriting narratives, they form a complex domain that is partly shared with and inspired by the industry. Fans may reproduce tendencies from the industry, such as a bias towards male characters, in their transformative works.

This chapter provokes thoughts on the gendered identity of the fan author and media characters themselves. I am inspired by Alexander Doty (2000). who has suggested that queerness can be an analytical tool. "Queer" is thus not limited to a concept that captures non-normative gender and sexual identities, but it is a lens for textual interpretation. While queerness can clearly be part of a text that portrays gay identities, it can also be a way of signifying particular visual and textual clues. These elements function as a "gap or rip in the fabric of dominant textual homogeneity" (id., p. 81). Queerness can form a reading practice that provides additional meaning to the text. Within fandom, however, queerness also has a social meaning. Earlier research has qualified the cultural domain of fan fiction as a "queer space" that allows women to 
mediate intimacy through stories and discuss sexuality and gender together (Lothian et al., 2007).

My analysis, however, is primarily grounded in capturing the mediation processes of fan fiction. The intermediality of the fan work is not a simple translation of the source text - it is a much more fundamental adaptation. Rewriting not only inspires shifts in focalization and genre but also critically examines norms and motifs from the source-text. From a literary perspective, these strategies and their diversity need to be understood. Thus, the intermedial close-readings focus on the narrative strategies that young women use to reread, interpret and creatively transform popular culture.

\section{Glee}

With over 80,000 fan fictions, Glee is the most popular television series on Fanfiction.net (15 October, 2012). Glee is a high-school "dramady" - a mixture of comedy and drama that tells of the local show choir New Directions at William McKinley High School. The teenagers that join this musical group enjoy singing and dancing, which quickly marks them as the geeks of the school. The students are degraded by their classmates and the arrogant cheerleading coach Sue Sylvester. The series focuses on the students' social problems as well as those of the staff, while the glee club practices and builds its way to the regional and sectional competitions. One of the prominent features of the series is that in each episode, the glee club covers a set of songs based around a theme, ranging from musicals, rock tributes and 1980s' pop to hit songs by Lady Gaga.

Like the previous case study on Sherlock, Glee demonstrates generic intermediality through various levels of inter-/transmediality. Glee echoes an awareness of previous television texts and creates ample intermedial connections with them. Glee is an appealing series for a fan author to work with. Every character has a unique voice that suits his or her personality and has been written in an ironic manner with fastpaced dialog. The show builds on previous comical drama series, such as Buffy The Vampire Slayer (1997-2003) and Gilmore Girls (2000-2007), which were also characterized by their fast-paced dialog and pop culture references. The irony and quasistereotypical characterization of Glee stands out but is not exceptional today. Michaela Meyer (2012) argues that millennial television texts display 'a turn toward irony, parody, and satire as preferred modes of television discourse' (p. 265). Glee mixes these styles of referencing with serious, dramatic moments. 
Glee also demonstrates the importance of television authorship, in that it forms part of the recognizable oeuvre of Ryan Murphy, Glee's creator. Murphy previously produced the high school series Popular (1999-2001) and the medical drama Nip/Tuck (2003-2010). Murphy's recent comedy, The New Normal (2012-), stars a gay couple and the surrogate mother of their baby. The homosexual Bryan is clearly based on Murphy himself, and his role as a television producer of the show Sing creates ample opportunities to parody Glee and its success. Although Glee seems very upbeat at first sight, it manages to address serious issues, such as discrimination against gay youth in American high schools. The series takes an important, leading stance in the representation of sexual diversity as one of the few shows that incorporates gay characters in prime time TV.

Furthermore, Glee brands its content on different media platforms through advanced transmedia design and promotion strategies. Glee has several official novelizations and invests in its franchise, which now includes a line of merchandise ranging from lunch boxes to calendars. The creators produced a reality show, The Glee Project (2011-), which airs annually on the cable channel Oxygen, to find the new Glee cast members. The producers circulate the show through online content such as Facebook or the official Fox site. As Alex Leavitt (2012) writes.

To retain fan interest after season one ended, FOX partnered with CoincidentTV to create the "Glee Superfan Player". The online platform integrates social network sites such as Facebook and Twitter with other fanenticing elements - such as links to buy music on iTunes and to create "photobooth" pictures with the cast - in a unified space that plays episodes while viewers multitask.

This online software targets the show's fans and mediates the television content itself. However, many additional products from Glee focus on participation through song and dance and present Glee as a show that solidifies American musical culture. As Jenkins, Ford and Green (2012) state that '[Glee] represented an alternative transmedia approach, one more focused on extending performance rather than storytelling across platforms and supporting different forms of audience participation' (p. 146). Fans can enjoy the transmedia performance of Glee even if they do not know the series. Several karaoke games, such as Glee: Karaoke Revolution (Nintendo Wii) and Singstar Live! Glee 
(Playstation 3), allow both fans and non-fans to cover popular songs as featured in Glee. The Glee cast also gave live concerts all over the world, concluding with the production of a movie, Glee: The 3D Concert (2011). The songs of Glee are published in albums and online stores. They have peaked on hit lists across the globe and increased the popularity of certain pop songs, such as Teenage Dream by Kate Perry. The episode Power of Madonna (2010) was also - despite expensive licenses - lucrative for the famous pop star as well as for Glee's production team (2010).

By covering famous songs, Glee manages to appeal to a broad audience. Some viewers may be drawn to the show because they already like Madonna; other viewers may come to appreciate her anew through Glee's covers. Glee is characteristic in its mixture of narrative and dramatic modes. The show combines the genres of comedy and drama but also frequently incorporates lyrical modes. Within the songs themselves, Glee often creates intermedial depth, as its oeuvre is not just limited to covers but also pays tribute to artists in "mash-ups", in which two songs are combined. This genre has become popular online with users who specialize in remixing. The fact that Glee transforms existing content in a similar fashion as fans themselves do is certainly part of its appeal.

The intermedial role of music within the television drama deserves further attention as the lyrics, musical form and popular context shape the narrative. To account for the diverse ways in which the lyrical can be incorporated in the literary text, Krogh Hansen (2010) outlines a three-fold categorization. This categorization is a helpful tool to frame musical interludes and to understand both Glee and its fan texts. First, Krogh describes "assimilating", in which lyrics and score contribute to the narrative themes. His example is a scene from the film Royal Wedding (1951) in which Tom sings about his love interest in his arm chair. The musical moment is assimilated in the text and perceived to be natural as an emotional outlet.

Second, "differentiating" strategies are common to musicals, which introduce song and dance in a separate diegetic space that symbolizes events or examines character's traits or interiority. For instance, Chicago's (2002) We Both Reached for the Gun sketches narrative events as a sung puppet play. Finally, "conceptualizing" strategies flourish in the genre. Such strategies introduce the musical as real, often by focusing on settings or characters for whom singing and dancing are appropriate actions. This form is most common in "backstage musicals" - narratives about show and 
theater life (e.g., Fame, The Producers). As a backstage musical, Glee is set in practice halls and covers the teenagers' journey to regional or national competitions. In these three strategies, the lyrical mode deepens the narrative and propels it forward.

The three categories all occur in Glee. Lyrical and literal modes often reinforce each other in the show through clever montages or dream sequences that reveal the teenagers' anxieties. For instance, the songs are often speckled with narrative cuts that show how the teens or other characters come to terms with the show's dramatic events. For instance, in the episode Choke (2012), we see the New Directions' girls singing Shake It Out for Coach Shanon Beiste, hoping that she finds the strength to divorce her abusive husband. During the song, the audience is served with flash forwards of Shanon returning home, subjecting herself to this domestic abuse once again.

On another level, intermediality is also used as a conscious tool to hail viewers. The connections between the fans and industry in particular are expressed within the text and her periphery. For instance, Glee's producers have integrated the lingua franca of fans. Even in the first season, the writing incorporated fannish vocabulary by referring to the fan term Puckleberry, used by those who support Puck and Rachel Berry as a couple (Bad Reputation, 2010). In similar vein, the noun "gleeks" (a portmanteau of Glee and geek) that Glee fans used to describe themselves was adopted by the industry in promotional tours and featured on DVD boxes. However, the mainstreaming of the term gleek may also make it less special to the fans who associated with it. This colonization of fan language deeply connects the performance of the fan to that of the industry, suggesting that fannish identity formation can be motivated from the top-down.

Finally, the television show is intermedial in its integration of new media, which play a central role in the narrative. The "glee kids" clearly belong to a generation that uses new media thoroughly. In the pilot we see how Rachel Berry - the most competitive kid in the glee club - worries mostly about the views on her MySpace profile, which she compulsively updates daily with new songs. She hopes to achieve star status on the platform while she barely has any profile views. In fact, the only users we see navigating to her profile are the very cheerleaders who despise her. In later seasons, YouTube video blogs, Skype conversations and Facebook pages are regularly addressed and integrated in the show. Thus, Glee offers a complex and clever transmedia design that is also augmented in the show's content, which reflects fandom and media use. 


\section{Narrative Closure}

The fan fiction of Glee relies on narrative closure, a concept that is central to my understanding of these three fan texts and their appeal to the fan reader. Noël Carroll defines narrative closure as 'the phenomenological feeling of finality that is generated when all the questions saliently posed by the narrative are answered' (Carroll, 2007, p. 1). As the phrase "phenomenological feeling" implies, closure is affective. It is defined by the audience's investment, the expectations of the narrative and the intensity with which these desires are met at the ending. Closure means that all of the macro-questions that are posed in the narrative are answered. Will the character get the love of her life? Will she succeed in her dream job? Smaller micro-questions - What happened to the character's uncle? - may not be answered because they are less relevant for the solution of the plot.

Carroll (2007) suggests that narrative closure can affect the interpretation and resolution of a text in three ways. First, it can supply a satisfactory ending to the story that answers all of the macro-questions posed in the narrative with causal coherence. Second, closure can partly fail when it does not answer all of the questions that are raised. Side-characters or plot lines may not be finished in the text and ultimately leave the audience at a loss. Third, some endings refuse closure and purposely do not result in a satisfactory ending. Episodic formulas such as soap operas are one example of this; another example is the art movies of the 1960s that deconstruct recognizable narrative structures and thereby fail to meet the audience members' expectations (id., p. 2-3).

In the last case, however, the absence of closure - or purposeful non-closure does not immediately result in dissatisfaction on the part of the audience. Poetry, for instance, creates an open structure, and as such, readers prepare themselves for closure. As Barbara Hernstein Smith writes about poetry, 'Closure allows the reader to be satisfied by the failure of continuation or, put in another way, it creates in the reader the expectation of nothing' (2007, p. 34). Unlike the author of a television text or novel, the poet ends at a point of stability, and not at a point where the events are finished and the expectations are met (id., p. 35). After that, we may again re-read the work in total and marvel at its design. The sense of completeness in poetry stems from its significant design and thematic whole. As in painting, finality is met when the artwork is completed and the final stroke is made, not when all events are told (id., p. 36). 
Although Carroll defines closure as a characteristic of narratives, I argue that the wish for closure also comes from audiences themselves. Even if a narrative formally reaches closure, it may be unsatisfactory for those audience members who want to learn more about the future of the characters. At other times, the audience may not agree with the closure and envision alternatives to the romance at hand or a particular character's death. In Harry Potter fandom, for instance, many fans were uncomfortable with the epilogue of The Deathly Hallows (2007) that details how the character's family lives several years after Voldemort's demise. Fans created new categories in their fan fiction that do not follow this time line. Fan fiction reveals the need for closure, but always on the fan's own terms.

The need for closure in Glee persists for two reasons. First, Glee is an episodic television text, which was ongoing at the moment that this fiction was published. The show is an open text that lacks closure, similar to Carroll's discussion of other episodic television texts, such as soaps. Possible satisfactory endings in Glee depend on the closure of its story arcs that center around the glee competitions on a regional and national level. Second, the desire for narrative closure is also framed by the high school setting. Audiences of this teen fiction invest in seeing the characters develop and succeed and fantasize about the characters' adult lives. Glee fan fiction shows a need for an ending that is not yet written in the television text and is expressed through fan fiction.

Closure is not only manifested as the desire towards an ending but also as a hope that characters find happiness and comfort. The three stories that I examined aim to secure a stable gay identity for the main character Kurt. In particular, the fan texts respond to the failed closure that Noëll (2007) outlined; they grant closure to events that were unresolved in the source text. The fan texts respond to the relationship between the closeted homosexual Dave Karofsky and the openly gay Kurt. Dave harasses Kurt until the he leaves McKinley High to attend the all-male school Dalton Academy. There, Kurt joins the glee choir The Warblers, who are rivals to his old glee choir, The New Directions. Dave seldom reoccurs in the show after these events. For many episodes, fans may have wondered what happened to Dave after the arc ended. Does he feel remorse for bullying Kurt? Does he desire him? Occasionally Dave reoccurs in Glee as a background character. Dave's election as prom king returns to the coming-out plot line when Kurt is elected as his prom queen (Prom Queen, 2011). Kurt bravely accepts 
the award and later tells Dave to come out of the closet. Dave replies, "I can't," and walks away in tears.

Dave's story line is resolved in the third season, when he is outed by someone at school and is bullied himself. Dave tries to commit suicide, but he survives. Kurt visits him in the hospital, where Dave explains to him that he is happy to be alive. Dave reveals some of his problems since his coming-out: his mother thinks that he has a disease, and his best friend has refused to talk to him. Kurt talks him through these issues by envisioning the future and explaining to him that it gets better. He paints him as a successful sports agent with a husband and a son. Dave is visibly happy and relieved. The two hold hands and smile. This shocking suicide attempt was met with mixed responses by the fan community; however, at the time the fan texts were written, Glee seemed to have dropped the arc altogether.

\section{Literary Analysis and Method}

While the objects of these close-readings are the fan texts themselves, I also pay attention to the online culture around them, which is characterized by the possible interaction between the author and her readers. In this case, the readers are commonly other fans who may provide reviews of, or feedback on, the fan work. I investigate the different repertoires that the Glee fan authors mobilize and the intermediality of their stories. I look closely at the mediation of the source text and related popular texts as well as cultural texts, paying specific attention to gender. Moreover, I am interested in the medium-specificity of these online fictions and explore the social context in which these stories emerge. The responses of readers and the architecture of the media platforms themselves have been taken into account in the analyses.

Fan fiction is thus understood as a medium in its own right. Fan authors often pay ample attention to the study of character and its performance according to the media text - the question of whether the protagonist is "in character". Television scholars such as Robert Pearson (2007) and Paul Booth (2012) have suggested that the study of character in popular culture should be relational. While analyzing character features and development has its own merits, this cannot be done without a focus on the social environment that characters belong to and that shapes them. In Glee, that environment is contemporary high school and family life, which allows for many struggles of belonging, especially in American high schools, which are structured along clubs and 
hobbies. Television narratives progress through the dynamics between characters rather than the actions that individuals undertake in the text. These popular narratives rely on showing rather than telling; that is to say, interaction establishes the personality of characters and demonstrates their interiority.

Glee fandom poses several challenges for an Internet researcher. First, writing fan fiction is a flourishing culture in this fandom, which provides the scholar with over 100,000 stories on multiple platforms. These texts vary intensely in terms of quality and length because they are often uploaded and written per chapter. Moreover, many of the writers appear to be young women who are still learning the ropes of creative writing; as a result, the texts may be slightly incoherent at points. The online texts are added to for years or may be abandoned altogether, which also makes it difficult to demarcate finished from unfinished works. Undertaking an analysis of these stories is a challenge for the literary critic.

Second, fan fiction is published on different media platforms, each with their own social features (e.g., comments, favorites) and norms, which bring pros and cons to the research design. Fan authors also have the habit of "crossposting" their works on several platforms, while attentive readers may also occasionally redistribute fragments of a work. I chose my initial corpus based on the recommendations of different sites and by asking fan authors themselves what they considered to be outstanding works. The recommendation list of TV Tropes (2012) was crucial to acquaint myself with exemplary Glee fiction, to navigate through the private and public blogs and to get a feeling for the diversity of the material. Users of TV Tropes can recommend best practices of fan writing and list these on the site. While some stories were recommended to me by fans in informal conversations, it turned out that the sampled fiction was mentioned at TV Tropes, which again convinced me of its quality.

During the process of sampling, I also read the top 10 favorite Glee stories on Fanfiction.net (20 September 2012), but I noticed that many of the stories were popular because they were long and updated frequently. As a result, fans list these stories as favorites or follow the authors so that they receive an alert when a new chapter is uploaded. This downplayed the importance of the short stories that many fan authors write and that are also prevalent at LiveJournal. The top 10 was telling in terms of the genres of Glee fan fiction: it featured only slash fan fiction and no heterosexual romance. 
There were 5 Kurt/Blaine stories, 3 Rachel/Quinn, and 2 Brittany/Santana. My use of different media platforms amounted to a strategic sample.

While my initial sample was grounded in several media platforms, I finally decided to demarcate my field to LiveJournal to create coherence among the sample. In contrast to other platforms, LiveJournal has few features that show how popular particular fan stories are. This makes it more challenging for a scholar to select fiction, but the upside is that its fans document fiction extensively and operate through many recommendation sites. LiveJournal was very suitable for analysis of user comments, not only because of its interface but also because of its feminist reception culture. As Jenkins, Green and Ford (2012) state, 'In particular, female fans were early adopters of social network technologies such as LiveJournal and Dreamwidth, using the resources offered by new media technologies (podcasting, mp3's, video-sharing sites) to create their own distinct forms of participatory culture' (p., 29-30). Moreover, the bloggers are known for their "metafandom": their reflections on fandom itself as a cultural phenomenon.

The three Glee texts were thus selected based on their appraisal within the fan community. For instance, the three stories rank highly within the renowned TV Tropes list of favorite Glee fan fiction. I consider the three texts to be diverse examples of fan fiction that highlight the literary qualities of this online writing. This purposeful sampling for heterogeneity is also known as a "maximum variation sample". To assure internal coherence, I chose three fan texts that can be signified as "AU" or alternative universe: a genre that deliberately changes the setting of the source text or transforms the way in which its events unfolded. In addition, I chose fan fiction that explored the popular character Kurt. This tight focus aimed to make the study accessible to readers who are not familiar with Glee.

The stories include gay content or "slash". The cultural backdrop of slash requires further explanation in this chapter. Commonly, slash involves the queering of characters who are emotionally confronted with homosexual feelings (Bacon-Smith, 1992; Jenkins, 1992; Penley, 1991; Pugh, 2005). Slash emerged as an exploration homosocial and latent homosexual texts in television and movies. The portrayal of homosexuality through subtle visual and narrative cues has also been noticed by mainstream critics outside fandom (Doty, 2000; Dyer, 1990). In 1975, Laura Mulvey even theorized the increase of homosocial bonding as an effect of the male "gaze", which codes the woman as a passive character - a character only there to be looked and with lack of depth (Mulvey, 1999). 
She argues that homosocial buddy movies emerged in the seventies to resolve the problems of the female character and its resulting heterosexual relationship that hampers the narrative. However, in contemporary television texts such as Glee, gay content has migrated from subtext to a main motif.

As Jenkins (1992) notes, a typical slash story is set up according to the following steps: an initial relationship in which the characters are not together but are interested in one another; a dystopic stage in which they cannot address their emotions; a confession of love to one another; and finally a utopia where they are together (pp. 206219). The slash plot exaggerates the template of the genre of romance, in which the female character first dislikes a male character, goes through an unsettling time with him, and then experiences a change of heart. She learns to understand the hero, and eventually, the relationship becomes intimate (Radway, 1987). In media fandom, slash flourishes as a popular romance genre. While slash connotes erotic intimacy between men, the term femmeslash (also spelled femslash) is used to refer more specifically to fiction depicting sexual relations between women.

Slash and femmeslash both provide complicated representations of gender and focus on different types of sexualities, including asexuality and same-sex sexuality. Although the three stories reflect on slash, romance is not the main purpose of their narrative structures. They rely on diverse genres, repertoires and character interpretations. This echoes the idea of Mafalda Stasi (2006) that modern slash is best read as a "palimpsest": a deeply intermedial product that is not just informed by the source text but also by other media texts and contexts. My analysis focuses both on the narrative qualities of the texts and on their medium-specificity as online fiction by considering reader comments and developments in the writing process. However, the primary focus is on the writing itself and how it transforms Glee.

\section{Pick Up Right Where We Left}

Lookninja's has represented the events from Glee in, among others, her short story Pick Up Right Where We Left (2011). She offers a different perspective on an important event from Glee's second season, when Kurt is increasingly bullied by Dave Karofsky, a young gay man afraid to come out. This fan fic is set at Dalton Academy, a setting that has inspired many fan texts to consider Kurt's experiences there and his encounter with Blaine. The series only shows us the tip of the iceberg of this all-male setting, thus 
leaving blanks that many fans fill in. While many of the fan texts focalize either Kurt or Blaine and focus primarily on their relationship at the school, others have explored alternative viewpoints of Karofsky or other Dalton attendees, such as Sebastian and Wes. One outstanding example of solace and closure of the Karofsky line is Time and Again (2011) by Fyrewyre. She focalizes Karofsky through two different voices, painting two time lines that could also be read as two interpretations of one event. Both voices are mixed in the text, with one styled in plain text and the other between brackets. In the two stories, Karofsky faces similar events but handles them in a different way until in one story line, he marries Kurt, and in the other, he commits suicide.

Dalton Academy also provides fertile ground for much fiction. Some fan authors experimented with other romantic relationships, such as Readfah-Cwen, whose I'll Have to Say I Love You in a Song (2011) offers a sensual portrayal of the minor characters Logan and Blaine. This multimedial story offers hyperlinked YouTube videos to directly frame the songs that the boys sing to each other. Their relationship develops through these lyrics and their introspective reflections on them. A novel-length example that explores the Dalton setting is A-Glass-Parade's Miss Holliday goes to Dalton (2011), in which the author transfers Glee's substitute teacher Holly Holliday from McKinley to the boarding school. The all-male setting of Dalton is enriched through Holly's perspective because it allows us to imagine the classes and the teachers. Her playful feminine voice stands in contrast with those of the boys who attend her classes.

The selected story by Lookninjas was written during the second season and can be read as a response to the Glee episode Furt (2011), in which Kurt is harassed and finally leaves school. The author explores Dave's intimidation of Kurt, the confusion of his gay desire, and the motivation for his actions. In Lookninjas' story "Pick Up", Dave goes to Kurt's new school with ambiguous motives. It seems that he wants to try to apologize to him, after Finn has given him word that Kurt is at Dalton Academy. Dave reflects on his bullying of Kurt and how far these actions escalated because no one was there to stop him. The authority figures in his life - both his father and his teachers - did not understand the troubles that he was going through. At Dalton, Dave tries to communicate with Kurt and apologizes, but Kurt does not accept his apology. Instead, he gives Dave the wedding topper that Dave had previously stolen in the episode Furt, whereupon the frustrated Dave breaks the ornament. Kurt's classmates tell Karofsky to leave. 


\section{Queer Bully}

Lookninjas deepens Glee by narrating its side-characters and filling its blanks. Rather than starting with the content of the story, I would like to begin with its title Pick $U p$ Right Where We Left, a reference that already provides an intermedial lens through which the reader could examine the text. The author explains that the title is an allusion to Amanda Palmer's song Guitar Hero. Palmer's song, which tells of the game Guitar Hero, communicates depression and anger. It narrates the loneliness of the addressed gamer, portraying him as a false hero who sits at home gloomily, and as the lyrics underline, "making out to faces of death". The "faces of death" are those of the virtual audience in Guitar Hero, which applauds or boos after every song and solidify this loneliness. The lyrics suggest that the game provides a deep, immersive context that is at once shallow. The negative emotions that the game play evokes are seen as unnecessary and possibly a waste of energy. The bridge builds up to "I could save you baby but it isn't worth my time", thus abandoning the addressee.

Connected to the fan text, the song already discusses the repercussions of Dave's actions and his inability to come to terms with himself. However, "pick up right where we left" also carries much meaning when read as a statement by itself: a deeply meaningful desire to continue an event. The text is premised on issues that the source text abandoned and gives a voice to a minor character. I detail both fan texts and how they, as women's fiction, remediate the dominant perspective of Glee by voicing minor characters. "Pick Up" focalizes Dave through an angry inner monologue that reflects his confusion and anger. He is portrayed as a passive character who blames others for his own actions.

Sooner or later, someone's gonna stop him. It hasn't happened yet, although he's been waiting for it for a long time. Waiting for a teacher to step in before he can slam the next kid into the lockers; waiting for Coach Beiste to throw him off the football team for starting shit with Hudson or Puckerman or that wheelchair kid, whatever his name is; waiting for his dad to do something more than shake his head and sigh when he comes home with another shitty report card. Coach Sylvester tried for like a second, but she gave up quick as soon as Hummel transferred to his fancy new school, and Schuester's so fucking useless he actually told him to 
channel his energy into glee club, like he's just pushing kids around because there's nothing better to do.

The beginning of the fan text suggests that Dave has low self-esteem and that his negative acts are signals to the outside world. His bullying is a statement to his classmates and the tough coach Sue Sylvester. The responsible adults whom he addresses - all of them teachers, all of them in a position of power - overlook him because they do not read his behavior as it is meant, a self-destructive signal. The reader knows that Dave hopes to be stopped, as the first sentence already emphasizes: 'Sooner or later, someone's gonna stop him.' The narration afterwards highlights that he is "waiting" to be stopped and that he is well aware of his wrongdoings. Nonetheless, he persists because there are no repercussions to his actions. Dave, however, successfully manages to infiltrate the school and confront Kurt.

Dave's anger and passivity also color the following passage about Finn Hudson, a character to whom he once looked up, but not anymore, now that Finn is in the glee club. Dave effeminates Finn in his narration:

And Hudson, for all he acts like he's King Shit these days, is so pathetic that it makes Karofsky's skin just crawl looking at him sometimes -- he damn near cried when Azimio and Karofsky tore his letterman's jacket in two, and then he actually offered to take Karofsky straight to Hummel so they could hug and apologize and then sing songs or some shit, which is just fucking retarded. Because Karofsky's not going to apologize to Hummel, and even if he tried, he's not stupid enough to think for a second that Hummel would actually accept it.

The confused and violent mood of the fan texts effectively voices the frustration of its main character. The fan text thus explores the reasoning behind Dave's bullying and the self-loathing that is implied in Glee. The focalization of Karofsky exemplifies what Genette describes as "internal focalization," a character-bound way of telling that is close to the character's thoughts and feelings (1980). Still, the narration is also distant in its tone because the narration reflects a fragmented, confused self. The narrative also refers to him as "Karofsky" rather than Dave. The choice for his last name in part results from the source text, in which the glee kids often refer to Dave as "Karofsky", thus distancing 
themselves from him. It also closely resembles the language of Glee, in which the athletes or "jocks" - the group to which Dave belongs - often address each other by their last names.

However, this mediation alone does not answer the question why a fan text that so closely follows Karofsky's thoughts would refer to him with his last name. I propose that within the context of the fan text, this name carries significant meaning because it both highlights the character's distance from himself and operates as a stylistic device that reinforces the idea that the protagonist's self-image is dependent on others. By incorporating "Karofsky" rather than Dave in the author's voice, Dave is again staged as a persona, as the mask that he wears rather than the individual that he could become. This underlines that Dave is more emotional than we see in Glee; he is someone who cannot be himself. The distance in this focalization thus reflects his performance of selfhood.

Similarly, the inadequate style of the narrative draws out Dave's ineptitude through chaotic sentences, curse words and casual indicators (e.g., "yeah", "whatever"). The narrative tone supports his rudeness and anger but also his pretense and flaws. Despite this limited perspective, Dave's focalization is clever on several occasions because he demonstrates unpopular but true insights about the glee club. His perspective allows the fan author to go into interpretive actions and character studies that would otherwise be more difficult. It reveals the fraught sentiment in Glee and the naivety of its main characters, such as Finn, who gives Dave Kurt's address to apologize to the boy. As one of the fans cleverly replies, 'It's kind of insane how much you were able to tell us about the entire Glee canon through five slimy minutes in Karofsky's head. And you've done something I wish the show could do, which is make Karofsky human, and smart in his own way, and even worth thinking about, without making me feel guilty for not wanting to forgive him.'

Kurt can be read as a positive mirror image of Dave, a more comfortable young queer on whom Karofsky projects his self-loathing and the part of himself that he cannot accept. An additional dimension is created by the idea that Kurt is the only one who can stop Dave's aggression and possibly redeem him. Dave looks up to Kurt as a strong and proud person, and that is exactly why he thinks that Kurt will not accept an apology. 
Because Karofsky's not going to apologize to Hummel, and even if he tried, he's not stupid enough to think for a second that Hummel would actually accept it. Because yeah, Hummel's a fairy, and he dresses weird and acts like a girl like 99\% of the time, but Hummel's also been the only person to ever stand up to Karofsky with any kind of consistency.

These lines suggest that Dave presumes that Kurt would not want an apology but would instead want Dave to own up to what he did. In his interpretations, he reads Kurt with an insight similar to that of the fan reader. However, though Dave knows that Kurt will not forgive him, he hands him the wedding cake topper that he stole in the episode Furt. Thereby, the fan author continues the events that the television text suspended and reminds us of the wedding cake topper that symbolized the marriage of Kurt's father with the mother of the main character, Finn. In line with Karofsky's reasoning, however, Kurt does not forgive Dave in the fan text. It is clear that Dave can neither take control of his life nor feel responsible for his own actions.

The fans who read the text appreciate the depiction of Dave and that his actions towards Kurt are not interpreted as romantic but rather as a type of queer projection. Whereas Kurt is successful and comfortable with his homosexuality, Dave cannot acknowledge his desire and lashes out at Kurt as a result. Within Glee fandom, Dave's actions have led to different interpretations of the source text and even conflicts. Some fans romantically invest in the relationship between Kurt and Dave and develop this within their own slash fiction. They seek to explore Dave's desire and resolve the source text by forgiveness and intimacy between the two characters. Other fans purposely do not want to do this and even naturalize any romantic motives as an incorrect motif that is not in line with the characters and Dave's psychological state. Some draw a line under Dave's characterization, which radically changed through his acts of sexual intimidation (or desire) such as those portrayed in Never Been Kissed. As one reader states, 'I get so frustrated when I see people casting Karofsky as obsessively in love with Kurt or admiring of his courage because that reads so false to me (if we are to take his treatment of Kurt in The Substitute and Furt seriously).'

Although both readings have their own merits and could be teased out of Glee, the fans make distinctions between those that develop the pairing romantically and those that closely rework other tensions between the two characters, ranging from hatred to possible forgiveness or friendship. The fan fic suggests a more complex view. Dave's 
intimidation of Kurt is understood as a pleasure of its own and reveals his motivations as slightly sado-masochistic. When Dave finally goes to Daltons to apologize to Kurt, this dark queer drive can be read very clearly.

It takes Karofsky a few seconds to find Hummel's pale, stunned face in the crowd of blue-jacketed boys, and when he does, he smiles. He'd forgotten how good it feels, that first moment where Hummel can't cover up how scared he is. It never lasts long, but that's why Karofsky likes it so much. (It makes him a little sick, actually, how much he likes it. But not sick enough to stop.)

When Dave scolds Kurt and his friends at Dalton, Kurt calls him a fag who is scared of himself and resolves his issues through violence. Dave protests.

\begin{abstract}
"I'm not -" Karofsky's voice is too loud, and he cuts himself short before he even knows what he was going to say next. Not a fag? Not scared? They're both lies, and they both know it, even if Hummel's the only one who'll actually say it out loud. "You are," Hummel replies, and his voice is flat but his eyes are wide, glittering like he's about to cry or something, and his hands are shaking. "You're a pathetic, cowardly, self-loathing fag; you're just too scared to -" Karofsky steps in fast, only barely able to stop himself punching Hummel, punching the wall, punching anything, and he doesn't miss the way Hummel looks, quickly, back at the double doors. And maybe he should hit him, or at least say something to make Hummel run back into that choir room, something to make it worthwhile when those Dalton boys push him out into the street again. All he can say, though, is "Stop."
\end{abstract}

Dave apologizes to Kurt, but like he envisioned, Kurt only laughs and says that he cannot accept his gesture. Dave has come to Kurt to redeem himself, but he first needs to accept who he is. Connections can be made to the narrator of Guitar Hero as a counter-voice to Dave's anger: 'I could save you baby but it isn't worth my time'. The line reminds us of Kurt, who tried to help Dave but got into trouble instead. Now, Kurt will not bother because Dave must first take responsibility and accept who he is. Thus, Dave is the only one who can redeem himself. This is clearly symbolized in the continuation of the motive of the wedding cake topper from Glee. Although Dave returns the stolen centerpiece to 
Kurt in the fan text, Kurt does not accept it. At the end of the text, he returns the centerpiece to Dave, suggesting that it is too late to make amends. Whether Kurt means to provoke him is unclear, but that is how Dave understands this act, upon which he breaks the topper.

This act suggests that Dave's relationship with Kurt, and with himself, is still fragmented and damaged. He is not at ease with himself. The symbol of heterosexual love and intimacy that he once claimed is now broken. The fan text can also be read in a different vein, as Kurt perhaps returned the previously stolen topper to Dave as a positive amorous symbol, suggesting that he should be comfortable with himself and his sexual identity. Though the author suggest in her comments that she does not perceive Dave's feelings towards Kurt to be romantic, symbols such as the topper show that Kurt and Dave's struggle is deeply emotional and intimate. Although this should not be read as romance per se, they find common ground in a shared sexual identity.

The fan text is an exemplary character study. Dave's focalization and distance from the Glee cast echoes the reading strategies of fans themselves as they make sense of the characters. By explicitly portraying Glee events through the eyes of side characters, new ideas on characters and events emerge in an original text. This transformation creates a context for Dave's problems and flaws. The text shows an intimate mirror relation between Kurt and Dave, but the relationship is never quite revealed as that romantic. Its readers' discussions also dovetail with the idea that Kurt deserves true romance and that even if Dave even has genuine feelings for Kurt, these feelings are too dark and messy for Kurt. The fan readers thus share positive ideas of romance that allow them to naturalize the fan fiction and Glee itself through repertoires of intimidation rather than queer desire. The interpretive community of this fan text, in so far as comments reveal it, thus deconstructs the possibility of slash between these two main characters. Nonetheless, the fan text demonstrates interpretations about the darkness within Dave and the realm in which his sexual fantasies may be projected upon Kurt.

\section{The Lost Nightingale}

The Lost Nightingale is a noir fan fiction by Mothergoddamn who posts her work on LiveJournal (2012). She writes original works and Glee fan fiction but is also inspired by Ritchie's Sherlock Holmes (2009) and Kiss Kiss Bang Bang (2005). Her interest in noir is evident, as she also published another Glee noir, The Girl in Room 17 (2010), a Sherlock 
Holmes noir called Looking for Mary (2010) and stories about her original detective character, Nash. Mothergoddamn excels in the alternative universe genre. She has positioned the Glee cast in thrillers, zombie apocalypse, and superhero drama. The Lost Nightingale also has a sequel, The Swan Song (2010), a reworking of the aforementioned Sherlock Holmes fan text (2010).

The Lost Nightingale rewrites the popular teen drama as a mature crime story that stars Kurt's love interest Blaine as a queer detective in Los Angeles. We meet Blaine in the 1940s when he is requested to solve Kurt's disappearance and slowly learn about the detective's past as a police officer through first-person narration and flashbacks. While Blaine is matured in the fan text, Kurt seems hardly any older than his character in Glee. Slowly the reader finds out that Dave Karofsky is behind Kurt's disappearance in an attempt to cover up the crimes of his boss, Jesse St. James. When Blaine finds Kurt, their love story unravels parallel to the detective story. Kurt flees to Club Pavarotti, where Blaine finds him and is assaulted by Jesse St. James and his goons. They manage to kill the criminals, but Blaine's old partner Sam is himself killed. The ending is grim: Blaine admits his love for Kurt but lets him return to Ohio.

This genre analysis is led by the idea that noir is a transgeneric phenomenon that is composed of recognizable aesthetic and structural elements. These elements do not form a coherent whole but emerge in texts that surpass genres, repertoires and media. In the American cinema of the 1930s and 1940s, noir elements bridged genres, appearing in crime melodrama, detective movies, thrillers and woman's pictures. Film noir borrowed from existing popular traditions such as literary pulp fiction that deconstructed the classical detective story by offering a more pessimistic world view, debatable closure, and hard-edged first-person narration (Palmer, 1994, p. 34).

Historical noir films reflect the anxiety of the American post-war period and deconstruct the American dream with its darker tone, style and themes (Hirsch, 2001, p. 19-20). As Palmer notes, 'Violence and moral ambiguity, as well as murky character and action, create the effect of film noir, which is nothing less than making the spectator experience what these desperate characters feel: anguish and insecurity' (1994, p. 19). Since noir's traditional days in the 1940s and 1950s, its aesthetics echo through different media texts. Its common structures, however, as I show in this analysis, can be clearly identified as belonging to the body of work known as noir. 
The Lost Nightingale positions itself as part of this post-war movie landscape by depicting the social anxiety of urban life in Los Angeles. The text deeply associates itself with Hollywood's early values as witnessed through the Glee characters, Kurt and Rachel, who long to be stars. This is backed by references to stars as Bette Davis, Mae West, Fred Astaire and Ginger Rogers, as well as other canonical texts and actors. The writing is interlaced with one-liners reminiscent of the 1940s movies. "Frail must not like you much, bub" (chapter 4), "Always with the Quips" (id.) and "Wise crack all you want, Gum Shoe" (id.) are transfers of this use of language. Through these references, the text explicitly frames itself as part of a particular historical and cultural tradition.

\section{Darkening Glee}

We meet Blaine as he is requested to solve Kurt's disappearance and slowly learn about the detective's past through first-person narration and flashbacks. Blaine, however, does not solve the mystery disappearance but runs into Kurt by chance. The boy explains the crime, while the detective can only guess at the circumstances. As an ex-cop and P.I., Blaine stands between crime and the law. Blaine strikes the reader as a much older character, considering his extensive history as a cop and detective. He appears to be middle-aged like most noir detectives (Borde, Chaumeton \& Hammon, 2002, p. 9). In contrast, Kurt, a young boy who wants to be a star, seems hardly any older than in the source text. Thus, the author matured some characters to befit the genre while others retained their original age.

Blaine's narration in The Lost Nightingale echoes the sense of disenchantment characteristic of the noir genre (Silver \& Ward, 1992). He signifies the rottenness of the town and its characters. His tone is rife with anguish.

Unfastening the top buttons and pulling up my sleeves, I listened to the quiet fill the room. I leaned my head back and tried to clear my mind listening to the drone of the shower. After a while my eyes shut and I began to drift. Drift from car crashes that left innocents maimed. Drift from thugs who tied men to chairs and killed them. Drift from boy's with pretty faces and big problems (id.).

The reader almost hears the characteristic, cynical voice-overs of noir as the detective observes the crime scene. The dark urban sphere and its inhabitants are contrasted with the outsiders. Unlike Blaine, Kurt and Finn do not live in L.A. but are visitors from Ohio. 
The story emphasizes their innocence in opposition to the morals of the other characters. When witnessing Finn's difficulty in phrasing Kurt's homosexuality and his apparent embarrassment, Blaine muses, "An out of towner, for sure" (chapter 1). Finn is concerned with Kurt's homosexual lifestyle that is "illegal in England, you know?" (id.), hinting at the deviance of his half-brother's lifestyle. When Kurt, at the end of the story, asks Blaine to join him, the detective refuses.

I winced and turned away, shoving my hands in my pockets. "I don't think I'm cut out for small time life, Kurt." He stepped up behind me, pressing his stomach to my back and wrapping an arm around my waist, his breath layering the flesh of my neck. "I can't leave this town, Kurt. As corrupt, dirty and seedy as it may be it's all I know. I'm it and it's me. I wouldn't know how to be anything else.

The Lost Nightingale tells the story of a crime through the eyes of a private detective - a common trope in noir. It shows the ambiguity of both the criminal and the main character. In the story, crime is depicted not as a moral or social problem but as a fact of life, a sign of the decaying town and modernity itself. The culprits commit their crime for personal reasons, financial gain and pleasure. This wrongdoing is not depicted as a social problem or a tragic circumstance: 'The bleak America where the private dick practices his profession holds out no real hope for restoration of order and justice' (Palmer, 1994, p. 73). Crime is a sign of its time and inevitably tied up with modern life. In this case, crime is embodied by Jesse St. James, a ruthless capitalist who wants a monopoly over the city's nightclubs.

The dark setting playfully refers to Glee. The "Cheerios" club is named after the cheerleaders in the series; "The Fury" echoes Karofsky's nickname; "Daltons" is the boarding school that Blaine attends. The relevant characters are all associated with the groups to which they belong in the series. Jesse's interest in buying out these clubs mirrors his drive to eliminate his competition in Glee. As in the source text, his interest in Rachel serves only to learn more information about his rivals. The murky public sphere of noir fiction mirrors the high school competition and in-groups that are central to Glee.

Blaine has been hired explicitly as a gay detective to solve Kurt's disappearance. He asks Finn, 'I assume you think that due to my own alternative lifestyle, I'll be able to seek out your brother quicker?' Although Blaine manages to unearth some clues over the 
course of a month, Finn is dissatisfied. The clues are provided through chance rather than wit, and Blaine eventually shows an inability to put the pieces together. He fails to trace Kurt himself and to connect his own past to the crime. This is not an uncommon formula because noir is often ambiguous and depends on surprise more than on obvious clues that guide the reader. The plot development of noir deconstructs the rational detective genre in which every clue has a function and every crime reaches closure. Eventually, the noir crime is reconstructed, but during the progression of the narrative, the pieces may seem random and difficult to follow (id., p. 169). The resolution of the crime in The Lost Nightingale is typical of that of the noir detective story, in which "chance, not intention, governs the human experience.' (id., p. 73).

The incorporation of a gay plot and possible hate crime connects the gay detective to the gay victim. Blaine is interested in finding the illustrious Kurt, whom he has never met but to whom he already feels attracted. His assignment shapes the desire that he feels for this imaginary Kurt that he cherishes as a photograph. 'I glanced back down at the photograph and felt a chill in my throat. The image was black and white but it filled my mind with color' (chapter 1). Although the tone of the text is as dark as we may expect in noir, the homoerotic themes clearly add a romantic touch and even modernize the early genre. In this sentence, the author combines the colored aesthetics of television with the gray atmosphere of early film.

Romantic narration is integral to the fan story. Melancholy prevails over romance, as Blaine realizes early in the text that he must eventually let Kurt go. The boy is on the run and should return to his family. Kurt is portrayed as fragile, an innocent in need of protection. 'He placed a hand onto my arm. It felt like a stray eyelash' (id.). Blaine describes his skin as "ivory" (id.), which makes him seem not only fragile and pale but also rich and precious. Blaine's narration signifies queer desire, but his idolization of Kurt also purposely distances himself from a love that cannot be.

The motif of Kurt as frail and exotic is furthered by comparisons to song birds. The boy's first stage name is "Nightingale" (chapter 2), while Pavarotti's owner considers dubbing him "The Black Bird" (chapter 6). Club Pavarotti refers to the song bird from Glee, named "Pavarotti" in honor of the famous opera singer. Pavarotti is the Dalton students' pet and carries much symbolic meaning in the series. Wes explains to Kurt, 'This bird is a member of an unbroken line of canaries who've been in Dalton since 1891. It's your job to take care of him, so he can live to carry on the Warblers' legacy. Protect 
him. That bird is your voice.' (Special Education, 2011). The metaphor between the bird and the voice is significant. The canary dies shortly after The Warblers have competed in the regional competition for show choir. His death reminds Kurt and Blaine of their relationship together (Original Song, 2011). During the pet's funeral, Kurt sings The Beatles' Blackbird, to which the fan text alludes.

The relationship between Kurt and the song bird is thus already closely drawn in Glee and mediated even more strongly in this fan creation. The metaphor of the bird as a voice is again a prime motif within the noir. As in Glee, Blaine and Kurt's significant moments swirl around Pavarotti, which is now symbolized by a club. When Blaine enters, Kurt is singing the jazz song Body and Soul, a tune that emerged in the 1930s and was covered by Ella Fitzgerald, Frank Sinatra and Billie Holiday, to name a few. This classic and melodramatic piece seems an appropriate choice for a nightclub song. This embedded song allows Kurt to express his feelings: 'My heart is sad and lonely / For you I sigh, for you dear only / Why haven't you seen it? / I'm all for you body and soul.' The mediation of the lyrics expresses both loneliness and queer desire that could otherwise not be named.

The love triangle involving Karofsky, Kurt and Blaine is central to the narrative. Both Karofsky and Blaine are enamored, perhaps even obsessed, by the young singer. At first, the reader assumes that the aggressive Karofsky is to blame for Kurt's disappearance. As Mercedes, the nightclub singer at The Fury, explains, 'He'd work Kurt until his voice was hoarse and still want it again. Better. Louder. More' (chapter 2). Her last observations give an erotic dimension to Kurt's practicing. Finally, Karofsky keeps Kurt back late and Mercedes hints at sexual harassment. Echoing the events in Glee, Karofsky battles against his feelings and kisses Kurt; the television moment that has been interpreted by some fans as sexual intimidation and by others as repressed desire. While "Pick Up" portrayed Dave as a threat to Kurt, the latter suggests the sincerity of Dave's feelings and provides a romantic interpretation of the characters. The historical setting problematizes Dave's queer sexuality even more and marks it as taboo.

Although a detective's erotic interest in the victim is nothing new, the gendering of the victim as male and gay deconstructs the role of the female victim. Kurt's presence is emphasized as one of an understanding lover who could perhaps redeem the detective. Kurt is not portrayed as many heroines in noir who are "vicious, deadly, venomous or alcoholic" (Borde, Chaumeton \& Hammond, 2002, p. 12). The part of Kurt is that of the 
"good woman", the one woman in noir detective stories who is faithful, morally just and not promiscuous (id., p. 94). Early noir movies tend to give an erotic and sometimes vicious view of women, while actual sexual activity is never shown (id., p. 9). The female characters are "femmes fatales": mysterious, seductive and dangerous women who are cast as both lovers and suspects.

The Lost Nightingale stands out in its tragic portrayal of the nightclub singer Rachel as a femme fatale, who turns out to be an associate of Jesse St. James. She manages to become closer to Blaine, earns his trust, and eventually turns him over to St. James himself. Rachel is referred to as “Jesse's Girl” (chapters 6 and 7), a reference to the song that Finn sings for her in Glee (Laryngitis, 2010). He expresses his interest in Rachel through this song, but she chooses Jesse. The story also brings out Rachel's desperation to become a star, no matter the cost.

\footnotetext{
“Rachel Berry. I know you're scouting. I know you think you've found something in Mercedes Jones, but just let me convince you that your success lies with me. I'll sing anything you want.' Her fingers twinkled softly up my arm and she cast her eyes to the floor shyly. "Do anything you want."
}

Rachel's flirtation bring to mind the episode Blame it on the Alcohol (2011), when Rachel and Blaine kiss to see if Blaine is not bisexual after all. In The Lost Nightingale, Blaine is not attracted to her. He describes her in the fashion of her name, Berry, as a "fruit," suggesting that she seems delicious but that he is not intend on picking her. 'If I'd been a man of different tastes,' he muses when he sees her in a night dress, 'I'd have been picking my tongue off the floor.' The fan text plays with the tension between Rachel and Blaine that also occurs in Glee. Although the fan fiction is shaped by homosexual interests, the heterosexual relations are also drawn out as loves that cannot be.

The focalization of the queer detective thus functions as a means to escape the anti-female sentiment common to noir (Hirsch, 2001, p. 21). The male gaze in The Lost Nightingale is directed at men rather than women, which also allows for more playful, friendly interactions between the detective and the opposite gender. The first sentence, for instance, reads thus: 'Finn Hudson was a tall streak of handsome in the right light. And my office had dimmers. He was doing just fine.' (chapter 1). The gay identity of the detective allows for different interactions with the men in the narrative. The dynamics between former police duo Sam and Blaine, in particular, stand out. Sam now works for 
Jesse St. James but eventually betrays him to help Blaine and Kurt escape at the end of the story. Sam's death is touching and unexpected because Blaine's trust in Sam has been violated several times.

This relationship fascinates me particularly because Blaine and Sam had little interaction in Glee itself at the time that this fan text was written. Their classic partnership in The Lost Nightingale may even have additional queer appeal for later readers because Blaine develops a crush on Sam in the fourth season of Glee. In this example, we witness a moving back and forth between fandom and source text. As the television text continues, new readings may be projected onto the early fan works.

Although the noir setting may seem highly transformative, the story affirms dominant themes and relationships in Glee, such as the road to stardom. Many times, the transformation of the text also emphasizes or exaggerates the source text. For instance, Rachel and Kurt's wish to become stars shines bright in the dark nightclubs of historic L.A., a town filled with the ambitions of young actors and artists. Similarly, Karofsky's struggle with his sexuality is augmented in a 1940s setting. The focalization of the queer detective in The Lost Nightingale not only adds to Glee but also effectively deconstructs the heterosexual topography of noir itself.

\section{Mostverse}

The budding friendship between the roomies Kurt and Rachel is central to Mostverse, a collection of stories that are all set in a future time. This story offers a different approach to the alternative universe genre by outlining the hopes and dreams of the glee kids. This fan text is a "future fic" that is set in a possible future for the characters of the series. It takes place after the students of McKinley have graduated. The older Glee characters graduated at the end of season 3 (2011-2012), but the fan text was written during the show's first season. Many authors in Glee fandom are concerned with the future of the characters. The top 10 favorites of Fanfiction.net features Color (2010) and Mischances, Stances and Stolen Glances (2011-), which are both concerned with telling the story of the relationship between an adult Brittany and Santana.

Within Glee fandom, Miggy is a celebrated author. She stands out as an author of "gen fiction", or generic fiction, which may incorporate romance but commonly explores other relationships such as friendship, parenthood or student-mentor relationships. Miggy excels in comedy (e.g., Predators, 2010) and short fiction written from the point of 
view of different Glee characters. As many fans indicate in comments on her fiction, she does an excellent job at voicing their personalities. Her serial stories include Mostverse and The 25th President of the United States (2010). The latter is a tragic story reminiscent of Columbine, in which several gunmen shoot students from McKinley High. The social anxiety raised by high school shootings is brought even closer to home by incorporating Glee's beloved characters. The theme of shootings has been picked up by other fan authors, such as Gandalf0123's And Innocents (2010-2011). Miggy has won several awards for her fan fiction at the "Glee Fic Awards" (2010) and hosts her fiction on LiveJournal, Archive of Our Own and Wordpress. I analyzed her fiction on LiveJournal, her primary publication venue, where readers posted ample comments whenever she uploaded a new part of Mostverse.

While the previous texts discussed Kurt's relationship with Karofsky, Miggy's Mostverse (2010) represents the rivalry between Kurt and Rachel in Glee and develops their relationship into an intimate friendship. Set after graduation, Mostverse describes Rachel and Kurt's disappointments in New York and the loss of contact with their former friends, while its sequel focuses on the beginning of their careers. Mostverse is a universe consisting of various stories that are all connected. While the stories are focalized by different characters, the budding friendship of Kurt and Rachel is a central motif. Early in the television series, both characters make it clear that they want to be on Broadway. Miggy has used this motif as a starting point.

The story begins as the Glee kids graduate. Rachel and Kurt are both accepted to schools in New York, Rachel at the classical performance school Julliard and Kurt at the Fashion Institute for Technology (F.I.T.). Because Rachel's school is quite expensive, she asks Kurt to be her roommate, and he agrees. They hardly go out and invest all of their time in their study. Both of their schools are demanding, and among like-minded, ambitious individuals, they do not stand out in the way they were able to in high school. Although Rachel and Kurt do not get along at first, they slowly become aware that they share many qualities, drives and ambitions. The plot swirls around break-ups and even more serious themes, such as eating disorders, depression and possible sexual harassment.

Mostverse has been met with much acclaim within the Glee fan communities. Interestingly, the third season of Glee includes similar story arcs between Rachel and Kurt, who also become roommates in New York and are confronted with the 
professional worlds of Broadway and fashion. Overall, Mostverse stands out as a beautiful portrayal of an unlikely friendship and intimacy.

\section{Growing up}

The fan fiction develops the relationship between Kurt and Rachel as portrayed in the first season, in which they tolerate each other as best. In New York, the two behave awkwardly around each other. Rachel is afraid that she is getting in Kurt's way and tries not to bother him. She is in his apartment, after all, and it is because of the expense of her education that they had to move in together. She feels that she forced herself upon him. Eventually, Rachel realizes that they should communicate and bond as friends.

The two friends become more sociable by creating and uploading YouTube movies together, but it is clear that Rachel uses these movies to fill her own void. She uses them to show that she does have friends and to remind her old friends of Kurt and herself. YouTube also fills the emptiness of her unsuccessful, lonely Manhattan life. The movies are free from pressure and provide instant gratification, unlike school.

Their sessions were so easy. They would practice performances, record them, and finally find a take they were pleased with. Up it went to YouTube. No auditions. No permission needed to step forward. And, stupid as it was, Rachel looked at every single thumbs up that came in and it felt like a round of applause. (Most Changed since High School, 2010).

This online presence on YouTube helps Kurt and Rachel stay in touch with their old friends elsewhere. Eventually, Kurt becomes less invested in uploading these movies, and it becomes clear that Rachel depends a great deal on the success of their movies. College has made her insecure because she faces dozens of talented individuals every day. She voices her fears to Kurt.

"I work so hard," Rachel forced out. "But I'm surrounded by people also on the top of their game, and... and I might lose, and all I want in the world is for someone to make me their number one again." That was all she needed. For someone to make her their number one. Their top choice. (id.). 
Kurt, however, is sick of her complaining and emphasizes that she never once asks him how he is doing. He understands the world of singing and auditions from high school but she does not realize that he is putting so much effort in his fashion education that it is wearing him out, too. Eventually, they sympathize with each other and realize that they are very much alike or, as Kurt puts it, "are each other" (id.). Kurt and Rachel slowly become better friends who realize that they have similar ambitions and doubts.

As the story progresses, the two friends start to care deeply about one another. However, their lives are not happy ones. Their perfectionism prevents them from making new friends and maintaining long lasting, intimate relationships. Mostverse reflects upon the character's futures and develops their personalities accordingly. The text contains a great deal of anxiety propelled towards the future that construes the character's actions and emotions. The characters' dreams hardly add up to reality and even have a self-destructive element.

One of the most emotional passages in the text is when Kurt's half-brother Finn notices his eating disorder. The pressure of school and his perfectionism are getting to Kurt, and as a fashion designer, he feels that he needs to look his best. Kurt's problems have escaped Rachel's attention, and she feels guilty for not noticing that her best friend was so sick. Because Rachel predominantly focalizes the fan fiction, the disorder might also come as a surprise for readers. Rachel explains the disorder to Finn as a result of their perfectionism.

\footnotetext{
"We have to be perfect. The entire world will seek reasons to cast us aside." She looked down. Her shorter hang hung around her face like a shield. "They do look for reasons. He's doing better than me on the major things but... but it's still hard. Even if I'm the only one to admit it. You don't know how many criticisms we've heard. We've heard things we weren't supposed to hear. I don't sell my role onstage. He can't edit his work. We have heard exactly how we fail and it's the most painful thing I've ever felt in my life" (Least likely couple, 2010).
}

The possibility of failure and the need to compensate through perfectionism is furthered in the fan text by the idea that conflict is not a source of strength but of increased weakness and vulnerability. 
Rachel was glad they were together, so glad, but suddenly felt as if the two of them had grown very hard. And when things grew too hard they became brittle. She hoped it wasn't too much to promise, saying she would look out for him. They should be healthy on their own. They should be happy on their own. She'd still try. Besides, she didn't know if the two of them really could make it apart (id).

The characters are unhappy with their lives but at the same time make no changes in the pursuit of their dreams and thus remain immature in their social lives. The fans who read Mostverse on LiveJournal applaud this grim realism but also convey at times that they are still rooting for a happy ending. The comments on the final story, Most Talented, particularly reveal the sentiments of the fan readers. Although all of the fans expect closure and root for satisfactory closure in which the characters' dreams are fulfilled, they acknowledge that the ending of the text might be depressing or open (as it was initially before Miggy wrote the sequel, Most Talented). The medium-specificity of online fiction is clearly revealed, as readers can interact with the authors and authors can continue a story when it is appraised by the readers.

In the final installment of Mostverse, the characters are slowly landing jobs. Kurt's career is advancing more quickly than Rachel's, which is a source of friction. However, Kurt collapses after his colleague asks him out for dinner because he fears that he might be an actual date rather than a formal appointment. He is committed to go through with this for the sake of his career, but the prospect of the dinner thoroughly damages his self-esteem. He even feels that he deserves such abuse, as he tells Rachel.

\footnotetext{
"I'm a whore," Kurt laughed, wiping at his eyes. "It's what I've been doing all this time. Never saying no. Flattering my instructors. Telling everyone I met anything they wanted to hear. Turning myself into their fantasy, no matter how badly it hurt. Should have seen where this was headed. I thought I knew myself, I thought I was strong. All you had to do was dangle a big enough dream in front of me and I'd keep dropping little pieces of myself with each step" (Most Talented, 2010).
}

Finally, it turns out that Kurt gets a promotion and that the appointment is not a date at all. This event is telling in terms of characterization, however, because it suggests that Kurt's sexual harassment in Glee has a traumatic afterlife. The characters are clearly 
burdened in the fan story, but their friendship is depicted as one of the good things that help them overcome difficult circumstances.

When Kurt and Rachel finally return to Ohio, they host a small workshop for the new glee kids. Both emphasize that their dreams came at an expense and explain to the teenagers that "it's not easy to be amazing" (Most Talented, 2010). Kurt also visits his old cheerleading coach, Sue Sylvester, who is happy that he is progressing well. She emphasizes her loneliness at the top and tells him that he is lucky to have Rachel. Sue is the most ambitious and arrogant character in Glee, taking pride only in her many trophies and achievements. She wants her cheerleading troop to win, whatever the cost. After Kurt has a heart-to-heart with Sue, he asks Will Schuester if he believes that Sue is happy. He replies that she is not, though the number of prizes that she has may suggest otherwise. Will emphasizes that it is friends and family that give life meaning, not achievements.

Kurt and Rachel are portrayed as successful adolescents at the end of the story, but their success comes at a price. Neither has a longstanding relationship and they hardly go out. Still, they love each other dearly. In the conclusion, Rachel contemplates having a baby with Kurt because he is the only person who understands her and with whom she feels comfortable. This touching ending convincingly draws out an intimate friendship that can progress as an actual relationship, even if it is not sexually consummated. Thus, Mostverse concludes with the premise of asexual romance and familyhood that goes beyond mainstream paradigms of parenthood and sexuality.

\section{Conclusion}

Intermediality allows genre comparisons to be made and cultural influences to be assessed. When analyzing these processes, looking merely at the mediation of the source text to the fan text does not suffice. Fans mobilize different repertoires, such as genres and pop culture references. Fan fiction is not a mere textual echo of Glee. Rather, the source text functions as a template through which fan authors convey new ideas. Fan fiction is especially grounded in the desire to provide immediate closure to the episodic and inexhaustible television format.

I have shown that fan authors have unique focal points and aesthetic styles through which to explore, extend and finish the source text. The first work changes the focalization of the narrative. The author voices the concerns of Dave and distils his 
personality from fragments of the source text. Second, The Lost Nightingale deconstructs Glee's context and aesthetics as a high school drama by shifting its tropes to a historical, alternative universe. The fan text closely follows the plot lines from Glee, but its effect is ultimately more estranging because of its displaced crime setting that stars a queer detective. Through this strategy, the text also talks back to noir's heterosexual demands. Finally, Mostverse alters the narrative time of Glee. The text elaborates upon the characterization established during the show's first season and pursues the characters' hopes and aspirations. The practical problems of a highly competitive job market dismantle the American dream that Glee salutes, which is also subject to critique in The Lost Nightingale. Through careful development, Miggy's Kurt and Rachel gain depth and credibility. Mostverse not only mediates and continues Glee but also effectively deconstructs some of its teen ideals as the characters are forced to grow up.

The three stories thus transform the characteristic elements of Glee by extending textual meaning and possibilities. Still, the texts also work quite closely with the existing material; that is to say, the authors do not stretch the characters too far and work within certain limits. The characters, for instance, retain their recognizable qualities and histories even in a historical or future setting. The stories also actively provide new views of gender and sexuality as they integrate emancipative themes, such as comingout problems, historical queerness or portrayals of asexual family life. Glee itself has often been applauded for its diverse gender portrayals, but the fan texts enhance these motives even further. Online, the fans can include thoughts, sex scenes and queer identities that the television show does not permit. Similar to the results of a recent Glee study (Ellison, 2013), I found that fan fiction did not subvert the canon but expanded upon the queerness of Glee, thereby exploring its latent subtext. The sexual openness of Glee may also be one of the reasons why this source text is particularly prominent in media fandom.

Critically, this selective transformation also means that some aspects of the text can be lost in the translation/mediation process. Glee's official texts emphasize transmedia performances where the lyrical functions as an important access point to draw in casual viewers, non-viewers and fans; however, the autonomous female fandom of Glee shows a different tendency that focuses on characters' interiority. Rather than scratching the surface of the performance, the fans go beyond the personal reproduction and appropriation of songs to deepen the text. The lyrical matters only when it serves to 
demonstrate the characters' emotional lives, and although the incorporation of songs was important in the latter two fan texts, the overall emphasis was on drama.

The mediation of the lyrical thus poses challenges for fan fiction. Creative writing cannot readily mediate the transmedia performance of Glee, its songs and visual spectacle. Online fiction, however, can provide thoughts on the inner lives of televisual characters and thereby provide great depth. These results should not be read as a claim against the quality of Glee fan fiction, but rather as a notion that demonstrates the medium-specificity of the television text as opposed to written fiction. Moreover, Glee fan fiction cannot be analyzed in quite the same way as written texts because its context in online blogs is fundamentally different. Readers and authors interact in a shared space of fandom and influence each other's creative and interpretive work. While the fan text can tease out new meanings and provoke ideas, its attachment to the existing story shapes its meaning. After all, fan fiction caters to an informed audience. 


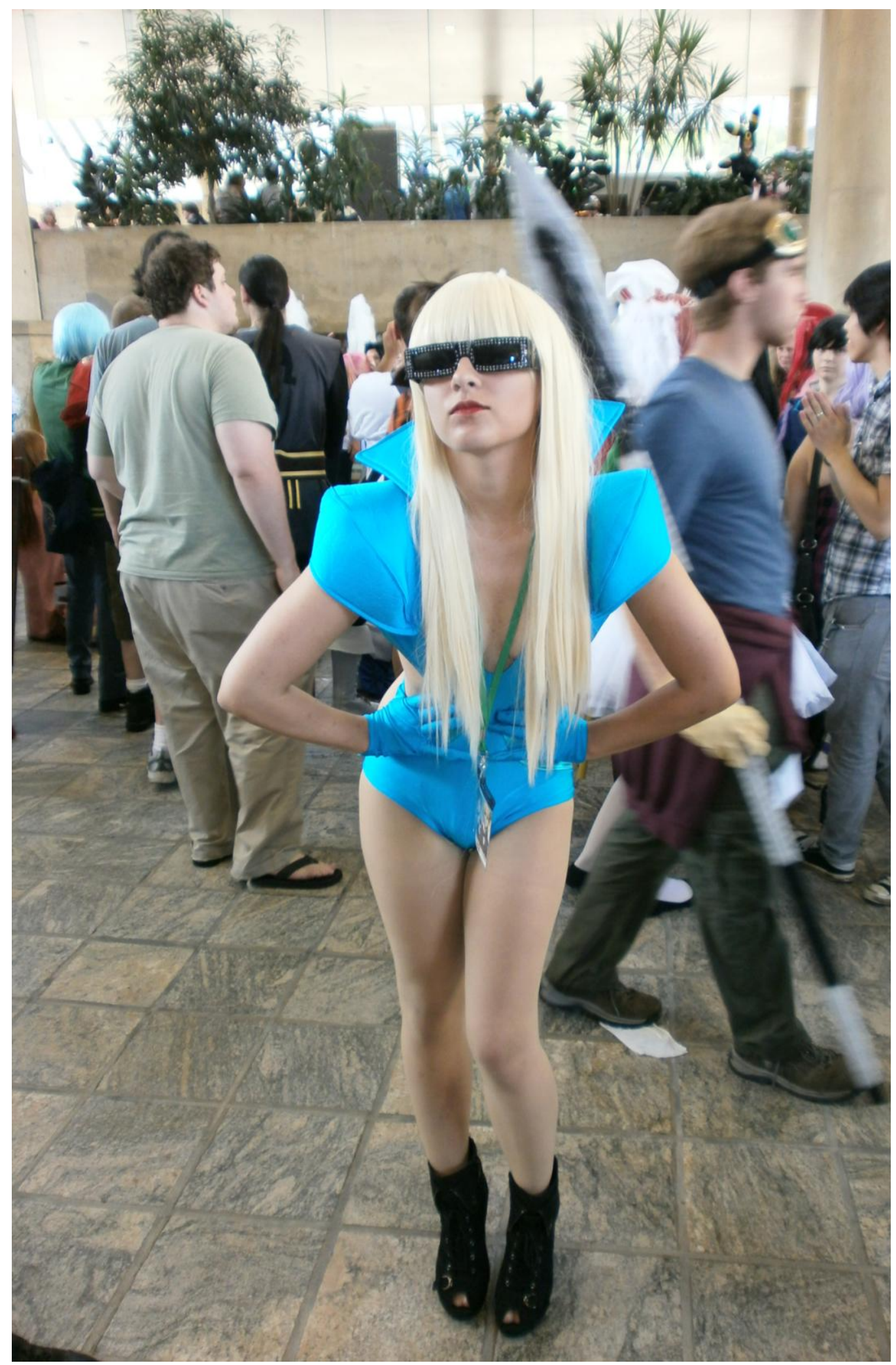

Photograph of a Lady Gaga cosplayer by Nicolle Lamerichs 


\section{OTAKON 2011}

The Intimacy of Strangers

\section{Becoming a Tales fan}

Before I started working on this dissertation, I had always limited myself to visiting European fan conventions. In 2011, I decide that this needs to change. In order to get a good feel of fan cultures as a global culture, I combine my holiday with a visit to Otakon in Baltimore. The convention is held on July $31^{\text {st }}$ until the $2^{\text {nd }}$ of August and had drawn up to 30,000 visitors the previous year. Although comic and science fiction conventions are sometimes bigger, this is one of the largest conventions around Japanese popular culture on the East Coast. My sister has attended the convention before and allows me to join her and her friends.

Though the convention started out in Pennsylvania, it has been hosted in Baltimore since 1999. For Baltimore itself, the Otakon has become an annual event that generates quite some tourist income. Shops and restaurants put notices on their doors that welcome the Otakon visitors and their waiters are eager to draw them in with flyers and a kind word. All the hotels in the area are booked by eager "otaku", the fans of Japanese popular culture which the portmanteau Otakon refers to.

As opposed to smaller conventions, Otakon has a pre-register day on Thursday on which there are no activities, but you can already pick up your badge. If you want to attend the events immediately on Friday morning, pre-registering is basically a must. We arrive early on Thursday, but since the line is very long and the heat is unbearable, we decide to register later. Outside the building, a few water vendors eagerly try to profit from the long line though, singing 'ice cold water, only one dollar!'

With an internet friend of my sister Corinne, "Luna" from Washington D.C., we check in at the hotel. We wait for a few other friends and roommates to arrive. Though I had met Luna before when she flew over to visit Corinne last year, I have never seen the others. What I know is that they all role-play together in an online community on LiveJournal. Luna for instance plays Emile, from Tales of Symphonia: Dawn of the New World (2008), while my sister interacts with her as Richter from the same game. Since I am not a part of their community, many of the references that they make seem obscure 
to me. My sister asked me to cosplay Fourier, a character from Tales of Graces (2009). In the game, Fourier is the sister of the character that my own sister represents, Pascal, so she found this to be fitting. After some hard work, I had finished the outfit which I immediately unpack in our hotel room to see if it is in good shape.

Otakon has a surprisingly interesting guest list with amongst others Japanese voice-actors, animators, and even celebrities, such as composer Nobuo Uematsu, who wrote the score to countless Final Fantasy games, one of the most critically acclaimed RPG franchises today. A special part of the building is reserved for autograph sessions with these important guests. The other activities at Otakon include a lot of panels held by fans or the industry, videos (from official content to fan parodies), a large game room, a bar and karaoke. Ongoing events include a LARP (live-action role-playing game), "otachan" (a room to entertain your kids with arts and crafts) and an otaku variant of Idols in which fans try to give the best song or dance performance.

On Friday, I attend Peter S. Beagle's panel to which I have particularly looked forward. He wrote the book The Last Unicorn (1968) which became a major animation in 1982. The core animators of the studio would later be part of the establishment of Miyazaki's studio Ghibli, in Western countries often referred to as "the Japanese Disney". Their typical traces are already visible in The Last Unicorn of which Beagle himself wrote the screen play. Beagle turns out to be an older but very energetic man. He talks about his novels with passion and apparently, still has a lot of projects. He also has some big news. Though he had worked on the animation of The Last Unicorn, he had never gotten paid for his labor. Now that the rights to the movie are expired, Beagle had become a shareholder of the title again and an artist who can profit from this title. Beagle had gotten fans onboard in his battle against the company and thanks the audience for their investment.

Beagle is quite progressive. He tells us that he is inspired by fan works that are based on his characters, though he does not receive that many. He also talks about the projects that he has in the pipe line, including a codax to The Last Unicorn and another novel. I also find out about a sequel to The Last Unicorn, Two Hearts, which I am determined to read. It is a good thing that we can see the HD version of The Last Unicorn on blue-ray Sunday on a huge screen. I mark the event in the small pocket schedule that Otakon distributed. As it turns out, some of the visitors of Beagle's panel are aspiring 
writers as well. Beagle gives all of us one word of advice: 'Whatever you do, show up for work!'

I leave the panel feeling nostalgic. Now, it is time to explore the convention grounds a bit before meeting Corinne and her friends again. We participate in a photo shoot at 16:00 in the large lobby of the building that is organized by cosplayers of the Tales series who want to have their pictures taken together. Most photo shoots are held in the lobby. Final Fantasy characters are meeting at one end of the lobby near the fountains, at the other end a group from Avatar: The Last Airbender (2005-2008). This happening is a great way to meet fellow fans, if only for one or two minutes in between various poses, before everyone scatters again and meets up with his or her friends. We become a small crowd for several minutes, bound by shared interests.

At our photo shoot, we have a lot of double Tales characters but no Yuri or Emile looks quite alike. I am one of the only side-characters, though. I pose with other nonplayable characters, motivated by a few girls who argue that 'NPCs need more love!' As I am standing next to a cook from the game series, I smile because the relationships that we construct are so unlikely and strange. They emerge just by taking a few group pictures.

In the late evening, we attend the panel of the Tales series and see many of the players again that we took pictures with. The Tales panel is clearly set up as a fan panel that aims to tell people about the games and show them some of the titles that have not been published in America and Europe. The two fans that host the panel are dressed up as Tales of Phantasia (1995) characters and are enthusiastic fans of the franchise, ready to update us on the latest news. They instruct us about new titles and show new trailers and merchandise which promotes the games very well and professionally. They have translated some of the newest content themselves specifically for the panel. Other translations come from sources such as YouTube or other platforms. Though some of the information is hardly new for the Tales fans that I am with, they are surprised by the latest updates.

For instance, the fans applaud the fact that the two hosts got their hands on a long trailer of the new Tales game, Tales of Xilia (2011). Apparently no one that I am with has seen this on YouTube yet or at the Tales forum so it must have been hard to come by. The girl who sits next to me is excited that the game will be so dark and political and cannot wait to play it. She is afraid that she will buy a Playstation 3 just for 
this title so I recommend her some other games. Like the others, I have little hope that Xilia will actually be translated since many Tales titles have not been published outside of Japan. The host motivates us to buy the games nonetheless: 'Buy the Japanese titles and buy Graces once it comes out, hell, I even bought it three times! Show them there's a market!'

\section{Cosplay Masquerade and Anime}

On Saturday, we draw our separate plans. I have overslept and missed out on some interesting panels, including a fan fiction discussion. Instead, I enjoy a few other theoretical panels and these events make the convention exceptional to me, since such an extensive event schedule is not common in Europe. In the late afternoon, I make way to cosplay competition or "masquerade". Since the event is always well-attended, Otakon hired the big Arena in town which is quite impressive. There are large screens near the stage so that even in the back, you can see what is happening. The entire event lasts a few hours of which I see the last hour, another hour of judging and the prize ceremony.

The skits have a similar quality to the ones in the Netherlands and abroad. They are pre-recorded though, with the cosplayers mouthing the words of the audio tracks. That is a bit unconventional in some European traditions where live performances are preferred. However, I can understand that it might overcome technical difficulties with the microphones. My favorite act is a dancing act to Blue Exorcist (2009-) with a complex choreography. Some of the people sitting next to me walk in and out. Between the acts, we sing throughout the stadium. When one part of the room sings "got tha ice cold wata", the other end goes "only one dolla!" Our chants draw from shared Otakon experiences and create a sense of community.

Afterwards, I decide to visit some adult events again and settle for cosplay burlesque, which sounds interesting. The line is very long and suggests that this event is quite popular. Some fans joke that the lines for $18+$ events are much longer than the other queues. Though I wait in line for some time, and befriend another woman who is also by herself, in the end we do not get in the room. Behind us, several hundred people look disappointed, or even infuriated. I pass some video rooms and eventually end up with a panel that gives women information on "hentai" or Japanese porn cartoons. The event draws a full house of interested ladies and a few guys. Two comical female hosts 
provide us with good titles and show some clips of the anime that they like. I leave early and head back to the hotel.

On Sunday, I start the day by roaming around the game room that I have not had the chance to explore yet. Though the room is large, its offer in games is similar to those at other conventions. Some rhythm games are present (Beatmania; DDR) and various shooters, fighting games and racing games (Mario Kart). For single players, there are some retro games (Sonic, Street Fighter) and new titles to try out. Catherine (2011) by the game design company Atlus is a title that I am happy to spot and try out. Atlus is one of my favorite Japanese companies, known for their Persona series that has met some critical acclaim the past years. Catherine combines puzzling levels with interactive drama. The gorgeous style and the interesting game play appeal to me and I leave satisfied, hoping that it is released in Europe soon.

Not much later, I proceed to watch The Last Unicorn in the big video room. Peter S. Beagle and his business manager give a short Q\&A about the film in advance. Then the credits start rolling. I had forgotten how beautiful this film was and wish that some of my friends could have been here to experience it with me. Though the movie draws a fair crowd, the front rows are pretty empty. I get sucked into it and enjoy how everyone goes "aaaw" and laughs at the same time. It feels comfortable to share the story with these people and it seems a bit more intimate than cinema because we participate more. We talk, laugh and are in it together. The kitsch parts of the movie are mocked, the pretty parts are admired. I never knew how much I missed these characters until I became reacquainted with them. One of the few things that I buy at Otakon for myself is a signed copy of the novel.

\section{Home}

Later that day, I go through the artist alley again with one of Corinne's friends. I still address her with her online nickname "Vil". We try to locate some nice One Piece merchandise for a friend of mine, but end up with Harry Potter buttons instead. Otakon is nearly over. By myself, I visit the closing session, which shows the best AMVs (anime music videos) that fans submitted to the convention. Since the AMV competition lasted for four hours - I saw exactly 15 minutes of standard editing and submissions and left this is exactly what I needed. The submissions are beautiful and one Princess Tutu 
(2002) video to the Dutch band Within Temptation really hits the spot. It also makes me miss home, just a little bit.

I leave the closing discussion early since we have to get our bags at the hotel. We spend ages waiting for the tram and see a Ghostbusters car drive by. It has the logo of the show painted on it and the model is almost exactly like the one in the movie. They play the theme song. Then the city quiets down. There are fewer and fewer costumes every minute. Our enthusiasm quickly declines because we are all worn out and the first tram is apparently cancelled. One guy asks me to take a picture of him and his friends before they head back to their own home towns again. 'We don't see each other that often,' he says. I assume that they met online too. While waiting for the next tram, I flip through the novel of The Last Unicorn. I set my mind to making some fan art when I am home.

I look around and see all the otaku, leaning on their suit cases, tired but not too eager to go home. I hardly know these people and yet I feel connected to them. We flock together here at Otakon based on a like-minded spirit and hobbies that others might find trivial. Now, we are going our separate ways again. 'Back to reality,' one fan says, 'some go to school and some to work.' Our big anime community scatters and slowly, we become strangers to each other again. 


\section{5.}

\section{TRANSMEDIA PLAY}

\section{Approaching the Possible Worlds of Firefly}

\section{Virtual Encounters}

The sun beams at the hot military airport where the ship Serenity has just landed proudly. The sight of her, a grey beacon against a blue sky, is marvelous, and I take several pictures. Although her thrusters are in bad shape, she still makes a prestigious impression. I walk past the hangar bay, trying to reach the entrance to the landing field. Passing trees and a bridge, I scurry past the long wall that fences off this site from the rest of the world. A virtual world, that is. Everything around me is composed of bricks of data: the trees, the ship, even my virtual self, "Setsuna", a gothic-styled young woman with long dark hair. The world does not look particularly realistic in terms of graphics, and getting a feel for the camera takes a minute, but then I peek through the pixels and feel at ease, immersed, perhaps.

The ship, a Firefly class vessel, is abandoned, and so is the hangar bay itself. I pass a sign that explains that this digital property has been on sale since March 2012 (Shuftan, 2012). This disconnected roleplaying site at Second Life honored the television series Firefly (2002-2003) for five years. Fans had devoted themselves to building this digital space and socializing in it as if they were actually on board the starship Serenity, but ultimately, they had enough and left the virtual world. The roleplaying adventures of these fans continue on blogs and other media, leaving this hangar bay as a small reminder of their endeavors and their affect towards Firefly. I discovered this virtual site when I was googling for Firefly sites in Second Life. A detailed GPS map of the world suggested a site. I logged in and teleported to the coordinates.

Although devoid of users, the site does not disappoint. As a virtual tourist, I take pictures of all the sights. Setsuna poses neatly with the ship in the background as I fiddle with the camera. I enter the ship, walking past the cargo bay, making my way to the kitchen. In the series, this was the most important part of the ship, the space that united the small crew. Everyone came together to eat at the long table and shared intimate moments. This diverse crew - composed of renegades, traders, a doctor, a priest, a courtesan - did not always get along, but in the kitchen, the heart of the ship, they 
shared food and laughter. I stand near the empty kitchen table. There is no action I can undertake there because the object has not been programmed for interaction. I only wish that I could sit there, absorb this digital home, this simulated fan art - then maybe I could feel a little like the crew. I think back on Firefly and what it meant to me. The digital data are like a museum that preserves the ship, but even more so, the data are like a memory space, one rife with nostalgia and affect driven towards the past.

I like to engage in virtual tourism every now and then, but I cannot remember it ever being this sentimental. Virtual worlds, aesthetically pleasing and socially rich, are a space to wander through. I am what Bart Simon (2006) and others have called a "cyberflaneur", admiring the sights and sounds of the virtual space. This strolling is a joy in itself and partly a necessity because I cannot reserve much time for the social interaction and community-building that Second Life offers. Luckily, Second Life has many wastelands similar to this Firefly site. Being invested in other fan and game practices, these online hobbies are too demanding for me, but that does not stop me from having a good stroll every now and then. Still, there is a striking difference between wandering through inhabited regions of Second Life and staring at a table in a desolated space ship. The loneliness is profound and solidifies my relationship towards the text as intimate and private.

I make way to the cockpit that, like the kitchen, is cleverly built and accurately resembles the television set. The engine room looks just as majestic. Compared to the many user-created artifacts, buildings and content in Second Life, it seems that the fan builders did an excellent job. Finally, I leave the ship, feeling morbid for having taken so many pictures, as if it were the actual television set. Outside, I run to the hangar bay and discover the Firefly logo, positioned carefully in a building like a small Easter egg, a special perk waiting to be found. Somewhat further along, I spot a shrine for the main character Kaylee. Her swing from the series dangles there. It is my guess that the builders wanted to position it in the ship and create her room eventually. Maybe they just never got around to it. There is a small donation box positioned there and a banner of Kaylee, begging me to take a few more pictures.

Finally, I run to the houses that remind me of the Western planet where the crew boards in one of the earliest episodes. However, it turns out that this street was created by someone else, who asks me to join their cowboy club. I feel disappointed that the Firefly space is not larger and go back just to see if I missed something. I take a different 
road, passing the shop of a clothing designer for Second Life characters. In this wealth of user-generated content, narrative spaces blend. You can buy a piece of land, maintain it, and socialize on it until you refuse to pay the bills. The consumer logic behind the world does not diminish the experience, however. Firefly is again mediated in these compounds of data. The virtual world has a real sense of presence, and its architecture reveals a digital materiality that is difficult to convey. This Firefly setting is a permanent echo of the series and its fandom that united here for five years. It allows me to enter the science fiction universe that I cared about so much once again.

This digital tour triggers affects and memories. It would be accurate to describe these transmedial remains of Firefly as a memory space - a permanent echo of both the series and its fandom that were united here for five years. The digital site allows me to re-enter the science fiction universe that I cared so much about. Still, this experience is slightly morbid, and I constantly feel out of place. I simply observe and borrow, unwilling to pay for the property. For the first time, I feel like the textual poacher whom Jenkins suggested in his early work (1992): a transgressive figure who walks right into the realm of the media industry and takes what he can. This, however, is not the media industry, and the Firefly site is long forgotten because interest in Second Life declined. The tour is more like squatting than poaching, really. On Facebook, a friend reminds me that the virtual remains of Firefly - carefully built, cared for and lived by fans - are much like the abandoned space ambulance from the show, found in 2008. This prop was left in the desert and then picked up again by fans who all volunteered to get it into a museum. This is what our favorite shows turn become: dusty heaps of sand or pixels that the media industry has forgotten, but not us fans.

Although Firefly has ended, the universe is remediated by fans in various media and objects. Fans dotingly call this story world "the "Verse", an expression that originates from the text itself. How can this fictional world be examined if it is spread over countless professional and fan-authored story worlds, systems and narratives? Traces of Firefly are scattered across the Internet and construe textual echoes. The universe is given shape through intermediality, more specifically inter-/transmedial processes, as it is developed through different media platforms. In this chapter, I focus on the story world of Firefly as a place that is explored and interrogated through fan role-playing. I unravel the pleasures of this type of play as it unfolds new worlds and stories based on the narrative potential of the source text. Moreover, ample attention is paid to the role of 
the fans themselves, not only as players but also as designers and non-fans. After all, these derivative games cater not only to the fans of the original media product but also to other audiences interested in rich story worlds.

In terms of methodology, this chapter is based on a multi-sited ethnography of online and offline sites. By participating and playing, this study took shape as part of a longer history of insider research on game communities (Boellstorff, 2008; Pearce, 2009; Taylor, 2006). As the Second Life introduction suggests, the ethnography was highly situated; in some cases, this also meant that the relevant sites of play had been closed down before the researcher had accessed them, resulting in data that indicate the afterlife of role-playing. Perhaps this situation is best captured as ethnography of play that could have been, which can be reflected upon methodologically because it shows the wanderings of the researcher through contingent and temporary sites.

The story world of Firefly is accessed through multiple role-playing games or RPGs. The initial cases are situations of online role-playing that I observed, while the main cases are two traditional RPGs in which I participated as a player. During play, I tried not to be obtrusive by making field notes but instead took small breaks to write down observations. As is common in game studies, many of the notes were made after play, and no recordings were allowed so that play would not be hindered. I also include documents related to the games, such as handbooks, as well as descriptions by players and designers. Through this play, I can unearth how and why fans mediate the worlds that they love.

\section{Firefly}

Firefly takes place in a science fiction setting approximately 500 years in the future. Planet Earth is abandoned, and its people have migrated to another solar system. This system exists of core planets, outer planets, and a dangerous rim region. The core planets are controlled by the Alliance, a totalitarian regime that is composed of two cultures: one Western and the other pan-Asian. The series stars a small crew of rogues that travels in the transport ship Serenity - a Firefly class vessel - that becomes their home. The Serenity is manned by a crew of nine people, the most important of whom is Captain Malcolm "Mal” Reynolds. He is a former "Browncoat" sergeant who fought on the side of the Independents in the war against the Alliance - but the Independents lost. With his old war companion Zoe, Mal bought the Serenity to preserve their freedom 
from the Alliance. Serenity is named after the battle of Serenity Valley that sealed the fate of the Independents or "Browncoats" in their war against the Alliance (Bushwacked, 2002).

The crew of the Serenity consists of various other characters: the pilot Hoban "Wash" Washburne, who is married to Zoe and the main source of comic relief; Inara, a classy "companion" or courtesan; Kaylee, a slightly obsessive but capable female technician; Jayne Cobb, a hired gun man; and Shepherd Book, a benevolent priest. Conflict arises in the first episode when two other people hitch a ride on the Serenity: Simon and River Tam, a brother and sister who fled from the Alliance. Simon is a skilled doctor who takes care of River, a schizophrenic who was subjected to human experimentation. Although these characters oppose the Alliance, the tragedy is that they gave up fighting the regime long ago. This family of outcasts travels in a worn-out ship with little food to spare but taking great pride in their freedom and integrity.

Firefly is a character-driven series: each episode revolves around one or several of the crew members and slowly reveals their backgrounds. The show is action-packed and comedic with dark sentiments. The narrative emphasizes the characters' struggles with the Alliance and distrust of one another's political loyalties. Simon, for instance, is seen as a refugee at the beginning of the series - a potential traitor and danger to the crew - but slowly becomes a friend. Firefly also darkens space exploration itself as bizarre enemies and strange happenings threaten the protagonists. For instance, the crew speaks of "reavers", eerie beings that raid ships at the outer rim, leaving their victims raped and skinned. Because the series was unexpectedly cancelled, narrative closure was never reached, and many questions about "the 'Verse" remained.

During its run, Firefly was not the success that its broadcast network had hoped it to be. Fox cancelled it in September 2002 when the crew was shooting the last episodes. With the universe downsized to fourteen episodes, transmedia design and franchising have played a significant role in providing narrative closure. The movie Serenity (2005) resolved some ongoing story lines but left many loose threads. Several short graphic novels also continue the events between the series and the movie: Serenity: Those Left Behind (2006), Serenity: Better Days (2008) and Serenity: The Shepherd's Tale (2010). In the short stories Serenity: Downtime (2010), The Other Half (2008) and Serenity: Float Out (2010), creator Joss Whedon explores several plot strands intended for the series. 
While the graphic novels are interesting, they only extend the narrative marginally and can hardly be compared to the original series and movie.

In terms of intermediality, the show can be interpreted in relation to various source texts. First, it can be read through the oeuvre of the show's creator, Joss Whedon. His cult shows include Buffy the Vampire Slayer (1997-2003), Angel (1999-2004) and Dollhouse (2009-2010). Whedon is a popular television author who is known for his close interaction with the fan community and his self-identified geekiness. Whedon is also known for his innovative projects, such as the lucrative Internet musical $\mathrm{Dr}$. Horrible's Sing-Along Blog (2008). This parody of video blogs was produced against the backdrop of the writer strike (2007-2008), when Hollywood authors pressed networks to pay royalties for online content, hitherto qualified as unpaid promotional activities. Whedon's independent musical was hosted online and became a statement of how profitable Internet videos could be. Whedon's different series share qualities such as fast-paced dialog, colorful characters and the blending of different tropes from speculative fiction. This is supported by the returning actors who create unity in his oeuvre, such as Nathan Fillion, who plays Captain Mal and Dr. Horrible's nemesis, Captain Hammer.

Second, Firefly's writing stands out as a blend of cultural repertoires. As a science fiction series, Firefly explores references to modern culture and presents us with a dystopic future. Due to scientific experiments and progress, mankind is facing grim circumstances in outer space. The planets in the series form a bricolage of cultures that viewers can recognize. Many planets combine old American Western themes with Asian influences. Chinese culture is also dominant in this universe, undoubtedly an allusion to China's emerging economic and demographic power (Mandala, 2008). This becomes apparent in street signs, fashion, architecture, and the language spoken in the series. The logo of the ship Serenity features not only the Western alphabet but also Chinese signs for "Serenity" in the background. The combination of Asian and American tropes is reminiscent of earlier science fiction films such as Blade Runner (1982).

Third, the series interweaves different genres and cannot be primarily understood as science fiction. In interviews (e.g., Huddleston, 2002), Whedon has explained that he was greatly inspired by war fiction, such as Killer Angels, a book on the American Civil War. Interestingly, the series narrates the losing side of the war. Its characters are immigrants and pioneers who lost the war and are trying to cope with the new regime. 
This renegade point of view stands in stark contrast to other science fiction series (e.g., Star Trek, Babylon 5) whose main characters belong to federations that explore and unite other cultures. War is often seen through the eyes of the colonizer or pacifist that is commonly represented by humanoid races, starring a male, Anglo-American captain. The movie Serenity negotiates the colonization motif darkly, as it concludes with some of our beloved Independents left dead or wounded. Although the last moment is one of group bounding, the shots prior to it depict the remaining crew members standing near the graves of their companions on a deserted planet. They cannot win; they can only keep on fighting.

Fandom has played a prominent role in the success of this story world and its further development as a movie. Upset by Firefly's cancellation, fans united and called themselves "Browncoats" to honor their heroes. As a result of Firefly's cancellation, fans started writing letters and created petitions to show their support of Firefly. "The cancellation brought fans together who, as Browncoats, started to lobby against the media industry,' Wilcox and Cochran (2008) write, 'The Fox executives who killed Firefly probably did not intend to increase its longevity, but in one of the ironies of cultural history, they may have done so, all unwitting' (p. 3). Browncoats gathered on online discussion boards, created art and lobbied to spread their love for the series (Cochran, 2008). The fan documentary Done the Impossible (Hadlock et al., 2006) captures these fans as a family like the crew of Serenity. While online friendships have often been considered strong and intimate, these fans also share a common social goal. The official Browncoats website also carefully distinguishes these activists from fans.

A fan is someone who watches the show and likes it--simple enough. But a Browncoat (in my mind, anyway) is much more of a fan activist. [...] A Browncoat is not satisfied with the way things are and takes action to make things the way s/he wants them to be. A fan can be passive; a Browncoat never is (http://www.brown-coats.com/2010).

The Browncoats' lobbying helped generate interest in a DVD release of Firefly that included the last episodes never aired by Fox. Browncoats used these box sets for their own "guerilla marketing" (Done the impossible, 2006). Many of them bought more box sets than they needed, giving them away as gifts or selling them to friends. Some visited stores to put up posters of Firefly or switched the DVD boxes to the front of store racks. 
The fan girl $11^{\text {th }}$ Hour made fan art that she posted everywhere and that other fans distributed. Later, she was asked to do the official art for the Serenity RPG (Cochran, 2009, pp. 246-247). Finally, Universal Pictures decided to reboot the franchise by producing the movie Serenity. Whedon often emphasized how important the fans were in all of the decisions regarding Firefly and Serenity. Thus, the movie is a clear accomplishment of fandom (Abbott, 2008).

The cancellation of Firefly meant the end of an extensive story world rife with potential. Although Firefly received a proper finale when Serenity was made, it was not the ending for which most fans had hoped. Based on the remarks of the production team, many Browncoats believed that there would be a sequel or a trilogy (also called the "big damn trilogy" or BDT). Rumors of an animated series after New York Comic Con (2012) also generated a buzz. Even today, Firefly and its vast universe hold a special place in the hearts of fans.

\section{Transmedial Worlds}

In literary studies, story worlds are often outlined as an ontological given - a necessary condition for engaging with fiction and imagining it at all. For Genette (1980), telling, or "diegesis," necessarily implies a spatiotemporal world in which actions and characters are situated. Whether the genre is science fiction, fantasy or naturalism, narratives presuppose a view of the story world. To engage with fiction at all, the reader has to accept that $\mathrm{s} /$ he enters a fictional world that differs from his or her own. Spatiotemporal elements structure narratives in different ways, however, and depending on the genre, can be a dominant motif in the story. A story world such as Firefly can be performed anew and is cherished in fandom. Contemporary narratology can profit from a better understanding of the production and reception of these story worlds.

The fictional instances of Firefly can be analyzed through the concept of transmedia storytelling, which focuses on the dispersion of narrative content across multiple platforms (Jenkins, 2006); however, the concept emphasizes events rather than the narrative space or characterization. To broaden these ideas, Klastrup and Tosca (2011) coined the concept of the "transmedial world":

Transmedial worlds are abstract content systems from which a repertoire of fictional stories and characters can be actualized or derived across a variety of 
media forms. [...] A distinct characteristic of transmedial worlds is that audience and designers share a mental image of the "worldness" (distinguished features of its universe)' (id. p. 48).

The concept allows us to step away from the story and perceive the larger diegetic space to which all of these narrative instances belong. Like Jenkins (2006), Klastrup and Tosca (2011) remark that the world is not created by a single narrative instance but that it is instead a larger idea construed in various media that retain background stories and histories. The authors emphasize the construction of the world not only by the industry but also through audience interpretations. This idea rings true with fandom, where interpretations of characters are created as much through official information as through fan values.

The characteristics of the transmedial world are topos, mythos and ethos (Tosca \& Klastrup, 2004). Topos refers to the spatial and historical knowledge of the fictional world. It captures "the setting of the world in a specific historical period and detailed geography" (p. 4). The genre qualities that are part of a fantasy world, for instance, would abide by other rules than those of a historically accurate Rome. Mythos refers to the "establishing conflicts and battles" within the world, the important events and myths within the story. As the authors remark, 'One could say that the mythos of the world is the backstory of all backstories - the central knowledge one needs to have to interact with or interpret events in the world successfully' (id.). Finally, ethos means how to behave in the world, or 'the explicit and implicit ethics of the world and (moral) codex of behavior, which characters in the world are supposed to follow' (id.). The ethos is also the code of conduct to which fans refer when considering which actions are acceptable "in character" behaviors and which are inappropriate.

Analytically, the concept of the transmedial world offers new ways to analyze intermedial processes because it focuses on the diegetic space. The different instances of Firefly - ranging from the television series to graphic novels and fan role-playing - can be signified as part of this overarching world. The subdivisions of mythos, topos and ethos are helpful tools to construct an analysis of this universe and the ways in which fan expressions and official texts connect. Until now, the concept has been primarily discussed in official transmedia designs such as the game Lord of the Rings Online (LOTRO) (Klastrup and Tosca, 2011) and the interactive fiction and social community 
Pottermore (Lonberg, Rasmussen, Lorentzen, \& Nygaard, 2011). However, transmedial worlds are shared universes that are also mediated by fans in their own play, stories and communities.

The inter-/transmediality of the story world is relevant to the interpretation of the narrative. Klastrup and Tosca write: 'LOTRO players experience intertextual play [...] as direct references to their own repertoires of knowledge and understanding of the transmedial world' (id., p. 65). As a literary structure, Klastrup and Tosca carefully distinguish the world from genre. A genre can be seen as a pattern, form or basic structure that emerges in different works and signifies their topical resemblances. A fantasy world, for example. can include imaginary flora and fauna or magic, characteristics that are also part of its genre repertoire. The transmedial world, however, is more specific than a genre. The concept refers to a common background story and a shared universe in which the stories and characters are set.

I would add to their argumentation by saying that the transmedial world seems to me to be a fundamentally different structuring device than genre. For one, the world embraces different genres, story lines and media. Firefly, for instance, consists of various games and comics with deviating plot lines. Similar to Glee, its fan fiction mediates such genres as romance, action and even detective stories. The world functions as an overarching structure that brings together divergent texts. The concept, however, falls short in signifying the multiple alternative universes that fans spin off from the official story world. In fan practices, histories, places and characters may be altered. Moreover, fan activities often bring story worlds together. For instance, Firefly can be understood in relation to other stories of the television author Whedon, which fans dub the "Whedonverse" in their practices.

To make more room for the different universes that can be created, I advance the idea of the transmedial world with the "possible worlds theory" (PWT). This literary concept originates from philosophy and logic, which use it to express modal claims about the world. PWT supposes that our actual world and any actions therein are only one possible state out of a variety of outcomes. Within literary studies, the concept is often used to investigate fiction as a separate space from reality, an autonomous world that abides by its own rules. The literary world, after all, has its own actuality and possible states that emerge as possible events, decisions and morals. As summarized by Herman and Vervaeck (2005), 'The theory of possible worlds envisages the world as a 
composite complex of potential and existing realities' (p. 149). Theorists such as Marie Laure-Ryan, Thomas Pavel, Lubomir Doležel and Ruth Konen have often applied this concept in an ontological fashion to investigate truth in fiction and the relationships between narratives and reality.

I use the concept to strengthen the understanding of fictional worlds and their transmedia instances. The concepts of the transmedial world and the possible world are not mutually exclusive; in fact, their characteristics have much in common. Doležel's (1998) categorization of possible worlds dovetails with several modalities that are comparable to Klastrup and Tosca's characteristics, such as the world's natural laws, its ethics and the knowledge that characters have of events. However, the scope of PWT is more ontological because it primarily seeks to discern the relationships between fiction and reality. There are two reasons why I believe that this concept helps to strengthen theory on transmedial worlds.

First, the concept resonates well with the reader-response theories that ground this study. It enables an open discussion about the text that reaches beyond hermeneutical or formalist claims (Ronen, 1994, p. 21). A possible world can be understood as a reader's construct of how events can unfold and be understood in light of the "Erwartungshorizont" that constantly shifts. Possibilities shape our reception and create parts of the joy of reading. Significantly, Doležel has used Iser's theory to show that the possible world is construed by the reader as an image of the text. He has refused Iser's notion of blanks, however, as these voids suggest that the reader can construct an ontological whole of the text. Doležel argues that a fictional world is necessarily incomplete and that showing and hiding regulate the disclosure of narrative information. He proposes the concept of "texture" - with varying degrees of saturation over blanks. Through this notion, Doležel presses us to consider the presence and absence of textual elements and how they are regulated by the aesthetic form. The elements of visibility and invisibility are central to textual interpretation and shape how readers perceive the fictional world.

Second, the concept draws attention to events and actions that are structured as possibilities. As Marie-Laure Rynan writes, "The consideration of the could-have-been is an integral part of narrative comprehension' (2006, p. 142). This resonates with the behavior of fans who explore the potential of stories by adding their own creative value and ideas. Through this imaginative reception, even propositions that are not in the 
literary text become part of the possible world. Herman and Vervaeck (2005) believe that these "non-events" are crucial (p.155). Novels such as The Remains of the Day, Madam Bovary and Anna Karenina are driven by the unfulfilled desires of their main characters, by possible loves and possible lives. Fans and readers explore these possible events and conditions continuously; games, however, are one central medium where this use of narrative potential requires theorization because they are structured through choice and branching.

\section{Game Worlds}

Players who engage in existing worlds combine the joys of gaming with textual intents and fan modes of reading. The primary focus of this study is to analyze how players structure "transmedia play", hybrid genres of play that rely on multiple media platforms, texts and environments. In this case, transmedia play is specifically structured through existing narratives that players mediate into a possible fictional universe. In this analysis, possible world theory is a powerful tool that has hardly been used to understand our advancements of play. A narrative study by Jan van Looy (2005), however, integrated the theory to better understand the immersive drive that occurs within digital games, although this forms a different point of entry from my argument.

My suggestion to study transmedia play by focusing on the story world has several implications for the field of game studies, which grounds this analysis. First, my understanding of the game space through PWT illuminates the different choices that players make within a game, how they interact with its design and how they expand upon story lines. Thus, I aim to advance the understanding of the ludic space itself. Recent studies have been more open to studying both the ludic and narrative aspects of a game, but they currently lack the terminology to signify these elements. Notions such as "procedurality" (Bogost, 2007) have been coined as a bridge between these modes, suggesting that computer games are fundamentally different media because they rely on interaction and software procedures to structure their rhetoric. While interaction is emphasized, possibilities and their narrative implications are not considered.

Second, a focus on the story world offers an innovative way to examine the game space itself. The semiotic and rhetorical way to analyze the game space has hitherto been dominated by the concept of the magic circle. In his anthropological study of play, Homo Ludens (1970 [1938]), Dutch scholar Huizinga envisions the game space as 
demarcated by rules that form a "magic circle" defining the context of the game. This concept has been picked up by Salen and Zimmerman (2004) in their influential handbook Rules of Play. They argue the following: 'In a very basic sense, the magic circle of a game is where the game takes place. To play a game means entering into a magic circle, or perhaps creating one as a game begins' (p. 95). While the circle can be understood as a semiotic domain or context, the concept is contested and interpreted differently throughout game studies. The most helpful studies that apply the concept perceive the circle as a porous membrane (Castronova, 2005), a social contract that preserves illusions (Harvianen, 2012) or a social contract that can be broken through spatial, social or temporal negotiations (Montola, Stenros, \& Waern, 2009). Studies on online gaming also specifically rephrase the circle because such games function as valuable vessels for identity formation and social grouping (Pearce, 2009).

Deconstructions of the magic circle often use fandom and game culture as an example. Fandom of games and media is considered to be one way in which the magic circle is broken and socially negotiated. After all, fans extend the playful moment through their social and creative activities (Consalvo, 2007; Taylor, 2006). Moreover, digital games offer fans the tools to create their own play by disrupting the hardware or the code that creates the play. While the concept has been redefined in functional ways, I ultimately believe that the circle is not a powerful analytical tool because it lacks precision and ultimately, no matter how porous the circle may be, relies on logics of division. Possible world theory directs our attention away from the ontological division of games and reality by emphasizing the story world through choice and branching.

Third, focusing on possible worlds brings about the fantasies of the individual player, which are integral to role-playing. It can adequately phrase personal fantasies and make-believe. MacCallum-Steward (2011) argues that role-play is strongly dependent on "quiet role-play" - individual fantasies that legitimatize the playercharacter's motivations and development that cannot be captured as constructs of ludic or social interaction. She highlights that the private worlds of players may fundamentally diverge from the social consensus, especially in those role-playing environments where players meet less frequently. In other words, the possible and imagined worlds of players differ. I propose that quiet role-play can be stimulated by transmedia play that is shaped by the players' past experiences with a narrative world. 
Particularly in these derivative games, players build up personal story lines and associations inspired by media content.

Possible worlds raise the question of what games do and how we can perform in them. The different branches in a game may be considered unique worlds, but so can the players' individual fantasies, which are widely divergent. Possible worlds theory can help raise questions such as the following: What possible actions and narrative strands does a world allow? How do audiences respond to different possibilities and solidify them in their own work? How are genres developed as part of this world? Rather than drawing a fine line between the semiotic domain of the game and the other, PWT draws the line between different performances and options. The concept resonates with the idea that a story world does not end but can be mediated time and time again with renewed interest and engagement by audiences and designers.

There is, however, one fundamental challenge to examining transmedia play with a focus on the world itself: it lumps together the identity of the fan and gamer perhaps too easily and raises the question of where these two identities converge. An example of this is Kurt Lancaster's study (2001) of the Babylon 5 (1994-1998) games, which discusses player behavior readily as "fan performances". Some of these games, however, do not require additional knowledge of Babylon 5 and can also appeal to the casual player. The practices of game fans have already led to debate. Andrew Burn (2006) argues that gamers' fan practices are fundamentally different from other media fandoms, such as television series, because games have different modalities. Gamers can focus on both the game state, which results in more instrumental products such as walkthroughs, or on the narrative, which amounts in expressive products such as fan fiction. This analytical division has been scrutinized by Wirman (2007) and Albrechtslund (2010), who argue that it is nearly impossible to discern whether fans are actually invested in the game play or the narrative.

The difference between the practices of fans and gamers is fuzzy at best. Searching for practices in games that are inspired by existing stories offers a way out but is hardly satisfactory. Throughout this chapter, I therefore chart the ludic identity of fans through the figure of the player. Similar to the previous cases, I try not to narrow down the fan but use the concept as a starting point to discuss the different intents, motivations and interpretations that ground transmedia play. 


\section{Role-Playing}

Although transmedia play can cover a wide array of practices, such as dress up and mixed media games, this particular chapter focuses on role-playing, a genre characterized by its emphasis on storytelling. Loosely structured role-playing, or makebelieve, is a common genre of play for both children and adults. Over many years, structured forms of make-believe emerged as a game genre in and around fandom. While structured role-playing games (RPGs) originated in the fandom of speculative fiction, today their scope has broadened to psychological and historical games. Although role-playing may require elements of productive play such as dressing up as one's character, the play itself is characterized by performance rather than creative production.

Definitions for role-playing emphasize the following characteristics (Tychsen et al., 2006): a) storytelling with rules b) a shared understanding by multiple users (at least two) of what these rules consist of and how the game setting should be envisioned c) the control of a character to navigate through this imagined world, and d) a game master (GM) or referee who is responsible for the decisions in the world and for its players. Other studies (e.g., Hitchens and Drachen, 2009, pp. 12-13) have drawn attention to character development as a goal of these games. The characterization of the avatar changes throughout the story, often due to the player's own actions. Make-believe or "mimicry" (Caillois, 1961, pp. 19-24) is a crucial feature of role-playing because players create and perform their own characters, thus partaking of a story world that functions through shared conventions. It is important to realize that the individual player has a complex relationship to the textual world that is co-authored and thus constantly revised, meaning that a complete overview of the world, its events and character histories is often not available to all players. The entry point to the world is the single player-character with a unique history.

Role-playing can be mediated through many platforms and attributes. I pay attention to three forms of role-playing in this chapter: online role-playing through blogs and forums, table-top role-playing and live-action role-playing (LARP). These forms are central to my description of the genre and the different media involved. Historically, the first strand of role-playing can be traced back to the 1970s, when Gary Gygax and Dave Anderson created the table-top RPG Dungeons \& Dragons as an amateur production that targeted war gamers. Today, the table-top genre is still popular. It allows players to 
enact their characters through speech, commonly while sitting at a shared table with minimal props. The characters are created through guide books that offer statistics about their abilities or "skills". Interaction is structured through a guide book with dungeon maps and through dice rolls that check the success ratio of an action (e.g., magic attack on monster) and determine whether it is successful.

In the 1990s, various table-top role-playing systems emerged that focused more on storytelling and less on ludic actions such as combat checks. The World of Darkness system is exemplary in this sense as first used in Vampire: The Masquerade (1991). In this liberal system, players can explore their own stories using the system as an input for skills and character construction, although many guide books - written by the official team or by players themselves - provide inspiration. Interestingly, the designers also encouraged embodied, "live-action" game play by stressing that players could dress up, use props and create a fitting atmosphere (Rein-Hagen, 1992, pp. 24-25).

The designers of Vampire brought two strands of role-playing closer together: table-top and live-action role-playing (LARP). LARP, based on table-top RPGs, historical re-enactment and fantasy literature, began in the late 1970s. Similar to table-tops, LARPs are mediated by skills that create rules for this embodied play. In some LARP cultures, however, rules may be downplayed in favor of theatricality and free play. Particularly in Scandinavian LARPs, character psychology and performance is privileged, while the play is less structured through systems and skills (Stenros, Belarbi, \& Montola, 2010). The genre developed more in lines with improvisation and psychodrama, as opposed to the more rule-based, continental culture.

With the emergence of Internet platforms, role-playing also became more common as an online activity in the early 1990s. Textual RPGs were among the first online games altogether with the development of MUDs, short for "multi-user dungeons", large textual environments with various rooms or settings (Murray, 1999). These programs have been around since the mid-1970s in several varieties (e.g., Ryan, 2001, p. 310). MUDs facilitate programmed content such as fixed descriptions of characters, objects and settings, as well as spontaneous chats and actions by participants. Before the turn of the millennium, role-playing became a prominent genre in digital games that flourished, especially through well-known massively multiplayer online role-playing games (which can be shortened to MMOs). World of Warcraft (2004) is the most studied of these (Chen, 2012; Corneliussen \& Rettberg, 2008; Glas, 2010; Nardi, 2010). 
The online examples that I discuss below, however, are inspired more by creative writing than digital games. In media fandom, it is a common practice to perform characters through blogs or other media. Usually these games emphasize free play and social interaction and have few rules and systems (Stein, 2006). In other words, though role-playing has emerged as a structured form of play, there are increasingly divergent and liberal instances of character re-enactment. In some cases, the online and offline performance of characters go hand in hand. Within LARPs or table-tops, it is quite common for players to continue performing their characters through e-mail correspondence, blogs or chats. The time between sessions is often called "down time". While my groups refrained from actively using their down time, I have seen other roleplayers develop their characters during these intervals, for instance, by interacting through e-mail.

Firefly in particular has been mediated into a wide range of RPGs, some more spontaneous, others facilitated through official role-playing guides. The universe is appealing to play in because of its mixture of genres and its diversity of character types. It also allows for questionable morals on the part of the main characters rather than typical heroes through groups such as the resistant movement, the smugglers and companions. The cultures in the 'Verse are outspoken, with much attention paid to fashion, language, ethnicity and class. These visual and cultural elements function as blanks that players can draw from the television text and expand upon. Firefly is a wellcrafted world - it is easy for a television audience to envision that they have only seen small parts of it.

\section{Online Firefly Role-Playing}

RPGs are a highly intermedial genre in which derivative games hold a special place. Until now, studies have largely focused on games with original characters and settings. Despite attentive to their intermediality, these studies engage in a more descriptive approach to role-playing and look for similarities in their cultures, media use and national backgrounds (Stenros et al., 2010). Exceptional studies on transmedia play include Pearce's (2009) analysis of Uru role-playing on Second Life and the intertextual readings of Lord of the Rings Online (Krzywinska, MacCallum-Stewart, \& Parsler, 2011). The emerging topic of transmedia play needs further exploration because online roleplaying creates an intermedial bricolage of characters and fictional universes. Moreover, 
audiences with different backgrounds and identities - both fans and non-fans - may connect through this play.

Firefly has spawned various online role-playing games on different media platforms. Some of these, such as The Verse, which I observed in November 2012, include a cast of original characters to explore the Firefly universe. Players can subscribe with a character that they have written themselves by filling in a template and creating their own ships. This is done through a forum structure that has various tabs that players use to navigate through the universe (e.g., White Sun System; Kalidasa System). The players communicate in the third person, thus creating a novel-like structure similar to fan fiction. They respond to each other's comments, or "prompts", to engage in a coauthored narrative. The Verse is an interesting space to examine, but it seems that the forum has moved around it and that activity on the site is minimal. I notice a mixture of types that bring to mind the cast of Firefly: researchers, mercenaries, priests and renegades. The social interaction is minimal, but the atmosphere of Firefly clearly emerges from the community's posts and the joys of creating a ship together.

In media fandom, the games on LiveJournal, where players perform the existing characters through blog entries, thus mediating the emotional and social lives of the characters, are more common. These games are very comparable to fan fiction because they are generally written in the first person, though they sometimes contain segments of third-person narration to demonstrate the character's interiority. Creative writing thus becomes a way of performing the characters, reminiscent of theater (Coppa, 2006). LiveJournal games stand out in their strong attention to character voice - the typical statements, modes of talking and habits of characters. LiveJournal games often treat the blogs as actual blogs rather than dialog between characters, which means that fan authors may sometimes have to think about how a character would write rather than speak.

Moreover, many LiveJournal RPGs blend fandoms. Although some may be devoted to Firefly, most cast members will emerge in "multi-fandom role-playing games". An example of this is Luceti, a community that started on LiveJournal (2007) and then moved to Dreamwidth (2011), which offers players the freedom to choose their favorite media characters. As they interact, an overarching plot brings to light the plot that brought them together. Strikingly, the emphasis is in these games is on characterization, not character development. The fans emphasize the value of staying in character, even 
when their characters have been in a game for a long time. The general idea is to act out the characters in this new environment but retain their characterization. This leaves little room to deviate from the common interpretations of characters in fandom.

To illustrate this phenomenon, I would like to reflect on a particular situation in the multiverse role-play Luceti. In this community, a player performed River under the nickname "Highlyintuitive". Her first diary entry at Luceti stages intermedial connections with the opening song of Firefly, particularly the lyrics "I don't care/ I'm still free/ You can't take the sky from me". River's first entry opens thus: "They took away the sky, put up a dome and made a snow globe they can shake up just to see how it all falls down." River reflects on the false universe of Luceti where inhabitants are imprisoned in a village under a dome and the sky is a mere projection. River speaks in philosophical contemplations and reflects her schizophrenia, as in Firefly. In the following fragment, she emphasizes the difference of this alternative game universe with the 'Verse. She also confesses that she misses her friends and Serenity, the ship that is her home.

[Another breath, focus. No one else can help her focus now, the crew isn't there. ] I know I can't go home. They took away Serenity and gave me something that can't fly instead. They changed the stars and now they're wrong, no way to chart the way home even if I could ('Wave 01,' November 29th, 2012, http://highlyintuitive.dream-width.org/)

The blog structure of Luceti differs from forum RPGs such as The Verse. Each individual blog is created and subscribed to the community. The blog is treated as an actual diary through which the characters communicate their thoughts in first person. Other narration is placed in brackets. As in Firefly, the central motif is exploration and finding a home, but in Luceti, River cannot travel. She has gotten small wings, as does every character who gets caught in this universe, but they are dysfunctional. Although Luceti draws different mass media characters from games and anime, the characters that share intermedial connections with River are among the first to talk to her. Characters from other Joss Whedon shows, such as Spike from Buffy The Vampire Slayer, explain the universe to her and make small talk. River's player is quick to compare Spike to Badger, a shady character from Firefly who shares a similar accent. Loki and Hawkeye from the 
Marvel movie The Avengers (2012), directed by Joss Whedon, follow suit and share long ontological conversations with River.

This is only one short example of online role-playing to illustrate its inter/transmedial connections and the social interaction between users. Online role-playing shares characteristics of fan fiction, as the above quote makes clear, but often switches in its first and third person narration. Overall, the writing is also shorter and depends on other players and the dialog and events that they provide. Luceti in particular is a strongly enclosed setting where the fiction is more character-driven and relational than exploratory. While The Verse echoes existing character types, Luceti transports existing characters to new worlds. Topos and mythos have a double function in Luceti, as they refer both to the source text as well as to Luceti itself.

Ethos clearly emerges in the character relationships that are shaped through friendliness and distrust, among other aspects. This is a slightly different understanding of ethics than that which Klastrup and Tosca originally intended. The opportunities for ethos to be played out on a political or social level are quite rare in these role-playing games. The afore-mentioned situations emphasize ethos but not as a moral quality. Rather, players negotiate ethos as character-driven relationships by illuminating the narrative potential of unlikely heroes.

\section{Serenity Table-Top}

While online RPGs are created by fans themselves, the industry also produces official table-tops inspired by existing franchises. The games are licensed as part of the official franchise and include, for instance, Warcraft: The Role-Playing Game (2003); Babylon 5: A Call to Arms (2004) and the Battlestar Galactica Role-playing Game (2007). Some are produced by independent companies such as the Spanish Final Fantasy-inspired Anima: Beyond Fantasy (2005). In contrast to many derivative digital games such as movie adaptations, transmedia RPGs have often been well received because they offer players a large degree of freedom to remediate the story worlds that they love. They cater to both fans and gamers. As the Serenity Role-Playing Game states: 'You might be a Serenity fan ready to jump into gaming for the first time or you might be an experienced gamer ready to try a new system and find out just what the 'Verse is all about' $(2006$, p. 6).

Although these RPGs can be officially licensed, as is the case with the Serenity Role-Playing Game, they are often written by expert role-players. Serenity Role-Playing 
Game author Jamie Chambers is also a self-identified Firefly fan. He brought information from the franchise and official production documents together to author the text. He explains (2006a), 'I only had a few extra resources to set about my work than any other fan. Aside from the television series and fan-compiled information on the Internet, I had the amazing script (which I had nearly memorized by the time the first sneak screening happened) and a short memo that was recently published as part of the Serenity Visual Companion.' Chambers thus highlights that his development of the universe is an interpretation, but it is supported by official (or "canonical") material. While the tabletop game is licensed, it has few implications for Firefly's overall transmedia design. He adds that Joss Whedon is not restricted by the representations of history and events in the guide book: 'As we Browncoats are fond of saying, Joss is Boss. He can - and should tell his stories the way he wants. The environments, characters, and details should serve the structure and needs of the story - just like any good Serenity game master should do when creating adventures for his or her crew.'

Chambers emphasizes that players and fans should be transformative by drawing several analogies. First, he draws attention to himself as a fan who brought together information but who cannot be equated with the authors of the text. Second, he emphasizes that he and the role-players are Browncoats, thereby emphasizing their independence. Third, Chambers argues that fans should explore the universe in ways that befit their new characters and story, just as Joss mediates the universe in ways that befit his. Fans should author their own texts like the television author himself does. Chambers highlights that the possible worlds of fans and media authors differ but are on the same narrative level; there is no fundamental difference between their storytelling capacities. Through these analogies, Chambers explains that fans have to create their own stories and use official texts as a guide, not a norm.

The guide book emphasizes the imagination of players and their shared fantasy: 'Think of this book as a set of tools - papery, wordified tools that aren't so good for hammering in nails, but will help you recreate all of the adventure, drama, danger, and humor in the movie, serenity. Think of the game as a form of group storytelling where the only limits are those set by the players. All you need are a few friends, some of those "funny looking” dice, and your imagination' (Chambers, 2006b). The system of the game streamlines the storytelling and ensures that the action and capabilities of the characters are fair and easy. While you can play with the existing Firefly cast - templates 
are included - you can also create your own character. The book provides original characters and examples to inspire players, particularly the crew of gamblers on the ship Aces and Eights. Included are maps of the 'Verse and ship layouts and extra information about the Alliance, guilds and other parties, as well as the cultures on the planets. It offers plenty of information and gaps for anyone who wants to narrate a session, whether it is staged in a dance hall, part of the Blue Sun Corporation or focalized from the Alliance point of view.

The characters are constructed by assigning points to "attributes" (e.g., strength, agility, vitality) and "skills" (e.g., artistry, medical expertise, combat). The characters have "complications" that include character flaws such as overconfidence but also weaknesses, for example, for drugs or alcohol. While they are envisioned as having talents, they are not perfect. If play progresses well, these flaws may be erased through points. Players are not constrained by how many sessions they need to do. Performing the characters in one session or "one-shot" is fully possible, but a "campaign" of several sessions is recommended. The guide emphasizes that players can perform the characters liberally, no matter their gender, race or age. The ship is also treated as an extra character with specific skills and limitations. While special skills for the ship are practical in combat, this motif also echoes Joss Whedon's statement that the ship Serenity is the "tenth character" of the crew.

In addition to the Serenity table-top, there are various other guides published by Weiss that elaborate upon the system and offer potential narratives that players can perform. Some of these guides focus on improving the role-playing system. While the Serenity table-top gives some statistics and ideas on the creation of vessels, for instance, many role-players felt this system was not ideal and published their own guides on this topic. The Cortex Shipyards (Lynn le Fey, 2008), for instance, offers a more extensive system to construct ships and a larger set of ships from which to choose. The publication of fan guides that tweak existing games is a genre by itself in role-playing, comparable to the production of modifications in digital games.

Other official and fan-created guides, however, focus on the narrative of the RPG and offer inspiration. Serenity Adventures (Davenport et al, 2008) and Out in the Black (Hickman \& Hickman, 2006), for instance, provide a few exemplary narratives or "scenes". For instance, the latter book offers a scenario for a fancy dress ball in which former captain Regina tries to seduce an Alliance lieutenant. Statistics are provided as 
an example to show what happens when she succeeds or fails to meet his charm. Different possible narrative strands or worlds unfold as a response to this action. These scenes are very general plot lines that can be played out. Players can use these characters or envision their own in similar circumstances. Some field notes of a session would most likely illustrate the game play best.

\section{The Many Suitors of Lady Arden}

'Brace yourselves, we're landing!' Pilot Morwenna calls out as the small bumblebeevessel "Nomada" docks the parking area of a large Mississippi steamer. The boat loaded with weapons - is called "The Heart of Lady Arden". Our hired crew aims to infiltrate it to steal a necklace that will be auctioned in several hours. This dangerous assignment is commissioned by the companion Egwin, who aims to sell the piece and give us half of her earnings. This will help cover our expenses for the next few weeks - or so we hope.

Our crew is a bunch of thugs, trying to get ahead by smuggling and heists. The characters are a diverse team: John Clayton, our captain, is our charming forty-year-old leader. His mother Claire, a stingy old woman with a bionic leg, is also on board the ship. They used to run Clayton's mining company on an abandoned asteroid until the Alliance got word of their activities and brutally took over their mine. The crew also includes the aforementioned pilot Morwenna, or "Mori", who has a twin sister in the Alliance; "Essie", a Latina who is into hacking and technology; and "Dodger", a female technician who loves anthropomorphizing technology - addressing every piece of gear by an individual name. Last but not least is Go Tai, a Buddhist martial arts expert, who is not joining us today because his player leads the session. Go Tai is most likely off meditating somewhere or drinking, he suggests.

Seated at the game table in the living room is our host, Jeroen, this session's game master. He describes The Heart of Lady Arden's appearance in detail: "The Lady Arden is crowded with ships of all shapes and sizes. The visitors all seem well-off and line up for the auction. They complain while they wait: 'The heat is unbearable. How much longer do we have to stay here?'” A few vendors who reside on the boat take advantage of the situation to sell their last goods: fans, glasses of water, and bowls of noodles. All four of us enter the ship undercover with invitations from our host. Morwenna, meanwhile, prowls the deck and hears that an Alliance vessel has docked at the Lady Arden. 
Meanwhile, the rest of the crew spreads through The Heart of Lady Arden. I play Claire and after looking for an auction guide, I move to the bar, where I enjoy a drink or two while examining the guide. 'Do I notice anything special about the necklaces?' I ask. Jeroen shrugs. 'Roll for knowledge and investigation.' I do the skill check, but I am not very successful. 'Some of them stand out,' Jeroen says, 'and the prices vary from 50,000 "creds" to 1,000.' A short time later, I am addressed by a charming old man - a nonplayable character voiced by Jeroen - who compliments my beauty. I am over sixty and have been single throughout most of my life, so I act a little bit awkward. 'Dear sir, surely you don't mean me?' I look around. Yes, he means me, and he introduces himself as the captain of Arden, the Spaniard Iguiollo. He kisses my hand. The players laugh. Is this a Spanish version of Captain Iglo, the Dutch icon of a frozen food company? I notice the strange ladies at the captain's side. 'Roll for perception, 7 dice points,' the game master suggests. I fail by one. 'You notice a weird walk but you cannot quite place it. There is something wrong with them.'

Meanwhile, my son and the companion prowl through the ship and enter the display room. 'Don't look, but the third glass case that we passed, that's the necklace!' John glances at it but there is nothing extraordinary about the piece. 'It's a very simple golden necklace with a white cube on it,' Jeroen says. The role-players are visibly excited. Getting the necklace off the ship is not easy, however. Our tech-girl Essie notices the sharp red lasers that protect the cases. Dodger goes to the engine room, hoping to dismantle the Arden's weapon systems, but a peek at the engine already tells her that the weapons are not routed to this particular engine - they have to be routed elsewhere. Meanwhile, departing the ship has increased in difficulty. Large fences have gone up, preventing every visitor from going outside. The only way off is through the small deck of the ship which cannot hold our large bumblebee-vessel.

Our plan becomes even more complicated - dismantle the lasers and the fence, get the necklace, get to the deck, get out. We get together to discuss this privately. Luckily, I have just met the captain. We assume that all of the lasers and fences can be disconnected at the bridge of the ship. I locate the captain at the casino and convince him to bring us to the bridge. Pretending that Essie and Dodger are my adopted daughters, I introduce them to him and ask him if they can join us. We hope to create a diversion to allow the others to dismantle the systems. Meanwhile, my son and the companion have to grab the necklace while the lasers are off. 
The bridge is beautiful and highly modern. The captain chats on and on about the systems and I encourage him to continue talking. We are interrupted when Egwin enters again, addressing me privately. 'She's a bit of a scatterbrain, this one, it's my son's wife, you see,' I explain to the captain. She drags me along and I am glad that we did not raise any suspicions. 'The necklace has been sold!' I emphasize that we are running out of time and that she needs to find it fast. Can she do this? Yes, she believes that she can and that John can help her. We return to distracting the captain, and Essie tries to turn off the system. Essie's rolls his tech skills and manages to do this without anyone noticing. The ship's systems malfunction: 'The lights flicker, the systems break, the lasers go down but the fence is still up. You can only leave the ship through the upper deck,' Jeroen presses, before his cinematic style of narration "cuts" to Egwin and John.

The two have discovered the new owner of the necklace: one of the daughters of Iguiollo, and she is on deck. John tries to win her over. A skill check for charm and persuasion allows him to dance with her and snatch the necklace right off her neck with a kiss. 'You need a very big success rate to accomplish this,' Jeroen presses, but Daan succeeds amply. His charm, persuasion and agility - all special talents selected for the suave captain - provide him a good success rate to begin with. He flaunts the necklace and then observes a pistol coming out of the girl's arm. Her eyes glimmer. Is she a robot? He runs off and rolls for combat. The game master, who now plays the robot, rolls a higher average and hits him. Meanwhile, the others reach the deck, but the ship is not there.

In the air, Morwenna is distracted by a blot on the radar. Either it is a malfunction or a ship is directly behind her, tracking her every move. She turns the ship around. 'Roll for pilot skills and agility.' She rolls and reaches an extraordinary success. 'You twist and turn Matrix-style with the ship; you are one smooth flyer and are now eye to eye with... yourself?' The player is excited that a part of her personal story has been woven into the session. She says, 'Mori is perplexed. She goes back to the most basic form of communication imaginable.' She raises her hand. 'Hi?' Then, she turns on the communication system and reaches the Alliance vessel. 'Sis, where have you been? Why haven't I heard from you? I thought you were dead!' The game master plays the sister and responds, 'It's only been a few weeks!' Morwenna replies, 'Eight months is not a few weeks!' Her sister shrugs, "I have to stop you. You're in my way. Don't force me to shoot you.' 'But I still need to pick up my friends!' 'Your friends?! You met them a few months 
ago and only did two heists with them! Are these people friends?!' She is clearly upset. 'People depend on me too, you know!' Mori replies, 'But you are the one who let me promise never to kill someone. If I leave here, these people will be dead.' The player rolls for persuasion and manages to convince her sister to let her go. The sister is distraught and flies away. Emotional, Morwenna steers the bumblebee towards the Arden.

At the Lady Arden, all hell has broken loose because the guards have just discovered the stolen necklace. We combat and keep rolling against the guards. Essie and Dodger are especially badly wounded. Our initial plan was to leave the ship by air using our rope ladder, but now we are too badly hurt. The fence, however, makes it impossible to dock. Morwenna decides to land atop the fence, flattening it under the weight of the carrier ship, while taking some damage to the hull. As we make our escape, Essie checks the data cube, which reveals a list of color codes, a hit list maybe. At the Jinsen Liyu, we want to sell the necklace, but the buyers turn up at the ship very early. 'I didn't expect that,' the companion says, visibly nervous. We make a copy of the data cube and hide the necklace. Dodger can bring the piece of jewelry once the captain has his money. The buyers - sleek men with black gloves - pay the companion. John takes 5,000 for us and calls in Dodger. The men inspect the necklace. 'This looks excellent. You have done a mighty good job,' Jeroen inserts a meaningful pause, 'for the Alliance.'

Afterwards, the players are excited and one of them calls out, 'This was a great first session, just like an episode of the actual series!' She winks at John's player. 'Except that the companion didn't leave the captain stranded in the desert... naked.'

\section{Medium-Specificity of Serenity}

Our table-top group launched its campaign in March 2013. All of us were in our late twenties and early thirties, two women and four men. We had met through the fan culture of anime and manga in the Netherlands and found that we shared a common interest in gaming. While two of the others had also participated in the Firefly LARP, I had never joined forces with the other four. What unfolded was a rich, co-created narrative that brought to mind the crew of the Serenity but also established characters that were interesting on their own terms. The table-top was a medium that offered us the opportunity to create a clear, original narrative in fashion of Firefly. Several mediumspecific characteristics emerged. 
First, the table-top structure structures the make-believe and grants players the freedom to perform characters that are quite different from themselves. Our group, for instance, was entirely Dutch, but our characters were of American, Latin, Asian and Irish origin. Their backgrounds reflected the ethnic and cultural diversity of Firefly. The players were not hindered by their gender. Both Essie and Dodger were played by two men, for instance, and in terms of age, I played a woman much older than myself. Claire allowed me to be a very different character than I had been in LARPs, where I was more defined by my own body and age. The characters were fuelled by our opportunities rather than constraints. Sometimes, we looked up diverse media images that could tease out an idea of what the characters might look like to visualize them further.

Second, although the table-top technically provides opportunities to act out the existing characters, our players constructed original characters without much ado. We wanted to create a diverse cast for a space ship, as a group endeavor and joint story, rather than out of shared, individual fan passion. We also created this crew together during a brainstorm to ensure diversity, shared histories and that the characters could play well together. This allowed us to entwine the backgrounds of our characters. For example, I wanted to explore the perspective of an elderly woman who was sixty years old but tough and hardened. The idea that her son should be the captain came up right away as we envisioned that the relationship to her unmarried son could be a source of complexity, friction, and humor but could also be defined by love, respect and codependence.

Third, the table-top is a medium in its own right. Possible events are facilitated not only through the conditions of the narrative but also through those of the system, such as skills and elements of chance. Anticipated events also have a different meaning as the narrative unfolds through the expectations and input of different players. For instance, our sessions often relied on music to set the atmosphere. Several of the game masters enjoyed creating custom soundtracks that included country music, blues, folk and Chinese classical pieces that were played in the appropriate settings.

While the table-top is medium-specific, its narration can be inspired by different media. Our sessions strongly echoed the aesthetics of television. For instance, while it is common to have one storyteller in a campaign, we had several. The four veteran roleplayers in the group felt that an episodic campaign authored by different storytellers would not only be practical but would also relate well to the episodic narrative of Firefly. 
In terms of transmediality, it is striking that the form of television emerged in the narrative styles of the players. The game became very cinematic in our sessions, which referred to the role-playing situations as "scenes" or "scenarios" bridged by "cuts" when the focus shifted from one player to another. Our first session was concluded by Jeroen as follows: "As the camera slowly pans back we see the characters bickering at the kitchen table. What will happen to them next? Let's find out in June!"

The transmediality of this world can again be characterized through topos, ethos and mythos. The topos was mediated as we braved the skies with our ship, visited distant planets and bargained our way along. Our locations were diverse as we travelled through the 'Verse, always driven by the idea that we might at some point take revenge on our colonizers. In our mediation of the topos, we also limited ourselves to the technology of the text. Robots, for instance, are an interesting blank in Firefly represented only by the android wife of Mr. Universe in Serenity - that was picked up during our session. Ethos was central for the characters as Alliance outcasts who stuck together and who echoed the moral of the colonized, the former-Independents. The first session already tested these ethical boundaries, as it turned out that we had been working for the Alliance, our worst enemy, all along. The mythos of Firefly also emerged as a base line for cultures, politics and law. We developed our own mythos, particularly around several new networks and organizations as well as a larger plot that explored the motives of the Alliance. Every game master also added to our own lore, which often returned to the large space station Jinsen Liyu, invented by our first game maker.

Thus, the table-top offers a rudimentary system - based on fairness and narrative branching - that fosters storytelling. How the story is narrated is more or less up to the players and the group dynamics. The system generates actions and possibilities that can have different consequences, thereby forcing the players to improvise. These choices and alternatives, emphasized in the game system through skill checks, can best be understood through the concept of possible worlds, where experiences and stories unfold through different chains of events.

At the same time, the individual players have their own ideas about the world and envision it differently, which I previously conceptualized as quiet role-playing. Often, role-players do not even realize that much of what they do is quiet role-playing or what fans call "head-canon": they envision certain facts about the world that are never shared. For instance, during our second session, the game master narrated how two officers 
approached our humble ship: "They walk around the ship for a minute, studying it up close. They walk up to the door... and they pull the bell." Immediately, all the players were surprised and laughed. "We had a bell?!" Our game master smirked. This event drew our attention to the co-creation of the story, to the elements that we had not envisioned or thought about. Its comic effect depended on self-reflexivity - an awareness that not everyone knew what the ship looked like in detail or how it was equipped.

Thus, possibilities are integral to role-playing and are constantly actualized one way or the other. The game design of the table-top furthers this branching through skill checks and by streamlining the fantasies of the individual player. To see how this possible world differs from the live-action role-play, I once again present some field observations.

\section{Boarding New Carolina}

I introduce myself as Layla, a researcher, although you would not know it if you saw me slinging my gun. I was employed at the Blue Sun Corporation to experiment with new food products that I tested on animals and humans. I know more about chemical compounds than you are comfortable with and can make a properly educated guess about what their effects on the human body will be. With a crew of ex-Blue Sun employees, I fled my home world. The Alliance targets us because we know too much about their involvement in the Blue Sun Corporation. While the company seemingly produces food and basic necessities, it is only a lucrative cover up for their experiments on human subjects. We hope to find a safe haven in the outer rims. It is dangerous, but we believe that we are far more likely to survive here than in the colonies. With a stumbling businessman and a young mercenary, I brave the sky, only to pick up two hitchhikers along the way: a gun slinger named Esper and a sturdy doctor. Both make fine additions to our crew.

We arrive in a vessel located at the outer rim of planets, a place that has not yet been colonized by the Alliance. The promise of a new life awaits us. Six ships have harbored at this station, called the New Carolina. The attending passengers have their own agendas. While many fled to the outer Rim to avoid troubles with the Alliance, others are at New Carolina for business. They are interested in fair trade, gambling or establishing contact with the nearby planets. My crew consists of former Blue Sun 
employees, a reference to a fictional food company in the series, and we have been on the run ever since we found documents that proved Blue Sun was double dealing with Alliance companies.

The owner of the ship comes in to welcome us. His name is Montgomery, and he is clearly a man of money, a wealthy industrialist whose sole interest is a rare statue that is somewhere on board New Carolina. He offers us his hospitality and invites us to make this flying wreck in space our home. My crew mates and I are eager to find this statue. We leave our two hitchhikers to pursue their own paths. They offer us help in return for the ride if we ever need it. During our walk over the large vessel, we meet many new people. Some of them are tough assassins; others are whores, gamblers, unlikely heroes or benevolent priests. We shake hands with many of them and, if they are open to us, tell them about our adventures and why we have boarded New Carolina. A short time later we reach the engine room, where a leak in the oxygen tank is causing problems. Our spare oxygen tank solves this problem but only for a limited amount of time. Luckily, Montgomery pays us because our help does not come cheap.

Finally, Montgomery is found dead and, if we are to believe the rumors, murdered. Headed by a notorious duke, the Alliance boards our vessel and stages a coup. The laws do not change, but our freedom and trading routes are severely compromised. However, the duke informs us that the ship can be ours if we have enough credits and can choose an executive leader to run the ship. The duke's legislation will still hold, but the executive power will belong to the inhabitants of New Carolina. Gradually, it becomes clear that the duke's regime is far worse than Montgomery's, especially in his tendency to execute condemned criminals. Because his power far outweighs our own, staging a coup is nearly impossible.

Luckily, the trader's federation is willing to invest in New Carolina. We elect a captain who can negotiate with the Alliance and are finally freed and allowed autonomy. At that point, pirates board the ship. After a heated battle, our new captain proudly proclaims that we are one crew. I am skeptical, but you would not know it if you saw my poker face. The Alliance is good at fooling people, and I believe that we have just been fooled again. 


\section{Design of the Fan Game}

This story details a LARP session in Eindhoven in the summer of 2010, where I conducted my ethnography. The student society "Knights of the Kitchen Table" hosted a Firefly game that was joined by fifty players with six ships. The LARP was a one-shot that lasted a day, roughly ten hours, although in terms of narrative time, it was re-enacted over several weeks on New Carolina. This is by no means the only Firefly-inspired LARP that players have created, but one that I consider to be representative of how the universe can be mediated. The United Kingdom has a Serenity LARP that is held on a regular basis, while in Norway, a group of players thrives on the darker sides of Firefly, as seen in their session "Life is Cheap" (2013), which explores slave markets in particular. I share my experiences to show how the local Dutch session described above mediated its own Firefly world.

While table-tops are usually played on a table without much ceremony, LARPs are performative and embodied. The genre is based on immediacy. Players physically act out their characters and use real-life settings as a game space. They dress up for their roles and use props that can further make-believe. Some players and organizations may address this in a modest way, as performance in LARP is emphasized over dress up. The games usually take place in real time, with sessions spread over a long day or weekend. During a LARP, players carefully negotiate the boundary between fiction and reality through conventions or symbolism. The threshold between fantasy and reality is limited by playing out roles and the game space as though it were real. Costumes and props function as markers that actualize the setting for players. These props may actually resemble the objects but often they are "symbolic markers" - they represent the object or subject indirectly (Montola et al., 2009a, p. 84-85). In a LARP, a girl wearing a towel on her head can be a seer. Traditional role-playing relies more heavily on symbolic interaction, whereas LARPs try to be more "pervasive" and convince their players of the game reality. Similarly, real life may be negotiated at points, for instance, by holding up your hand when you are out of character and thus not participating in the game world.

Structuring a LARP and its narrative is not an easy task. During the Firefly LARP, the game masters have an important leading role as the designers of the system who both organize the event and function as referees during the play. As players, we refer to them as "staff" because they cover all of these roles. First and foremost, it is good to provide some background about the authors of the LARP I attended. They are students 
enrolled at the technical university in Eindhoven, three men and one woman, all of whom are in their twenties. They had never organized a LARP before but had ample experience in role-playing. To assure cohesion, they decided to divide the organizational tasks and the design among themselves. Two wrote the plot; one was responsible for the organization and trading system, and the other constructed the props and information systems within the game. Throughout the session, they maintained these roles, and each used his or her specific knowledge as a game master to guide the players. The game masters also functioned as designers in that they wrote their own guide book and roleplaying system. They were inspired by the Serenity table-top game but created a different balance and skill division and a larger template for the construction of ships. The four believed that creating a LARP would be a suitable way to explore the 'Verse.

To gain more insight in the social context of the LARP and how it was developed, I interviewed Firefly staff member Jaap (8 December, 2010). When I explain to him at the start of our conversation that this book would be about fandom, he tells me that he is reluctant to describe himself or the others as fans. 'Like many of the players, we saw the series rather late,' he emphasizes. Moreover, he explains, the idea of hosting a Firefly LARP came up spontaneously and not out of fan interest. During the Dutch Star Wars LARP, the four friends were brainstorming about organizing a Star Trek LARP and were reminded of Firefly. They were immediately enthusiastic about the universe. While their interest in science fiction is obvious, using an existing story world was partly a practical choice too. Jaap explains: 'You don't have to pick existing material but it helps. It was a point of reference for us.' For these young designers, mediating an existing world fosters originality and creativity.

The staff also favors Firefly for other reasons. First, the series explores casual characters and features little or no exceptional heroes, as opposed to Star Trek, where the heroic captain sets the tone. 'In Firefly, there is no epic hero,' Jaap says. 'If you're a ship captain you have to stand up for your fellow crew members, but that's it.' Second, Firefly features very small, regular ships that can easily be imitated in a LARP. While it is difficult to re-enact the large bridge of Star Trek, the rogue vessels of Firefly are nothing fancy and may even have strange, anachronistic technology built into them. A sense of actuality is thus easier to achieve in a Firefly universe than in a different setting. Third, Firefly has an interesting ethical dimension because the players can take up many 
stances towards the Alliance, smugglers or other parties. Ethos, then, is a quality that they favor in the story world.

The Firefly staff thus put ample thought into what universe would be suitable for role-playing. Their guide book emphasizes original character construction and a mediation of the unique atmosphere of the series. As a result, our game session did not re-enact the plot or characters of Firefly but instead created its own interpretation of this existing story world. Within a game, a story world is somewhat different than in a television text, where it refers to the overarching narrative setting and genealogy. As game designer Chris Crawford explains, 'A story world is composed of closely balanced decisions that can reasonably go either way' (2005, p. 54). Crafting a story world means creating opportunities for play rather than driving players towards a specific story line. To make sure that a LARP is not limited to individual play, game masters usually provide an overarching event or "überplot" (Tychsen and Anders 2006, p. 255). The game masters may trigger this event, but it is up to the players to react to it and determine the consequences. The original outline for Firefly's überplot was drafted by two staff members, with one of them also creating a "mission board" with various events that could be used at any time. These generic situations are usually facilitated by nonplayable characters or "NPCs" that are written by organizers rather than players. These additional performers keep the setting vivid and the player occupied when the main narrative is progressing slowly or involves only a few players.

During the session, the game masters consciously performed as background characters, or refrained from playing altogether, to properly instruct both NPCs and players. While many game masters take up leading positions in LARPs to control the plot and keep an eye on the progression of the game, these four occupied a marginal position during the session. Jaap emphasizes that they believe that they can help players better by remaining in the background and providing useful tips. Thus, one of them performed as the bartender to ensure that he was always centrally located where players and NPCs could find him. This also befitted the organizational role to which he was assigned, namely, taking care of the trading system. This is also appropriate as a narrative motif because the bar masks shady trading activities.

Although the game masters are responsible for the overarching story, they are also ready to improvise. While they had scripted key moments for the session, such as a space battle against the pirates, the players were encouraged to create the play as they 
saw fit. In addition, they often received helpful in-game comments from NPCs. The organizers had a defined overview of the session and worked with what players offered them as input, which meant that they frequently needed to change their plans. As a result, they had to let go of their script entirely halfway through the session.

Thus, the designers of co-creative games face the challenge of keeping the plot defined while still offering players opportunities to develop the game as they see fit. In the interview, Jaap emphasizes that bottom-up play is best and argues that meaningful play emerges from player behavior. Players should push each other to develop their characters and elaborate on the narrative in unforeseen ways. He explains that "skills and resources should be a means to achieve this and not a goal by themselves". Overall, the Firefly staff carefully balanced between their motivations as role-players and their responsibilities as designers, organizers and game masters.

\section{Mediation and Embodiment of Firefly}

Our play session mediated the universe of Firefly on several levels, the most mediumspecific of which are dress up, the fan-created role-playing system and the diegetic space. First, dress up is an important element of any LARP because one's appearance has to match one's role. For instance, I prepared for the LARP weeks in advance and spent ample time finding the right clothes for my character, Layla, buying a corset and sewing a pair of new pants. Attributes also support the character. One of my friends, for instance, designed Blue Sun badges for our crew that visualized our connections to the company. In the game, these could also function as visual cues that could invite other players to ask us questions. While some players clearly invested ample time in their outfits, others sported cowboy hats, sun glasses or Chinese ornaments. This diversity also fits Firefly, where the variation in dress styles reflects the different cultures that blend in the series.

Second, the LARP aims to be as immediate as possible and therefore embeds Firefly motifs in the game mechanics. The game design is largely based on skill checks that ensure fair play. The skills that players can procure are limited and, as a result, the players often try to help each other out. In one of the oldest accounts of RPGs, Fine (1983) dubs this task specialization (p. 174). Most crews have assembled players with different skills (e.g., pilot skills, or medical skills, or fighting skills); however, the more specific skills (e.g., electronics) are rare and force players to interact when necessary. 
The skill checks are done with a deck of cards rather than a roll of the dice, which contributes to the Old West atmosphere. Similarly, money or "credits" are mediated by poker chips. Although these objects are still symbolic in that they represent money, their presence in the story world is deemed more natural.

Third, the game space itself mediates this possible world of Firefly. Props are not supposed to hinder play, and much attention has been given to their immediacy. Many of the objects are not symbols but share qualities with the objects that they represent they are "indexical" rather than symbolic (Montola \& Stenros, 2009, p. 84-85). A computer in the game, for instance, can be actually used as one. The Firefly staff spent ample time programming the technical equipment, from software to lights, to create a pervasive and hands-on experience.

By extending the universe of Firefly to the Rim territory, the LARP emphasizes topos or narrative space more than the other cases. Our own session is characterized by ethos because it tested the moral stature of characters. Mythos was less apparent in the narrative but could be perceived in the lore of New Carolina and its rumored background that included lost treasures, murders and dark regimes. Our transmedial Firefly world created new characters and filled in blanks in the 'Verse. The changing regimes at New Carolina provided opportunities for our characters to construct new politics, legislations and business relationships. Executions by the Alliance and even a suicide mission triggered players to act against the new policies at the New Carolina. Individual play, however, focused on smaller situations as our characters got to know one another and pursued their dreams. In fashion of the source text, our play ended with the idea that we all became one crew and emphasized the possibility of becoming a family - much like the crew of Serenity.

Ultimately, the LARP session staged a possible world of Firefly, but perceiving it as one world is not sufficient. The characters have many possibilities in their design that were not actualized, in terms of both skills and narrative backgrounds. While our tabletop focused on a small crew, the LARP drew a large population. Commonly, players only learn part of the background histories of the characters with whom they communicate when playing, though they may have additional knowledge about them out of character. As in the table-top, information can be withheld or only matter for the individual performance of the character; in other words, some knowledge will remain latent or even purposely a secret. This also structures players' responses as they determine 
whether other characters are trustworthy companions. The LARP offers a tight community and codes of conduct, but it also pushes players to engage in individual missions and quiet role-play to develop characters and histories as they see fit. While the actual fictional world is singular, the potentially pretended and experienced worlds are multiple because individual fantasies and success rates in the game design steer the play.

\section{Conclusion}

The diversity of story worlds complicates narrative theory but has not been adequately investigated. While readers and viewers clearly respond to ideas of "worldness", narratology emphasizes events and causality rather than opportunities and possibilities. Firefly exists as multiple worlds that share qualities of the official universe narrated in the series and movies and proliferate in official plenary texts and merchandise. Its worldness can also be embedded in new places, however, such as the virtual world that is a part of Second Life. Finally, the universe is mediated in the many player worlds that are represented through role-playing on multiple media, among which are the Serenity table-top game and the LARP.

Role-playing games can offer rich transmedia play. Through their storytelling, fans create a stage on which to perform original characters and ideas. However, mediating Firefly into a game brings its own challenges. Fans not only incorporate the story world into their storytelling but also evoke it in their games' designs and rules. This rhetoric emerges most clearly in the idea of skill checks that allow characters to support their roles, but the specific media structure role-playing activities differently and allow for new intermedial patterns to arise. Whereas blogs stimulate role-playing through creative writing, the table-top still echoes the legacy of Dungeons and Dragons as players collectively imagine their stories.

These different media platforms structured topos, mythos and ethos in unique ways. Our table-top sessions expanded the history of the world through ships with their own backgrounds, strongly emphasizing mythos and topos. The LARP, however, expanded topos further through the motif of settling in an unexplored space. It seems to me that LARPs often heavily rely on diegetic space in that characters genuinely do not travel because this is difficult to play out in a small area; therefore, the area in which the characters are confined needs to be strongly written, meaningful and allow for 
mysteries. I have summarized the findings in the table below but want to emphasize that these are highly situated. I am convinced that all three characteristics can potentially emerge in the three genres, depending on how the sessions are constructed. In general, however, it seems that that the genre of online role-playing is more suitable for character interaction because it is heavily driven by social media and blogs that also facilitate character-to-character interaction.

Characteristics of Firefly ethnography

\begin{tabular}{|l|l|l|}
\hline Genre & Media & Narrative emphasis \\
\hline Online role-playing & Forum, LiveJournal & Ethos \\
\hline Table-top & Guide book, dice, sheets & Topos, ethos, mythos \\
\hline LARP & Guide book, props, dress up & Topos, ethos, mythos \\
\hline
\end{tabular}

The biggest differences in these transmedial worlds did not result from the features of topos, ethos and mythos, however, which were highly contingent and present to some degree in all three genres. The unique moments took place at the level of the characters themselves and their relationships and the manner in which these were performed. While this is not an aspect of the transmedial world, this feature does gain in importance when we consider how a story unfolds. Transmedia theories need to be better equipped to signify these characterizations, differences in focalization and multiple outcomes.

I argue that the different cases offered instances of transmedia play that are best viewed as multiple possible worlds of Firefly. Interpreting these instances as one coherent transmedial world of Firefly makes little sense because these are narratives develop in their own right with unique characters, histories, spaces and events. Especially in online role-playing, on LiveJournal, for instance, the situations are part of a virtual heteroglossia that brings together media texts. The stories of The Nomada and New Carolina, however, can be interpreted as part of the same transmedial world because they do not exclude the story lines of Firefly and, indeed, build on them actively. PWT can help us reflect on the creative choices that structure game design and storytelling.

Although fans participated in this transmedia play, the cases show that fandom should not be seen as inherent to the genre. First, players and designers do not always identify themselves as Firefly fans. Some are simply drawn to the unique atmosphere of 
the 'Verse and use it as a stage for their own stories. Others may appreciate existing characters such as River and see opportunities to perform them. Furthermore, the motivation of the fan may be guided by values of re-enactment and loyalty towards the source text, which may be at odds with his or her values as a role-player aiming for the most entertaining play and original storytelling. This difference is underlined by the author of the Serenity table-top who motivates fans to imagine their own stories and be transformative.

Finally, it is difficult to assign players to particular interpretive and game communities. The participants in these games belong to different communities in addition to the interpretive communities of Firefly (e.g., student societies, online communities) and display divergent repertoires in both role-playing and fandom. In their performances, however, players seem to emphasize the pleasures of re-enactment and make-believe first and foremost. By focusing on transmedia play as an array of possibilities, the form and aesthetics of play unfolds as a unique practice, one that brings together different technologies, imaginations and outcomes. 


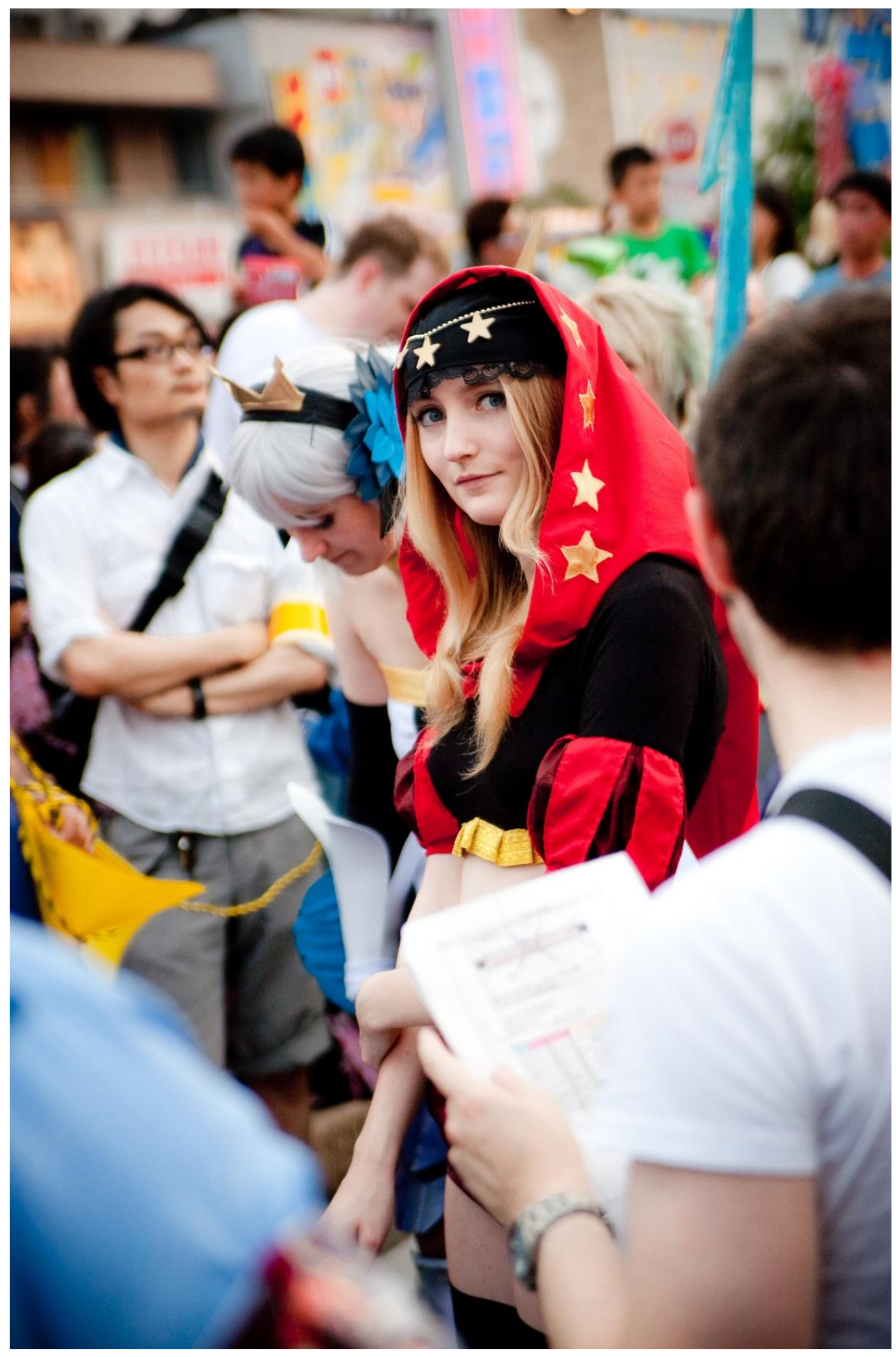

Photograph of Dutch WCS team by Mario Vargas 
$\infty$

\section{WCS \& COMIC MARKETS 2012}

Pilgrimage to Japan

\section{Pokémon muffins}

In the summer of 2012, I fly to Japan for the first time in my life. For the purpose of this research, I want to attend various fan events. After all, the fan communities of manga and anime are often discussed in this book as a global phenomenon. The uprising of Japanese fiction has not only changed the Western television and comic culture but also considerably influenced its different audiences. The sub genres of Japanese pop culture, and the lingua franca of their audiences, shape how Western audiences interpret Sherlock, for instance, and resonate in the fan art that they produce of Glee. Similarly, many of today's fan practices are inspired by Japanese anime and manga fandom, such as the creation of fan comics or doujinshi.

Anime and manga shape how Western fans of Japanese fiction view the country itself. In fact, many anime fans go to Japan fairly late. They often become acquainted with Japanese pop culture in their teens and only go there as adults years later. For young Western fans, going to Japan is a dream. My first flight to Japan is no different. This media pilgrimage takes me straight to places that I have only seen in popular culture or heard about from other fans. Japan does not disappoint. Even small things, like eating a Pokémon muffin at the convenience store, or shopping for cosplay wigs at stores in Tokyo's fashion town Harajuku, make me feel intimately connected to its popular culture, but also aware of its intermediality. Characters and stories are omni-present in this consumer society.

Japan exports a flow of products that is widely recognizable and hailed by consumers all over the world. Many fan studies rely on the assumption that the internet has made content and communities globally accessible, when in fact they study a small community. Commonly scholars focus on Western fan cultures where English-speaking members converge. In anime and manga fandom, language and cultural differences divide Japanese and Western fans, online as well as offline. Even though Japanese fans pay homage to the same fictional content as Western fans, the two communities exist separately. 
Western fans show an interest in Japanese fan activity. They are prone to checking Japanese art sites, such as Pixiv, and buy Japanese products online. This Western "Japanophilia" expresses a longstanding cultural appreciation and even obsession with Japan. However, Japan itself seems less interested in seeing how its market and audiences develop in other countries, which makes the dialogue seem one-sided. The cultural dynamics of manga and anime raise many questions that might be answered at fan events themselves. How global are the fan events that Japan offers? What moments of cultural exchange can be observed there? I share my experiences of two fan events: the World Cosplay Summit and Comiket.

\section{World Cosplay Summit}

The World Cosplay Summit (WCS) is an annual, international cosplay competition in Nagoya. WCS is also broadcasted as a live show by TV Aichi. This year marks the tenth anniversary of WCS in which the Netherlands participates for the second time. The event is held in the rather futuristic Oasis 21 , a public venue that also accommodates the bus terminal and shops. Free of charge, cosplayers from the region can watch the event and participate in activities around it. For this international event, cosplayers from different countries are elected at local fan conventions to represent their countries.

At Animecon 2012, Stichting J-Pop nominated the Dutch candidates through an intense competition. The winners were Sophie and Liza with a performance based on the video game Kid Icarus (2012), a game well-known for its references to Greek mythology. Their play made a strong impression in terms of acting and pacing. Their performance showed how Medusa, the villain of the game, captured and nearly killed main character Pit, an Icarus-like angel. Sophie and Liza had clearly invested time in the story, but their costumes and props were also detailed. Medusa's wand showed great skill and Pit's wings, which spread out mechanically at the end of the act, even more so. The craftsmanship and acting of the girls led to a well-deserved first place.

I join Stichting J-Pop and the candidates to WCS to document their experiences. When we meet up at the airport, Sophie and Liza are exhausted and nervous. They have been working hard to improve their outfits before the competition. For instance, they had to change their props to make them suitable for the travel to Japan. Medusa's wand, for instance, had to be cleaved in two to fit in the luggage. The candidates also had to practice for the show and changed parts of their act. The script has now been rewritten 
with a grim ending, in which Medusa triumphs over Pit. With this ending, the cosplayers want to evoke the hybris of the Icarus myth. They explain to me that it is also faithful to the game. 'Without his magical arrows,' Sophie says, 'Pit doesn't stand a chance against Medusa.'

The entire trip to Japan the girls worry about their costumes, but once we arrive it turns out that all the parts are still intact. The candidates have to be in Nagoya a week before the official competition starts so that they can participate in parades, pay official visits to municipalities or TV shows, and practice their cosplay acts. Though the competition is international, the acts have to be in Japanese to make them understandable for the local audience. The WCS uses audio tapes of the performances though, meaning that the candidates only have to record their act and mouth the words on stage. The Dutch candidates have already translated their act in the Netherlands and received many compliments from the Japanese WCS organization. Their pronunciation is clear and their European accents befit the Greek characters.

Before the competition, the candidates are also judged by the international WCS organization. These judges focus on the craftsmanship of the costumes and props by examining them up close, and the candidates also get some time to explain how they constructed the challenging parts. During the competition itself, the acts are judged by a professional Japanese jury in the categories "performance", "costume" and "fidelity" towards the original narrative. A special section of the audience can also vote by raising a like or dislike sign.

The morning of the competition, the candidates participate in a red carpet parade to Nagoya's busiest district, Sakae. The street has been closed off for this event. The parade starts with prominent historical costumes: kimonos, samurai outfits and even a group of girls performing calligraphy on a large fabric in yukata. This part of the parade, followed by the cosplayers, sums WCS up nicely. Cosplay is welcomed in Nagoya as Japan's cultural heritage and framed as a contemporary continuation of Japan's long tradition of dress-up and art. The global cosplayers thus illustrate the wide impact of Japanese popular culture. Dressed up as Zelda, Link and other characters, the candidates compliment Japan's cultural success.

The live event and competition draw a large audience. Many fans are dressed up but certainly not all. Next to the stage, sponsors of WCS have set up their promotional booths. In general, WCS is sponsored by many tourist and travel companies, which 
highlights that this event only caters to the non-Japanese as visitors. In fact, before the competition, several teams of WCS are also interviewed for the promotional video "Is Japan Cool?" for Nippon Airways. The cosplayers promote the different countries that they are from but also affirm the image of "cool Japan", a country that foreigners love to visit. The prizes for the competition are flight tickets to Japan, permitting the cosplayers to return to the country for a vacation. Through WCS, Japanese tourist companies boost their visibility.

The competition itself turns out to be a spectacular event that shows the state of the art of cosplay in every country. Though anime and manga fandom is associated with industrial countries, other participants are also included. Brazil, for instance, shows great craftsmanship and so do Singapore and Taiwan. Many countries sport one or more robot "mecha" costumes in their act. Others created elaborate dresses, such as Russia and France. The stage props that some teams invented are quite big and range from Australia's huge puppet spider queen to China's silhouette painted screen. The acts themselves are often dramatic echoes of the original narratives. Many teams perform battles or re-enactments of anime with a strong choreography. The different countries aim to deliver stellar performances that make a strong impression. As a result, there are not many comedy skits. The last acts are broadcasted on television and the breaks are filled with musical intermezzos by pop star May'n.

Ultimately, the winning team is Japan itself with a battle inspired by the franchise Hakuõki Shinsengumi Kitan. The second prize goes to Singapore for a beautiful, melodramatic act while Indonesia wins the third place with an action-packed performance, which included the candidates back flipping in their foam robot costumes. Sophie and Liza get the eleventh place and are very pleased with that. On the second day of WCS, there is no competition, only live music. The program features many "anison" bands that cover songs from popular anime. Many fans and cosplayers listen eagerly or just sit on the grass, socialize and do casual photo shoots. At the end of the two days, the international participants are called on-stage. They sing along with the opening of one of the most critically acclaimed anime, Neon Genesis Evangelion (1995-1996) which has been broadcasted in many countries all over the world. The song, Zankoku no Tenshi no Thesis, echoes through Oasis as Japan's global siren song. 


\section{Comiket}

From the $10^{\text {th }}$ until the $12^{\text {th }}$ of August, I attend Comiket 82 at "Tokyo Big Sight", the popular name for Tokyo International Exhibition Centre (Tokyo Kokusai Tenjijo). Comiket, an abbreviation of Comic Market, is the world's largest self-published comic book fair. It is held twice a year in Tokyo, Japan. Comiket primarily functions as a market space for the exchange of self-published comics or "doujinshi" and other fan works such as games or art books.

The doujinshi that are sold at Comiket are often exclusive since many artist groups or "circles" hardly reprint their material. Though doujinshi are non-profit items, some publications can be found at second-hand stores such as Mandarake or online sites such as the Japanese Amazon. Comiket's organization explains in their catalogues that the market is a fan space where an artist community is created and supported. They describe the motives of doujinshi artists as follows: 'For most do[u]jinshi circles, earning profits is not the goal for their activities, but instead they aim to interact with their fellow participants through their own creations' (History of the Comic Market, 2012).

Historically, Comiket is the first comic market in Japan and heavily influenced the institutionalization of anime fandom. Comiket was also crucial in the development of the manga medium since many professional artists debuted there. The first Comiket was held on December 21, 1975, with about 32 participating circles and an estimated 700 attendees (History of Comiket, 2012). Half a million visitors attend Comiket every edition. This year, about 35,000 artists sell their self-published works at Comiket. Despite its popularity, Comiket is still run as a non-profit organization by volunteers, the Comic Market Committee.

For three days, I go to Tokyo Big Sight in a crowded monorail with my colleague Nele Noppe. Women with trolleys and men with shopping bags make their way to the conference center. Japanese security constantly manages the crowd at the stations and at Comiket itself. Many fans immediately go to the sections that are relevant to their interest before the newest doujinshi are sold out. Since the set-up of Comiket changes each day, many visitors attend all three days. Together with Nele, I explore the catalogue which is interesting as an object by itself. It shows the location of all the "circles" or artist groups, genres (e.g., video game doujinshi) and series (e.g., Final Fantasy VII). In addition, the catalogue features short comics that reflect on the culture of Comiket. 
Though observing these fan works is interesting, I am painfully aware of my position as an ethnographer. My position as an outsider has particular implications and challenges. First and foremost, the language barrier is inconvenient and hinders me in doing some of the things that are regular market behavior for most, like skimming through the catalogue easily. I also realize that I am a woman, who sometimes moves through rows of erotic doujinshi admired by men, or who cuts through lines of male photographers. Often, I feel like I should not be at certain places, do certain things or behave in certain ways because of my gender. Lastly, I am also a European, one of the few "gaijin" (non-Japanese) attending these venues, who is met with enthusiasm or confusion by artists when examining their doujinshi.

As a "gaijin", I am surprised to see many fan creations that are inspired by Western popular culture. Some hundred tables sport books inspired by CSI (2000-), X-Men First Class (2011), Pirates of the Carribean and BBC's Sherlock (2010-). Many of these are "boy's love" doujinshi that cover queer pairings that are also popular in Western slash fan fiction: Will Turner and Jack Sparrow, Professor Xavier and Magneto but also Holmes and Watson, and Kirk and Spock. There are little to no differences with how the Western fan community has romanticized these narratives. In fact, when I buy a gay Sherlock doujinshi from several girls, they are not only happy that I buy it as a foreigner (who is closer to source text) but that I express interest in John and Sherlock as a couple.

Many products at Comiket seem to suggest that there is a cross-fertilization of our popular cultures. For instance, I buy one English fan photo comic of Tiger and Bunny (2011). This doujinshi exaggerates the style of American superhero comics with blatant comic fonts, sound effects and colorful balloons. Tiger and Bunny is a series that heavily draws from American superhero comics and this stylistic aspect of the source text is augmented in the doujinshi. In the non-fiction section, I also buy a tourist guide to German fan conventions, written by a Japanese fan. The booklet offers help and information for Japanese fans who want to go abroad and experience Western fandom. He is happy that I buy the product and approaches me in English. A German friend of his is sitting next to him in a cosplay inspired by Sailor Moon.

I admire the booklet and realize that I have been looking for globalism in all the wrong places. Anime fandom transcends national boundaries because modern citizens travel the world and adapt this cultural capital. That is to say, fandom is a transcultural endeavor: a mix of characters and stories that we can reiterate anew and elsewhere. 


\section{6. \\ EMBODIED CHARACTERS \\ The Affective Process of Cosplay}

\section{Introduction}

In fan studies, the personal, the domestic and the material have often been overlooked in favor of a discourse on texts and realism. Practices such as dressmaking or model building were seen as different from fandom because they were not text-driven (Abercrombie \& Longhurst, 1998, p. 150). Fan cultures, however, also contain many material practices that use the text as a starting point for new forms of play and productivity. The textual bias in fan studies has led to the neglect of object-oriented fandom visible in, for example, dressmaking, model building and collecting. In terms of narrativity, I would suggest that these two things - the material and the textual - are not in opposition but are both ways to understand and interpret media texts. Stuff - bodies, fabrics, plastic - allows us to tell stories. Especially in fandom, material practices support narrative inquiry and creation but also have their own aesthetic qualities as media texts.

In this chapter, I focus specifically on "cosplay" - dressing up as fictional characters in homemade outfits. Cosplay is a heavily embodied and affective practice, which are perhaps the reasons why fan scholars have thus far ignored it, despite its visibility at conventions worldwide. The aim of this chapter is twofold: first, to unearth this unexplored territory through cultural analysis and second, to socially explore it through qualitative methods. The first part of this chapter provides a cultural reading of cosplay that signifies its affective and embodied dimensions, and I pay particular attention to the relationship to one's own body and gender.

I then move towards my specific, concrete data on cosplay, which focus on Japanese popular culture in particular. I conducted interviews with Dutch and Belgium cosplayers of Japanese video games and use them as an entry point to discuss Japanese popular culture. While digital games were the focal point in our discussions, these could not be separated from Japanese anime or manga altogether because in Japan, these franchises are a highly interrelated "media mix" (Ito, 2005). The Japanese entertainment industry shares media content through comics, animation and games, as well as through 
merchandise and consumer goods. Thus, intermediality is highly important in Japan's creative industry and fan cultures.

Theoretically, I view the production of and performance within the costume as an embodied and affective process. I analyze cosplay as a practice through which fans of popular culture (e.g., television series, games, movies) display their intense attachment to games by producing their own costumes inspired by fictional characters. I understand this process as one that is anchored in various moments and situations in which affect is directed at the social group, the costume itself and the media text. Based on theories of affect, as outlined below, I thus claim that cosplay is an "affective process" that, in spite of being time-dependent, has different entry points and objects of devotion.

Historically, the fan tradition of dressing up is extensive and goes back to historical reenactments and Renaissance Fairs where earlier time periods are a source of inspiration. Dress-up in media fan communities dates back to American science fiction conventions in the 1960s and 1970s at which fans wore outfits from series such as Star Trek or Star Wars. In game communities, another example of dress-up is LARP, which began in the 1970s, where fans started to re-enact their favorite table-top games, such as Dungeons and Dragons. In LARP, enthusiasts base costumes on genre-fiction (e.g., fantasy) or historical periods in a co-creative game for which original characters are designed and reenacted. In all of these examples, fans of speculative or historical fiction re-enact their interests in cloth. In virtual communities, dress-up is equally important and pertains to the physical construction and customization of one's avatar or virtual self.

The term "cosplaying" was coined in the 1980s by the game designer Takahashi Nobuyuki when he encountered the costuming practices of American fans on a visit to the United States (Bruno, 2002; Winge, 2006). In Japan, cosplay has become very prominent. Many contemporary Western fans learn about costuming not through science fiction or fantasy genres but through Japanese fiction. As a fan practice, cosplay is associated with Japanese popular culture. In Western settings, there seems to be significant overlap between cosplay and other forms of dressing up such as (live-action) role-playing but also customizing one's avatar. In cosplay, games are embodied and transposed to new, physical settings. Players explicitly relate their own body and behavior to those of fictional characters. 
Cosplay is gradually influencing the professional game and media industry. Some media companies are already very aware of the quality of fan's costumes and use them for promotional activities. Cynthia Leigh (2007) draws attention to the fact that the game conference E3, once dominated by "booth babes" or professionally hired models, has 'now become a mix of both agency girls and cosplayers'. One recent cosplay success story involves a Russian cosplayer who had uploaded a few images of herself as a character from Bioshock Infinite (2013) before the game was released. The developers stumbled upon her pictures and include her in the marketing campaign. Photographers and artists also show an interest in cosplayers both as models and as subjects for installations, as in the work of Cao Fei, or as portraits of players or fans themselves (Austin \& Correa, 2006; Hancock, 2011). What makes cosplay an interesting practice to examine is that it is highly visual and staged in close connection to one's own felt body.

\section{Ludology of Cosplay}

Dressing up is a regular activity in most societies. Cosplaying, however, is a fannish subculture and has its own limits and possibilities. It always takes place in a specific social context, usually in discrete spaces such as fan conventions or get-togethers. Cosplaying is more entwined with the public domain in Japan than it is in the West. For instance, cosplayers gather in the parks of the district of Harajuku in Tokyo. Here, costuming practices are part of consumption culture. Shops sell cosplay articles such as wigs and even full costumes. Cosplay restaurants draw in fans by having waiters and waitresses dress up as fictional characters or types (e.g., maids, butlers). Particularly interesting are the Miss Dandy bars, in which women dress up as men to cater to other women (Robertson, 1998, pp. 143-146). Although this is a professional practice rather than one initiated by fans, it is clear that costuming has a more prominent role in Japanese society than it does in Western society.

Cosplay cannot be restricted to the dress alone. A study of this type of play, a "ludology" if you will, requires an awareness of its transmedial and commercial aspects. The costumes that fans wear are usually homemade, although in some cases, they are purchased from Japanese stores or commissioned from other fans or professional tailors. Most cosplaying sites (such as Cosplay.com) design their user profile pages based on the assumption that players make their outfits themselves and include options for players to discuss the creation of the costume. Online forums and communities are 
devoted to providing mutual help with difficulties such as styling wigs; tutorials made by fellow fans and these forums lead to a culture in which fans help one another as peers. The community is crucial to the development of costuming skills. The process of sewing the costume and guaranteeing its authenticity is therefore very important. The costume is a cultural product that can be admired at a convention, and spectators thus also play a role in guaranteeing authenticity (see also Winge 2006, 69). Fans may evaluate the costume, appreciate the character being portrayed, or take photographs that again remediate the object and player.

Competition is another important element of cosplay. Cosplaying at a fan convention is partly institutionalized through and motivated by specific events. The most common of these are fashion shows, photography sessions, and cosplay acts. Fashion shows are organized much as they are in mainstream fashion culture and are usually held on a catwalk or stage where cosplayers can show off their costumes from various angles. At fashion shows, the costume is central. Because fans make the outfits themselves, they can earn praise for their sewing skills. Fashion shows are also entwined with the narrative on which the costume is based. Through body language and the choice of music that plays as they present their work, cosplayers can express their chosen characters.

Most conventions also organize an event in which cosplayers perform skits onstage. Cosplay acts vary in length and quality. Typically, they are less than 5 minutes long, but at the German AnimagiC convention, for instance, certain groups are allowed to perform for an hour or more. In these performances, a new narrative is created, much as in fan fiction. They vary from plays and dance acts to quizzes and martial arts and may use music and video, which may be footage taken from the source text or even created by the performers themselves. Craftsmanship thus gains an additional dimension of competition and sportsmanship as different theater teams compete for prizes. Increasingly, the competitions at local conventions are also structured as pre-rounds for international competitions. Cosplayers can win plane tickets and the opportunity to compete with others at, for instance, the World Cosplay Summit.

In photography sessions, which are sometimes held during or after a fashion show, the costume also plays a central role. The fans function as models for the photographers, but they can also use the photographs themselves to promote their costume activities. Fans who specialize in photography usually initiate the shoots, 
sometimes at specific times that the convention has arranged. Although many of the photographers are fans who want a snapshot of a cosplayer - or rather, a character they love, some may want to further develop their photography skills. Most cosplayers see getting their picture taken not just as something to be expected, but as a compliment (Leigh, 2007). Moreover, cosplay is increasingly documented in "cosplay music videos" high-concept music videos that are commonly shot at fan conventions themselves (Lamerichs, 2013a). These videos provide insights into the lived culture of cosplay and are styled to emphasize the outfits and poses of cosplayers. They may also involve narrative qualities or an interpretive function: some videos, for instance, function as studies of characters and their relationships. Cosplay is thus a highly mediated affair.

Cosplay cannot be analyzed without understanding its different mediations and its central role in the lived culture of fandom. Fan costumes are one example of how fans express their appreciation of existing stories and rework them using various media. Similar to fan fiction, fan movies, and fan art, cosplay motivates fans to closely interpret existing texts, perform them, and extend them with their own narratives and ideas. Previous research on the creativity of media fans generally examined at fan fiction in particular (Hellekson \& Busse, 2006; Pugh, 2005). When authors do discuss cosplay, it is often in a broader discussion of fan practices and fan conventions (Bacon-Smith, 1992; Crawford, 2012; Pearce, 2006; Taylor, 2006). Specifically, Daisuke Okabe (2012) has investigated cosplay as a social space for learning craftsmanship. Still, these forms of mature dress-up in game communities and fandom deserve more attention as a space of play (Fron, Fullerton, Morie, \& Pearce, 2007). Cosplay is a fertile cultural form through which to examine the affective and embodied elements of dress up.

Within fan and game studies, cosplay is an understudied form of appropriation that transforms and actualizes an existing story or game in close connection to the fan community and the fan's own identity (Lamerichs, 2011; Newman, 2008). The activity can be read as a form of dress up. In the field of game studies, dress up is an often overlooked but significant category of play with its own affordances (Fron et al., 2007). While dress up can involve actual costumes or fantasy play, it is also encouraged in digital games through "productive play"; that is to say, the customization and creation of virtual objects by users is increasingly incorporated in game mechanics (Pearce, 2006, 2009). Customizable characters and "dollhouse" structures in The Sims series are but one example of productive play and how it relates to dress up (Wirman, 2011). Similarly, 
cosplay provides the player with the joys of make-believe through the creation of her own outfit and the freedom to perform in it.

Moreover, cosplayers engage in pretend-play, or mimicry as Caillois (Caillois, 1961) defines it, as a category of play in which reality is transformed into an alternative scenario. Other forms of adult make-believe include live-action role-playing, which also actualizes the imagination in daily life and mediates it through costumes and props (J. Murray, 1999). It seems to me, however, that cosplay is less about developing or performing a character and more about constituting a visual resemblance with it. Although a cosplayer can perform the character in part, for instance, by walking around with that character's attitude, the overall idea is a visual one. Cosplay is based on recognition more than re-imagining.

In addition, cosplay is a deeply explorative and social play. Fans stroll around the hallways of fan conventions in their outfits. Reminiscent of Baudelaire's urban explorer, the flaneur (Benjamin, 2006), these fans wander through the convention both to admire the spectacle and to experience it first-hand by becoming part of the crowd and embodying the fiction itself. In this sense, cosplaying also differs from role-playing as a longer, joint project of telling a story and playing out one's own character. Because cosplay stresses the visual, it should be no surprise that, as mentioned briefly above, photography is also a part of the hobby. Fans enjoy having their pictures taken in their outfits. Amateur photographers can in turn specialize in photographing cosplayers as a creative hobby.

Cosplay has specific qualities and limits in comparison to other fan practices. Similar to customizing one's avatar, cosplay allows for a degree of appropriation and the embodiment of a character, and in many ways, it is about establishing your own version of a character (Crawford, 2012, pp. 133-137). Notably, James Newman (2008) has examined cosplay as a visual phenomenon. Although cosplay is mainly a reenactment of limited designs of arguably flat characters, it still manages to include narrativity. This narrativity, however, does not depend only on the game: 'Cosplay scenes remind us not only of the comparatively limited presentation of game characters but also of the rounded lives of the players that embody them' (id., pp. 88). Following Mitchell and Clarke (2003), Newman remarks that by mediating a game, cosplay hovers between the virtual and the real in a complex way and argues that it constitutes different types of realness (id., pp. 88). Cosplay re-contextualizes a game in a different play setting: the 
physical world, where its characters interact with other cosplayers and new surroundings.

Even so, terms such as real or virtual do not fully capture the cosplay experience. In recent studies, scholars have often criticized the dichotomy between the real and the virtual, from Internet platforms to games, and have shown that both frequently draw from each other (Kozinets, 2010; Pearce, 2006). Cosplay, however, is not about making the game real - one can even argue that cosplay is never the real thing, no matter how good it looks - but about personalizing it and drawing it close. It is as much related to the game and its characters as it is a creative practice that has its own rewards. Moreover, cosplay is about engaging with one's own felt body more deeply by relating it to fiction: in other words, cosplay fosters affect.

\section{The Affective Process}

Philosophy has often framed affect as a type of aesthetic touch, a moment in which the subject is "affected". Affect is particularly theorized by Deleuze and Guattari (1988), who see it as a pre-personal intensity, a bodily state that is independent of the subject that undergoes it. Inspired by this theory, their translator and philosopher Brian Massumi (2002) formulates affect as distinguishable from emotions as its predecessor, an unqualified bodily state or intensity in which we are touched by an encounter with another - an artwork, a human being, a place. Affect has no meaning, but emotions do. 'Emotion is qualified intensity,' Massumi writes, continuing the argument that it is a social translation process of the asignified affect (id., p. 28). While emotion involves the production of meanings, affect cannot and does not. Emotion 'is intensity owned and recognized' (id.).

The difference between affect and emotion is crucial in Deleuzian thought. Affect is understood as an intensity that allows the subject to produce meanings. Emotions are its conscious result and the way in which affect is digested and understood. These emotions are easier to examine and are my ethnographic focal point. These emotions are not separate from affect but can be understood as its aftermath, an aftermath that is especially important within fandom because affect is re-iterated consciously and productively. It is within the emotional reflexivity of fandom that my main differences with Deleuzian theory emerge. As I argue below, affect is not merely something that 
happens to you. It can also be an interpretive stance in which the subject prepares to be overwhelmed and invites a loss of self.

However, this understanding of affect as an overwhelming, ontological power is not what I unearthed in my empirical findings; instead, I found something more subtle that was partly regulated and motivated by fans themselves. I go deeper into this understanding of affect in relation to existing fan studies on the affective and emotional lives of fans. Then, I unpack affect further by stressing its relationship to gender, identity and the body. As I noted in the first chapter of this book, fans of games and media have been analyzed as social communities that invest in particular fiction. The key to fandom, however, is the combination of interrelated social, affective and creative moments. Increasingly, social studies have frontloaded the social and participatory regimes of fandom, but I suggest that we may turn towards fandom and its affective structures more as feelings that are integral to the experience of fandom. This resonates with the attention to negative feelings in fandom and hate, symbolized through the figure of the "anti-fan" (Gray et al., 2007). An affective angle may fit well within fan studies because it attempts to distinguish between negative and positive affects as forces of community formation.

I suggest that cosplay is a fertile testing ground to view affect in fandom and understand its complexity as an embodied and affective process. Marrying fandom with the cultural theories on affect seems to be a logical move. The creative practices of fans, such as writing and drawing, have often been understood as affective engagement or investment. Fans themselves also capture their activities as a "labor of love", signifying that textual love is the predominant inspiration for their activities. In fan and game studies, however, affect remains underexplored and is often used as a colloquial term, synonymous with "emotion" or "feeling". Rather than treating it as a theoretical concept, scholars often understand an affective disposition as an integral part of fan practices that pay tribute to existing fiction. Feelings are then understood as a pre-condition of fandom but are not understood in terms of their dynamics.

Within fan studies, two works have primarily shaped my understanding of affect and fandom. In his study on fans, Lawrence Grossberg (1992) characterizes fandom as an affective endeavor and echoes the philosophical discourses on affect as grounded by Spinoza. He writes: 'Affect is not the same as either emotions or desires. Affect is closely tied to what we often describe as the feeling of life' (p. 56). Grossberg's idea of a 
"mattering map" (1992, p. 60) is a particular stand-out in this chapter. The concept implies that we can chart the intensities through which we make sense of the world and ground ourselves in it at different points. These intensities are provoked by media texts. Grossberg thus understands affect as closely related to fan identity. As opposed to cultural theories on affect, Grossberg does not discuss affect as an embodied state but rather as an abstract drive of fan investments and textual responses.

Still, the affective reception of fans cannot be divided from the social community that thrives around these texts. A later analysis by Matt Hills (2001) captures fandom as an "affective space" by explicitly considering the fannish community. Hills' study examines fan communities through the lens of Anderson's "imagined community" (1991), which supposes that communities such as the nation are constructed because people envision their membership based on a shared affinity with the group. Hills, however, explains that fandom is a community of imagination in which fans direct their affection towards a text first and foremost and not to the community itself or its members. By dividing text and social context, Hills neglects many affective relationships in communities through which fans find and recommend new texts to one other, thereby initiating others into the fandom. Although these relationships are mentioned in the article and in his other works (2002b; 2005), they should also be embraced in this affective theory.

Although the role of the body is nearly absent in both of these studies, their analytical value lies in the idea that affect, as a felt and shared experience, is central to fan identity formation. Both scholars show that affect must not be understood in a generic sense but as a strong feeling of attachment, as intensity. Hills mentions that affect thrives on "attachment rather than desire" (2001, p. 148). Here he suggests, like Grossberg, that affect in fandom operates in the domain of identity. While the social is not included in Grossberg's analysis per se, his notion of the mattering map offers ways to understand fan identity as grounded in the social environment. Textual response - a sliding scale from apathy to sublime connection - gives meaning to our lives and provides a lens through which to view the world and ourselves. Fans are connected by these affective structures. As Ike Kamphof (2010, p. 5) summarizes Grossberg's chapter: 'Affect makes us belong'.

Based on my readings of cultural studies on affect, I would suggest that affect is a more complex play of affinities than outlined in previous fan studies. Based on my 
empirical data, which I present in the following sections, I am convinced that a new idea of affect is needed to account for the diversity in fan practices. Thus, I speak of an "affective process": a range of emotional experiences that can lead to investments in the world through which we constitute our identity. The emphasis is on process rather than on space or practice because it is something that we simultaneously undergo and socially construct. Process also highlights the dynamics of our relationship with fiction, in which some elements matter more than others at different points in our lives. We constantly work through our favorite narratives again through references and rereading.

I find that affect in cosplay is a complicated trajectory, a highly intersubjective and interobjective process that is dependent on time. I propose to analyze these feelings as they are produced within the social, the fashioned and the felt body. I suggest that the best concept for this is not an "affective space" but rather an "affective process". Although the affective process develops over time, it has different entry points and objects of devotion. The moment supreme often occurs when a costume is worn at a convention. Whereas some cosplayers are interested in a game first and cosplay it as an homage, others may learn to love games through the community or other media. The initial affective spark may be with the visual design rather than the narrative, which is exactly what makes cosplay so interesting. Fan membership, craftsmanship and embodiment influence and solidify each other.

Importantly, actors not only undergo this affective process passively but also actively produce affects. They evoke them in anticipation of the fan convention or enact it when creating the costume. Through different media and derivative texts, fans purposely foster their own affect towards particular games. Thus, I show that affect is actively given shape and is more complex than accounted for by current theories. My definition of an affective process aims to chart the emotional and aesthetic qualities of cosplay. It also aims to capture the element of duration that is central to cosplay and the stakes for those involved.

I have two further remarks that relate to the process. First, the emphasis on emotional experiences is important because players carry a wide range of emotions towards games. I mention emotion or affection as a broader term when I speak of cosplayers' passion for games, but I suggest that these feelings often involve criticality and self-reflexivity and can be negative. Attachment can also stem from oppositional 
tastes. The figure of the "anti-fan" or "hater" is but one example of how identity can be aligned to negative rather than positive feelings (Gray et al., 2007). Similarly, a gamer may dress up as a game character that he likes while he hates most of the game, or he can represent a character to mock it. On another level, the fan may enjoy dressing up but can also feel shame towards other fans or non-fans because $s /$ he engages in this practice. As Joke Hermes (2005) also argues, such "negative" feelings have long been neglected in media studies (pp. 96-114).

Second, this affective process can also be captured as a personal aesthetic pursuit. Although fans may want to rationalize this affect within fan communities, fandom appears to be grounded in an aesthetic moment that is constantly re-lived (Jenkins, 2006, p. 23). Fans do not throw a text away, but they keep it and go back to it as they seek elements of re-interpretation and surprise (Hills, 2005). It is important to note that affect is not something that simply arises but that it is something that is prepared for. Creating the right circumstances for wearing the costume and being that character is a central part of the aesthetic experience. This is comparable to Gomart and Henion's research (1999) on music fans, which argues that music fans and drug addicts have a striking similarity in that both of them want to create an optimal aesthetic experience to consume the products that they love. Their unique combination of affect theory and social constructivism has been applied to opera fans, for example (Benzecry, 2011). Similarly, cosplayers live up to the convention as a special moment that is to be prepared for. They take on an active disposition and want to be overwhelmed. A similar conjuncture of reflexivity, feelings and embodiment can be found in other media spaces, such as the museum (Vall, 2008), suggesting that such trajectories are relevant to different audiences, users and spectators.

I understand affect as closely related to identity and embodiment. Cosplay provides us with an angle to view both of these elements because it foregrounds the player's body as well as those of others, including fictional characters. Before I present my findings, I would like to detail the implications of these affective encounters further in the next two sections by first detailing gender, identity and the role of the body.

\section{Grounding Identity and Gender}

While the gender dimension in cosplay is apparent and a common topic of discussion among fans and in the media, studies on how cosplayers negotiate gender patterns are 
rare. For years, the assumption was that gender and sexuality are not a real issue for many cosplayers, as in fan communities at large. This consensus seems partly construed from the observations that cross-gender cosplay or "crossplaying" is a fairly common activity at fan conventions. While a previous study of mine foregrounded the elements of drag in cosplay (Lamerichs, 2011), I believe that there is much to be gained in seeking how the practice affirms rather than subverts the gendered body. Broussard (2009) has examined the ways that male cosplayers construct their masculinity through cosplay and explains how men can utilize dress up, which is often associated with women, to confirm their masculinity as they show off their bodies.

Even among fans themselves, cosplay is still not completely accepted and is subject to debate due to its gendered aspects. Part of the reason is that dress up has particularly flourished in the separate scene of anime fandom for many years. Now that cosplayers actively appropriate the male spaces of Western comic books and games, some visitors have their first encounters with cosplay and form misunderstandings about the practice. Comic book author Tony Harris instigated a debate in 2012 when he drew attention to female cosplayers in a blog post, implying that female players only engaged in the activity for the attention and that these sexy media representations were a way to turn male fans on. In addition, he doubted that these women were even fans and presumed that they had not read the comics that they costumed (Romano, 2012).

This debate was rather ironic given that the author criticized women for flaunting the very character designs for which he and his colleagues from the media industry were responsible. Cosplay led to debate among fans and professionals who asked themselves: Is this empowerment or exploitation? For male fans, the gendered dimension of cosplay also leads to problems because some of them are identified as gay when they dress up as female characters or are criticized when their masculinity - body hair, size, muscles are at odds with a female or androgynous character. Two famous examples within fandom are "Man-Fay" and "Sailor Bubba", two chubby men who playfully dressed up as scantily-clad women, but whose parody was not always understood as such. Thus, gender in cosplay is complicated because it is always deeply connected to particular media representations that are not merely repeated but also criticized and subverted.

As a fan practice, cosplay thus creates an intimate and complex relationship between the fan and the character. This relationship is characterized by gender and embodiment, and it is most telling in terms of identity. I would like to unpack this idea 
through both cultural studies and philosophy to further our understanding of cosplay. In this section, I shall frame identity primarily in relation to Butler's concept of performativity, which in turn can also be exemplified and criticized in comparison to cosplay. Judith Butler describes performativity in Gender Trouble (1990) and elaborates on it in her other books, such as Bodies That Matter (1993). The term performativity stems from the work of Austin (1962), but Butler uses it in a different, less linguistic sense. Butler's theory is related to gender, but it has been adopted by many scholars interested in performance or identity. She argues against older discourses of identity politics claiming that gender is fixed in our selves as a pre-given structure and shapes who we are. To Butler, gender is an expression of what one does, rather than what one is. In her theory, Butler emphasizes the "reiterative power of the discourse," the repetition of the signs that constitute the act and in turn shape the subject's identity (1993, p. 2). Re-citation and repetition, not single acts, bring the subject into being.

Thus, in Butler's theory, identity is not invented but is the temporary result of ongoing imitation. Her notion of performativity shows an uncertain subject without a core, which is shaped by the repetition and citation of existing discourses. Surprisingly, Butler's theory does not rely on the autonomy of the subject. The subject can gain agency only through its acts, which are limited because they rely on imitation of the discourse. Performing one's identity is not a voluntary act here, but rather one that is always confined to discursive practices in a certain society. This is also one of the main points on which her theory is critiqued (Stuart Hall, 2000; Lloyd, 1999). Her theory is deterministic in that it provides little to no space for the intentions of the subject. Still, Butler is not frequently as deterministic because one of her most remarkable case studies, that on drag, seems to suggest that playing with or even subverting one's identity is possible. Cosplay seems similar to drag in this regard and even involves temporal drag on occasion as its subjects engage in gender play. This raises the following question: If we can express ourselves through a multitude of costumes and characters, are we not consciously constructing our identities?

Butler's account of drag is often seen as a prime example of her theory of performativity. It seems to suggest that identities, especially gender identities, are malleable and can be subverted, but that is not what Butler tries to show. She explains this in her interview with Segal and Osborne (1993): "There are restrictions in drag. In fact, I argued toward the end of the book that drag has its own melancholia." This 
melancholia inheres in the fact that drag is confined to the same gender discourse as other identities. Ultimately, she analyzes drag not as a form of empowerment but as a parody of femininity (Butler, 2004; Lloyd, 1999). Drag is based on gender, which is itself imitative. Rather than showing how cross-dressing can erase existing boundaries of gender identity, Butler emphasizes how it reconfirms heteronormativity, or the categories that define man, woman, and heterosexuality as the norm (Butler, 1993). Drag exposes all of these notions as constructed, but it is not subversive because it also reconfirms them.

Two minor criticisms of Butler's theory are relevant when examining the construction of the subject in cosplay. First, Butler discusses drag as a form of lived expression. Drag, however, occurs in other contexts as well. Drag can be performed at a carnival, within the theater, or at political interventions such as protest marches. Here, the context is more playful and less explicitly related to identity politics. Drag and cosplay explicitly come together in the subgenre of crossplay, in which players dress up as characters of the opposite gender (figure 3). This practice is occasional and, to some degree, ludic. Second, Butler does not take the intentions of the subject dressing in drag into account. The motivations of crossplayers, for instance, vary. Crossplay can be an occasional practice, enacted because the player likes a certain character of the opposite gender; it can be part of a parody (e.g., Man-Fay and Sailor Bubba); or it can be motivated by a player's preference for a certain outfit despite the gender of the character. Some crossplayers enjoy the challenge of behaving like a member of a different gender, while others see themselves as publicly declaring the fluidity of gender. Additionally, some crossplayers choose their characters according to factors other than gender; for example, a number of crossplayers whom I know lean toward certain character tropes, such as regal characters or cute girls.

Forms of dressing up like cosplay and drag combine a sense of identity and playfulness with wearing an outfit. While Butler limits the acts of the subject to discursive practices, we see that in fact cosplayers play with identity on a regular basis and understand the meaning of what they are doing in various ways. Moreover, cosplay and crossplay give us a different view of drag, which here is not confined to gender or political interventions but involves a range of aesthetic practices. In Stuart Hall's works (e.g., Hall 2000), identity is seen as twofold, as not only the subject determined by discursive practices, as in Butler's writings, but also the subject him- or herself, and how 
she or he uses culture. Identity is seen as a meeting point of discourses that affect us as social objects and, at the same time, a process that subjects themselves produce. The subject invests in his or her position. What Hall calls the "articulation" of one's identity is an important factor in the construction of identity (19).

As stated above, in Butler's theory, there is little room for this type of agency on the part of the subject. She suggests that we are deeply ingrained to behave the way we do through the concept of "performativity" and that perhaps parody is the only way in which social critique can emerge. As I discussed in an earlier article, the power of cosplay does not lie in its political potential but in its aesthetic endeavor (Lamerichs, 2011). As Butler once remarked, "I think we need to pursue the moments of degrounding, when we're standing in two different places at once; or we don't know exactly where we're standing; or when we've produced an aesthetic practice that shakes the ground. That's where resistance to recuperation happens. It's like a breaking through to a new set of paradigms" (Segal \& Osborne, 1993). These aesthetic moments of fluidity and indeterminacy are exactly what cosplay facilitates for its subjects.

\section{The Felt and Fashioned Body}

Affect theory, which emphasizes materiality and bodies, hands us the tools to work through these aesthetic and felt phenomena. Eve Sedgwick (2003) proposes that affect theory, particularly shame, offers us powerful tools to examine the performativity of queer identity. I suggest that affect helps further our understanding of how identity is performed and negotiated.

Affect theory's particular strength is its emphasis on relationality draws attention to the dual force of "acting on" and "being acted upon", a notion that already emerges as early as Spinoza's writing (Spinoza, 1999), which distinguished between passions or passive affects that we undergo and active affects that are formed by the active disposition of the subject. Affect can then be interpreted as an encounter with another body to which the felt body responds. Applied to cosplay, the other bodies are not only those of other cosplayers but also the interaction with the costume and even the estrangement from one's own body. Acting on is also relevant in cosplay in that it is an active devotion and structured to re-live an aesthetic moment of media reception. Moreover, it is also acting on its own terms by creatively producing the outfit that alters or stimulates one's affective relationship with the text. 
Cosplay showcases emotional ownership over a media text or character by forging a personal, embodied relationship between player and character. While heteronormative values and restrictions may have a role in this practice, my goal in this chapter is to uncover its interiority as part of an affective process. I would now like to turn more towards the body within cosplay, which is not a simple medium but a fashioned and visual subject; that is to say, it is simultaneously a very personal and subjective identification and an object to be admired, influenced by media imagery. Characterized by visual culture, cosplayers don outfits and cosmetics that make them resemble the characters that inspire them. The aim is not simply resemblance but the "embodiment" of fiction. In this process, the body is both enhanced and reduced. The body is specific, a combination of media imagery and flesh.

Thus, the cosplayer articulates the dynamic body images, as represented by Japanese pop culture. Featherstone (2010) suggests that these dynamic representations influence their audience: 'Other bodies and the images of other bodies in the media and consumer culture may literally move us, make us feel moved, by affecting our bodies in inchoate ways that cannot easily be articulated or assimilated to conceptual thought. Here we think of the shiver down the spine or the gut feeling. Affect points to the experience of intensities, to the way in which media images are felt through bodies' ( $p$. 195). The media images that affect cosplayers can thus be read as encounters with other bodies, albeit those of fictional characters that are designed or represented by actors. The cosplayer animates these bodies affectively after the encounter. They are no longer the other but aligned to the self.

This implies that players must actively give shape to their bodies to model the characters. For instance, they may exercise more or find ways to overcome their body size and genitals through prosthetics, corsets and makeup (Hernandez, 2013). The affective preparation for cosplay may go hand in hand with more ambiguous emotions such as shame, as it draws attention to the body's flaws. When the cosplayer's physical appearance is too masculine or feminine, too young or too old, too skinny or chubby, s/he may be criticized as a model. Preparation is therefore crucial for the cosplayer. The body itself becomes a type of medium, a fleshy texture that can be molded through work-outs, clothes and cosmetics. A male friend of mine once enthusiastically showed me the prosthetic breasts that he had ordered for his dress - squeezable plastic shapes from Japan with an elastic band to hold them in place - so that he could perform a female 
character with cleavage with ease. This was liberating and comical for him, but hidden behind the parody was the sadness of what his body could not do or be.

Sobchack's Carnal Thoughts (2004) has helped me voice these latent thoughts about embodiment. Within Western visual culture, we have adopted an extrovert body image, she writes, one that emphasizes what the body looks like toward others and constructs it as an object but neglects its interiority and subjectivity. Sobchack also shows that in certain circumstances, such as the loss of her own leg, the body is experienced anew. While the crossplayer has not lost his breasts, he may well experience gender melancholia as a feeling of absence and possibly envy. The extrovert body image of the crossplayer with prosthetic breasts brings to mind Sobchack's prosthetic leg, forged by the industry but made particular and singular in the ways that she used it and learned to work around it. The prosthetic breasts of a crossplayer are no different. Although they are only worn periodically, they become fantastically real through repeated wear.

Cosplay may provide this newness because it repurposes our bodies phenomenologically, a practice through which the body becomes alien but at the same time, more of a self than ever. This process is dual in nature, a pulling of the body as object and subject. We are even, as Sobchack would say, an "objective subject", a material and fleshy construct that is perceived and acted upon by others. At the same time, we are also a "subjective object" because we constantly define ourselves through our materiality. Cosplayers find a source of bodily affirmation, alienation and liberation. It is within the feelings of cosplay - its digested affect and internal processes - that we can find transformation, not so much in its evidently disrupting practices but in terms of crucial differences such as gender and ethnicity. Although cosplay is theatrical, it has a more private truth to tell about bodies as they mix at the convention space. They are restructured through pride and generosity as well as shame and jealousy.

I believe that we may learn from cosplay what it means to playfully engage with our bodies. It is exemplary of self-presentation in fandom as well as the passion for characters. In a broader sense, the case is an excellent example of a highly topical discussion because media imagery influences and polices our embodiment through fashion, advertisements and Hollywood culture, among others. Within fandom, the body is subjected to these perils but is in part liberated as it is aligned to narratives and characters. Moreover, cosplay equals craftsmanship, a stage of the affective process that 
cannot be neglected. In these affective patterns lies the beauty of cosplay. By embodying fictional characters, cosplayers examine their interiority and bodies in conjuncture with the materiality of the convention space and their fellow fans. I dovetail what happens in these affective processes of dress up. By speaking to diverse cosplayers, I gathered data that helps analyze what types of affects and emotions are staged through media-inspired drag and dress up.

\section{Engaging with Media Texts}

Methodologically, my field work resulted in thirty informal interviews and four in-depth interviews. The informal interviews were gathered at the Dutch convention Abunai!, which was attended by over 3,000 visitors (August 26-28, 2011). While this event is based on Japanese culture, it also attracts cosplayers of Western popular culture. I interviewed a total of over thirty cosplayers about their feelings towards games and their motivations for portraying certain characters. Due to the crowded nature of the convention space, these were informal talks, often barely five minutes long, in which I briefly explained my research, asked a few questions and took a picture for additional use.

I supported the data with four longer, in-depth interviews with informants held in October-November 2011. Due to issues of locality, two of these interviews were performed via Skype telephone calls, which posed few problems for this project because I had already met these cosplayers in real life and had established a bond of trust with them. The informants were aged from their late teens to mid-twenties and consisted of three female students in higher education and one male young professional. To protect their identities and ensure a free discussion on gender and embodiment, I opted to use the pseudonyms "Sara", "Ron", "Miranda" and "Ria" rather than their real names. This stands in contrast with other chapters, where fans favored the use of their actual names to gain credit for their work. While I am usually open about the fans whom I interview, I hoped that these in-depth interviews would profit from a confidential dialog.

The interviews give a view of Dutch fandom and how cosplay is understood in these local contexts. This European analysis contributes to fan studies as a field with an Anglo-American bias, and the local view is representative of how cosplay can be constructed but is also site-specific. It cannot readily be read as Western because there are differences in how Dutch, German and American cosplayers, for example, construct 
and experience their practices (Lamerichs, 2013b). Nonetheless, the differences among cosplay practices seem to fade increasingly as international competitions encourage the crossfertilization of the local fan scenes.

At first sight, cosplay can be understood as a public performance of a fan's affect towards the media text. I specifically spoke to game fans to demarcate my topic and found that many cosplayers see their costumes as a tribute to their favorites. They sometimes intensify this affective relationship by creating more outfits from one game. At Abunai!, I met several cosplayers of Ace Attorney, a visual novel series in which players assume the role of a defense lawyer. They explained to me that they enjoy portraying different characters from this series. One of the girls was dressed as the girl magician Trucy, a character from the latest installment of the series. 'I have borrowed this from a friend,' she explained, 'who wore it two years ago.' They relive their experience of the series and are happy to talk about the positive qualities of the game. For them, the text is up front, not the costume, and the two are even perceived to be interchangeable.

The affective stances of the gamers are diverse and ever-shifting as they grow older. One affective stance towards the game, for instance, is a nostalgic one in which fans contextualize game experiences according to their life histories. Fans of the The Legend of Zelda adventure games and the RPG-series Final Fantasy told me that the games hold a special place in their heart as franchises that they grew up with. One cosplayer of the ninja Sheik from Ocarina of Time (1998) assured me that she has enjoyed the Zelda series "ever since she could walk". Another cosplayer dressed as Zelda, while her boyfriend represented Link. She said, 'We have been fans of the games for years!' Particularly in these cases, affect is closely related to nostalgia as a sentiment towards past experiences that are reminisced and re-enacted (Gordon, 2003). "Being a fan for years" is simultaneously a statement of how close a game is related to one's fan identity and a sign of status. In this sense, it is a token not only of one's attachment to a game but also of the context in which one played it. The meaning is also derived from what the game meant many years ago.

Surprisingly, many of the cosplayers have not actually played the game that they represent or have played only parts of it; they do, however, consider themselves to be fans and rely on different repertoires and media to ground their fandom. The nonplayers have familiarized themselves with a game's content through specific social 
situations or other media. Their fan identity is a strange thing, considering that they have not consumed the full text. For all of them, fan identity was related to being a cosplayer rather than a fan of a specific text. The craftsmanship and performance of cosplay thus created their identities rather than the games themselves, but these cosplayers also acquainted themselves with the source text on various levels. I shall capture four consumption patterns of non-players that emerged in my field work.

First, cosplayers may not have played a game at all but still enjoy its designs; after all, a game's visual mode can be accessed through other media. Fans learn about the game through other players as well or even through the fan practices that surround it. Some of the players spent time looking for characters to perform and told me about their ideas and wish lists. Cosplayers familiarize themselves with a game through their traditional or online communities. Sometimes, they group together online or offline when peers are still looking for characters from a particular game that they want to perform at a convention. The non-player who joins these groups often makes a decision based on the visual features of characters that s/he sees in other media (e.g., websites). As far as I know, social hierarchies from other domains are not imposed on the character roles. Rather, it seems that players specialize in certain types of characters and exploit their skills, such as creating sewing patterns, styling wigs or writing theatrical skits.

However, designs were often a fundamental reason for non-players to choose a particular character. Within Japanese popular culture, these designs are crucial in the media mix. Characters, Hiroki Azuma (2009) has suggested, are structured through "moe" that tease out affect for particular tropes of characters, such as school girls or cat girls (pp. 25-48). Their "hyperflatness" thus makes the characters appealing and recognizable. It assures that character aspects can flow from medium to medium, from story to story. Japanese popular culture, Azuma (id.) suggests, functions as a database in which tropes and features are conserved and constantly remediated.

Second, cosplayers can enjoy the narrative of the game. They watch YouTube playthroughs, read summaries, or enjoy watching others play it; that is to say, even if they have not played the game themselves, they intensely study the characters and their canon. Others acquaint themselves with the game through a position of spectatorship. As one Final Fantasy XIII cosplayer - dressed up as the tribal girl Vanille while her sister portrayed the heroine Lightning - told me: 'She plays, I just watch.' She is fond of Vanille despite not having played the game herself, which she considered to be complex. These 
practices of social gaming and watching games are very common, but until now, they have scarcely been studied as a way of engaging with games or as a mode of reception. Video game audiences are not necessarily players; they can also be spectators who can watch a game and enjoy the story without playing it (Crawford, 2011, pp. 33-34).

Third, Japanese popular culture is highly intermedial in that its elaborate franchises often depend not only on a game but also on anime and manga. As Jenkins (2006a) suggests in relation to transmedia storytelling, other media become entry points to a fictional world, and the audience will look into the other parts of the narrative as well. For instance, I spoke to a group of four Final Fantasy VII cosplayers, but only one member had actually played the original game. The others had watched Final Fantasy VII: Advent Children (2005), an animated movie-sequel to the popular game. Similarly, several cosplayers of the RPG Tales of the Abyss also based their outfits on the anime rather than the original Playstation game, which has not been released in Europe.

Throughout the field work, I noticed that the distinction between player and nonplayer is not always easy to make. Many cosplayers do not have a relationship with a game a priori but will start playing it once they consider cosplaying a character. Many of them admit that they will need to have some connection with the game and its characters and try it out at the same time that they are conceptualizing their cosplay. Interviewee Sara started to play the action role-playing game Kingdom Hearts II (2005) as part of a traditional cosplay group in which she learned to sew outfits and create patterns. The group wanted to perform as the antagonists of the game, the mysterious villains of Organization XIII. Because these characters wear the same coats, she could pick a different character if she did not like the one that she had opted for. 'You were making that coat anyway, so you could still change. It didn't really matter,' she said, suggesting that she did not have a strong opinion about what character suited her best or was her favorite. Her reception of the game and the creation of the costume thus went hand in hand, co-constructing the affective process.

Many cosplayers admit that they have played parts of the game but have not finished it because the game play did not appeal to them. The aforementioned Final Fantasy XIII cosplayers, for example, told me, 'We love the characters and the story!' When I asked them if they actually enjoy the game, they told me that they find it very difficult. It turned out that they were actually stuck at an early point in the game "at 
some kind of ice plain where you have to switch roles". In terms of play, then, a game might be annoying, too difficult or boring for some players who, instead of feeling challenged, simply put it down. Although the narrative and characters might appeal to the gamers, the system of the game or the time that it consumes does not always motivate them to continue. Here, there might be a connection with the characters or a type of game love, but the functionality of the medium can also hinder and frustrate the players.

\section{Becoming the Character}

In cosplay, the character is foregrounded. Fans have their favorites and portray them in many contexts, such as icons at forums or customized avatars in games or in costume. Sometimes a player enjoys being that character so much that $\mathrm{s} / \mathrm{he}$ creates different outfits that the character wears, transforms the original design or refines one costume for later venues. At first sight, it would seem that cosplayers identify with particular characters quite deeply, but this is an incorrect assumption. Identification in cosplay is also deeply connected to game fans' individual receptions. The activity is not just a projection of the self but also an interpretive process of engaging with the character. In many cases, cosplayers suggest that the activity is not so much about being the character as it is about getting to know him or her. The character is given an independent existence. Fans speak of the characters favorably, carefully distinguish them from themselves, and often entitle them with a sense of personality that is consistent or "in character". When there is an anomaly in the plot of the game that portrays a character differently, fans often justify these actions or explain them by pointing to the conditions of the media production (e.g., different writing teams).

Choosing a character is part of the affective process in which cosplayers engage, but it is often compromised by the cultural context. First, physical appearance or preferences play a role because cosplay is a highly visual practice. Practical choices may involve characters' age, skin color and even gender. Some cosplayers have strong gender preferences and enjoy crossplaying, whereas others look at the physical characteristics of specific men and women. Second, particular fans cosplay in groups and may not choose a certain character when his or her friends favor it. Moreover, an ongoing practice at Dutch conventions is to announce which character you will perform in the 
hopes that other fans will not show up in the same outfit. The social context thus also compromises what players choose.

Fans primarily base themselves on how the character is situated in the narrative and respond to that. For some, the character is clearly an object of devotion. Sometimes, female fans voice this as love quite clearly by calling the character a real "bishie" (from the Japanese bishounen, which means 'pretty young boy'). Women can appreciate these men by becoming them and staging them as subjects but also adore them as objects of affection, as the handsome men that they are. One Ace Attorney cosplayer at Abunai!, for instance, portrays prosecutor Gavin - the opponent of the main character in Apollo Justice - and invests in homosexual interpretations of him. She tells me how much she likes the other prosecutors in the previous games and apparently adores this character type. Her feelings towards Gavin seem to be a mix of desire, admiration and identification, a theme that appeared in many of the interviews. In this case, taking on alternative roles is not only a simple play-pretend but also a sign of one's attachment to a particular character and an interpretive stance to further understand this person.

Size, posture and attitude are categories that cosplayers often mention as restrictions in representing a character well, as opposed to classic identity features such as gender or ethnicity. Interviewee Sara explains that gender matters to her but is not always what she considers first. 'I wouldn't like to be a Japanese thin girl. I'm just not that small, thin or young, but I could still pass for a Japanese guy.' Ria, like Sara, mentions age. When I interview her, she is dressed up as Misty from Pokémon, an orange-haired character estimated in her early teens. Ria recently turned twenty recently and feels that this is the last time that she can portray a young character, 'before it is too late'. Although Misty's age is debatable and her design suggests a thin or developing female figure, Ria is at odds with cosplaying a young character during adolescence.

Some cosplayers have pragmatic reasons for choosing a character. Ria once represented the titular character from the gothic action-adventure game American McGee's Alice (2000), an unofficial sequel to the Carroll's Alice in Wonderland in which Alice goes mad after her parents die in a fire. Ria chose the character for pragmatic reasons: she did not want to wear a wig and already had boots that looked like the ones from the game. Such pragmatic considerations also help limit cosplay decisions. Ria explains that she did not relate to the character back then. 'I don't really identify with 
Alice,' she confesses. 'Though I guess that in similar circumstances, I would have acted the same as her.' Interestingly, she does mention that she sometimes feels like Alice when she wanders through a physical environment that reminds her of the game. Thus, the game space is something that she relates to more than the character itself.

Importantly, cosplay culture itself helps narrow the choices. Especially when their favorite character has already been claimed by many other cosplayers, fans are not always motivated to portray them. They find their own strategies for handling this, by making their own original versions of the characters or opting for extraordinary versions of a character, for instance. Many Zelda-fans at Abunai! explained that Zelda and Link have been amply cosplayed and that they thus felt the need to carve their own niches. One Zelda cosplayer focused on the cross-over fighting game Supersmash Brothers (2001) in which the colors of Zelda's dress can be changed; she represented the black version. Another designed an outfit of her alter-ego, Sheik. Two other players had already made Zelda and Link outfits from Skyward Sword long before the game was released (November, 2011) to show their anticipation and to be the first to represent these new designs. Here, cosplay culture clearly interferes with the affective process, but fans tackle the problem in inventive ways.

This pretend-play is not limited to cosplay but often extends to other domains such as the game itself. After all, a game character is often an avatar that is playable and positions us in the game (Burn, 2006). In some cases, the love for a character is innately tied up to the experience of also being the character in-game. As cosplayer Ron explains regarding his performance as characters from fighting games, 'I always participate in the Soul Calibur compo with Tira. She is one of the most difficult characters to play with. I always drop out the first round, but I always try again next year anyway.' Though Ron is not the most skilled player of the Soul Calibur games, he persists because the social activity and the game are important to him. He likes the idea of embodying the character simultaneously in dress and on the screen. Investment in a character can also be performed in other types of play or creative fan practices; interviewee Miranda, for instance, has performed the antagonist Xemnas from Kingdom Hearts II and has played him in LiveJournal RPGs, where she interacted as the character with other users. Others create fan fiction or fan art of the characters. Being a fan means establishing these type of performances in which the character is foregrounded. 
The performance of the character is also entwined with the creation of the costume. Interviewee Sara tells me that the character is very much alive when she creates her cosplays. She describes a wall in her bedroom that functions as a cosplay mood board. 'For me, it's like, you play a game and someone is cool - at the moment, Ezio (from Assassin's Creed II) is really cool - and then I put up pictures from art books and other things on my wall and he really starts to live until at some point, suppose I've created and worn Ezio, he's put in the closet and I'll do something else. It evolves.' As with others who work in groups or duos, she tells me that constructing a cosplay has a very particular atmosphere to it in which footage from the game is re-watched, the soundtrack is played and the characters are re-enacted. 'If you work together with someone, you have this atmosphere and you are partly in character. I've never seen something like that before. You already start to go in character while that character is just there as fabric on the ground. That's something really special.'

The creation of the outfit becomes a way of already enjoying the cosplay and the aesthetic experience that it fosters. Many cosplayers are skeptical about transforming into the character at a convention itself, however. Performing the character is limited in this space and mostly consists of having the proper attitude and posing correctly for pictures. Furthermore, the activity is often compromised due to the stress of competing with others in a fashion show or physical discomfort inherent in the costume. 'Then you are more concerned with your wig than the fact that you are walking there as Grell,' Miranda says, referring her performance as the flamboyant grim reaper from the anime Black Butler. Cosplayers describe the fear that parts of the outfit will break or their makeup smudge. At other times, the social context causes friction when the player encounters others who represent the same character or seem more skilled. These encounters can be positive - the similar character becomes a friend; the better cosplayer becomes a mentor - but may also cause feelings of jealousy, insecurity or confusion.

Sometimes, it is more difficult to pinpoint why a transformative moment is lacking and a cosplay does not feel like a positive experience. Here, affect reminds us of the Deleuzian force that cannot be signified or placed. Ron confesses, 'With some cosplays, I thought, this does not fit.' 'On a personal level?' 'Yes,' he answers me. 'Seventy percent of it was okay and wearable but the other 30\% lacked.' I carefully probe whether this was related to his male body and the drag, but he conveys that he is unsure. He simply missed that extra click with the outfit but could not tell me what that was - the 
character, the text, the outfit itself. In fact, it becomes clear that there is no reason that Ron does not relate to the costume, other than his inability to experience affect during the performance itself. He simply did not enjoy it as much as he had hoped.

Generally, identity in cosplay is a highly relational phenomenon that depends on the social context of the performance. My informants often explain that they only feel like the character when they are addressed as such and that other times, they are more themselves. However, some are more careful and hint at transformation. Ron describes it thus: 'It's kind of like I leave behind part of myself in the hotel room. (...) I start to behave more feminine, more elegant. That's partly due to the costume and partly an attitude.' Others explain that they experience the characters as roles that they can learn from and that inspire them. They relate the characters closely to their own identities and tell me that the cosplay somehow has worn off on them. 'If you really like a character,' Sara says, 'you learn what aspects of yourself you don't know so well. Sometimes you see a character and you think: 'Why does this person appeal to me?' Then it often turns out that he has a connection with you, at least, that's how I experienced it.' By cosplaying strong, secure characters, Sara learned to be less shy because she saw that people reacted to her differently when she was playing. In this case, affect has clear transformative potential and teaches the player about him or herself.

\section{Crafting and Preserving the Outfit}

After this initial interest in the text and choosing a character, cosplayers may construct an outfit. The outfit and its construction can fuel the relationship with a character or game but can also give ground to affective experiences that are not related to the game context per se. As in other creative domains, the process of making or combining the outfit is not only preparation for a performance but is also a meaningful act by itself. Some cosplayers explained their love for sewing and passion for learning new skills. Interviewee Ron tells me that in some cases, outfits outweigh characters for him because he is interested in new sewing challenges and thus picks his outfits based on difficult designs. He wants to make a new outfit for Tira from Soul Calibur $V$ that will involve latex, which he has never worked with, many separate pieces of cloth, and a complex styling of the wig. He explains that he is interested in the creative challenge, but it is striking that Tira often returns as a fundamental character in his oeuvre. 
Creating the costume involves many feelings. It can be bothersome when an outfit does not turn out as it should, especially when sewing an outfit alone. 'I used to let these nerves guide me,' Ron confesses, who has recently started to construct what he considers to be challenging outfits. Some cosplayers have similar insecurities but resolve them by cooperating with friends. In fact, most cosplayers learn to sew by appropriating existing outfits or by sewing with friends or family. Some look for patterns online and try to make sense of them, but this is usually at later stages. Interviewee Ria even created her first cosplay, Alice, by putting her favorite dress on the fabric and drawing its contours. Thus, while the creation process can depend on other people, this is not always the case.

Cosplaying can be challenging at first, but players grow more comfortable as their skills develop. Creating itself is an affective process in which you grow, and the community's feedback concerning your costume can be supportive and maybe even decisive in the decision to continue (Gauntlett, 2011). Still, not all cosplayers create their own outfits. At Abunai!, I stumbled upon many cosplayers who bought their costumes online or commissioned them from art sites or other cosplayers. However, the process of looking into diverse costumes or finding the right seamstress also requires effort. Cosplayers who purchase their outfits tell me that they are often quite picky, negotiate with seamstresses who sell custom outfits, and wait in suspense until their wig or outfit arrives. When you create the costume yourself, finding the right pieces and notions is also challenging and involves similar shopping experiences, even before the costume is sewn.

Thus, creating or buying the dress and wearing it solidifies the fan's relationship with the character and game, and the costume itself usually takes up a special place in the cosplayer's heart afterwards. My informants and other players whom I know confess to the idea that a cosplay experience needs to be exclusive. Others wear their outfit several times, especially when it fits well, simply refining the costume each time. Cosplayers have very different opinions and even norms about this. Many players with free time on their hands - usually those who start cosplaying when they are still in high school or college - will create several outfits for a convention and find this very acceptable, while others might invest more time in one outfit and wear that for two days or at several conventions. These attitudes towards wearing the costume also convey that affect depends on the community as much as one's personal creative goals. 
After its debut, the outfit is preserved or worn again at a later point. Some interviewees had so many costumes that they had to sell some of them. 'That was quite difficult,' Ron shares with me. Sara also has strong feelings about selling costumes: 'It is weird to put your memories in an envelope and send them off to someone else. It's somehow unnatural.' The memories related to a costume are not only personal but also the result of a creative process that players have undergone and accomplished. 'When I see my costumes,' Sara says, 'I immediately know where the sewing machine stopped and where I spilled coffee. You see bits and pieces of your life in it.' Moreover, the outfit is carefully constructed to fit one's body, which makes the cosplayer wonder whether a different player will look equally good in it or be satisfied with it.

This attachment to the costume also results in cosplayers' wishes to preserve their outfits properly. Informants such as Sara tell me that they only put the outfits on display when they are working on them. After the convention debut, the costume is then carefully placed in the closet as a keepsake or preserved for a second appearance. Others exhibit the dresses on tailor's dummies for months, and some share that they dream of having a separate closet for their outfits.

The need to preserve the outfits is not only related to the idea that they are carefully constructed artworks, however; it also stems from the very real idea that these outfits are a part of the cosplayer. 'They are more than just costumes,' Miranda argues. 'They remind me of the convention where you meet people and do nice things.' The costume is a souvenir of the convention experience, like photographs and videos, and on top of that, they are a reminder of the narrative or character that the fan has grown to care about. The costume is a combination of the fan's life history and the people whom $\mathrm{s} /$ he met at a convention. It is an intensely biographical and social artifact. At the same time, the dress is a reminder of the character and game that holds a special place in the cosplayer's heart. The outfit is a token, one of the few material remainders of a deeply personal experience.

\section{Conclusion}

Cosplay is an affective process with different entry points, felt experiences and results. The interchange between player, game and costume is central here, rather than the media text. This study furthered thoughts on cosplay as a cultural domain as well as addressing fundamental points on fandom and audiences overall. 
Specifically, my findings on the reception of gaming are remarkable. Based on my empirical results, I have shown that the reception of games is wider than in gaming only. This notion is tied up with recent transmedia phenomena. First, as the theory of transmedia storytelling (Jenkins, 2006) suggests, audiences increasingly find entry points to a game narrative through other franchises such as movies. Second, games have different modes on which gamers rely and that motivate these inter-/transmedial interpretations. The enjoyment of games through other media is a common state of reception that we tend to overlook in audience studies. These different audience positions are possible because some game modes can be stored and enjoyed individually. We can listen to game music, examine its designs, watch the cut scenes or game play, and enjoy its reviews. Interestingly, this content can become a primary text and the only text on which audiences rely.

The informants did not perceive this as a problem per se. This can be explained, first, by understanding that these modes of reception are a voluntary choice on the part of audiences who only want to enjoy a product to a certain degree or within a certain social context. Furthermore, cosplay is a very visual performance in which it is possible to invest in a character without investing in the game. Some cosplayers simply want to make a great outfit, cosplay with their friends or convey something other than a positive relationship towards a game. What remains of these diverse experiences are the costumes that players cherish along with photographs or videos, a residue of the performance that are also media texts that can be interpreted in their own right.

In terms of affect, a cosplayer's attachment to a game can be directed towards specific elements of the text and the context in which it is consumed. This affective process has different entry points and affective moments that range from the costume to the game itself. This relationship does not necessarily precede a passion for the original game. In fact, the cosplay is often created parallel to the familiarization with the game or the replaying of it. As opposed to more aesthetic theories on affect that discuss the concept as a pre-personal state, it becomes clear that these audience members take on an active disposition and partly construct the affective process. Fans purposely advance their attachment by making a costume and wearing it. Affect is thus not only articulated but also nourished, created and performed. 


\section{7. \\ CONCLUSION}

Prospects for Fan Studies

\section{Challenges of an Emerging Field}

Productive Fandom reflects on a contemporary popular culture that is constantly changing and increasingly valued. Fan studies long based itself on the idea that fans are an active or subversive audience that can be opposed to passive viewers. In today's participatory culture, however, fans are hardly seen as exceptional in their activity. Jenkins (2007) even argues that fandom is nearing its end now that all audiences have become active. Fandom is almost entirely embedded in mainstream culture.

When I began this book, it seemed that this increase of audience activity had rendered "fandom" obsolete, but the opposite occurred as the field suddenly started to flourish. Academic interest in fans has been sparked anew in recent years, with the founding of fan studies networks, journals and conferences. The field of fan studies was praised because it focused on unique audience activities undertaken by users, gamers, crafters and artists. For many media scholars, fan studies became a hallmark in the analysis of new media studies and digital culture. Many scholars also tried to differentiate fans from other audiences. This study contributes to that debate by offering a detailed examination of fan activity and productivity.

I have shown that contemporary fandom is more than a subset of participatory culture. These audience groups are defined by unique social spheres, interpretive stances and forms of creativity. While fans can be described as active audiences, this description overlooks the specificity of their cultures. Indeed, there are fundamental differences in how audiences participate and how critical, creative or social this behavior is (Takahashi, 2010). While studies on audience behavior fare well, it is still unclear what activities or user patterns underlie the identity of the fan. I suggested turning towards the creative and the affective. I captured the identity of the fan as it is lived and felt by fans themselves and as it shines through their creative works. While fans are often portrayed in research as a coherent group, I hoped to do justice to the dynamics of their networks and textual consumption. 
My findings show that fans form heterogeneous groups that migrate within popular culture on several levels. Primarily, fans are more flexible than many fan studies presume. Fans are often loyal to different communities that revolve around texts and genres. What most research fails to highlight is that fans are usually not confined to one series. They actively draw connections between texts and invest in different narratives at particular points in their lives. Some scholars make this explicit, such as Steven Bailey (2005), who defines his fans as "geeks" interested in a particular type of popular culture, or Matt Hills (2002), who analyzes cult fans. Looking at one specific community or fandom can be problematic because it hardly tells us how fans engage with genre or media culture at large. I drew attention to the cultural dynamics of fandom through an intermedial framework and included cases on genres, such as anime fandom and science fiction.

Furthermore, until now, many fan studies focused on digital fandom at the expense of offline fandom. I, however, showed that it is also crucial to examine how fans interact in traditional communities. Research on the convention space, for instance, proved vital to understand these audiences. While online data can reveal patterns in fan communication and creativity, the offline space reveals fan cultures as they are lived and provides ample situations in which to observe fans' identity markers and lingua franca. The offline space can also be used in addition to online findings in a mixed methods approach. This book is representative of how fans construct their identities and experience narratives because it examines online and offline cultures in conjunction with each other.

Finally, while fandom can be signified as a subculture, it is increasingly part of a larger participatory culture of appropriation and reflection on media content. New movements such as crowd funding projects make it clear that fans have a liminal position towards the industry: they are not only producers or consumers but increasingly function as stakeholders, investors and brand advocates. Moreover, television hails the fans and their culture in its narratives. Glee's approval of "gleeks" is one example of this, and Sherlock's appeal to slash fandom through queer subtexts is another. Media producers are aware of their audiences and engage in discussions with them. Thereby, the industry includes and validates the participatory culture of its audiences. 
I hope to have shown that fandom still is largely an autonomous endeavor, however. These critical and creative audience cultures are staged in relation to the media industry but never truly belong to the industry. The relationships between the producer and the consumer are increasingly intertwined, but although they often show similar motivations and dispositions, these roles must not be confused. The negotiation processes are more complex and should be examined on a case by case basis on a situational level that accounts for the tactics of audiences and industry.

Fandom teaches us that many rudimentary notions of ownership in today's media landscape do not account for the dynamics of audience reception. The text is lived and shared - understood as a public domain that readers enjoy, rework and re-imagine. The ability to creatively rework stories deserves more attention in that it is integral to the reception of fiction, which always requires the reader's active disposition. Audiences' expectations are constructed throughout the media text and allow a sense of wonderment to emerge. Thus, the narrative is continuously given shape by the interpretive play between text and reader.

\section{Ethnographic Approach}

This research project started with a keen eye for the creative and narrative activities of fans, but the cultural domains in which this production takes place have never been out of sight. I unearthed these structures through a mixture of traditional and virtual ethnographic methods. This combination seemed to be the only way in which I could make sense of fandom, which is increasingly performed in interrelated social and mediated contexts. While the convention space is one space of fandom where individuals meet up, they may extend this experience on media platforms such as forums or Facebook. Throughout the book, I developed my ethnographic voice within the chapters and the vignettes. My interview approach combined in-depth and formal techniques with informal conversations.

Methodologically, Internet platforms played different roles within this research. First, they were a site for preliminary research, as in the Sherlock case. Second, they provided networks of productions in which fan activities were developed, published and altered, for instance, as in the case of Glee. Third, I analyzed them as sites of play where fan texts were co-authored and performed, as in the cases of Firefly and cosplay. These different considerations of digital spaces carried methodological implications for the 
type of ethnography that I conducted. At times, my view was personal because this was the only way to access certain media; at other times, it was more distant. Being a dynamic and self-reflexive scholar was not only a joy but also a pure necessity to obtain certain data and provide solid views on popular culture.

These mixed methods were theoretically combined with different types of narrative analysis, such as naturalization and possible worlds theory, and more phenomenological or philosophical concepts, such as affect. These theories informed my conceptual model, which is revisited below. A special place in this book was reserved for the vignettes that made the cultures of fandom accessible and introduced their cultural themes, such as fan labor, gender and globalization. The vignettes stand in their own right as interrogations of offline fandom. They opened the discourse on transcultural media fandom by providing a more personal view of what being a fan is like. As these ethnographic situations and encounters unfolded, I let myself be surprised.

While I visited over twenty fan conventions the past four years, I have only included five accounts and posted others on my blog or analyzed them in new publications. I have learned much about these cultures, but what continues to surprise me most is that all over the world - ranging from the United States to Japan, Germany and the Netherlands - fans find a common ground and expression. I hope to have shown the unique culture of these events and their similarities. Although fan practices emerge in particular local contexts that should not be overlooked, it is most inspiring that fans around the world share these creative and social practices.

\section{Core Concepts and Findings}

Throughout the book, I applied and revisited narrative and social concepts to analyze fan works. The focal points of this ethnographic approach can be extended to different creative domains of today's participatory culture. I detail some of my findings below, following my core concepts.

Intermediality: Intermediality provided a useful framework to analyze the mediation of fan texts and source texts. Intermediality can imply different creative structures that need to be analyzed according to their visual, textual and material modes. Increasingly, the media industry also integrates intermediality as a commercial and promotional device through transmedia design. I suggested that transmedia design is more than just 
storytelling because it includes play and performances, as in the musical spectacle Glee. Moreover, today's media texts stand out through their transmedia story worlds. The unexplored universe of Firefly, Sherlock's London and the high school setting of Glee offer provocative settings. These are not only spatio-temporal constructs with their own myths and lore but are also models of textual alternatives and possibilities. Scholars have inadequately observed these different transmedia designs and their implications. I suggest that performance, characterization and world-building are fundamental to the analysis of transmedia design. Another important finding in my study is that many fan texts do not play out in the field of transmedia design - a domain of extension and alternatives - but instead focus on increasingly refined iterations of beloved characters and tropes. In this case, intermediality has a prototypical and sociological function because it relies on recognition more than on structural elements and narrative enhancement.

Characters and story world: Media texts are understood as experiences in fandom. The fictional worlds and the characters that live in them are fundamental to fan interpretation and productivity. Characters make a conscious appeal to their readers and have a sense of realness, a process that I signified through Fludernik's notion of experientiality. Fictional worlds - iterated in different media texts - are also central to the experience of popular culture. Fans envision new stories and unexplored territories in these worlds. Something special happens in fandom that is characteristic of reading in general: we learn to understand characters as individuals and open new worlds and possibilities.

Affective reception: I argued that the reception of text is not only a rational and critical process but that it is also felt, embodied and personal. While fans display critical readership, as illustrated by the Sherlock case, their readings are also characterized by the love of the text and immersion therein. This affect is the driving force of their fan activities. Fans show that texts are not only felt but also read in a personal and embodied way, and this embodiment pertains to both the fan's own identity and that of others. The bodies of actors, characters or other fans generate intimacy that may even be solidified in fan practices. The performance of affect in fandom is most apparent in cosplaying. While these feelings emerge in a social and industrial context, they also have 
a clear role in the reception of popular culture itself. Fans not only respond to fiction but also actively extend these feelings, reposition them and carry them further.

Networks of production: Fan texts are created in particular media ecologies. Today, these texts are increasingly entwined with the participatory culture that media designers stimulate around their franchise. Nonetheless, fandom is still autonomous on online platforms, such as LiveJournal, or traditional platforms, such as fan conventions. The production of fan texts occurs in specific systems where fans can provide feedback to each other and create specific fan values. Fandom consists of communities of authors, readers and critics who appraise and advance each other's work. New norms and genres emerge within these networks. These pertain to gender and sexuality, as my references to cross-gender performances, asexuality and slash have illustrated. Fandom, then, is a critical audience culture. A fan author often affirms and mimics the content of media texts but never loses sight of their clichés and tropes.

\section{Fan Identity}

Throughout this book, I searched for the identity of fans and how their identities were constructed. This analysis occurred on several levels and focused on different contexts that create membership and affinity in fandom. In each chapter, we saw a different face of fandom, fan artists and authors. The identity of fans was phrased as creative (Glee), playful (Firefly) interpretive or critical (Sherlock), and affective (cosplay).

First, the creative identity of fans was central in this book. This identity as an artist or player is created through widely divergent creative practices that support fandom but at the same time help artists develop their own style and voice. The identity of the fan artist and the artist are thus intimately related as fandom becomes a place to develop one's skills. Each chapter demonstrated a different creative practice, ranging from cosplay to fan games. In the chapters on Glee and Firefly, the creativity of fans and their negotiation of existing context were most central. I showed that fans deployed literary strategies to develop their own styles. They had different stances towards the source text in terms of focalization, genre mediation and gender, as the Glee chapter shows. Their mediation processes were not simple mimicry but were about transformation and the creation of new meanings. 
Second, the playful or "ludic identity" (Raessens, 2010) of the fans emerged within the chapters. Fans can be seen as players on two levels. First, they dabble with existing content and adopt a playful disposition of imagination and make-believe. They are players even if they are writing or drawing art because they engage with the content through their fantasy and playfully recreate it within a social group. Second, fans are players in a more narrow sense when they engage with genres of play, such as roleplaying games or cosplay. Fan identity is solidified in this play by the relation of one's self to a game character. Thus, when we speak of identity and identification in cosplay, we speak of two things. On the one hand, players actualize a narrative and its meaning; on the other hand, they actualize their own identities. To put it bluntly, by stating that a narrative or character is related to me - that I can identify with this particular story or person - I make a statement about myself. There is transformative potential in this ability to express who we are through fiction.

Third, fans turned out to be critical, independent thinkers. The repertoires of fan communities partly construct their meanings and help inform them, but they also make sense of content through other media texts that they have consumed. Fans demonstrate a type of intermedial reception, as I have shown in the case of Sherlock. This interpretive dimension of fandom becomes even more relevant when we consider the widespread nature of contemporary media. Fandom presses scholars to reconsider how viewers watch, feel and make sense of these narratives.

This fan identity is not isolated from other social contexts and repertoires, however. My analysis actively traced fan identity back to social repertoires of nationality and gender, for instance, and uncovered the local sentiments that underlie fandom. While fandom is often perceived as a global phenomenon, I often found it to be rooted in local cultures. Nonetheless, certain elements of fandom are transcultural, such as the websites that fans use, the widespread nature of certain fan activities and the basic characteristics of fan conventions.

Moreover, fans share a lingua franca that becomes apparent offline and online. They help establish a basic canon of quality popular culture (e.g., the relevance of Firefly) and refer to their activities through specific subcultural terms (e.g., "slash", "Mary Sue"). These patterns also emerged in the multi-sited ethnography that is described throughout this book. The widespread fan and geek culture of contemporary websites and media platforms allows a transcultural fan identity to emerge and flourish. This fan 
identity is not a given, but it is actively and lovingly constructed in relation to the media environments and social contexts in which one is embedded.

\section{Future of Fandom}

Fandom proved to be a daring and innovative topic to examine in today's popular culture. Productive fandom is increasingly staged in new media, such as games, applications and industry websites. We face a challenge as fan scholars to constantly redefine what a fan is and what the concept allows us to do. The shape of our media culture is contingent, dynamic and murky. It is constantly redefined by its producers and participants. Fandom is not a social utopia or a limitless playing ground - it abides by or responds to the property rights set by the industry and the quality checks of other fans. It is kept at bay by participants who are producers, users, consumers, publishers, stakeholders and anything in between.

The study of fandom is not merely an online phenomenon, but it is mediated through television, social media, conventions and media events. A cultural reading of these activities requires thinking through materiality, feelings and bodies as well as media. Upcoming studies need to face these challenges and experiment in their methodologies to produce critical audience studies. The institutional and individual contexts of fandom need to be examined in academic work.

The transcultural dimensions of fandom cannot readily be captured through generalizations. I have shown that these cultures are local, heterogeneous and dispersed. Moreover, fans rely on different forms of social and intellectual capital to ground their practices. For instance, some may value world-building; others invest in character relationships or romances. Despite these different motivations, fans share a social and creative culture as well as an affective mode of reception.

What constructs the status of the popular media text and the fans who consume it? In Productive Fandom, I gave some answers and motivations. I unearthed media culture as a terrain upheld by the creative industries and its audiences. I hope that this book can contribute to the recent debates on digital culture as it is lived, shared and constructed. These unique audience activities are not marginal but increasingly valued and integrated in the media landscape. Fandom matters. Ultimately, it shows us that contemporary popular culture is not raw material that is produced by industries. Instead, it is the dynamic and productive domain of adoring audiences. 


\section{Bibliography of Fan Works}

A-Glass-Parade. (2011). Miss Holliday goes to Dalton. http://a-glass-

parade.livejournal.com/6411.html

Ellisbell85. (2010-). Mischances, Stances and Stolen Glances.

http://www.fanfiction.net/s/7032218/1/Mischances-Stances-and-Stolen-

Glances (Accessed 15 October, 2012).

EverShadow. (2010). Color. http://www.fanfiction.net/s/6177788/1/Color (Accessed

15 October, 2012).

Fanlore. (2012). 'Transformational Fandom.'

http://fanlore.org/wiki/Transformational Fandom (Accessed 15 October, 2012).

Fyrewyre. (2011). Time and Again. http://fyrewyre.livejournal.com/7319.html

(Accessed 15 October, 2012).

Gandalf3213. (2010-2011). And Innocents.

http://www.fanfiction.net/s/6354640/1/And-Innocents (Accessed 15 October, 2012).

Lookninjas.(2011). Pick Up Right Where We Left.

http://lookninjas.livejournal.com/123513.html

Lookninjas.(2011). A Thousand Paper Cranes.

http://lookninjas.livejournal.com/125086.html

Mothergoddamn. (2010). Looking for Mary.

http://mothergoddamn.livejournal.com/193904.html (Accessed 15 October, 2012).

Mothergoddamn. (2010). The Lost Nightingale.

http://goddamnwrite.livejournal.com/3048.html (Accessed 15 October, 2012).

Mothergoddamn. (2010). Swan Song. http://goddamnwrite.livejournal.com/11591.html (Accessed 15 October, 2012).

Mothergoddamn. (2011). The Girl in Room 17.

http://goddamnwrite.livejournal.com/9384.html (Accessed 15 October, 2012).

Mothergoddamn. (2011). The Dapper Highwayman.

http://goddamnwrite.livejournal.com/2464.html (Accessed 15 October, 2012).

Miggy. (2010). Mostverse. http://miggy.livejournal.com/851279.html\#mostverse (Accessed 15 October, 2012).

Miggy. (2010). Predators. http://miggy.livejournal.com/841091.html (Accessed 15 October, 2012).

Miggy. (2010). The 25 $5^{\text {th }}$ President of the United States. http://miggy.livejournal.com/843744.html (Accessed 15 October, 2012).

Obsession_Inc. (2009). Affirmational vs. Transformative Fandom. http://obsessioninc.dreamwidth.org/82589.html (Accessed 15 October, 2012)

Readfah-Cwen. (2011). I'll Have to Say I Love You in a Song. http://readfahcwen.livejournal.com/5602.html (Accessed 15 October, 2012). 


\section{Bibliography}

Abbott, S. (2008). Can't Stop the Signal: The Resurrection/Regeneration of Serenity In R. Wilcox \& T. R. Cochran (Eds.), Investigating Firefly and Serenity: Science Fiction on the Frontier (pp. 227-238). London; New York: I.B. Tauris.

Abercrombie, N., \& Longhurst, B. (1998). Audiences: A Sociological Theory of Performance and Imagination. London; Thousand Oaks, Calif.: Sage.

Adler, P. A., \& Adler, P. (1987). Membership Roles in Field Research. Newbury Park, Calif.: Sage Publications.

Albrechtslund, A.-M. (2010). Gamers Telling Stories: Understanding Narrative Practices in an Online Community. Convergence: The International Journal of Research into New Media Technologies, 16(1), 112-124. doi: 10.1177/1354856509348773

Alvermann, D. E., \& Hagood, M. C. (2000). Fandom and Critical Media Literacy. Journal of Adolescent \& Adult Literacy, 43(5), 436-446.

Anderson, B. (1991). Imagined Communities: Reflections on the Origin and Spread of Nationalism (Rev. and extended ed.). London; New York: Verso.

Ang, I. (1985). Watching Dallas: Soap Opera and the Melodramatic Imagination. London; New York: Methuen.

Austin, E., \& Correa, B. (2006). The Cosplay Show. Portrait Gallery. Mediamatic.

Austin, J. L. (1962). How to Do Things with Words. Cambridge: Harvard University Press.

Azuma, H. (2009). Otaku: Japan's Database Animals ([English ed.). Minneapolis: University of Minnesota Press.

Bacon-Smith, C. (1992). Enterprising Women: Television Fandom and the Creation of Popular Myth. Philadelphia: University of Pennsylvania Press.

Bailey, S. (2005). Media Audiences and Identity: Self-Construction in the Fan Experience. Basingstoke; New York: Palgrave Macmillan.

Banks, J., \& Humphreys, S. (2008). The Labour of User Co-Creators: Emergent Social Network Markets? Convergence: The International Journal of Research into New Media Technologies, 14(4), 401-418. doi: 10.1177/1354856508094660

Barthes, R. (1990). The Fashion System. Berkeley: University of California Press.

Baym, N. K. (2000). Tune in, Log on: Soaps, Fandom, and Online Community. Thousand Oaks: Sage Publications.

Benjamin, W. (2006). The Writer of Modern Life: Essays on Charles Baudelaire. Cambridge: Harvard University Press.

Benzecry, C. E. (2011). The Opera Fanatic: Ethnography of an Obsession. Chicago: The University of Chicago Press.

Bird, S. E. (2003). The Audience in Everyday Life: Living in a Media World. New York; London: Routledge.

Boef, A. H. d. (2005). Sherlockholmesing: Pastiches op Werk en Leven van Sir Arthur Conan Doyle. Leiden: Universiteitsbibliotheek Leiden.

Boellstorff, T. (2008). Coming of Age in Second Life: An Anthropologist Explores the Virtually Human. Princeton, N.J.: Princeton University Press.

Bogost, I. (2007). Persuasive Games: The Expressive Power of Videogames. Cambridge: MIT Press.

Bogost, I. (2010, July 29, 2010). Against aca-fandom: On Jason Mittell on Mad Men. Retrieved from http://www.bogost.com/blog/against_aca-fandom.shtml

Bolter, J. D., \& Grusin, R. A. (1999). Remediation: Understanding New Media. Cambridge; London: MIT Press.

Booth, P. (2010). Digital Fandom: New Media Studies: Lang, Peter, Publishing Incorporated. 
Booth, P. (2012). The Television Social Network: Exploring TV Characters. Communication Studies, 63(3), 309-327. doi: 10.1080/10510974.2012.674616

Brillenburg Wurth, K. (2013). Intermedialiteit \& Tree of Codes van Jonathan Safran Foer In Y. Van Dijk, M. De Pourcq \& C. De Strycker (Eds.), Draden in het Donker: Intertekstualiteit in Theorie en Praktijk (pp. 151-168).

Broussard, J. (2009). (Ad)dressing Masculinity: The Performance of Male Cosplay in the South. Paper presented at the Southern Anthropologist Society.

Bruno, M. (2002). Cosplay: The Illegitimate Child of SF Masquerades. Glitz and Glitter Newsletter, Millenium Costume Guild.

Bucholtz, M. (2002). Gendered Practices in Language. In S. Benor, Rose, M., Sharma D., Sweetland, J. and Zhang, Q. (Ed.), Gendered Practices in Language (pp. 277-307). Stanford: CSLI Publications.

Buckingham, D. (2003). Media Education: Literacy, Learning and Contemporary Culture. Cambridge: Polity.

Burgess, J., \& Green, J. (2009). YouTube: Online Video and Participatory Culture. Cambridge: Polity.

Burn, A. (2006). Reworking the Text: Online Fandom. In D. Carr (Ed.), Computer Games: Text, Narrative and Play (pp. 72-87). Cambridge: Polity.

Busse, K. (2013). Geek Hierarchies, Boundary Policing, and the Gendering of the Good Fan. Participations, 10(1).

Butler, J. (1990). Gender Trouble: Feminism and the Subversion of Identity. New York; London: Routledge.

Butler, J. (1993). Bodies that Matter: On the Discursive Limits of Sex. New York: Routledge.

Butler, J. (2004). Bodily Inscriptions, Performative Subversions In J. Butler \& S. Salih (Eds.), The Judith Butler Reader (pp. 90-119). Malden, MA: Blackwell Pub.

Caillois, R. (1961). Man, Play, and Games. New York: Free Press of Glencoe.

Carroll, N. (2007). Narrative Closure. Philosophical Studies, 135(1), 1-15. doi: DOI 10.1007/s11098-007-9097-9

Castronova, E. (2005). Synthetic Worlds: The Business and Culture of Online Games. Chicago: University of Chicago Press.

Certeau, M. d. (1984). The Practice of Everyday Life. Berkeley, CA etc.: University of California Press.

Chambers, J. (2006a). Jamie on Canon. from http://www.serenityrpg.com/features_articles.htm

Chambers, J. (2006b). Serenity Role-playing Game. Lake Geneva: Margaret Weiss Productions.

Chang, H. (2008). Autoethnography as Method. Walnut Creek, Calif.: Left Coast Press.

Chen, M. (2012). Leet Noobs: The Life and Death of an Expert Player Group in World of Warcraft. New York: Peter Lang.

Cochran, T. R. (2008). The Browncoats Are Coming! Firefly, Serenity, and Fan Activism In R. Wilcox \& T. R. Cochran (Eds.), Investigating Firefly and Serenity: Science Fiction on the Frontier (pp. 239-249.). London; New York: I.B. Tauris.

Conquerhood, D. (1985). Performing as a Moral Act: Ethical Dimensions of the Ethnography of Performance. Literature in Performance, 15, 1-13.

Consalvo, M. (2003). Cyber-Slaying Media Fans: Code, Digital Poaching, and Corporate Control of the Internet. Journal of Communication Inquiry, 27(1), 67-86. doi: $10.1177 / 0196859902238641$

Consalvo, M. (2007). Cheating Gaining Advantage in Videogames. Cambridge: MIT Press. 
Coppa, F. (2006a). A Brief History of Media Fandom. In K. Hellekson \& K. Busse (Eds.), Fan Fiction and Fan Communities in the Age of the Internet (pp. 41-59). Jefferson, N.C.: McFarland \& Co.

Coppa, F. (2006b). Writing Bodies in Space: Media Fan Fiction as Theatrical Performance. In K. Hellekson \& K. Busse (Eds.), Fan Fiction and Fan Communities in the Age of the Internet (pp. 225-244). Jefferson, NC: McFarland \& Co.

Coppa, F. (2012). Sherlock as Cyborg: Bridging Mind and Body. In L. E. Stein \& K. Busse (Eds.), Sherlock and Transmedia Fandom: Essays on the BBC Series (pp. 210-223). Jefferson, NC: McFarland.

Corneliussen, H., \& Rettberg, J. W. (2008). Digital culture, play, and identity: A World of Warcraft reader. Cambridge, MA: MIT Press.

Couldry, N. (2003). Media Rituals: A Critical Approach. London; New York: Routledge.

Crawford, G. (2012). Video Gamers. London, New York: Routledge.

Culler, J. D. (1975). Structuralist Poetics: Structuralism, Linguistics and the Study of Literature. London: Routledge \& Kegan Paul.

Deleuze, G., \& Guattari, F. (1988). A Thousand Plateaus: Capitalism and Schizophrenia. London: Athlone Press.

Dena, C. (2009). Transmedia Practice: Theorising the Practice of Expressing a Fictional World across Distinct Media and Environments. (PhD), University of Sydney. Retrieved from http://www.christydena.com/phd/

Deterding, S., Dixon, D., Khaled, R., \& Nacke, L. (2011). From Game Design Elements to Gamefulness: Defining "Gamification". Paper presented at the Proceedings of the 15th International Academic MindTrek Conference: Envisioning Future Media Environments.

Deuze, M. (2007). Media work. Cambridge etc.: Polity Press.

Doane, M. A. (2007). The Indexical and the Concept of Medium Specificity. Differences- $a$ Journal of Feminist Cultural Studies, 18(1), 128-152. doi: Doi 10.1215/104073912006-025

Doležel, L. (1998). Heterocosmica: Fiction and Possible Worlds. Baltimore; London: Johns Hopkins University Press.

Doty, A. (2000). Flaming Classics: Queering the Film Canon. New York: Routledge.

Dyer, R. (1990). Now You See It: Studies on Lesbian and Gay Film. London; New York: Routledge.

Ellison, H. (2013). Submissives, Nekos and Futanaris: a Quantitative and Qualitative Analysis of the Glee Kink Meme. Participations, 10 (1).

Ess, C., \& AoIR. (2002). Ethics Guide. Retrieved March, 2013, from http://aoir.org/reports/ethics.pdf

Featherstone, M. (2010). Body, Image and Affect in Consumer Culture. Body \& Society, 16(1), 193-221. doi: 10.1177/1357034x09354357

Fish, S. E. (1980). Is There a Text in This Class? The Authority of Interpretive Communities. Cambridge: Harvard University Press.

Fiske, J. (1990). Understanding Popular Culture (2nd ed.). London; New York: Routledge.

Fludernik, M. (1996). Towards a 'Natural' Narratology. London; New York: Routledge.

Foucault, M. (1984). What is an Author? The Foucault Reader (1st ed., pp. 101-120). New York: Pantheon Books.

Fron, J., Fullerton, T., Morie, J., \& Pearce, C. (2007). Playing Dress-up: Costumes, Roleplay and Imagination. Paper presented at the Philosophy of Computer Games.

Frost, V. (January 3, 2011). Critic's choice: Steven Moffat, The Guardian. Retrieved from http://www.guardian.co.uk/culture/2011/jan/03/critics-choice-steve-moffat 
Gauntlett, D. (2011). Making is Connecting: The Social Meaning of Creativity from DIY and Knitting to YouTube and Web 2.0. Cambridge, UK ; Malden, MA: Polity Press.

Gee, J. P. (2003). What Video Games Have to Teach Us about Learning and Literacy (1st ed.). New York: Palgrave Macmillan.

Geertz, C. (1973). The Interpretation of Cultures: Selected Essays. New York: Basic Books.

Genette, G. (1980). Narrative Discourse: An Essay in Method. Ithaca, New York: Cornell University Press.

Genette, G. (1997). Paratexts: Thresholds of Interpretation. Cambridge: Cambridge University Press.

Gillan, J. (2010). Television and New Media: Must-Click TV: Taylor \& Francis.

Glas, R. (2010). Games of Stake: Control, agency and ownership in World of Warcraft. (Doctor), Amsterdam University Press, Amsterdam.

Gomart, E., \& Hennion, A. (1999). A Sociology of Attachment: Music Amateurs, Drug Users. In J. Law \& J. Hassard (Eds.), Actor Network Theory and After. Oxfod; Blackwell: The Sociological Review.

Gordon, I. I. (2003). Superman on the Set: The Market, Nostalgia and Television Audiences. In M. Jancovich \& J. Lyons (Eds.), Quality Popular Television: Cult TV, The Industry and The Fans. London: BFI Publishing.

Gray, J. (2003). New Audiences, New Textualities. International Journal of Cultural Studies, 6(1), 64-81. doi: 10.1177/1367877903006001004

Gray, J., Sandvoss, C., \& Harrington, C. L. (2007). Fandom: Identities and Communities in a Mediated World. New York: New York University Press.

Grishakova, M., \& Ryan, M.-L. (2010). Intermediality and Storytelling. New York: De Gruyter.

Grossberg, L. (1992). Is There a Fan in the House? The Affective Sensibility of Fandom. In L. A. Lewis (Ed.), The Adoring Audience: Fan Culture and Popular Media (pp. 5065). London: Routledge.

Gwenllian Jones, S. (2003). Web Wars: Resistance, Online Fandom and Studio Censorshi. In M. Jancovich \& J. Lyons (Eds.), Quality popular television : cult TV, the industry and fans (pp. 163-181. ). London: British Film Institute.

Hall, S. (1973). Encoding and Decoding in the Television Discourse: Centre for Cultural Studies, University of Birmingham.

Hall, S. (1980). Culture, Media, Language: Working Papers in Cultural Studies, 1972-79. London: Hutchinson.

Hall, S. (2000). Who Needs 'Identity'? In P. Du Gay, J. Evans \& P. Redman (Eds.), Identity: A Reader (pp. xiv, 386 p.). London; Thousand Oaks: Sage Publications

Hancock, D. (2011). Cosplay. http://www.david-hancock.com/cosplay/index.html.

Hardy, J. (2011). Mapping Commercial Intertextuality: HBO's True Blood. Convergence: The International Journal of Research into New Media Technologies, 17(1), 7-17. doi: $10.1177 / 1354856510383359$

Harvianen, T. (2012). Systemic Perspectives on Information in Physically Performed Roleplay. (PhD), Tampere.

Hassapopoulou, M. (2010). Spoiling Heroes, Enchancing our Viewing Pleasure: NBC's Heroes and the Re-Shaping of the Televisual Landscape. In H. Urbanski (Ed.), Writing and The Digital Generation: Essays on New Media Rhetoric (pp. 45-57). Jefferson, North Carolina, London.

Hayles, N. K. (2004). Print Is Flat, Code Is Deep: The Importance of Media-Specific Analysis. Poetics Today, 25(1), 67-90. doi: 10.1215/03335372-25-1-67 
Helbig, J. (Ed.). (1998). Intermedialität: Theorie und Praxis eines interdisziplinären Forschungsgebiets. . Berlin: Erich Schmidt Verlag.

Hellekson, K., \& Busse, K. (2006). Fan Fiction and Fan Communities in the Age of the Internet. Jefferson, N.C.: McFarland \& Co.

Herman, L., \& Vervaeck, B. (2005). Handbook of Narrative Analysis. Lincoln: University of Nebraska Press.

Hermes, J. (2005). Re-reading Popular Culture. Malden; Oxford: Blackwell.

Hernandez, P. (2013). Cosplayers Are Passionate, Talented Folks. But There's A Darker Side To This Community, Too. Kotaku. http://kotaku.com/5975038/cosplayersare-passionate-talented-folks-but-theres-a-darker-side-to-this-community-too

Higgins, D. (1967). Statement on Intermedia Dé-coll/age 2013, from http://artpool.hu/Fluxus/Higgins/intermedia2.html

Hills, M. (2001). Virtually Out There: Strategies, Tactics and Affective Spaces in On-line Fandom. In S. Munt (Ed.), Technospaces: Inside the New Media (pp. 147-160). London; New York: Continuum.

Hills, M. (2002a). Fan Cultures. London; New York: Routledge.

Hills, M. (2002b). Transcultural 'Otaku': Japanese Representations of Fandom and Representations of Japan in Anime/Manga Fan Cultures.

Hills, M. (2005). Patterns of Surprise: The "Aleatory Object" in Psychoanalytic Ethnography and Cyclical Fandom. American Behavioral Scientist, 48(7).

Hills, M. (2012). Sherlock's Epistemological Economy and the Value of "Fan" Knowledge: How Producer-Fans Play the (Great) Game of Fandom In L. E. Stein \& K. Busse (Eds.), Sherlock and Transmedia Fandom: Essays on the BBC Series (pp. 27-40). Jefferson, NC: McFarland.

Hine, C. (2000). Virtual Ethnography. London etc.: SAGE.

Holbrook, M. B. (1995). Consumer Research: Introspective Essays on the study of Consumption. Thousand Oaks, CA: Sage Publications.

Huizinga, J. (1970). Homo Ludens: A Study of the Play Element in Culture. London: Maurice Temple Smith Ltd.

Hutcheon, L. (2006). A Theory of Adaptation. New York: Routledge.

Ito, M. (2005). Technologies of the Childhood Imagination: Yugioh, Media Mixes, and Everyday Cultural Production. In J. Karaganis \& N. Jeremijenko (Eds.), Structures of Participation in Digital Culture: Duke University Press.

Ito, M. (2010). Hanging out, Messing around, and Geeking out: Kids Living and Learning with New Media. Cambridge: MIT Press.

Jauss, H. R. (1984). Äesthetische Erfahrung and Literarische Hermeneutik (4 ed.). Nördlingen: Suhrkamp.

Jenkins, H. (1992). Textual Poachers: Television Fans and Participatory Culture. New York; London: Routledge.

Jenkins, H. (2003). Transmedia Storytelling. Retrieved from http://www.technologyreview.com/

Jenkins, H. (2006a). Convergence Culture: Where Old and New Media Collide. New York: New York University Press.

Jenkins, H. (2006b). How Transmedia Storytelling Begat Transmedia Planning. Retrieved from http://henryjenkins.org/2006/12/how_transmedia_storytelling_be_1.html

Jenkins, H. (2007). Afterward: The Future of Fandom. In J. Gray, C. Sandvoss \& C. L. Harrington (Eds.), Fandom: Identities and Communities in a Mediated World (pp. 357-364). New York: New York University Press. 
Jenkins, H., Ford, S., \& Green, J. (2012). Spreadable Media: Creating Value and Meaning in a Networked Culture. New York: New York University Press.

Kamphof, I. (2010). Webcams to Save Nature: Online Space as an Affective and Ethical Space. Foundations of Science, 16.

Keller, V. (2011). The "Lover" and Early Modern Fandom. Transformative Works and Cultures, 7.

Kelly, W. W. (2004). Fanning the Flames: Fans and Consumer Culture in Contemporary Japan. Albany, NY: State University of New York Press.

Knobel, M., \& Lankshear, C. (2007). A New Literacies Sampler. New York: P. Lang.

Kozinets, R. V. (2010). Netnography: Doing Ethnographic Research Online. Los Angeles, Calif. ; London: SAGE.

Kress, G. R., \& Van Leeuwen, T. (2006). Reading Images: The Grammar of Visual Design (2nd ed.). London: Routledge.

Krewani, A. (2001). Hybride Formen: New British Cinema, Television Drama, Hypermedia. Trier: WVT, Wissenschaftlicher Verlag Trier.

Kristeva, J. (1981). Desire in language: A semiotic approach to literature and art. Oxford: Basil Blackwell.

Krogh, H. P. (2010). All Talking! All Singing! All Dancing! Prolegmena: On Film Musicals and Narrative. In M. Grishakova \& M.-L. Ryan (Eds.), Intermediality and storytelling (pp. 147-164). New York: De Gruyter.

Krzywinska, T., MacCallum-Stewart, E., \& Parsler, J. (2011). Ring Bearers: The Lord of the Rings Online as Intertextual Narrative. Manchester; New York: Manchester University Press.

Kunne-Ibsch, E. (1977). Periodiseren: De Historische Ordening van Literaire Teksten. In W. J. M. Bronzwaer, D.W. Fokkema \& Elrud Kunne-Ibsch (Ed.), Tekstboek Algemene Literatuurwetenschap. Baarn: Ambo.

Lamerichs, N. (2011). Stranger than Fiction: Fan Identity in Cosplaying. Transformative Works and Cultures, 7.

Lamerichs, N. (2012). Holmes Abroad: Dutch Fans Interpret the Famous Detective. In L. E. Stein \& K. Busse (Eds.), Sherlock and Transmedia Fandom: Essays on the BBC Series (pp. 179-193). Jefferson, NC: McFarland.

Lamerichs, N. (2013a). Cosplay: Material and Transmedial Culture in Play. Paper presented at the DiGRA, Atlanta.

Lamerichs, N. (2013b). The Cultural Dynamic of Doujinshi and Cosplay: Local Anime Fandom in Japan, USA and Europe. Participations, 10(1).

Lancaster, K. (2001). Interacting with Babylon 5: Fan Performances in a Media Universe (1st ed.). Austin: University of Texas Press.

Landow, G. P. (2006). Hypertext 3.0: Critical Theory and New Media in an Era of Globalization ([3rd ed.). Baltimore: Johns Hopkins University Press.

Lanser, S. S. (1992). Fictions of Authority: Women Writers and Narrative Voice. Ithaca: Cornell University Press.

Leavitt, A. (2012). Performing with Glee. Retrieved from http://spreadablemedia.org/essays/leavitt/

Leigh, C. (2007). Cosplay Models: Real Life Japanime Characters, Helium. Retrieved from http://www.helium.com/items/207818-cosplay-models-real-life-japanimecharacters

Lloyd, M. (1999). Performativity, Parody, Politics. Theory, Culture \& Society, 16(2), 195213. doi: $10.1177 / 02632769922050476$ 
Lonberg, O., Rasmussen, P., Lorentzen, M., \& Nygaard, E. (2011). The Pottermore Concept and Transmediality. http://digitalismus.dk/?p=219

Long, G. (2007). Transmedia Storytelling: Business, Aesthetics and Production at the Jim Henson Compa. (Master of science), Massachusetts institute of technology.

Lothian, A., Busse, K., \& Reid, R. A. (2007). Yearning Void and Infinite Potential: Online Slash Fandom as Queer Female Space. English Language Notes, 45(2), 104-111.

MacCracken, S. (1998). Pulp: Reading Popular Fiction. Manchester: Manchester University Press.

Mandala, S. (2008). Representing the Future: Chinese and Codeswitching in Firefly. In R. Wilcox \& T. R. Cochran (Eds.), Investigating Firefly and Serenity: Science Fiction on the Frontier (pp. 31-40). London; New York: I.B. Tauris.

Markham, A. N. (1998). Life Online: Researching Real Experience in Virtual Space. Walnut Creek; London: Altamira Press.

Markham, A. N., \& Baym, N. K. (2009). Internet Inquiry: Conversations About Method. Los Angeles: Sage Publications.

Massumi, B. (2002). The Autonomy of Affect. Parables for the Virtual Movement, Affect, Sensation (pp. 23-45). Durham, NC: Duke University Press.

McLelland, M. (2002). Virtual Ethnography: Using the Internet to study Gay Culture in Japan. Sexualities, 5(5), 387-406.

Meijer, M. (1988). De Lust tot Lezen: Nederlandse Dichteressen en het Literaire Systeem. Amsterdam: Sara/Van Gennep.

Meijer, M. (2006). In Tekst Gevat: Inleiding tot een Kritiek van Representatie. Amsterdam: Amsterdam University Press.

Meyer, M. D. E. (2012). New Directions in Critical Television Studies: Exploring Text, Audience, and Production in Communication Scholarship. Communication Studies, 63(3), 263-268. doi: 10.1080/10510974.2012.684291

Mitchell, G., \& Clarke, A. (2003). Videogame Art: Remixing, Reworking and Other Interventions. Paper presented at the DiGRA: Level Up, Utrecht.

Montola, M., Stenros, J., \& Waern, A. (2009). Pervasive Games: Theory and Design. Amsterdam; Boston: Morgan Kaufmann Publishers/Elsevier.

Müller, J. (1996). Intermedialitat: Formen moderner kultureller Kommunikation. Münster: Nodus Publikationen.

Mulvey, L. (1999). Visual Pleasure and Narrative Cinema. In L. Braudy \& M. Cohen (Eds.), Film Theory and Criticism: Introductory Readings (5th ed., pp. 833-844). New York; Oxford: Oxford University Press.

Murray, J. (1999). Hamlet on the Holodeck: The Future of Narrative in Cyberspace (2nd pr. ed.). Cambridge, MA: MIT Press.

Murray, S. (2004). 'Celebrating the Story the Way it is': Cultural Studies, Corporate Media and the Contested Utility of Fandom. Continuum, 18(1), 7-25. doi: $10.1080 / 1030431032000180978$

Nardi, B. A. (2010). My Life as a Night Elf Priest: An Anthropological Account of World of Warcraft. Ann Arbor: University of Michigan Press.

Newman, J. A. (2008). Playing With Videogames. New York; London: Routledge.

Okabe, D. (2012). Cosplay, Learning, and Cultural Practice. In M. Ito, D. Okabe \& I. Tsuji (Eds.), Fandom Unbound: Otaku Culture in a Connected World (pp. 225-249). New Haven: Yale University Press.

Ong, W. J. (2002). Orality and Literacy: The Technologizing of the Word. London; New York: Routledge. 
Palmer, R. B. (1994). Hollywood's Dark Cinema: The American Film Noir. New York; Oxford: Twayne; Maxwell Macmillan International.

Patten, D. (2010). Madonna Stands to Profit from 'Glee' Episode., Media Bizz. Retrieved from http://www.msnbc.msn.com/id/36666635/ns/business-media_biz

Pearce, C. (2006). Productive Play: Game Culture from the Bottom-Up Games and Culture, 1(1), 17-24.

Pearce, C. (2009). Communities of Play: Emergent Cultures in Multiplayer Games and Virtual Worlds. Cambridge; London: MIT Press.

Pearson, R. (2007). Anatomising Gilbert Grissom: The Structure and Function of the Televisual Character. In M. Allen (Ed.), Reading contemporary television (pp. 9357). London: I. B. Tauris.

Pearson, R. (2012). "Good Old Index"; or, the Mystery of the Infinite Archive In L. E. Stein \& K. Busse (Eds.), Sherlock and Transmedia Fandom: Essays on the BBC Series (pp. 150-164). Jefferson, NC: McFarland.

Penley, C. (1991). Brownian Motion: Women, Tactics, and Technology. In C. Penley \& A. Ross (Eds.), Technoculture (pp. 135-161). Minneapolis ; Oxford: University of Minnesota Press.

Perryman, N. (2008). Doctor Who and the Convergence of Media. Convergence: The International Journal of Research into New Media Technologies, 14(1), 21-39. doi: $10.1177 / 1354856507084417$

Plate, L. (2011). Transforming Memories in Contemporary Women's Rewriting. Houndmills etc.: Palgrave Macmillan.

Polasek, A. D. (2012). Winning "The Grand Game": Sherlock and the Fragmentation of Fan Discourse. In L. E. Stein \& K. Busse (Eds.), Sherlock and Transmedia Fandom: Essays on the BBC Series (pp. 41-54). Jefferson, NC: McFarland.

Postigo, H. (2007). Of Mods and Modders. Games and Culture, 2(4), 300-313. doi: $10.1177 / 1555412007307955$

Pugh, S. (2005). The Democratic Genre: Fan Fiction in a Literary Context. Bridgend: Seren.

Radway, J. A. (1987). Reading the Romance: Women, Patriarchy, and Popular Literature. London: Verso.

Raessens, J. (2010). Homo Ludens 2.0: The Ludic Turn in Media Theory. Utrecht University, Utrecht.

Rajewsky, I. O. (2002). Intermedialität: A. Francke.

Rajewsky, I. O. (2005). Intermediality, Intertextuality, and Remediation. Intermédialités, 6, 43-64.

Reijnders, S. (2009). Watching the Detectives. European Journal of Communication, 24(2), 165-181. doi: 10.1177/0267323108101830

Rein-Hagen, M. (1992). Vampire: The Masquerade: White Wolf.

Rice, J., \& Saunders, C. (1996). Consuming Middlemarch: The Construction and Consumption of Nostalgia in Stamford. In D. Cartmell, I. Q. Hunter, H. Kaye \& I. Whelehan (Eds.), Pulping Fictions: Consuming Culture across the Literature/Media Divide (pp. 85-98). London etc.: Pluto Press.

Robertson, J. E. (1998). Takarazuka: Sexual Politics and Popular Culture in Modern Japan. Berkeley: University of California Press.

Romano, A. (2012). Sexist Rant against "Fake Geek Girls" Hits New Low, Daily Dot. Retrieved from http://www.dailydot.com/news/tony-harris-peacock-fake-geekgirls-cosplayers/

Ronen, R. (1994). Possible worlds in literary theory. Cambridge ; New York: Cambridge University Press. 
Ross, S. M. (2008). Beyond the Box: Television and the Internet. Malden: Blackwell.

Ryan, M.-L. (1994). Immersion vs. Interactivity: Virtual Reality and Literary Theory. Postmodern Culture, 5(1).

Ryan, M.-L. (2004). Narrative across Media: The Languages of Storytelling. Lincoln: University of Nebraska Press.

Ryan, M.-L. (2006). Avatars of Story. Minneapolis: University of Minnesota Press.

Salen, K., \& Zimmerman, E. (2004). Rules of Play: Game Design Fundamentals. Cambridge: MIT Press.

Saler, M. (2003). 'Clap If You Believe in Sherlock Holmes': Mass Culture and the ReEnchantment of Modernity, c. 1890-c. 1940. The Historical Journal, 46(3), 599622.

Schäfer, M. T. (2011). Bastard Culture! How User Participation Transforms Cultural Production. Amsterdam: Amsterdam University Press.

Scott, S. (2009). Repackaging Fan Culture: The Regifting Economy of Ancillary Content Models. Journal of Transformative Works and Cultures, 3.

Sedgwick, E. K. (2003). Touching Feeling: Affect, Pedagogy, Performativity. Durham: Duke University Press.

Segal, L., \& Osborne, P. (1993). Gender as Performance: An Interview with Judith Butler. Radical Philosophy, 67.

Shefrin, E. (2004). Lord of the Rings, Star Wars, and Participatory Fandom: Mapping New Congruencies between the Internet and Media Entertainment Culture. Critical Studies in Media Communication, 21(3), 261-281. doi: $10.1080 / 0739318042000212729$

Shuftan, B. (2012). Firefly RP Sim Closes. Second Life Newser.

Smith, B. H. (2007). Poetic Closure: A Study of How Poems End. Chicago: University of Chicago Press.

Smith, K. (2008). How to Be an Explorer of the World: Portable Art Life Museum: Perigee Books.

Sobchack, V. C. (2004). Carnal Thoughts: Embodiment and Moving Image Culture. Berkeley: University of California Press.

Spielmann, Y. (1998). Intermedialität: das System Peter Greenaway: W. Fink.

Spinoza, B. d. (1999). The Ethics: Part III. Champaign; Boulder: Project Gutenberg.

Spradley, J. P. (1980). Participant Observation. New York: Holt, Rinehart and Winston.

Stasi, M. (2006). The Toy Soldiers from Leeds: The Slash Palimpsest In K. Hellekson \& K. Busse (Eds.), Fan Fiction and Fan Communities in the Age of the Internet (pp. vi, 290 p.). Jefferson, NC: McFarland \& Co.

Stebbins, R. A. (2007). Serious Leisure: A Perspective for Our Time: Transaction Publishers.

Stein, L. E., \& Busse, K. (2012). Sherlock and Transmedia Fandom: Essays on the BBC Series. Jefferson, NC etc.: McFarland.

Stenros, J., Belarbi, S., \& Montola, M. (2010). Nordic Larp: Fëa Livia.

Takahashi, T. (2010). Audience Studies: A Japanese Perspective. Abingdon: Routledge.

Taylor, T. L. (2006). Play Between Worlds: Exploring Online Game Culture. Cambridge; London: MIT Press.

Thomas, L. (2002). Fans, Feminisms and 'Quality' Media: Taylor \& Francis.

Tosca, S., \& Klastrup, L. (2004). Transmedial Worlds - Rethinking Cyberworld Design. Paper presented at the International Conference on Cyberworlds Los Alamitos, CA. 
Tosca, S., \& Klastrup, L. (2011). When Fans Become Players: LOTRO in a transmedial world. In T. Krzywinska, MacCallum-Stewart, E., Parsler, J. (Ed.), Ring Bearers: The Lord of the Rings Online as intertextual narrative. (pp. pp. 46-69.). Manchester: Manchester University Press.

Vall, R. v. d. (2008). At the Edges of Vision: A Phenomenological Aesthetics of Contemporary Spectatorship. Aldershot, Hampshire, England ; Burlington, VT: Ashgate.

Van Looy, J. (2005). Virtual Recentering: Computer Games and Possible Worlds Theory Image \& Narrative, 12.

Ward, K. J. (1999). Cyber-Ethnography and the Emergence of the Virtually New Community. Journal of Information Technology(14), 95-105.

Watson, N. (2011). Fandom Mapped: Rousseau, Scott and Byron on the Itinerary of Lady Frances Shelley. Romantic Circles: Praxis Series.

Wenz, K. (2006). Transmedialisierung. Vom Computerspiel zu Digitaler Kunst. In U. Meyer, Simanowski, R. \& Zeller, C. (Ed.), Transmedialität: Zur Ästhetik paraliterarischer Verfahren (pp. 98-109). Göttingen: Wallstein Verlag. .

Wilcox, R., \& Cochran, T. R. (2008). Investigating Firefly and Serenity: Science Fiction on the Frontier. London; New York: I.B. Tauris.

Winge, T. (2006). Costuming the Imagination: Origins of Anime and Manga Cosplay. Mechademia, 1, 65-76.

Wirman, H. (2011). Playing The Sims 2. Constructing and Negotiating Woman Computer Game Player Identities through the Practice of Skinning. (Doctor), University of the West of England, Bristol.

Wyatt, S. (2003). Non-Users Also Matter: The Construction of Users and Non-Users of the Internet In N. Oudshoorn \& T. Pinch (Eds.), How Users Matter: The CoConstruction of Users and Technologies (pp. 67-80). Cambridge; London: MIT Press.

Ziegler, W., \& Hegerl, U. (2002). Der Werther-Effekt - Bedeutung, Mechanismen, Konsequenzen. Nervenarzt, 1. 


\section{Productief Fandom: Intermedialiteit en Affectieve Receptie in Fanculturen}

Productief Fandom analyseert en theoretiseert de creativiteit van mediafans. Fans zijn een interpretatieve groep die opvalt in productief, affectief en sociaal opzicht. Van oudsher wordt populaire cultuur gedragen en genoten door haar publiek, maar dat is geen eenrichtingsverkeer. Fans veranderen televisieseries, games, films en romans door hun appropriatie. In hun discussies interpreteren fans niet alleen bekende fictie, maar ze gaan er ook creatief mee aan de slag. Fans herschrijven, kostumeren, bewerken en visualiseren hun favoriete personages en werelden.

Fanactiviteiten vinden zowel online plaats, bijvoorbeeld op bekende sociale media zoals Twitter, maar ook offline, binnen fanclubs en fanconventies. Deze groepen en platforms worden vaak gevat onder het begrip 'fandom', een analytisch concept dat fans beschrijft van een bepaalde serie, zoals Glee; van een genre, zoals sciencefiction, of van een medium, zoals videogames. Naast deze sociaal en creatief ingestelde fans is 'fan' een term die ons allemaal bekend in de oren klinkt. Fanactiviteiten als het bewonderen van een muzikant, auteur of serie, of het 'liken' van een fanpagina op Facebook, zijn immers ook heel alledaags.

Deze interdisciplinaire studie combineert methodes van de geesteswetenschappen en sociale wetenschappen om een veelzijdig beeld van fanculturen te bieden. Empirisch richt Productief Fandom zich op verschillende populaire series en de vaak onverwachte fanactiviteiten die daaromheen ontstaan. Ik kijk specifiek naar de groepen rondom de BBC-serie Sherlock, het musicaldrama Glee, de sciencefictionserie Firefly en Japanse videogames. Ik onderzoek daarmee series en fanculturen die representatief zijn voor de fanactiviteiten die centraal staan in deze studie, te weten fandiscussies, fanfictie, roleplayinggames en cosplay. Fandiscussies, om te beginnen, kunnen online en offline worden gevoerd en geven inzichten in hoe fans bestaand materiaal interpreteren. Fanfictie betekent het creatief herschrijven van de brontekst door het transformeren van de setting, personages of delen van het bestaande plot. Roleplayinggames, vervolgens, geven spelers de gelegenheid bestaande of nieuwe personages op te voeren in hun favoriete universum. Cosplay, ten slotte, is het creëren en dragen van kostuums van fictieve personages, maar buiten mode zijn ook fotografie, theater en video belangrijke media die de cosplay-ervaring construeren.

Deze kwalitatieve studie hanteert verschillende etnografische methodes om inzichten te genereren in de geleefde cultuur van fans. Ten eerste richt ik mij op de 
verhalen van fans en bied ik analyses van hun producten. Ten tweede geef ik in deze studie fans een stem door diepte-interviews en informele interviews. Ten derde put ik uit participerende observatie vanuit verschillende rollen die ik zelf speelde in online en offline fanculturen. De rol van de onderzoekster als kritische insider is onderwerp van methodologische reflectie. De etnografische data wordt niet alleen behandeld binnen de theoretische hoofdstukken zelf, maar vormt ook een tweede lijn in het boek. De theoretische hoofdstukken worden namelijk afgewisseld door korte, persoonlijke essays over het veldwerk op fanconventies. Zo stelt de auteur zich niet alleen als criticus op, maar ook als gids door deze mediaomgevingen.

Theoretisch vormt intermedialiteit - het samenspel tussen verschillende mediaplatforms - een cruciaal concept in dit project. Fanactiviteiten zijn intermediaal op twee manieren. Ten eerste construeren fans hun producten in verschillende media, zoals kostuums en geschreven teksten. Ten tweede wordt populaire cultuur zelf steeds intermedialer. Tegenwoordig wordt een verhaal vaak verspreid over verschillende mediaplatforms. Voorbeelden hiervan zijn adaptaties van één verhaal of het verspreiden van één verhaalwereld, zoals de Star Wars-franchise, over verschillende media. Bovendien wordt het publiek aangemoedigd niet alleen televisie te kijken, maar erin mee te draaien en zich ermee te engageren door gebruik te maken van online platforms. Deze studie bekijkt de implicaties van de toename in zulke 'transmedia designs' voor interpretatie, promotie en bovenal voor de verhalen zelf. Centraal staan de appropriaties van bestaande teksten door de industrie en door hun fans.

Dit intermediale kader is verrijkt door culturele en literaire concepten die samen de theoretische grondslag van het boek vormen. Affect theorie en reader-response theorie zijn belangrijke handvatten. In tegenstelling tot bestaande studies behandelt deze dissertatie fanculturen niet uitsluitend als een cultuur van online groepen, maar ook als een transcultureel, offline en affectief fenomeen. De identiteit van fans zelf is bovendien onderwerp van discussie. Gender, seksualiteit en nationale identiteit worden op onverwachte en kritische manieren vormgegeven in deze transculturele groepen. Door de zorgvuldige combinatie van culturele en sociale studies vormt het boek een bijdrage aan huidig mediaonderzoek, maar ook aan de digitale en traditionele geesteswetenschappen. De studie demonstreert de vorming en doorleving van populaire cultuur in een intieme relatie met het publiek zelf. 


\section{Curriculum Vitae}

Nicolle Lamerichs (Brunssum, 1986) obtained her bachelor's degree in cultural studies at Maastricht University, where she also obtained her Master of Philosophy title in the two-year research program Cultures of Arts, Sciences and Technology (2007-2009). She functioned as a research intern at Van Abbemuseum and ICN (August 2008-January 2009) and as a guest lecturer at Utrecht University (2012). She received her basic teaching qualification (BKO) in 2013. Nicolle has published articles in edited collections and peer reviewed journals and has functioned as a reviewer for amongst others Transformative Works and Cultures. She hosts workshops and panels at fan conventions to present her findings and chairs the Dutch feminist fan convention YaYCon. She is also a guest writer for popular magazines, such as Aniway, and professional blogs, such as Crossmedialog. Nicolle wrote Productive Fandom at the Literature and Arts department of the Faculty of Arts and Social Sciences at Maastricht University (2010-2013). 